\title{
Liquefaction and Post-liquefaction Behaviour of Gold Mine Tailings under Simple Shear Loading
}

\author{
Submitted By
}

\section{Mahmud Amer Al Tarhouni}

B.Sc. Eng, Al Fateh University, Libya (1997)

A thesis submitted to the Faculty of Graduate Studies and Research in partial fulfillment of the requirements for the degree of Master of Applied Science

Department of Civil and Environmental Engineering

Carleton University

Ottawa, Ontario

Canada

(C) Al Tarhouni. M. A., 2008

The Master of Applied Science in Civil and Engineering Program is a joint program with University of Ottawa, administrated by the Ottawa-Carleton Institute of Civil Engineering 


$\begin{array}{ll}\begin{array}{l}\text { Library and } \\ \text { Archives Canada }\end{array} & \begin{array}{l}\text { Bibliothèque et } \\ \text { Archives Canada }\end{array} \\ \begin{array}{l}\text { Published Heritage } \\ \text { Branch }\end{array} & \begin{array}{l}\text { Direction du } \\ \text { Patrimoine de l'édition }\end{array} \\ \begin{array}{l}\text { 395 Wellington Street } \\ \text { Ottawa ON K1A 0N4 } \\ \text { Canada }\end{array} & \begin{array}{l}\text { 395, rue Wellington } \\ \text { Ottawa ON K1A 0N4 } \\ \text { Canada }\end{array}\end{array}$

Your file Votre référence ISBN: 978-0-494-44027-8 Our file Notre référence ISBN: 978-0-494-44027-8

NOTICE:

The author has granted a nonexclusive license allowing Library and Archives Canada to reproduce, publish, archive, preserve, conserve, communicate to the public by telecommunication or on the Internet, loan, distribute and sell theses worldwide, for commercial or noncommercial purposes, in microform, paper, electronic and/or any other formats.

The author retains copyright ownership and moral rights in this thesis. Neither the thesis nor substantial extracts from it may be printed or otherwise reproduced without the author's permission.
AVIS:

L'auteur a accordé une licence non exclusive permettant à la Bibliothèque et Archives Canada de reproduire, publier, archiver, sauvegarder, conserver, transmettre au public par télécommunication ou par l'Internet, prêter, distribuer et vendre des thèses partout dans le monde, à des fins commerciales ou autres, sur support microforme, papier, électronique et/ou autres formats.

L'auteur conserve la propriété du droit d'auteur et des droits moraux qui protège cette thèse. $\mathrm{Ni}$ la thèse ni des extraits substantiels de celle-ci ne doivent être imprimés ou autrement reproduits sans son autorisation.
In compliance with the Canadian Privacy Act some supporting forms may have been removed from this thesis.

While these forms may be included in the document page count, their removal does not represent any loss of content from the thesis.
Conformément à la loi canadienne sur la protection de la vie privée, quelques formulaires secondaires ont été enlevés de cette thèse.

Bien que ces formulaires aient inclus dans la pagination, il n'y aura aucun contenu manquant.

\section{Canada}




\title{
This thesis is dedicated to:
}

\author{
My late father Amer Omer Al Tarhouni
}

who inspired me to constantly reach for knowledge and wisdom

wherever I may find it. 


\begin{abstract}
Understanding the liquefaction and post-liquefaction behaviour of mine tailings is important for the safe design of tailings dams. An experimental study was carried out to investigate the liquefaction and post-liquefaction behaviour of gold mine tailings under simple shear loading conditions. Monotonic loading tests indicate that the tailings are susceptible to liquefaction especially at high void ratios and consolidation pressures. Cyclic loading tests show that the cyclic resistance ratio increases as the void ratio decreases at a given consolidation pressure. However, the behaviour of the tailings under cyclic loading appears to be relatively insensitive to the consolidation pressure. Cyclic resistance ratios for samples that were subject to significant matric suctions in simulated evaporation and rain events were considerably higher than those without a hydraulic stress history. The shear strength at post-liquefaction increases as the consolidation pressure increases at a given void ratio. In contrast, increasing consolidation pressures yield lower liquefied strength ratios.
\end{abstract}




\section{ACKNOWLEDGMENTS}

I would like to acknowledge and express my utmost gratitude to my co-supervisors Professors Siva Sivathayalan, and Paul Simms for their continuing support, guidance and encouragements throughout the coursework and this research. Without their timely advice and generous help, this endeavor would not have been successful.

Besides my advisors, I would like to thank the staff of the Ottawa-Carleton Institute for Civil Engineering for having enriched my knowledge with their excellent courses. Moreover, most sincere thanks are extended to the Civil and Environmental Laboratory staff at Carleton University, especially Ken McMartin, Stanley Conley and Pierre Trudel.

I would like to thank the Geological Engineering Department of Al Fateh University in Libya for granting me the opportunity to study abroad through the General Public Committee of Higher Education in Libya (G.P.C.H.E).

I wish to thank friends for their continuing interest and encouragement throughout this research, particular thanks to Logeswaran Paramaguru, Khalil Djalal, and Michael Killam. Also, a special thanks to my friend, Tarek Bader, for his help during my stay in Canada.

I would like to thank all of my family in Libya especially my brothers and sisters, and give a big hug to my mother, Aicha Jennan, for giving me a good life and inspiring me to gain knowledge and wisdom. Also, I would like to express my sincere gratitude to my father-in-law, Mr. Mohamed Sharif, and his family for encouraging me during my studies.

Finally, I owe my loving thanks to my wife, Reima Sharif, for her patience and for taking care of our daughter, Yakean, throughout our years in Canada. Without her encouragement and understanding, it would have been impossible for me to finish this work. 


\section{TABLE OF CONTENTS}

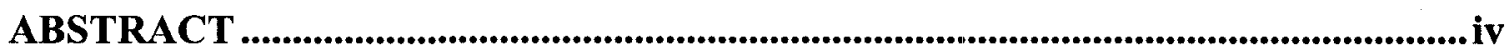

ACKNOWLEDGMENTS .......................................................................................................... v

TABLE OF CONTENTS....................................................................................................... vi

LIST OF TABLES ….................................................................................................................................. xi

LIST OF FIGURES ..........................................................................................................................xii

LIST OF NOTATIONS AND SYMBOLS .................................................................xix

CHAPTER 1: INTRODUCTION ............................................................................................... 1

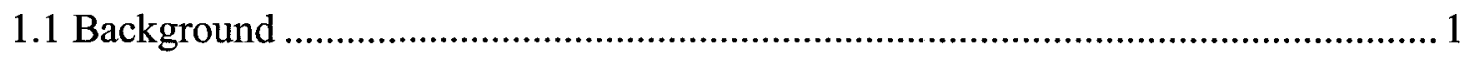

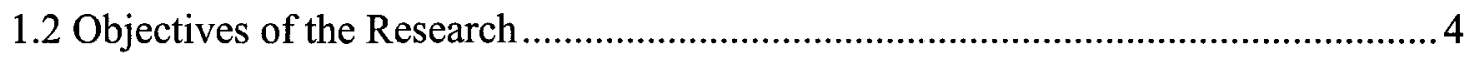

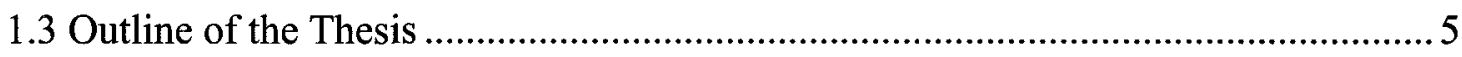

CHAPTER 2: LITERATURE REVIEW ................................................................ 6

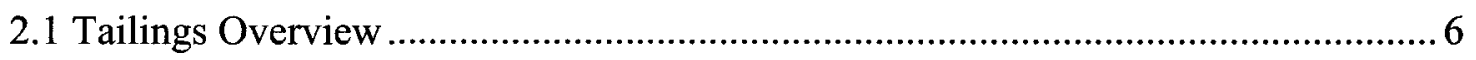

2.1.1 Definition of Tailings Based on its Water Content ............................................ 6

2.1.2 Tailings Storage and Disposal Techniques ...................................................... 7

2.1.2.1 Conventional Methods of Tailings Storage...........................................

2.1.2.2 Dewatered Mine Tailings Disposal ........................................................ 10

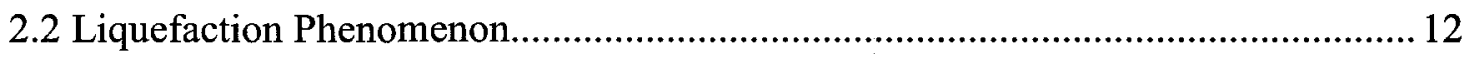

2.2.1 Monotonic Undrained Loading Behaviour ....................................................... 13

2.2.1.1 Type of Response ................................................................................. 13

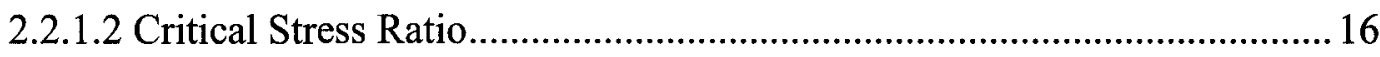

2.2.1.3 Phase Transformation and Steady States .............................................. 16

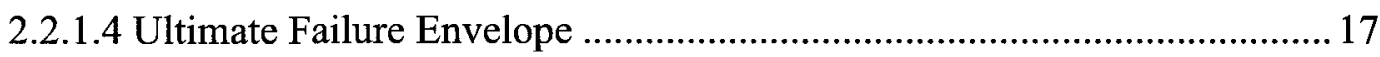


2.2.1.5 Steady State Concept........................................................................... 17

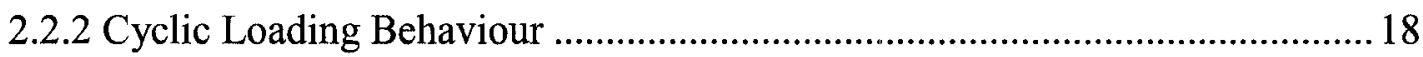

2.2.2.1 Type of Response ................................................................................. 19

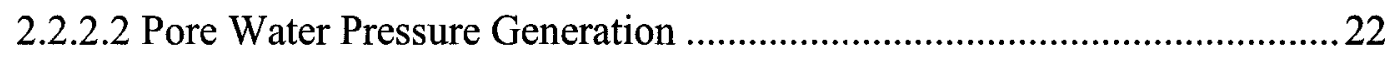

2.2.2.3 Effect of Initial State Variables on Cyclic Resistance ...............................23

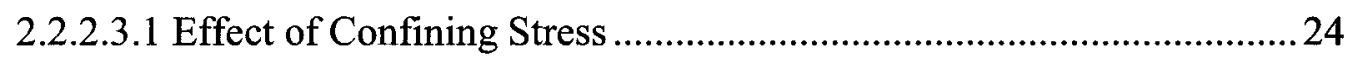

2.2.2.3.2 Effect of Initial Static Shear .............................................................25

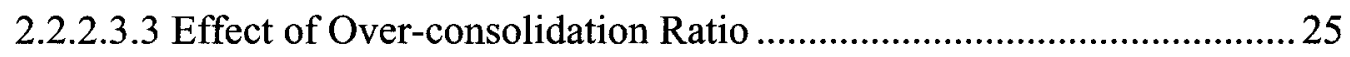

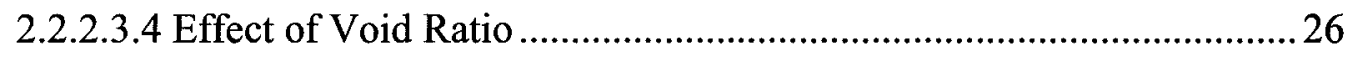

2.2.2.3.5 Effect of Fines and Plasticity Index ..................................................2

2.2.3 Liquefaction Criteria for Fine Grained Soil .................................................... 30

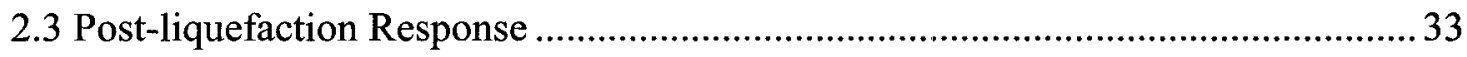

2.3.1 Post-liquefaction Deformation Mechanisms.......................................................34

2.3.2 General Response in Post-liquefaction Loading ..............................................35

2.3.3 Factors Affecting Post-liquefaction Behaviour...................................................38

CHAPTER 3: EXPERIMENTAL WORK ......................................................................... 41

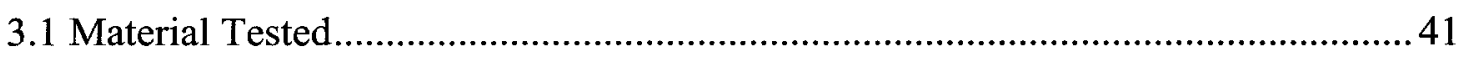

3.1.1 Mineralogical and Chemical Analysis of Gold Mine Tailings .........................42

3.1.2 Control Plan for Testing of Mine Tailings ....................................................... 42

3.1.3 Geotechnical Characteristics of Gold Mine Tailings ........................................45

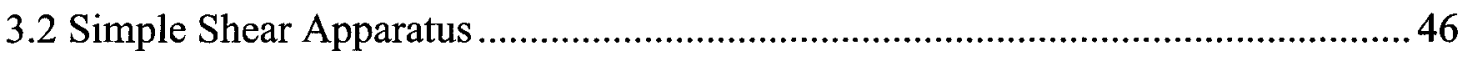

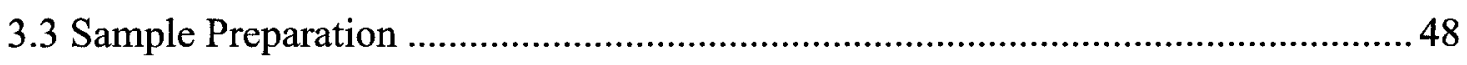

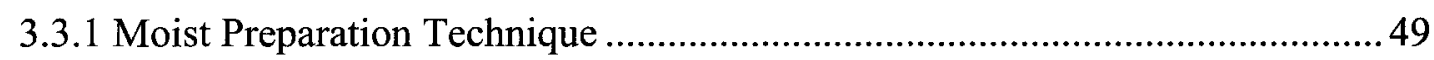


3.3.2 Wet-dry Cycles Preparation Technique ........................................................51

3.3.3 Placing the Tailings Sample under the Simple Shear Apparatus ......................51

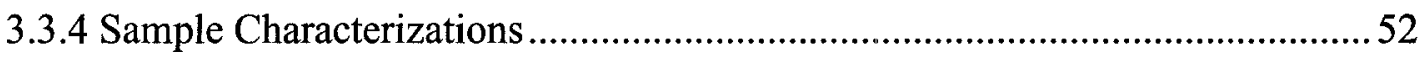

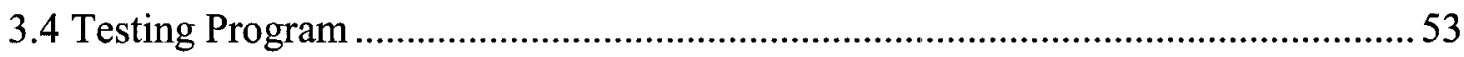

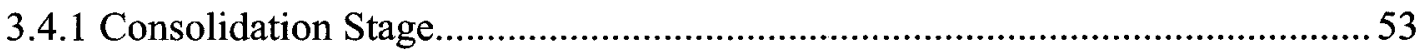

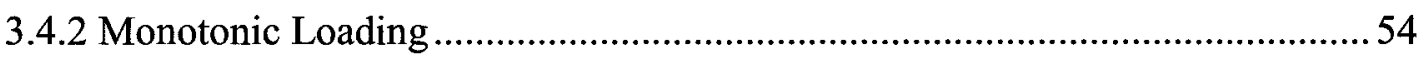

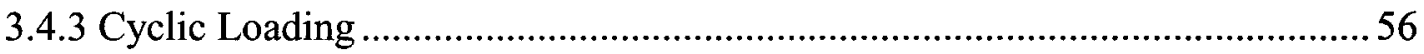

3.4.4 Post-liquefaction Loading ............................................................................5

3.4.5 Liquefaction Criteria of Cyclic Loading ..........................................................56

3.5 Repeatability of Sample Preparation...................................................................5

3.6 Characteristics and Limitations of the Simple Shear Apparatus...............................59

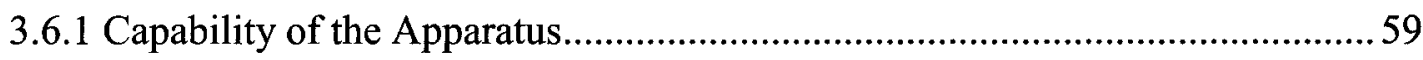

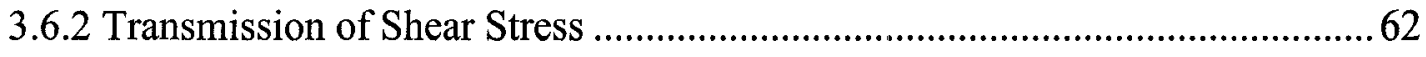

3.6.3 Influence of the Degree of Saturation under Constant Volume .........................64

CHAPTER 4: TEST RESULTS AND DISCUSSIONS ..................................................66

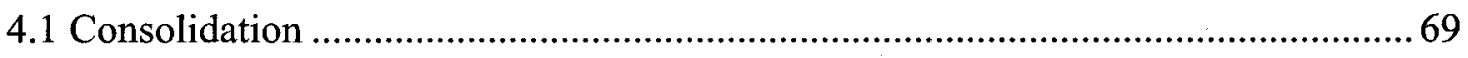

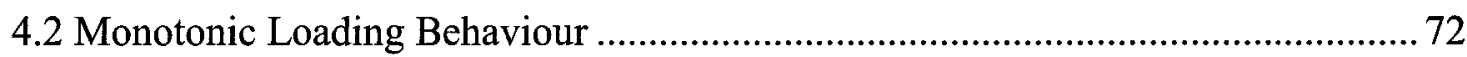

4.2.1 Monotonic Response at a given Void Ratio .................................................... 72

4.2.2 Monotonic Response at a given Consolidation Pressure …………................. 78

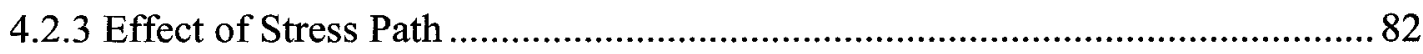

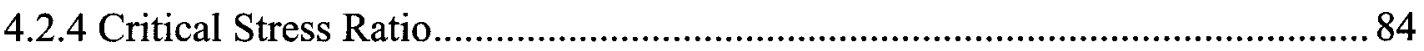

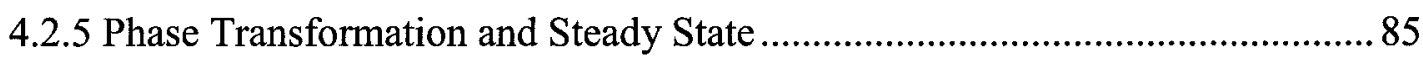

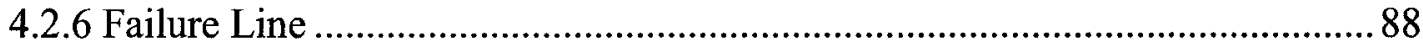


4.3 Cyclic Loading Behaviour

4.3.1 Stress-strain Response of Cyclic Loading................................................90

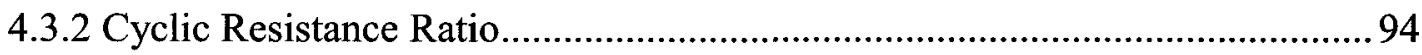

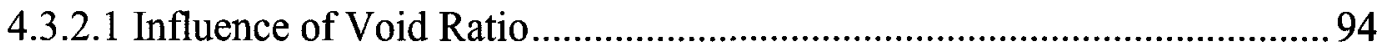

4.3.2.2 Influence of Consolidation Pressure ..................................................... 98

4.3.2.3 Effect of Loading Mode on Cyclic Resistance..................................... 101

4.3.2.4 Characterization of Cyclic Loading Resistance .................................. 102

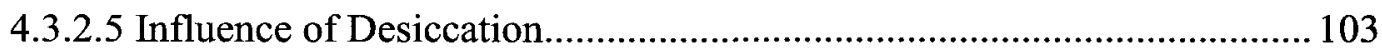

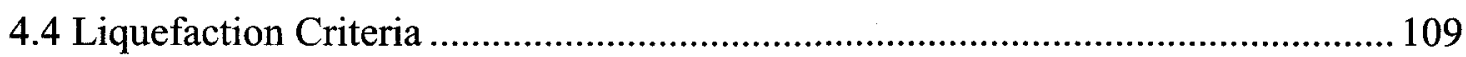

4.4.1 Evaluation of Liquefaction Criteria Based on Cyclic Loading Results ......... 109

4.4.2 Applicability of Liquefaction Criteria for Assessment of Liquefaction under

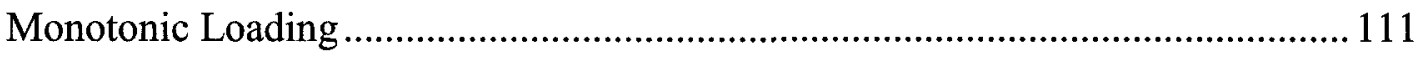

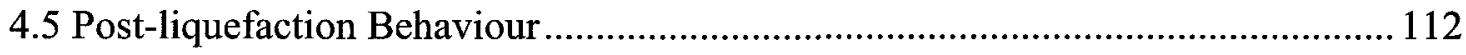

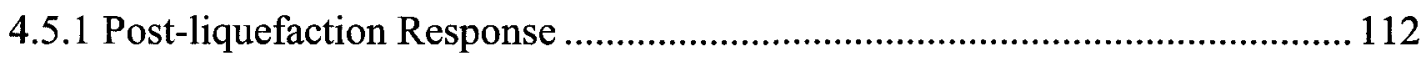

4.5.2 Factors Influencing the Post-liquefaction Response................................ 115

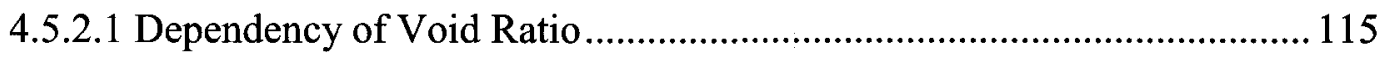

4.5.2.2 Effect of Maximum Pre-liquefaction Strain Level and Cyclic Stress Ratio

4.5.2.3 Effect of Consolidation Pressure....................................................... 121

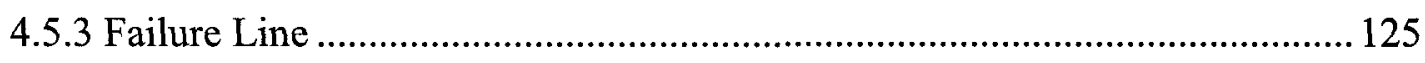

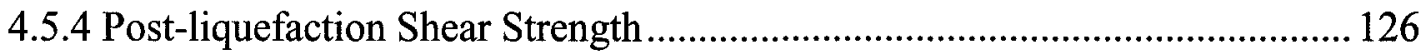

4.5.5 Comparison between Pre-liquefaction and Post-liquefaction Stress-strain

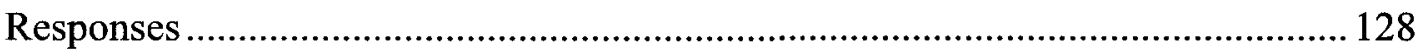




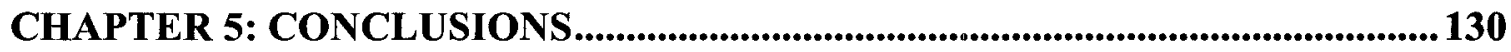

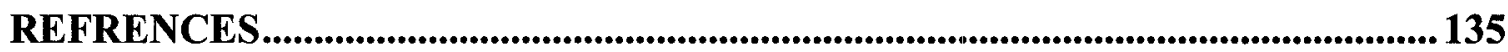

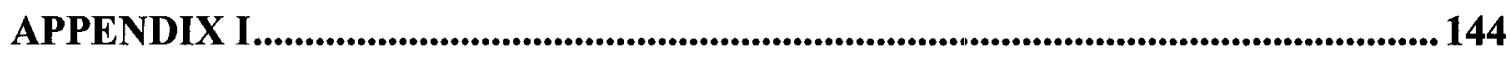

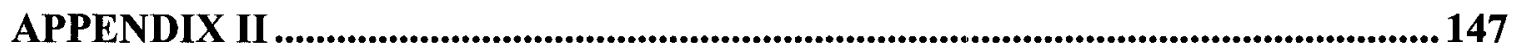




\section{LIST OF TABLES}

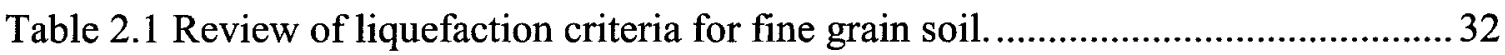

Table 3.1 Results of chemical analyses of gold mine tailings (Simms, 2006)................44

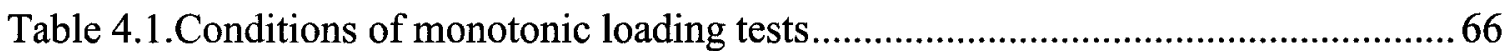

Table 4.2 Conditions of cyclic loading tests (samples prepared by moist technique) ......67

Table 4.3 Conditions of cyclic loading (samples prepared by wet-dry cycles technique) 68

Table 4.4 Liquefied strength ratio reported in the literature ....................................... 127 


\section{LIST OF FIGURES}

Figure 2.1 Diagram of upstream method: (a) started dyke, and (b) subsequent dykes.......9

Figure 2.2 Diagram of downstream method: (a) started dyke, and (b) subsequent dykes. . 9

Figure 2.3 Pictures of tailings disposal facility at Bulyanhulu site: (a) cyclic deposition of tailings, and (b) overview of part of the site from the plane, (Simms and

Bryan, 2007; Shuttleworth et al., 2005).

Figure 2.4 Soil loses its contact force with increasing of pore water pressure and becomes

in the liquefaction state.

Figure 2.5 Characteristic behaviours of three different relative densities of saturated sand under triaxial monotonic loading: (a) stress-strain response, (b) stress path, (Vaid and Chern, 1985).

Figure 2.6 Effective stress paths for remolded colliery tailings under load control triaxial test (Taylor, 1987). 15

Figure 2.7 Cyclic loading behaviour: (a) flow liquefaction due to cyclic loading,

(b) cyclic mobility due to cyclic loading, (c) limited liquefaction due to cyclic loading, (Vaid and Chern, 1985).

Figure 2.8 three different combinations of cyclic mobility: (a) no stress reversal and no exceedance of the steady-state strength, (b) no stress reversal with momentary period of steady-state strength exceedance, (c) stress reversal with no exceedance of steady-state strength, (reproduced from Kramer, 1996). .21

Figure 2.9 Comparison of typical silt sample and loose sand sample: (a) peak to peak strain with number of cycles, (b) pore pressure development with number of cycles, (Singh, 1996). .23 
Figure 2.10 Cyclic stress ratio with fine content of mine tailings (Troncoso, 1990) .......27

Figure 2.11 Cyclic stress ratio causing liquefaction $(M=7.5)$ with $\left(N_{1}\right)_{60}$ values for silty sand (Seed et al., 1985)...................................................................... 28

Figure 2.12 Atterberg limits chart showing Boulanger and Idriss (2004) criteria........... 31

Figure 2.13 Liquefaction and post-liquefaction stats of soil: (a) Soil in natural state, (b) soil in liquefaction state, and (c) soil after post-liquefaction state.................34

Figure 2.14 Typical post-liquefaction behaviour after cyclic mobility: (a) shear stressshear strain relationship, and (b) effective stress path, (Kramer, 1996)......... 36

Figure 2.15 Characterization of post-liquefaction stress-strain curve (Thomas, 1992)... 36

Figure 2.16 The influence of incomplete or complete liquefaction to the post-liquefaction shear strain response (Shamoto et al., 1998). 37

Figure 3.1 The dark gray and green minerals are Silicates and Carbonates (Quartz, Mica, Muscovite, Ankerite, and Calcite), the white-looking mineral is Pyrite and the yellowish one is Chalcopyrite (Bryan, 2008).

Figure 3.2 Grain size distribution of gold mine tailings. 45

Figure 3.3 Schematic diagram of the cyclic simple shear apparatus 46

Figure 3.4 Simple shear apparatus at Carleton University

Figure 3.5 Steps sample preparation for wet conditions: (a) sample placement in the cavity of reinforced membrane, and (b) measuring the sample height by using the dial-gauge. .50

Figure 3.6 Effect of strain rate on the monotonic shear response at vertical confining stress $\sigma_{\mathrm{vc}}^{\prime}=100 \mathrm{kPa}$. 55

Figure 3.7 Repeatability of monotonic response using two identical samples. 58 
Figure 3.8 Errors to measure the stresses and strains after the sample fail under simple

shear loading.

Figure 3.9 Influence of the interaction between the tailings sample, discs material and

shape on the monotonic behaviour.

Figure 3.10 Influence of changing degree of saturation on the monotonic behaviour of tailings under simple shear apparatus.

Figure 4.1 Design consolidation chart to predict the initial water content of tailings samples. 70

Figure 4.2 Design consolidation chart in terms of void ratio. 71

Figure 4.3 Effect of consolidation pressure on monotonic behaviour of gold mine tailings at consolidated void ratio $\left(\mathrm{e}_{\mathrm{c}}=0.551\right)$ 74

Figure 4.4 Effect of consolidation pressure on monotonic behaviour of gold mine tailings at consolidated void ratio $\left(\mathrm{e}_{\mathrm{c}}=0.585\right)$ 75

Figure 4.5 Effect of consolidation pressure on monotonic behaviour of gold mine tailings at consolidated void ratio $\left(\mathrm{e}_{\mathrm{c}}=0.629\right)$ 76

Figure 4.6 Effect of consolidation pressure on monotonic behaviour of gold mine tailings at consolidated void ratio $\left(\mathrm{e}_{\mathrm{c}}=0.660\right)$ 77

Figure 4.7 Effect of void ratio (water content) on monotonic behaviour of gold mine tailings at consolidated pressure $\sigma_{\mathrm{vc}}^{\prime}=100 \mathrm{kPa}$.

Figure 4.8 Effect of void ratio (water content) on monotonic behaviour of gold mine tailings at consolidated pressure $\sigma_{\mathrm{vc}}^{\prime}=200 \mathrm{kPa}$.

Figure 4.9 Effect of void ratio (water content) on monotonic behaviour of gold mine tailings at consolidated pressure $\sigma_{\mathrm{vc}}^{\prime}=400 \mathrm{kPa}$. 
Figure 4.10 Monotonic responses of gold mine tailings under triaxial compression tests at isotropic consolidation pressures 50,100 , and $150 \mathrm{kPa}$ (Crowder, 2004) ......83

Figure 4.11 Friction angles at critical stress ratio $\left(\varphi_{\mathrm{CSR}}\right)$ for different void ratios of gold mine tailings under monotonic loading. 86

Figure 4.12 Friction angles at phase transformation state $\left(\varphi_{\mathrm{PT}}\right)$ of gold mine tailings under monotonic loading.

Figure 4.13 Failure friction angles ( $\varphi_{\text {Failure }}$ ) of gold mine tailings under monotonic loading.

Figure 4.14 Typical cyclic loading response of gold mine tailings sample consolidated to $400 \mathrm{kPa}$ and subjected to a CSR of 0.075 . 92

Figure 4.15 Typical cyclic loading response of gold mine tailings sample consolidated to $400 \mathrm{kPa}$ and subjected to a CSR of 0.15 . 93

Figure 4.16 Cyclic stress ratio versus number of cycles to reach $(\gamma=3.75 \%)$ for tailings samples at consolidated pressure $\sigma_{\mathrm{vc}}^{\prime}=100 \mathrm{kPa}$ and range of void ratio.

Figure 4.17 Cyclic stress ratio versus number of cycles to reach $(\gamma=3.75 \%)$ for tailings samples at consolidated pressure $\sigma_{\mathrm{vc}}^{\prime}=200 \mathrm{kPa}$ and range of void ratio. ......96

Figure 4.18 Cyclic stress ratio versus number of cycles to reach $(\gamma=3.75 \%)$ for tailings samples at consolidated pressure $\sigma_{\mathrm{vc}}^{\prime}=400 \mathrm{kPa}$ and range of void ratio. ......96

Figure 4.19 Cyclic stress ratio versus number of cycles to reach $(\gamma=3.75 \%)$ for tailings samples at consolidated pressure $\sigma_{\mathrm{vc}}^{\prime}=800 \mathrm{kPa}$ at $\mathrm{e}_{\mathrm{c}}=0.537$.

Figure 4.20 Void ratio $\left(\mathrm{e}_{\mathrm{c}}\right)$ versus number of cycles to reach for tailings samples at consolidated pressure $\sigma_{\mathrm{vc}}^{\prime}=100 \mathrm{kPa}$ and different CSR 
Figure 4.21 Void ratio $\left(\mathrm{e}_{\mathrm{c}}\right)$ versus number of cycles to reach for tailings samples at consolidated pressure $\sigma_{\mathrm{vc}}^{\prime}=200 \mathrm{kPa}$ and different CSR.

Figure 4.22 Cyclic stress ratio versus number of cycles to reach $(\gamma=3.75 \%)$ for tailings samples at a void ratio of $\mathrm{e}_{\mathrm{c}}=0.546$ and different consolidated pressure levels.

Figure 4.23 Cyclic stress ratio versus number of cycles to reach $(\gamma=3.75 \%)$ for tailings samples at a void ratio of $e_{c}=0.582$ and different consolidated pressure levels. 100

Figure 4.24 Cyclic stress ratio versus number of cycles to reach $(\gamma=3.75 \%)$ for tailings samples at a void ratio of $\mathrm{e}_{\mathrm{c}}=0.618$ and different consolidated pressure levels.

Figure 4.25 Cyclic triaxial tests results from Crowder (2004) and the cyclic simple shear results of this study. 102

Figure 4.26 Cyclic resistance ratio versus void ratio to reach $(\gamma=3.75 \%)$ for tailings .. 103

Figure 4.27 Soil-water characteristic curve in terms of gravimetric water content of gold mine tailings from Bulyanhulu mine (Fisseha, 2008) 105

Figure 4.28 Soil-water characteristic curve in terms of degree of saturation of gold mine tailings from Bulyanhulu mine (Simms et al., 2007). 105

Figure 4.29 Comparison between cyclic stress ratio for tailings samples prepared by moist preparation technique and wet-dry cycles preparation technique $\left(w_{\mathrm{d}}=18 \%\right)$ at consolidation pressure $\sigma_{\mathrm{vc}}^{\prime}=50 \mathrm{kPa}$ 107

Figure 4.30 Comparison between cyclic stress ratio for tailings samples prepared by moist preparation technique and samples prepared by wet-dry cycles 
preparation technique $\left(w_{\mathrm{d}}=18,16\right.$, and $\left.13 \%\right)$ at consolidation pressure $\sigma_{\mathrm{vc}}^{\prime}=50$

$\mathrm{kPa}$. 108

Figure 4.31 Assessment of Bray et al. (2004) criteria based on cyclic loading results... 110

Figure 4.32 Applicability of Bray et al. (2004) criteria based on monotonic loading results.

Figure 4.33 Typical post-liquefaction behaviour of gold mine tailings under simple shear loading. 113

Figure 4.34 Effective of initial conditions on the post-liquefaction stress-strain response

at $\sigma_{\mathrm{vc}}^{\prime}=100 \mathrm{kPa}$.

Figure 4.35 Effective of initial conditions on the post-liquefaction stress-strain response at $\sigma_{\mathrm{vc}}^{\prime}=200 \mathrm{kPa}$.

Figure 4.36 Effective of initial conditions on the post-liquefaction stress-strain response at $\sigma_{\mathrm{vc}}^{\prime}=400 \mathrm{kPa}$.

Figure 4.37 Cyclic stress ratio versus maximum strain level during cyclic loading at $\sigma_{\mathrm{vc}}^{\prime}=100 \mathrm{kPa}$.

Figure 4.38 Cyclic stress ratio versus maximum strain level during cyclic loading at

$\sigma_{\mathrm{vc}}^{\prime}=200 \mathrm{kPa}$.

Figure 4.39 Cyclic stress ratio versus maximum strain level during cyclic loading at

$\sigma_{\mathrm{vc}}^{\prime}=400 \mathrm{kPa}$.

Figure 4.40 Effective of CSR and $\gamma_{\mathrm{c}-\max }$ on the post-liquefaction stress-strain response at $\sigma^{\prime} \mathrm{vc}=400 \mathrm{kPa}$ 120

Figure 4.41 Effect of consolidation stress on post-liquefaction stress-strain response and at fixed void ratio $\left(\mathrm{e}_{\mathrm{c}}=0.552\right)$. 122 
Figure 4.42 Effect of consolidation stress on post-liquefaction stress-strain response and at fixed void ratio $\left(\mathrm{e}_{\mathrm{c}}=0.582\right)$. 123

Figure 4.43 Effect of consolidation stress on post-liquefaction stress-strain response and at fixed void ratio $\left(\mathrm{e}_{\mathrm{c}}=0.618\right)$. 124

Figure 4.44 Stress ratios at the end of post-liquefaction tests superimposed on stress ratios at failure in pre-liquefaction. 125

Figure 4.45 Mobilized post-liquefaction shear strength at $13 \%$ shear strain. 126

Figure 4.46 Normalized post-liquefaction shear strength at $13 \%$ shear strain 128

Figure 4.47 Comparison of pre-liquefaction and post-liquefaction stress-strain response for gold mine tailings at $\sigma_{\mathrm{vc}}^{\prime}=100 \mathrm{kPa}$. 129 


\section{LIST OF NOTATIONS AND SYMBOLS}

CSR

CRR

FLS

LL

OCR

PI

PL

PT

QSS

SL

SS

SWCC

$\mathrm{e}_{\mathrm{c}}$

$\mathrm{e}_{\mathrm{i}}$

Gs

$\mathrm{K}_{\alpha}$

$\mathrm{K}_{\sigma}$

$P^{\prime}$

$q$

$r_{u}$

$S$
Critical stress ratio/Cyclic stress ratio

Cyclic resistance ratio

Flow liquefaction surface

Liquid limit

Over-consolidation ratio

Plastic index

Plastic limit

Phase transformation

Quasi steady sate

Shrinkage limit

Steady state

Soil-water characteristic curve

Void ratio after consolidation stage

Initial void ratio (before consolidation stage)

Specific gravity

Empirical correction factor for shear stress

Empirical correction factor for confining stress

Mean effective stress

Deviatoric stress

Excess pore pressure ratio (simple shear) $=\left({\sigma^{\prime}}_{v c}{ }^{-\sigma_{v}^{\prime}}\right) / \sigma^{\prime}{ }_{v c}$

Degree of saturation 


\begin{tabular}{|c|c|}
\hline $\mathrm{S}_{\mathrm{PL}}$ & Post-liquefaction shear strength \\
\hline $\mathrm{S}_{s u}$ & Steady-state strength \\
\hline$w$ & Water content \\
\hline$w_{c}$ & Water content at consolidation \\
\hline$w_{\mathrm{d}}$ & Water content after controlled desiccation \\
\hline$w_{\mathrm{ET}}$ & Water content at end of the test \\
\hline$w_{\mathrm{i}}$ & Initial water content (before consolidation stage) \\
\hline$\varphi_{\mathrm{CSR}}$ & Friction angle at critical state ratio \\
\hline$\varphi_{\text {Failure }}$ & Friction angle at failure \\
\hline$\varphi_{\mathrm{PT}}$ & Friction angle at phase transformation \\
\hline$\gamma$ & Shear strain \\
\hline$\gamma_{\mathrm{c}-\max }$ & Maximum shear strain during cyclic loading \\
\hline$\sigma_{1}$ & Major total principal stress \\
\hline$\sigma_{2}$ & Intermediate total principal stress \\
\hline$\sigma_{3}$ & Minor total principal stress \\
\hline$\sigma_{1}^{\prime}$ & Major effective principal stress \\
\hline$\sigma_{3}^{\prime}$ & Minor effective principal stress \\
\hline$\sigma_{\mathrm{V}}^{\prime}$ & Effective vertical stress \\
\hline$\sigma_{\mathrm{vc}}^{\prime}$ & Effective consolidation pressure/stress \\
\hline$\tau$ & Shear stress \\
\hline$\tau_{c y c}$ & Cyclic shear stress \\
\hline$\tau_{\text {static }}$ & Static shear stress \\
\hline
\end{tabular}




\section{CHAPTER 1: INTRODUCTION}

\subsection{Background}

Mine tailings are grain-sized waste material that remain after ore processing operations. Tailings are generally transported at high water contents (as a slurry) in pipes or flumes, and are stored on the surface within natural or man-made impediments (dam structures). Such tailing deposits are generally loose unless an adequate drainage system is installed and/or thickened disposal technologies are utilized. Tailings that are disposed through conventional disposal methods, which are called tailings dams, (e.g. upstream and downstream) take many years to consolidate, and likelihood of their susceptibility to liquefaction is fairly high especially under earthquake loading. A new disposal technique consisting of depositing the tailings in a dewatered form has gained more interest. One of the advantages of this technique may be the prevention or risk mitigation of liquefaction (ICOLD and UNEP 2001).

Liquefaction (static and cyclic) has been the cause of many catastrophic dam failures in different mine tailings sites (Dobry and Alvarez, 1967; Ishihara et al., 1980; Divies et al. 2002). It has been reported that static liquefaction is the most common mechanism responsible for tailings impoundment failure and it is not well understood (Divies et al. 2002). However, the liquefaction induced by cyclic loading is also a big concern in seismically active areas (Dobry and Alvarez, 1967). 
Tailings dam failures associated with earthquakes have been reported since the first quarter of last century. The Barahona tailings dam failure, which occurred at El Teniente copper mine in Chile on October 1, 1928, was one of the oldest flow failures in a tailings dam to have been recorded. Following the earthquake, 4 million tonnes of material flowed along the valley and killed 54 people (Dobry and Alvarez, 1967). Another catastrophic failure of a tailings dam in Chile occurred on March $28^{\text {th }}, 1965$, at the El Cober copper mine. The cause of failure of the tailings has been attributed to the triggering of liquefaction. On January $14^{\text {th }} 1978$ in Japan, the failure of Mockikoshi storage pond during the Near Izu-Oshiam earthquake was induced by liquefaction (Ishihara et al., 1980).

Davies et al. (1998) described a static liquefaction event that occurred in the Active Iron Pond tailings impoundment at the Sullivan mine (Canada) in August, 1991. It was reported that the failure of the upstream constructed facility was triggered by the initiation of shear stresses in the foundation tailings in excess of their shear strength. More recently in 1994, the Merriespruit gold tailings darn failure in South Africa was an interesting historical case on the liquefaction of mine tailings. The failure occurred a few hours after high intensity rain fall. The liquefaction phenomenon has been attributed as being the cause of the dam failure (Fourie and Papageorgiou, 2001).

Knowledge about liquefaction and consequences of liquefaction (postliquefaction) of the mine tailings is of prime importance for any tailings dam stability analysis. Unfortunately, limited systematic research has been carried out to investigate the influence of the initial conditions and consolidation pressure on the liquefaction behaviour of tailings especially for tailings classified as low plastic silt. It was reported 
that the cyclic loading resistance is nearly independent of the void ratio for mine tailings classified as silt (Ishihara et al., 1981). The development of excess pore pressure ratio in silt during cyclic loading is different than for sand. For silt, experimental results have showed that it is not possible for pore pressure to reach $100 \%$ (Singh, 1996). Therefore it is expected to have relatively less densification and shear resistance than sand in postliquefaction state (Hyde et al., 2004, 2007).

The post-liquefaction behaviour of tailings has not received considerable attention, even though the large deformation of tailings dams is often caused by the monotonic post-liquefaction loading due to the driving shear stress following the liquefaction occurring in seismic areas. The current knowledge of post-liquefaction behaviour of tailings mainly derives from sandy, soils (Thomas, 1992; Vaid and Thomas, 1995; Vaid and Sivathayalan, 1997; Shamoto et al., 1997; and Sivathayalan and Yazdi 2004). However, the excess of pore pressure ratio of silt-sized material during the cyclic loading is different than for sand. Therefore, the stress-strain response for the postliquefaction of tailings might be different than for sandy soils.

As mentioned earlier, ICOLD and UNEP (2001) considered that the thickened tailings may prevent the possibility of liquefaction by drying the tailings layers to the water content near their shrinkage limit; as a result, tailings would experience a dilative response under dynamic shaking. This claim has, however, not been proved to be general to all tailings. As the tailings deposited by this technique are not confined by impoundments, the liquefaction susceptibility of the tailings has to be thoroughly investigated. In addition, for the tailings with a shrinkage limit nearing the liquid limit, the above mentioned conclusion for thickened techniques might not be valid and more 
research may be needed to study the effect of desiccation on the liquefaction and postliquefaction behaviour of tailings.

\subsection{Objectives of the Research}

The objectives of this research are:

- To investigate the liquefaction potential of the gold mine tailings (lowplastic silt) by using direct simple shear apparatus (NGI-type). The liquefaction behaviour is investigated under monotonic and cyclic loadings over a range of void ratios (water content) and consolidation pressures. In addition, the effect of desiccation on the cyclic resistance ratio is explored.

- To have a better understanding of the post-liquefaction (post-cyclic) behaviour of gold mine tailings. The post-liquefaction behaviour has realized by applying monotonic loading after the cyclic loading criteria has been achieved. The factors that influence the post-liquefaction shear strength of gold mine tailings are also investigated.

To achieve the objectives of this research, two sample preparation techniques have been used; the moist preparation technique and the wet-dry cycles preparation technique. Most of the tests were conducted by using moist preparation technique and the limited tests by wet-dry cycles technique. 


\subsection{Outline of the Thesis}

This thesis presents the results of the monotonic, cyclic and post-liquefaction (post-cyclic) loading of gold mine tailings under simple shear apparatus. The relevant technical information, the role of testing and the results are presented and discussed. The first chapter provides a relevant historical background and delineates the motivation for this research.

Chapter 2 presents a review of the literature and highlights the current understanding of the liquefaction and post-liquefaction behaviour of tailings. Moreover, a short overview of mine tailings storage and disposal techniques is presented.

Chapter 3 describes the gold mine tailings test material, the testing apparatus, the test procedures, the sample preparation techniques, and a discussion of the factors that influence the experimental measurements.

Chapter 4 presents the laboratory experimental test results and it discusses and compares the results with available data in detail.

Chapter 5 summarizes the findings derived from the experimental work, and provides conclusions. 


\section{CHAPTER 2: LITERATURE REVIEW}

An overview of mine tailings storage and disposal techniques is presented at the beginning of this chapter. Liquefaction behaviour of gold mine tailings has not been extensively investigated. In contrast, liquefaction behaviour of sandy soils is relatively well understood. Due to the lack of mine tailings research, it has been necessary to review the liquefaction behaviour of sands to understand general concepts. This chapter provides a review of concepts, criteria, and factors influencing liquefaction and postliquefaction phenomena of soils, including mine tailings under monotonic and cyclic loading.

\subsection{Tailings Overview}

\subsubsection{Definition of Tailings Based on its Water Content}

The tailings storage and disposal techniques are dependent on the water content of the tailings and its subsequent impact on the rheological behaviour. Based on its water content, tailings materials are classified as slurry, thickened, paste tailings, or filter cake (Newman and Landriault, 1997; Crowder, 2004). Slurry is mine tailings with water content higher than that of tailings at critical flow velocity for pumps. Thickened tailings 
are defined as tailings that have been significantly dewatered to a point where the material still has a critical flow velocity, however if the flow is stopped then settled solids do not segregate. Reducing the water content further leads to a point where the tailings are considered as paste, characterized by the absence of a critical flow velocity and plug flow with zones of laminar flow near the edge of the pipe where the yield stress is exceeded. Paste tailings also do not exhibit grain size segregation during deposition.

\subsubsection{Tailings Storage and Disposal Techniques}

Tailings dam construction methods are developed to achieve (i) lowest cost, (ii) stability of the tailing deposit, and (iii) to facilitate recovery drainage for using the water in the flotation process (Dobry and Alvarez, 1967). The most widely used conventional methods that have been employed to store mine tailings in slurry form are of two types: the upstream method and the downstream method. Recently, a new disposal method has been developed to eliminate the risk of environmental contamination through the deposition of mine tailings in a dewatered form. Also, the technique may be the prevention or risk mitigation of liquefaction (ICOLD and UNEP, 2001).

\subsubsection{Conventional Methods of Tailings Storage}

The upstream method is the more popular design method because it incurs low costs initially due to minimal amount of fill material required for the first dyke. In the upstream method, the tailings are flowed from the top of the dyke crest thus creating a beach that becomes the foundation for subsequent dykes (Vick, 1990). Figure 2.1 
illustrates a simplistic diagram of the step by step of construction of an upstream dam method. Due to the discharge of tailings from spigot, slurry might be segregated as the coarse material will settle closest to the dykes and the fines will be transported away. It is well recognized that tailings deposits need a long time to consolidate and therefore, design by this method poses a high risk due to the liquefaction phenomenon. Dam failure may occur as a result of liquefaction phenomena induced by earthquakes and/or a loss of the strength due to the development of excess pore water pressure which would be a result of a relatively quick rise of the phreatic surface during the heavy rain season. Davies et al. (2002) studied various types of tailings dams worldwide and he noted that the key failure mode of the upstream method is static/transient load induced liquefaction.

The downstream method also begins with a starter dyke as in the upstream method. However, the starter dyke in the downstream method requires a large amount of fill of compacted materials to render it impermeable (Figure 2.2). This raises the construction cost of this method. A subsequent dyke is constructed on top of the downstream slope of the previous dyke (Vick, 1990). This method allows for the incorporation of drains and impervious cores to control the phreatic surface which results in more stability than is allowed by the upstream method. This method is also provided more resistant to failures during seismic events because the dykes are not constructed on the unconsolidated tailings. 


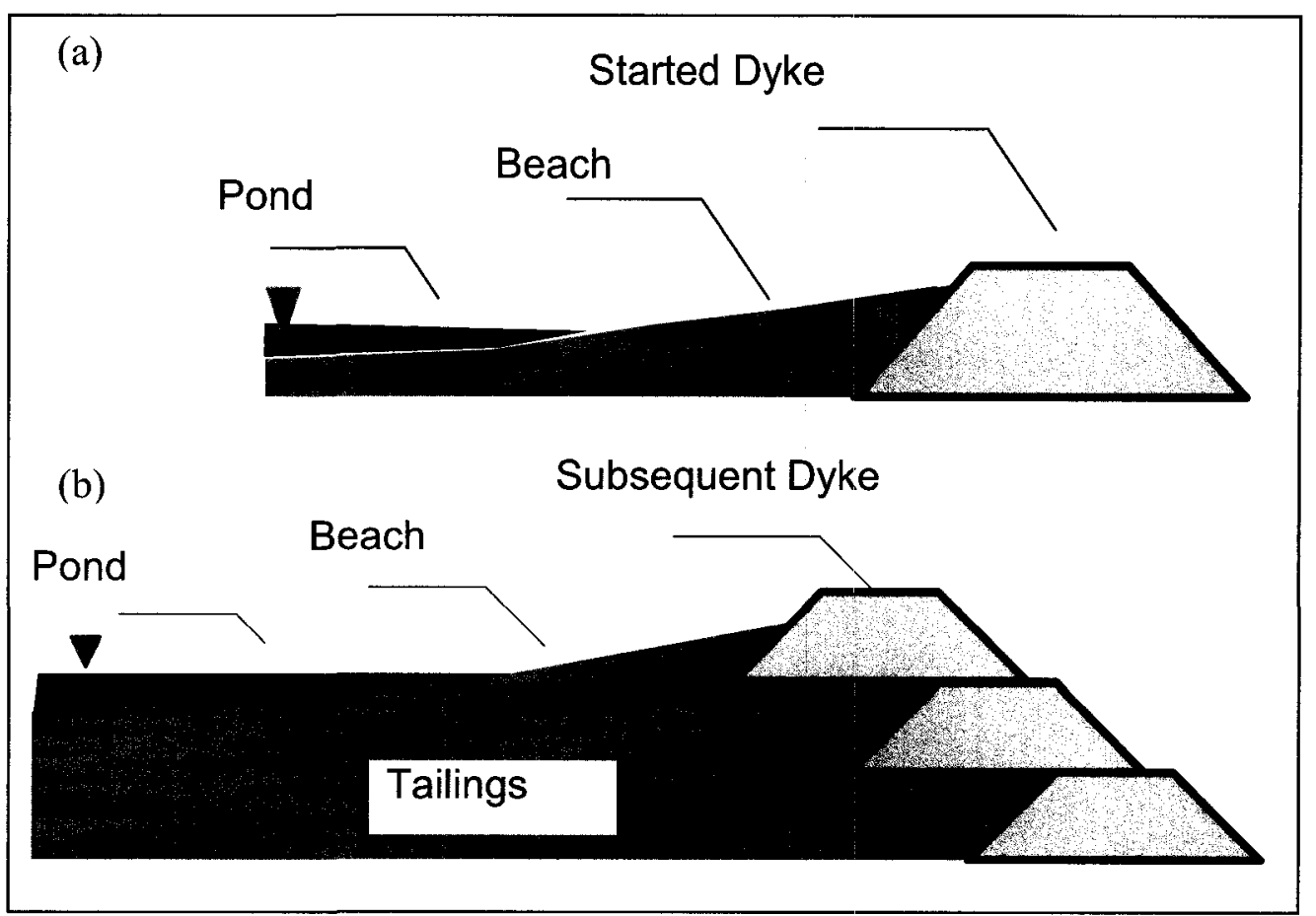

Figure 2.1 Diagram of upstream method: (a) started dyke, and (b) subsequent dykes.

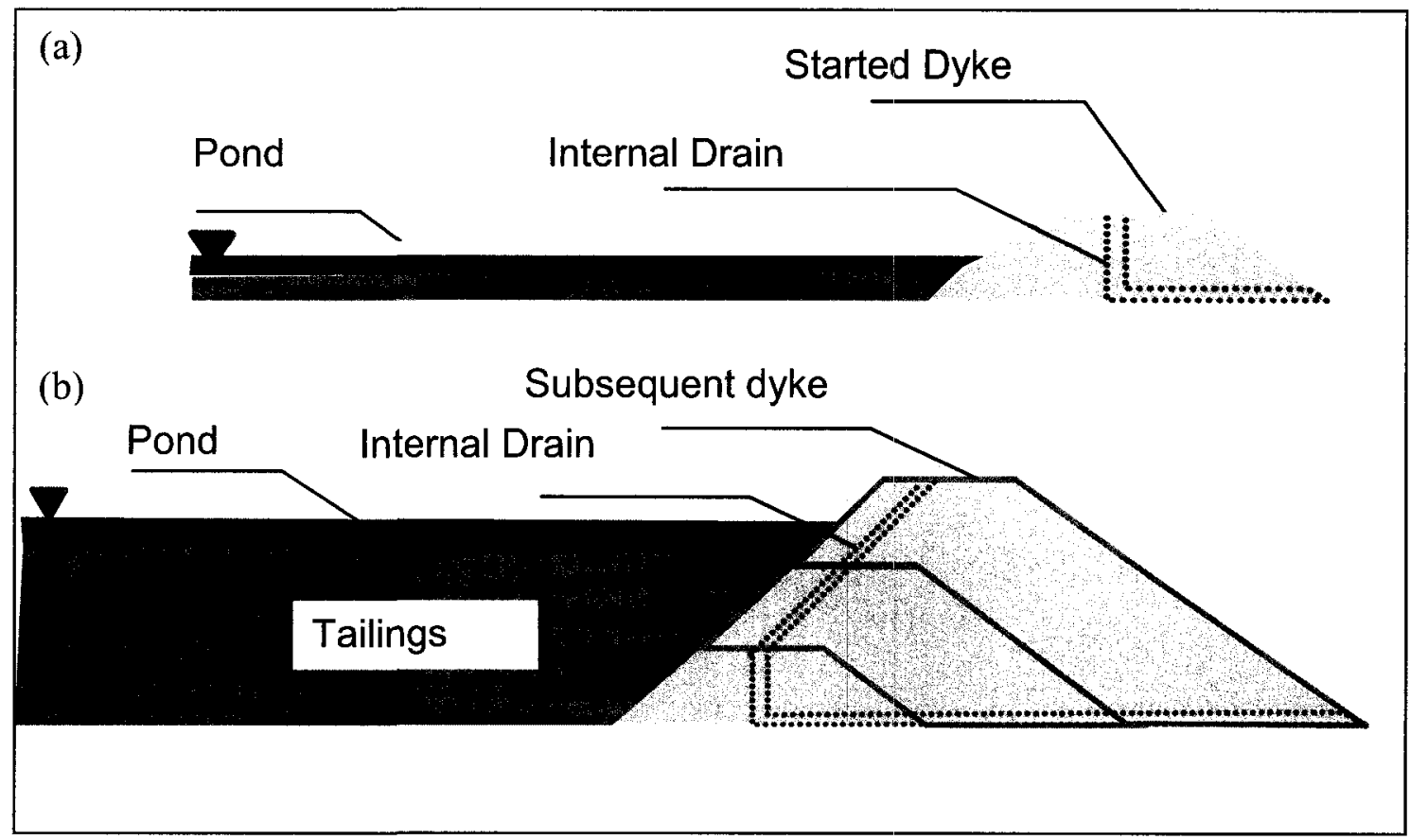

Figure 2.2 Diagram of downstream method: (a) started dyke, and (b) subsequent dykes. 


\subsubsection{Dewatered Mine Tailings Disposal}

Dewatered (thickened and paste) mine tailings are basically discharged from topographical high points by riser towers or central ramps creating conical piles which are sufficiently stable due to the dewatering process (ICOLD and UNEP, 2001). The slope angle typically ranges from 1 to 3.5 degrees for thickened tailings and from 3 to 10 degrees for paste tailings (Engels and Dixon-Hardy, 2008). This method minimizes the requirements for confining dams, and therefore eliminates the generation of ponds. The main goal of this method is to reduce the possibility of conventional mine tailings dam failures and to avoid the pollution attributed to conventional storage methods (ICOLD and UNEP, 2001). Therefore, thickened and paste tailings disposal are now becoming more popular.

The Bulyanhulu mine in Tanzania is a typical example for using the thickened tailings disposal method. Figure 2.3 shows images of the tailings disposal facilities at the Bulyanhulu site. The disposal site is located in a semi-arid environment; as a result, the tailings gain strength from self-weight consolidation and evaporation. The design of layer

thickness becomes a fundamental parameter, because it influences the amount of desiccation and the potential for acid generation (Simms et al, 2007; Theriault et al., 2003). A maximum layer thickness of about $30 \mathrm{~cm}$ is the goal at the Bulyanhulu site (Shuttleworth et al., 2005). This layer thickens was selected to ensure that the material achieves maximum density through desiccation (to ensure that the tailings reach the shrinkage limit). 


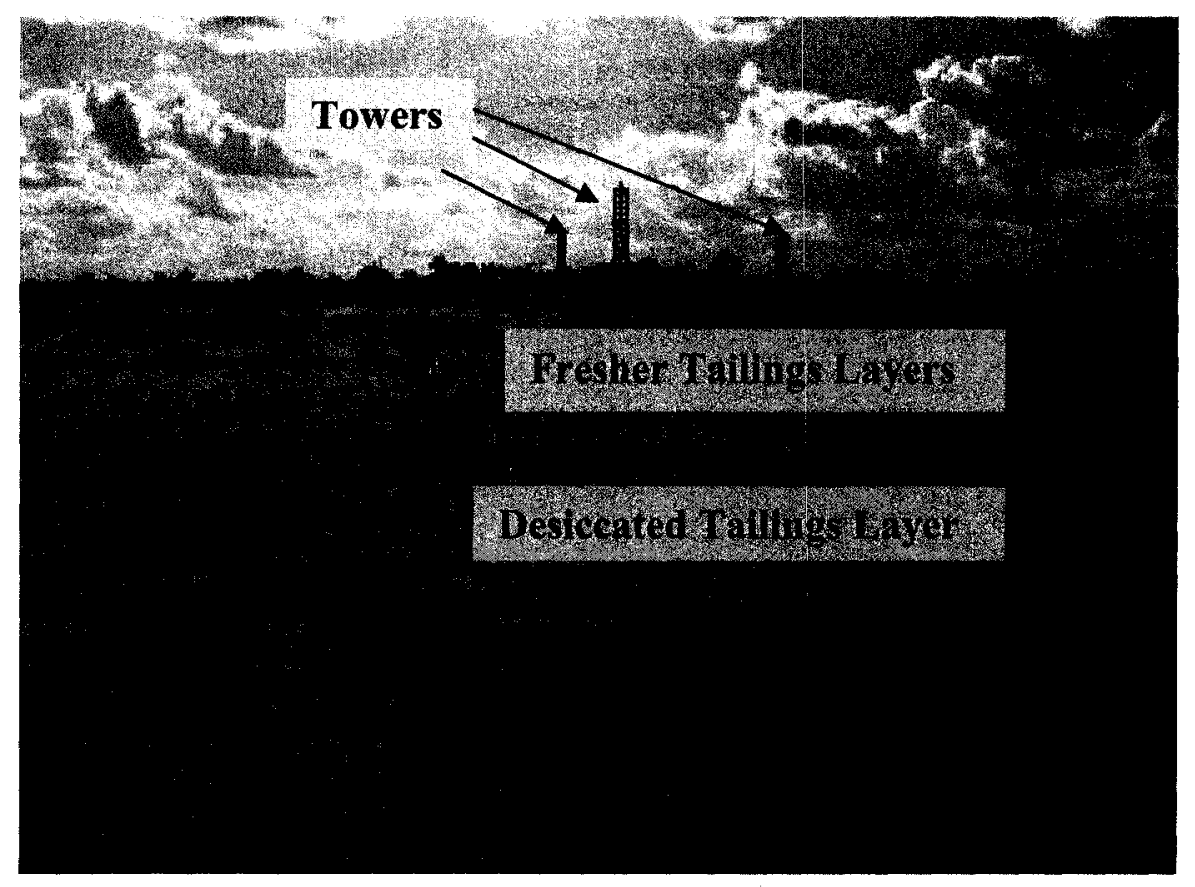

(a)

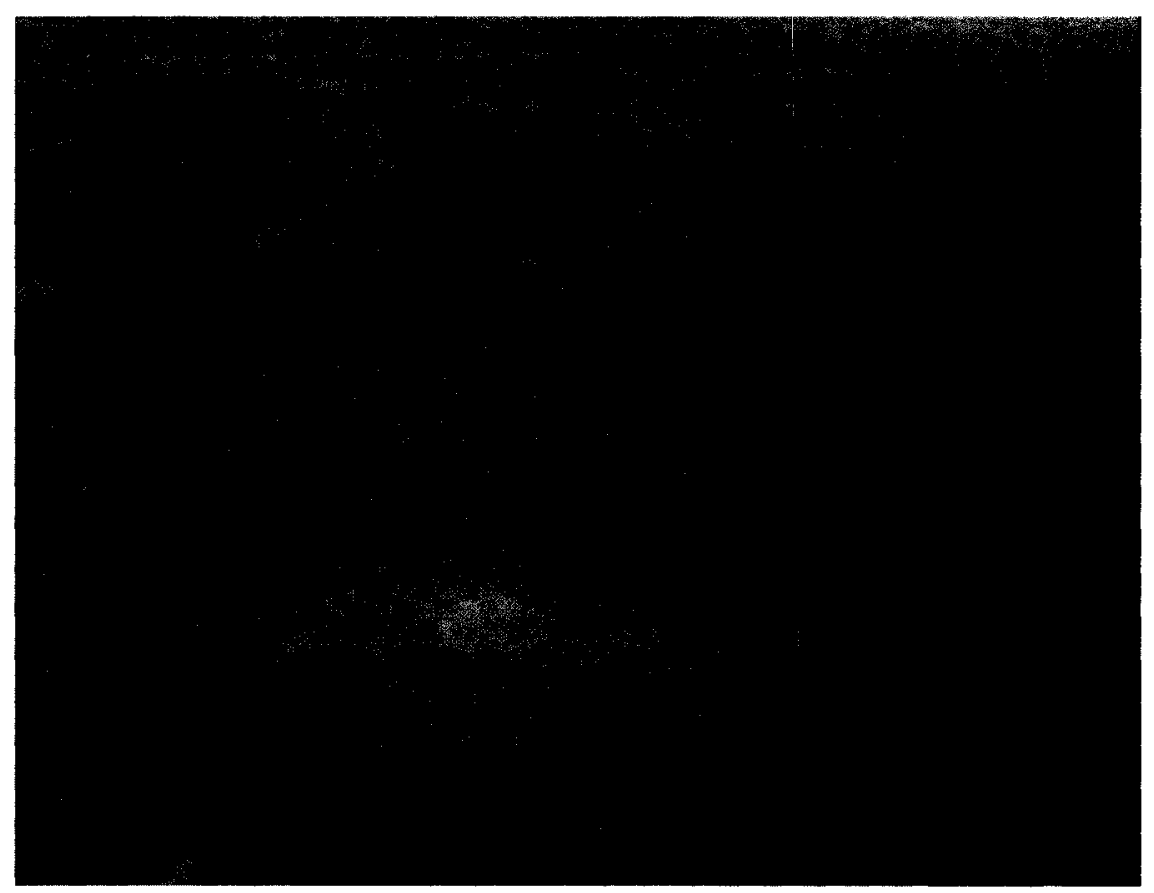

(b)

Figure 2.3 Pictures of tailings disposal facility at Bulyanhulu site: (a) cyclic deposition of tailings, and (b) overview of part of the site from the plane, (Simms and Bryan, 2007; Shuttleworth et al., 2005). 


\subsection{Liquefaction Phenomenon}

Liquefaction is a phenomenon in which soil loses a large percentage of its shear strength due to the generation of excess of pore water pressure under either monotonic or dynamic loading conditions. In granular soils, liquefaction takes place when the excess pore water pressure is high enough to overcome the contact force between the soil particles (Figure 2.4). Therefore, the effective shear strength is reduced due to loss of soil particle contact. When soil loses most of its contact force the behaviour changes from that of solid to liquid. This causes a softening and weakening of the soil which ultimately leads to liquefaction. The liquefaction phenomenon has been known for many decades (Terzaghi and Peck, 1948; Castro, 1969; Casagrande, 1975). Terzaghi and Peck (1948) coined the term "spontaneous liquefaction" to describe the event whereby sand experiences a sudden loss of strength thus resulting in flow slides. The liquefaction phenomenon is usually associated with undrained loading conditions in which excess pore pressure does not dissipate during shearing. The liquefaction behaviour under monotonic loading and under cyclic loading is discussed below.

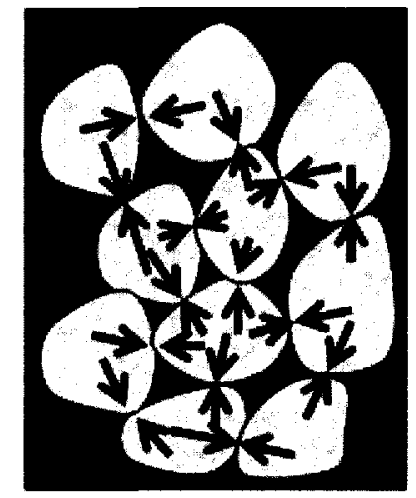

Initial state

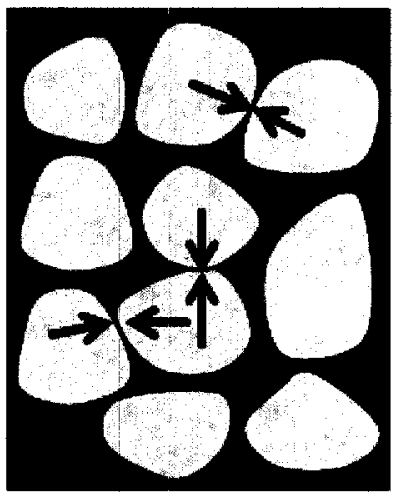

Liquefaction state

Figure 2.4 Soil loses its contact force with increasing of pore water pressure and becomes in the liquefaction state. 


\subsubsection{Monotonic Undrained Loading Behaviour}

\subsubsection{Type of Response}

Undrained monotonic loading behaviour of silt sized mine tailings and silts in general has not received as much attention as sand. Sands have been studied widely under different loading conditions by several researchers (e.g. Castro, 1969; Seed, 1979; Chern, 1985; Vaid and Thomas, 1994). Even though the behaviour of mine tailings might be different than in sand due to grain size and fabric, reviewing a typical stress-strain response of sand provides a basis for the analytical approach to the liquefaction behaviour of tailings.

Vaid and Chern (1985) identified three types of stress-strain responses in sands depending on the initial state of stress and relative density under triaxial monotonic loading. As shown in Figure 2.5, three different response types are presented with three different densities. In a very loose state, sand (curve 1) experiences large deformation associated with low shear strength, which is a result of strain softening (or contractive behaviour) after having reached a peak strength. This behaviour is termed "liquefaction" by Castro (1969) and has recently been commonly called "flow liquefaction" (Casagrande, 1975; Seed, 1979) and "true liquefaction" (Chern, 1985). Sand in the medium density state (curve 2) initially responds through strain softening (contractive behaviour) similar to the response of loose sand until reaching a minimum shear strength and then the response is hardening. This behaviour has been called "partial liquefaction" by Lee \& Seed (1967) and "limited liquefaction" by Castro (1969) and Vaid \& Chern (1985). 

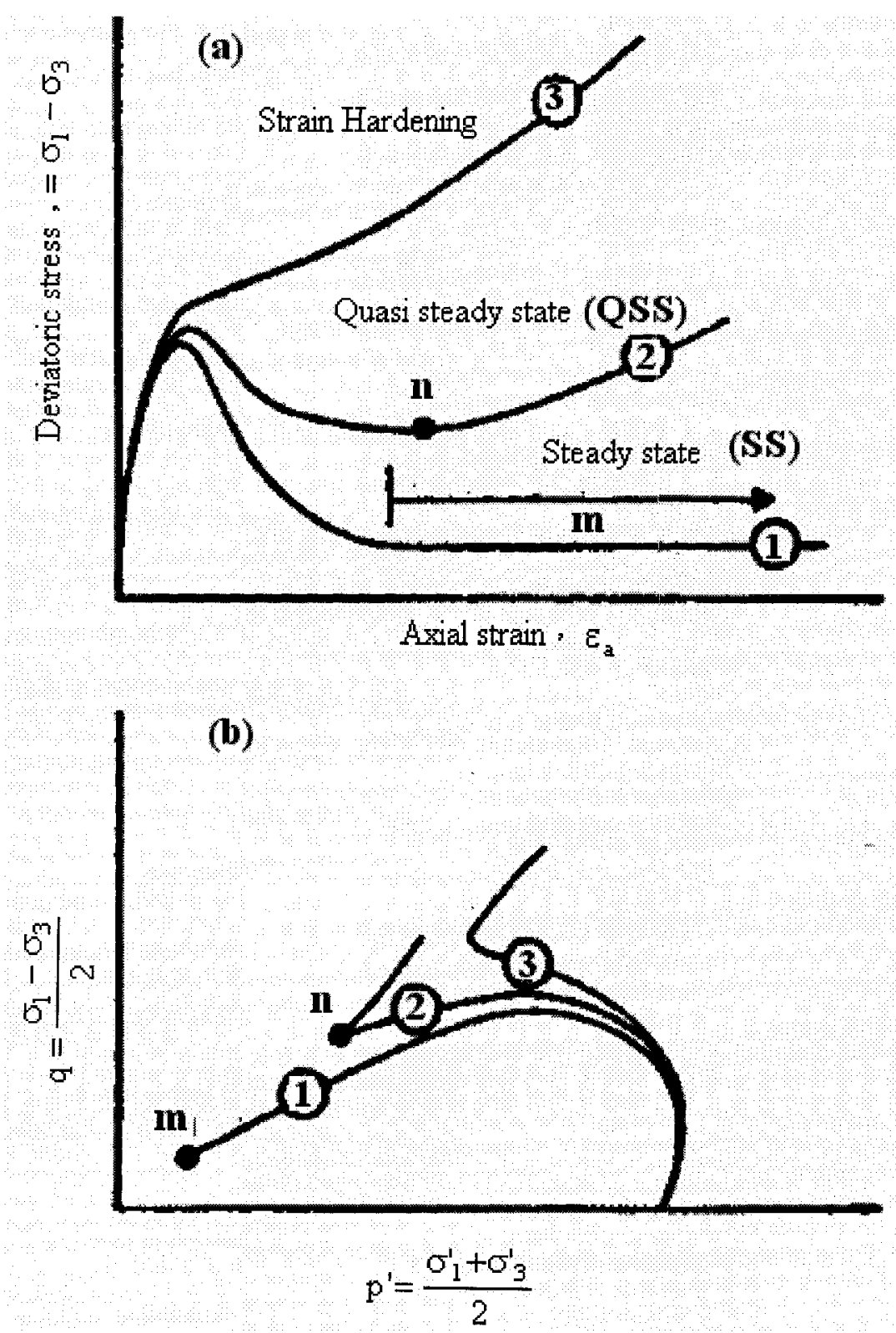

Figure 2.5 Characteristic behaviours of three different relative densities of saturated sand under triaxial monotonic loading: (a) stress-strain response, (b) stress path, (Vaid and Chern, 1985). 
For sand in a dense state (curve 3), the response is strain hardening. In this response there is no loss of shear strength and therefore the behaviour is always dilative. Clearly, stress-strain response is dependent on the initial state (relative density). As the relative density increases, the response changes from strain softening to strain hardening.

In the literature, few researchers have shown the full spectrum of monotonic loading behaviour from contraction to dilation of mine tailings. Taylor (1987) has displayed the full spectrum from dilative to contractive behaviour for remolded coarse colliery tailings samples tested under load control triaxial conditions (Figure 2.6). The three types of responses from contractive to dilative can be seen in Figure 2.6. These samples were fabricated from tailings ranging from significantly low densities to high densities.

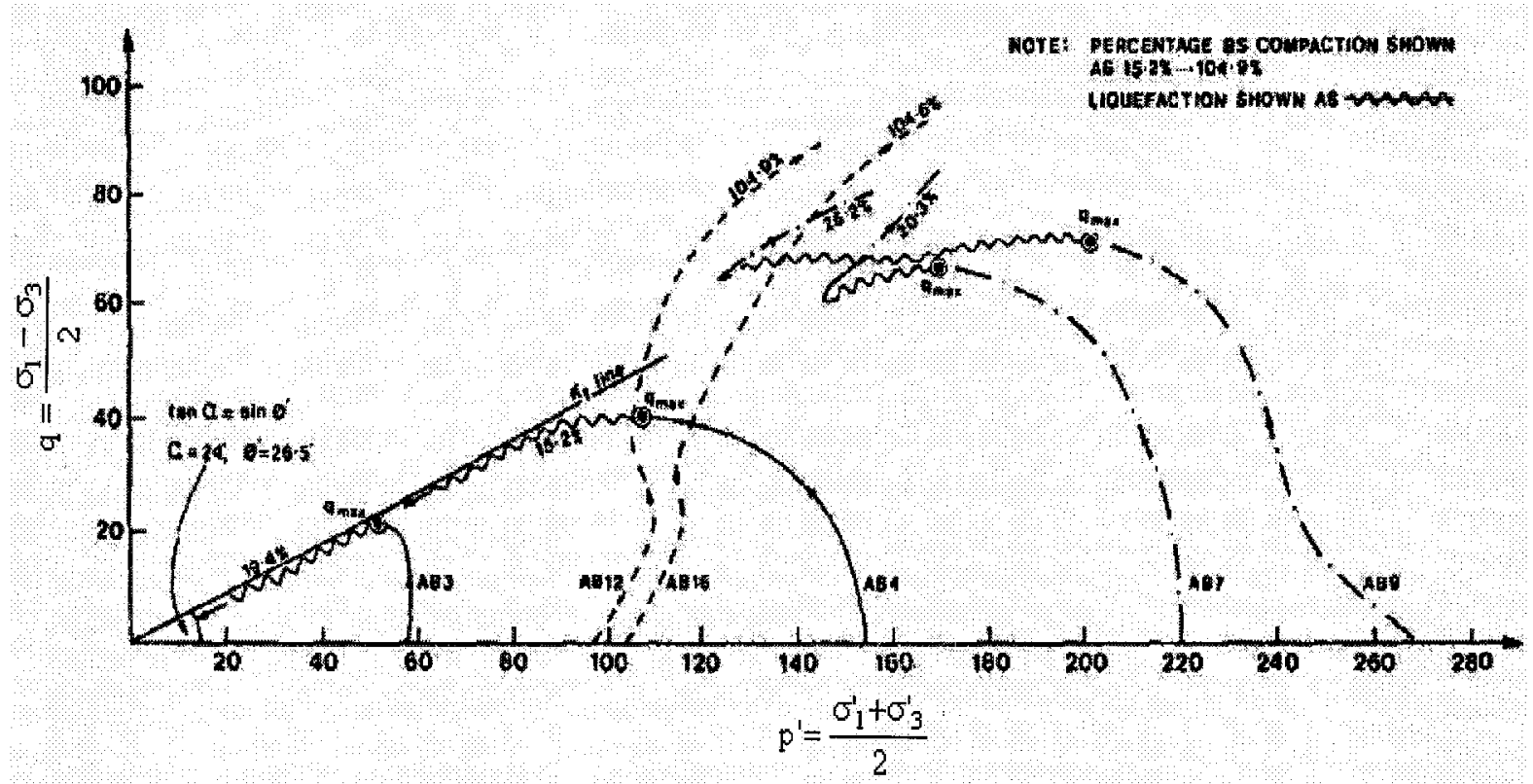

Figure 2.6 Effective stress paths for remolded colliery tailings under load control triaxial test (Taylor, 1987). 


\subsubsection{Critical Stress Ratio}

In undrained loading, the peak shear stress indicates the initiation of strain softening behaviour or flow liquefaction as shown in Figure 2.5 . The effective stress ratio $\left(p^{\prime} / q\right)$ corresponding to the peak shear stress is called critical stress ratio (CSR) (Vaid and Chern, 1983). Chern (1985) and Thomas (1992) have shown that a unique straight line can fit through the locus points of CSR and is only dependent on void ratio based on triaxial compressive tests on sands prepared by the water pluviation method. However, the confining pressures, sample preparation and load conditions might have an influence of the CSR line position. The projection of locus points of CSR to the origin has been called "flow liquefaction surface" (FLS). In fact, the FLS marks the boundary between stable and unstable states in undrained shear conditions, since the flow liquefaction cannot occur when the stress path is below the steady state point.

\subsubsection{Phase Transformation and Steady States}

The phase transformation $(\mathrm{PT})$ is the temporary state when the rate of excess pore pressure generation becomes zero (symbol $n$ in Figure 2.5). In this condition the behaviour of the sand transforms from contractive to dilative behaviour (Ishihara et al., 1975). It has been shown clearly for sand that the PT states fall on a unique straight line passing through the origin regardless of the relative density, confining stress and load mode (Vaid and Chern, 1985; Vaid et al., 1990; Thomas, 1992). Also, it is reported by Vaid and Chern (1985) that the findings of tailings sand were similar to natural sand. The PT and steady state might be treated within the same framework in stress $\left(p^{\prime}-q\right)$ space, even though their characteristics can be quite different in stress-void ratio $(q-e)$ space. 
The mobilized friction angle at quasi steady (limited liquefaction) state and at steady state (flow liquefaction) are essentially equal (Chern, 1985; Vaid and Thomas, 1994). These findings indicate that the friction angle at phase transformation or steady state is a unique material property and is depended only upon soil characteristics.

\subsubsection{Ultimate Failure Envelope}

Ultimate failure is the state in which the effective stress path approaches a straight line beyond the PT state and reaching the maximum obliquity (Ishihara et al., 1975). Some researchers contend that the angle of maximum obliquity is unique and is independent of the initial state prior to undrained shear loading (Vaid and Chern, 1985; Kuerbis, 1989; Thomas, 1992). In contrast, others have reported that the angle of maximum obliquity is changed with the change in the stress and strain level, and that the failure line angle is a function of relative density, loading mode and sample preparation (Miura and Toki, 1982).

\subsubsection{Steady State Concept}

Steady state is defined as the state in which the soil continuously deforms under constant effective confining pressure, and constant shear stress at constant volume and constant rate of shear strain. The concept of the steady state line has been demonstrated by using triaxial tests for sand (Castro, 1969; Castro and Poulos, 1977; Poulos, 1981). Steady state deformation is reached at large strains when there is no effect of initial conditions (fabric, stress-strain history, and load conditions) and it is only related to the 
void ratio (Castro, 1969; Castro et al., 1982). At the steady state, a special structure exists due to new particle contacts which results in minimum shear resistance with no volume change. Several researchers have argued that the steady state line is unique and can be presented within a framework of the three dimensional spaces of void ratio, shear stress and confining pressure (Vaid et al., 1990; Chern, 1985).

The steady state line is also defined as the boundary line between the contractive and dilative behaviour in void ratio and confining pressure space. However, a large number of researchers disagree with the uniqueness of the steady state line and maintain that its putative factors (fabric, sample preparation technique, confining pressure, load and drained conditions) may or may not affect it (Vaid et al., 1990; Riemer and Seed, 1997; Vaid et al., 1999). Recently, studies have demonstrated for mine tailings and silty sand soil that the steady state line is difficult to identify. This might be due to errors in measurement of the initial sizes of the tailings samples (Fourie and Papageorgiou, 2001) or to the steady state line may not always exist for silty sands (Yamamuro and Lade, 1998).

\subsubsection{Cyclic Loading Behaviour}

Several studies have shown that the concept of FLS for monotonic loading can be applied in the cyclic loading condition as well. Vaid and Chern (1983) conducted a series of triaxial tests on sand and applied FLS to both monotonic and cyclic loadings. Hyde et al. (2006) presented the stress path for the monotonic and cyclic loading of non-plastic silt in the same figure and applied the concept of FLS for both monotonic and cyclic loading conditions. In contrast, experimental evidence shows that the effective stress path 
moves slightly beyond the FLS when initial liquefaction has been reached (AlarconGuzma et al., 1988).

\subsubsection{Type of Response}

It is well known that the change of soil's initial state influences its behaviour by changing from flow liquefaction to limited liquefaction to cyclic mobility. Those behaviours have distinct characteristic mechanism, and thus different stress-strain responses (Figure 2.7). Flow liquefaction produced by cyclic loading only occurs if the following criteria are achieved: (i) the soil behaviour under static loading is contractive, (ii) the maximum shear stress must be greater than the steady state or quasi steady state strength $\left(\tau_{s t a t i c}+\tau_{c y c} \geq \mathrm{S}_{s u}\right)$, and (iii) the effective stress path hits the FLS within a sufficient number of cycles (Castro and Poulos, 1977; Vaid and Chern, 1985). As shown from Figure 2.7, flow liquefaction is triggered in a similar manner as in static liquefaction. Initially, the stress path starts moving to the FLS as a result of the changing loading and unloading cycles. This increases the pore pressure and accumulates strain. Once the effective stress path hits the FLS the soil becomes liquefied and strain softening develops until it reaches the steady state or quasi steady sate. This type of response is known in static liquefaction as type 1 . 


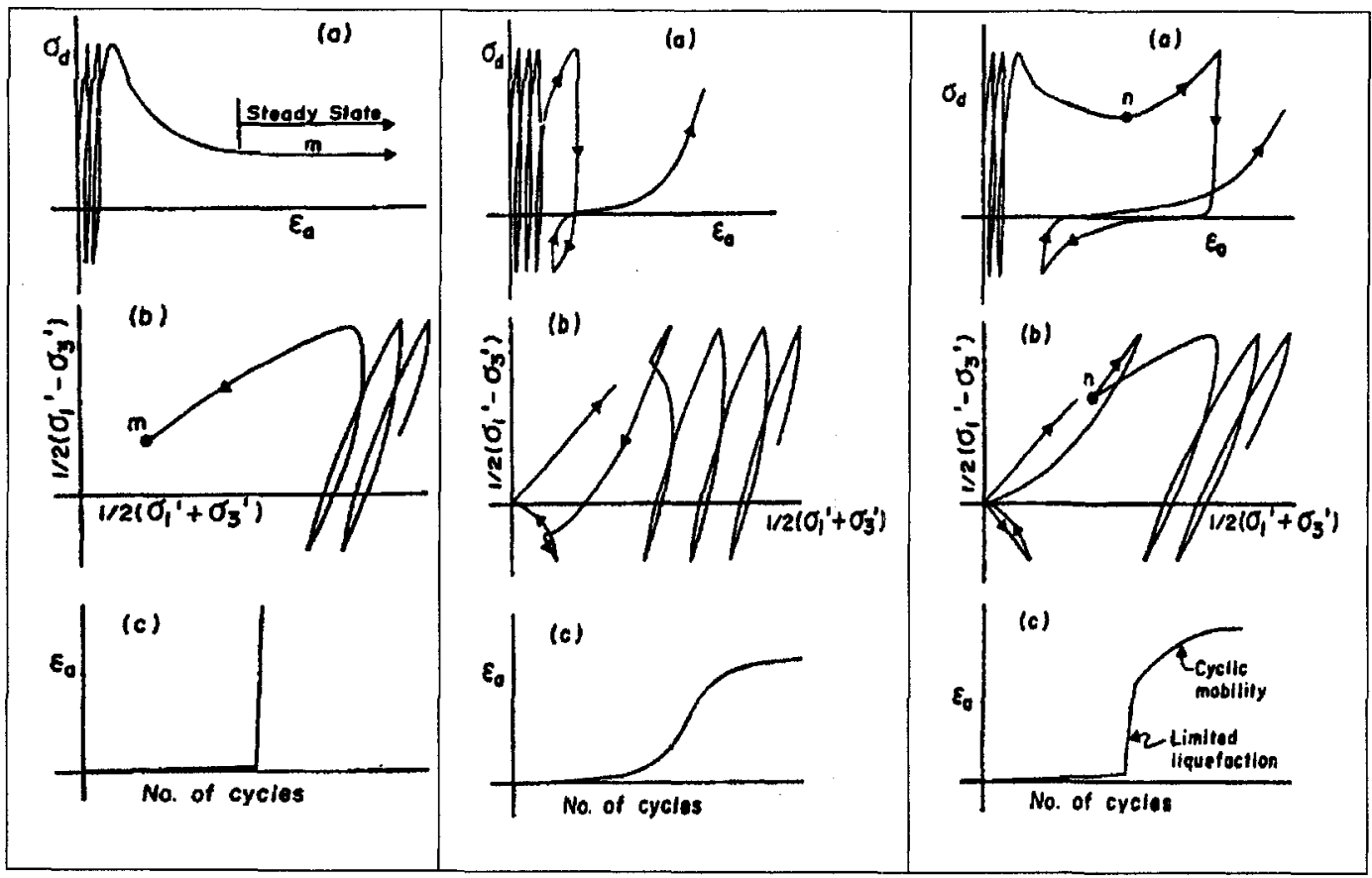

(A)

(B)

(C)

Figure 2.7 Cyclic loading behaviour: (a) flow liquefaction due to cyclic loading, (b) cyclic mobility due to cyclic loading, (c) limited liquefaction due to cyclic loading, (Vaid and Chern, 1985).

Cyclic mobility is developed when the static shear stress is smaller than the steady-state strength $\left(\tau_{\text {static }}+\tau_{c y c} \leq \mathrm{S}_{s u}\right)$. It is important to note that the cyclic mobility can occur regardless of the behaviour of soil (contractive or dilative) under monotonic loading. In cyclic mobility, no strain softening deformation occurs. Initially, the development of strain is small due to a decreasing normal effective stress with cyclic loading. The accumulation of strain is associated with stiffness degradation until the effective stress path reaches the FLS (Vaid and Chern, 1985). Subsequently, the cyclic loading causes a large increase in excess pore pressure and moves the effective stress close to zero; moving the effective stress path close to zero causes progressive stiffness degradation and strain accumulation. 
Figure 2.8 illustrates three different combinations of initial conditions responsible for cyclic mobility as proposed by Vaid and Chern (1985). The first condition occurs when there is no stress reversal $\left(\tau_{\text {static }}>\tau_{c y c}\right)$ and the steady state strength does is not exceeded by the effective stress path $\left(\tau_{s t a t i c}+\tau_{c y c}<\mathrm{S}_{s u}\right)$. The second condition occurs when there is no stress reversal $\left(\tau_{\text {static }}>\tau_{c y c}\right)$ and the steady state strength is exceeded momentarily $\left(\tau_{\text {static }}+\tau_{c y c}>\mathrm{S}_{s u}\right)$. The final condition occurs if there is stress reversal $\left(\tau_{\text {static }}\right.$ $\left.<\tau_{c y c}\right)$ and steady state strength is not exceed by the effective stress path $\left(\tau_{s t a t i c}+\tau_{c y c}<\right.$ $\left.\mathrm{S}_{s u}\right)$.

The last type of cyclic loading behaviour is limited liquefaction. In this behaviour, the response of the strain development is initially softening until the effective stress path reaches the FLS. Beyond the FLS, the effective stress transits to zero and a large strain deformation is induced due to cyclic mobility. The type of response in which the soil temporarily loses its shear resistance and regains with subsequent straining is shown in Figure 2.7(c).

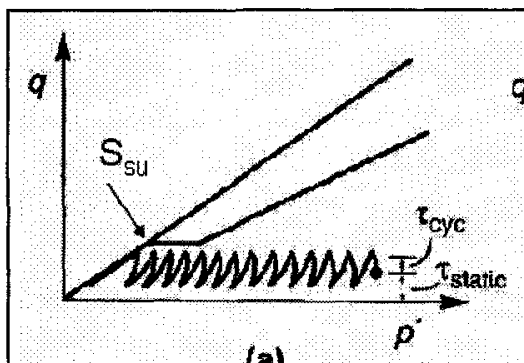

(a)

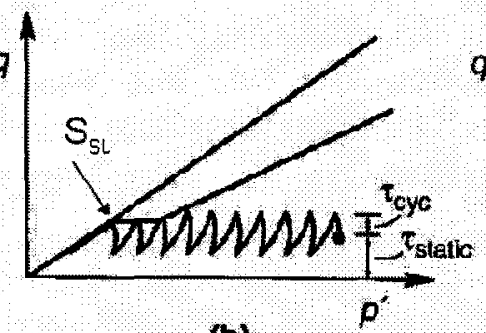

(b)

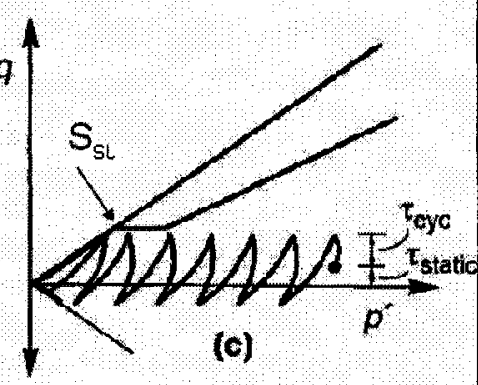

(c)

Figure 2.8 three different combinations of cyclic mobility: (a) no stress reversal and no exceedance of the steady-state strength, (b) no stress reversal with momentary period of steady-state strength exceedance; (c) stress reversal with no exceedance of steady-state strength, (reproduced from Kramer, 1996). 


\subsubsection{Pore Water Pressure Generation}

In the literature there are different views on the inducement of pore water pressure due to soil type. Investigations on undisturbed and reconstituted samples of silts with low to medium plasticity, show they behave differently compared to plastic silts and silt-clay mixtures. The build up of pore water pressure is responsible for having different behaviours and deformations under cyclic loading (Erten and Maher, 1995; Singh, 1996; Polito, 1999). The effects of fines content and plasticity on the pore pressure generation characteristics of silty and clayey sands have been investigated by Polito (1999). It was noted in Polito's study that the pore pressure ratio for sands with plastic fines varies as the plasticity of the soils vary. Soils with high plasticity and low plasticity produced pore pressure generation curves similar to those produced for soils with non-plastic fines susceptible to cyclic mobility and flow liquefaction, respectively.

Singh (1996) presented a comparison between silt and sand behaviours under cyclic loading as a function of the peak to peak strain versus the number of cyclic and pore pressure ratio versus number of cyclic loadings. Figure 2.9 shows clearly the differences in the strain developments and characteristic of pore pressure generation between silt and sand samples tested under cyclic triaxial loading conditions. Singh reported that the criteria to describe the term "initial liquefaction" by using pore pressure criteria (100\% pore pressure) is valid only for sand, because it is not possible to reach $100 \%$ pore pressure for silts. Thevanayagam and Martin (2000) reported that the trend of pore pressure generation characteristics in terms of $r_{u}$ versus $N / N_{l}\left(N / N_{l}\right.$ is normalized number of cycles, $\mathrm{N}=$ number of cycles, $\mathrm{N}_{1}=$ number of cycles to reach liquefaction at $5 \%$ double amplitude axial strain) for silty sand mixtures (silt $>25 \%$ ) was faster than for 
sand, however for silt less than $25 \%$ the trend followed to the trend of sand which was presented by Seed et al. (1976).

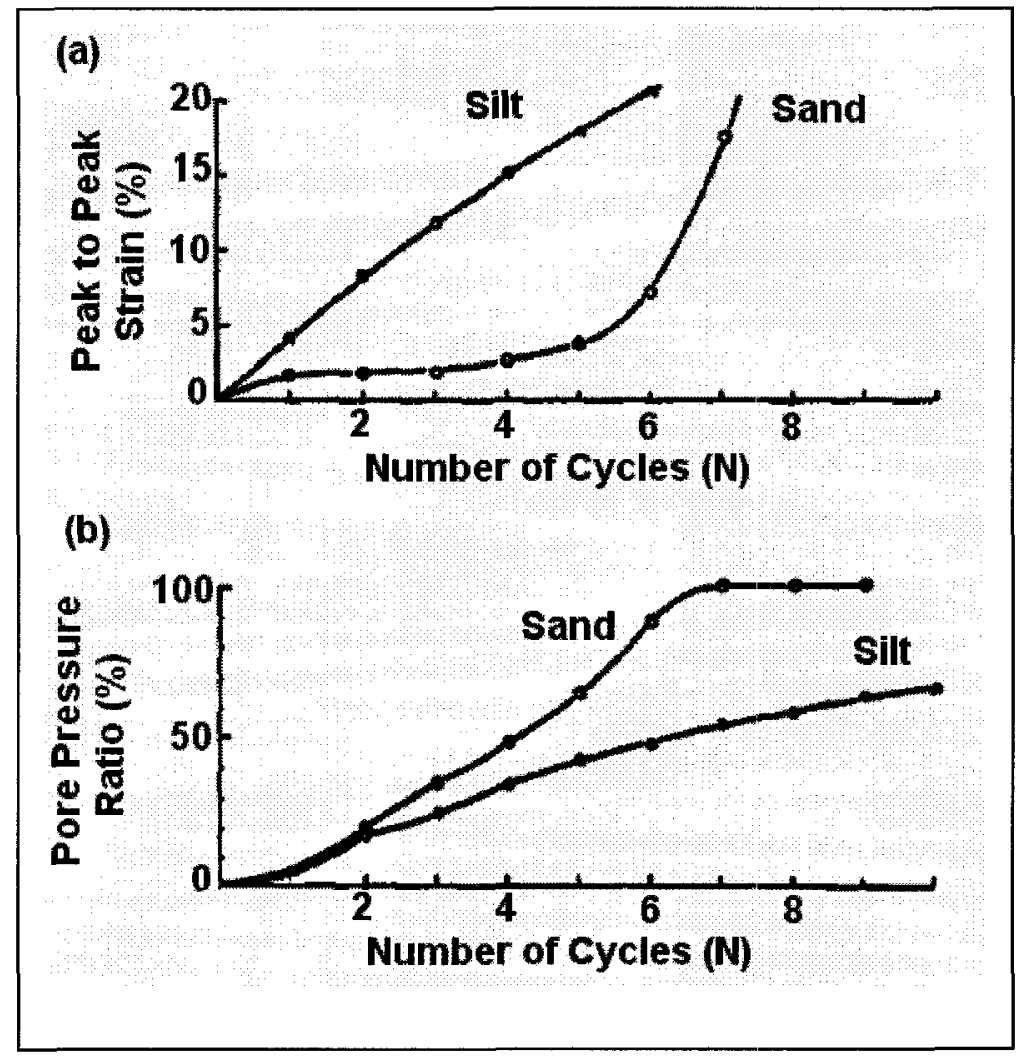

Figure 2.9 Comparison of typical silt sample and loose sand sample: (a) peak to peak strain with number of cycles, (b) pore pressure development with number of cycles, (Singh, 1996).

\subsubsection{Effect of Initial State Variables on Cyclic Resistance}

The definition of cyclic loading resistance is independent of the mechanism of strain development. The cyclic shear resistance is defined as the uniform cyclic shear stress amplitude that is required to cause a specified level of strain in a specified number of cycles. The cyclic stress ratio (CSR) is widely used to demonstrate the influence of the state variable in cyclic behaviour and it is basically cyclic shear stress normalized by the 
effective consolidation pressure when simple shear apparatus is used. Many factors such as void ratio, confining stress level, static shear stress level, sample preparation techniques, and load mode, have an effect on the cyclic stress ratio. The influences of these factors on the cyclic undrained response will be discussed below.

\subsection{Effect of Confining Stress}

The influence of confining stress in cyclic resistance of mine tailings and silty soil has not been demonstrated. Results of cyclic tests on laterite tailings showed that the cyclic shear resistance of the tailings increase with an increase in the effective confining stress (Wijewickreme et al., 2005) for samples consolidated at almost similar initial void ratio. For sand, it has been recognized that the increase of confining stress leads to decrease of cyclic stress resistance at a given relative density (after consolidation). In order to account for the influence of confining stress onto cyclic shear stress, Seed (1983) proposed a $K_{\sigma}$ factor which is defined as CSR at a reference value of confining stress $(100 \mathrm{kPa})$ and at no shear stress level. It has been observed in the laboratory that the

relationship between $\mathrm{K}_{\sigma}$ and confining stress is not linear. As a result the dependency of $\mathrm{K}_{\sigma}$ is not exclusively a function of confining stress as it is also effected by relative density and loading mode (Vaid and Chern ,1985; Vaid and Thomas, 1994; Vaid and Sivathayalan, 1996.a). A more recent comprehensive study on sand found that the initial static shear stress also has influence on the $\mathrm{K}_{\sigma}$ (Sivathayalan and $\mathrm{Ha}, 2004$ ). 


\subsection{Effect of Initial Static Shear}

The influence of initial static shear to the cyclic shear resistance has not been addressed for mine tailings. Even in the case of sand, this influence still has not been completely understood. It has been realized for a long time, that initial static shear is an important factor in the liquefaction assessment of slope grounds. Seed (1983) also introduced the factor $K_{\alpha}$ to account for the influence of initial static shear onto liquefaction assessments. $\mathrm{K}_{\alpha}$ is defined as the ratio of cyclic resistance at a given static shear stress level to that at no static shear stress. Studies by Vaid \& Finn (1978) and Vaid \& Chern $(1983,1985)$ demonstrated that the influence of cyclic resistance depends of the mechanism of strain development that causes liquefaction. If strain development is softening, then cyclic resistance decreases with an increase in static shear and the influence is vice versa if the cyclic mobility occurs. Sivathayalan and Ha (2004) proved that in addition to $\mathrm{K}_{\alpha}$ 's dependency on confining stress, static shear stress levels and density, the $\mathrm{K}_{\alpha}$ factor also depends on soil type and loading mode. The summary of NCEER (1996 \& 1998) workshop (Youd et al., 2001) recommended that $K_{\alpha}$ needs continued research, because the influence of $\mathrm{K}_{\alpha}$ is still ambiguous.

\subsection{Effect of Over-consolidation Ratio}

In geotechnical practice, stress history of the fine grained material on the mechanical properties is expressed in terms of over-consolidation ratio (OCR). The OCR is defined as the ratio by which the current effective stress in the soil was exceeded in the past, where OCR is equal to one for normally consolidated soils. Stress history has been found to potentially influence the development of pore pressure which in turn impacts 
cyclic resistance. Ishihara (1978) preformed cyclic triaxial tests on soils containing fines (passing sieve No. 200) from 0 to 100 percent by weight to investigate the effect of OCR values from 1.0 to 2.0. It was found that the OCR has a clear impact to the increase of cyclic resistance, and this impact becomes more marked as the fine content increases. More recently, Yasuhara et al. (2003) conducted a series of cyclic triaxial tests on low plastic silt. Results show that the stress ratio gradient (dp/dq) becomes smaller and approaches the gradient of the critical state $(\mathrm{dp} / \mathrm{dq})_{\mathrm{cs}}$ as the OCR increases. Furthermore, they reported that the silt samples become less prone to undrained cyclic failure as the OCR increases.

\subsection{Effect of Void Ratio}

From field and laboratory studies, it is well recognized for sand that an increase in void ratio causes a decrease of the cyclic shear resistance. However, for materials that have high percentage of fines such as silt, this causal relationship does not apply (Ishihara et al., 1980). In fact, there is a lack of information in the existing literature exploring the effect of void ratio of low-plastic mine tailings in cyclic resistance. Results of cyclic triaxial testing by Ishihara et al. (1981) showed that the cyclic strength decreases consistently with an increase in void ratio for mine tailings classified as sand, while for mine tailings classified as silt, the cyclic loading resistance is nearly independent of the void ratio and grain size characteristics of undisturbed sample. 


\subsection{Effect of Fines and Plasticity Index}

In the literature, both laboratory and field studies have demonstrated the trends of decreasing cyclic resistance, increasing cyclic resistance or decreasing and then increasing cyclic resistance with increases in fine content. These large discrepancies may be associated to different criteria which were adopted in field and laboratory studies and also the sensitivity of liquefaction resistance due to soil mixture to the type and amount of fines (non-plastic and plastic). Influence of fine content in the liquefaction resistance of mine tailings classified as sand is investigated by Troncoso (1990). It was found that the cyclic strength decreases with an increase of the fines content (Figure 2.10).

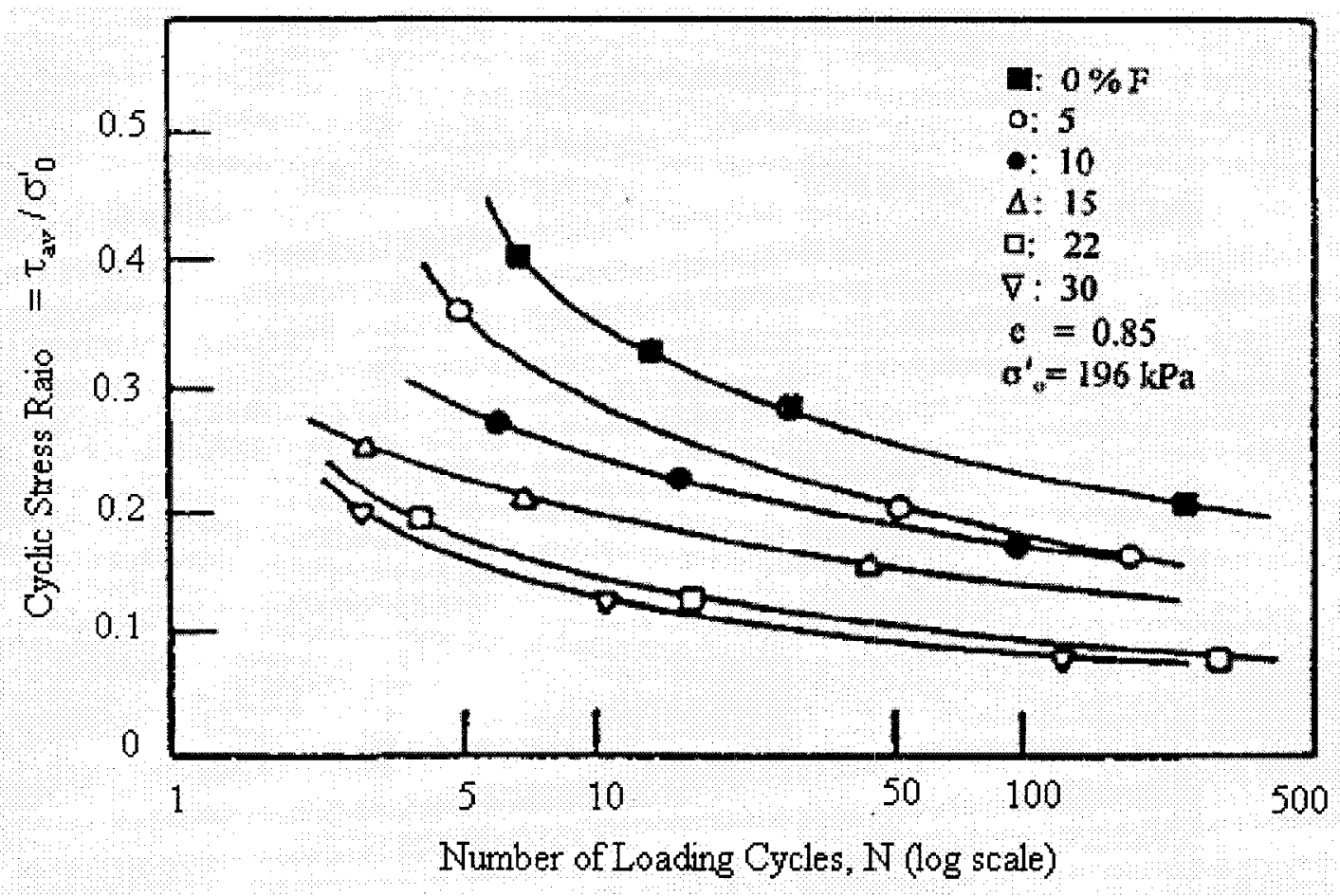

Figure 2.10 Cyclic stress ratio with fine content of mine tailings (Troncoso, 1990) 
Koester (1993) used laboratory results of sand silt mixtures from Chang (1990) to investigate the fines influence on cyclic resistance; at a same void ratio the cyclic resistance decreases with fines content increasing up to $20 \%$ fines in sand, and then it increases as the fines content increases. In contrast, Figure 2.11 shows that the field data observations from different sites were or were not liquefied under a 7.5 earthquake magnitude (Seed et al., 1985). It is clearly observed, the liquefaction resistance of sandfines mixture (silty sand) increases as the percent fines increases at a given standard penetration test $\left(\mathrm{N}_{1}\right)_{60}$. In spite of these studies, there appears to be considerable confusion about the effect of fines on liquefaction resistance. The confusion may be explained by the different ways in which the effect of fines is compared.

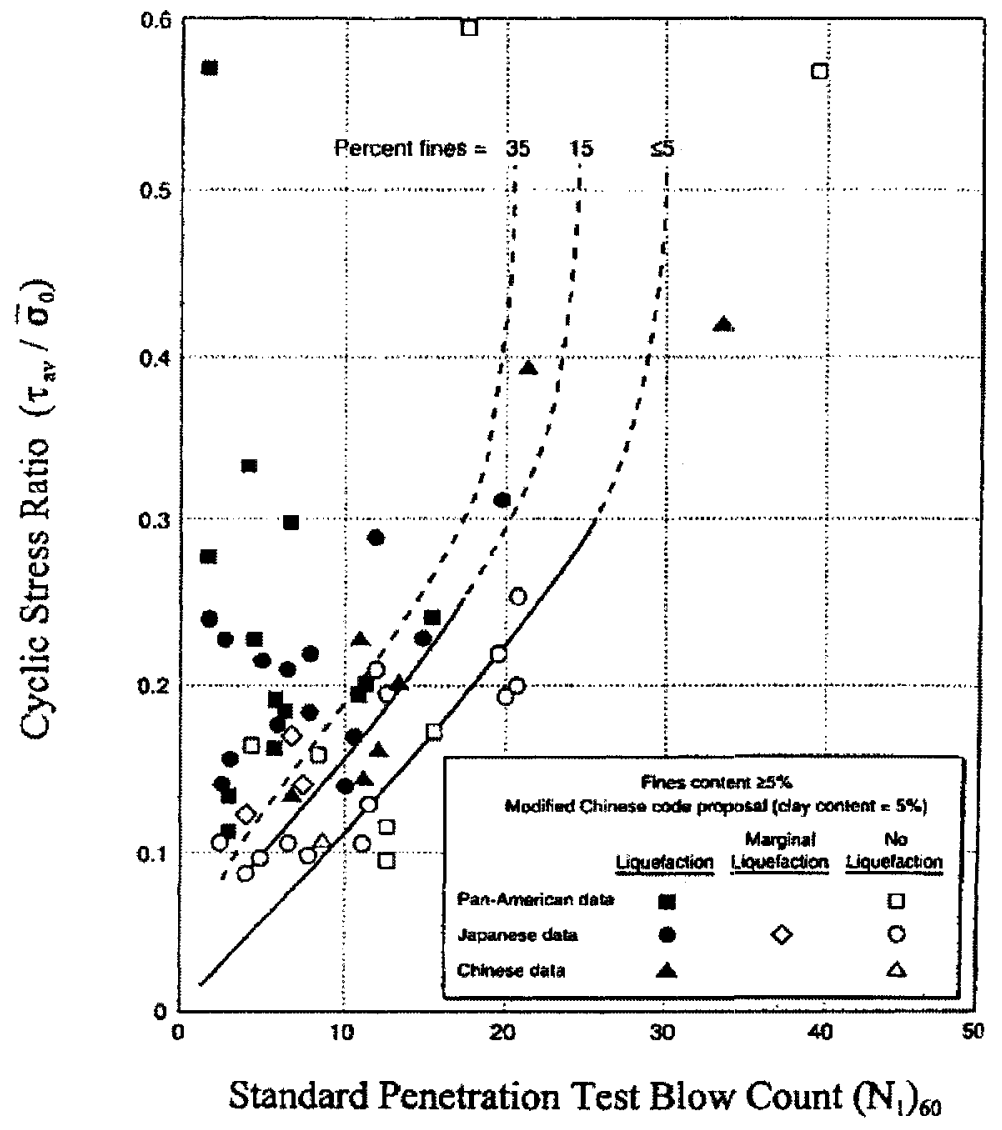

Figure 2.11 Cyclic stress ratio causing liquefaction $(M=7.5)$ with $\left(N_{1}\right)_{60}$ values for silty sand (Seed et al., 1985). 
The effect of plastic and non-plastic fines content on the sandy soil is investigated under cyclic triaxial test by Polito (1999). The results of Polito's study showed that the trend of increasing cyclic resistance with increasing fine content does not appear to occur in non-plastic silts. In addition, it has been reported in the literature that an increase in the cyclic resistance is likely due to the plasticity of the fines used in those studies. Polito found three distinct behavioural patterns for the cyclic resistance of soils composed of sand and non-plastic silt.

The difference in patterns is governed mainly by the limiting silt content. The soil mixture will respond as sand soil if the silt content of the soil is below the limiting silt content. The cyclic resistance of soil is independent of silt content, and is function of the gross void ratio of the sample. If the silt content is greater than the liming silt content, the cyclic resistance of the soil mixture is controlled by silt fraction void ratio. In the abovementioned case, decreasing silt void ratios lead to an increase in cyclic resistance. The soil mixture can be controlled by the void ratio and silt fraction void ratio if the silt content of the soil mixture is close to the limiting silt content, this type of pattern is called "transition zone". Polito (1999) reported that the cyclic resistance of sand with plastic fines is strongly dependent on the plasticity of the soil, more so than on the fine content, clay content, water content and liquid index. These findings support the observations of Ishihara et al. (1980) showing that the cyclic loading resistance increases slightly as the plasticity index of the tailings materials is increased.

For fine grained tailings, the cyclic stress ratio tends to increase as the plasticity index increases (Ishihara et al., 1980). The cyclic strength of the fine grained tailings which are classified as being non-plastic was found to be relatively small, whereas the 
fine grained tailings having a plasticity index within the range of 15 to 20 were shown to have much higher cyclic strength as compared to the non-plastic tailings.

\subsubsection{Liquefaction Criteria for Fine Grained Soil}

The most common liquefaction criteria used to distinguish between fine grained soils which are considered to be liquefiable from those considered as not being liquefiable is the Chinese Criteria (Wang, 1979). The criterion is based on the observation from sites where liquefaction did or did not occur in fine grained soil. The fine grained soil is considered to be susceptible to liquefaction as a result of earthquake shaking, if all of the following soil characterizations are satisfied: (i) fraction fine less than $0.005 \mathrm{~mm} \leq 15 \%$, (ii) liquid limit, $\mathrm{LL} \leq 35 \%$, and (iii) water content $\geq 0.9$ LL. Many researcher have demonstrated that the Chinese criterion may not always be valid for the assessment of the liquefaction susceptibility of fine grained soils (Atukorala, et al., 2000; Boulanger and Idriss, 2006; Bray et al., 2004). Therefore, the Chinese Criteria has been modified and re-developed many times in the past decades (Table 2.1).

It is important to note that all the proposed criteria (Table 2.1) were based on field and laboratory observations regardless of the type of liquefaction phenomenon (flow liquefaction and cyclic mobility) except Boulanger and Idriss (2004) criteria. This criterion is based on the mechanics of stress-strain behaviour of fine grained soil that is susceptible to liquefaction as a factor of the plasticity index (PI) (Figure 2.12). Soils that have PI $\geq 7$ are expected to exhibit clay-like behaviour and the cyclic mobility phenomenon will therefore occur. Soils can be expected to exhibit sand-like behaviour and flow liquefaction can occur if $\mathrm{PI}<3$. There is a transition zone in which soils exhibit 
clay-like or sand-like behaviour if PI values 3- 7. In this case the soils may exhibit intermediate behaviour, such that field and laboratory studies are required to investigate the behaviour of soils.

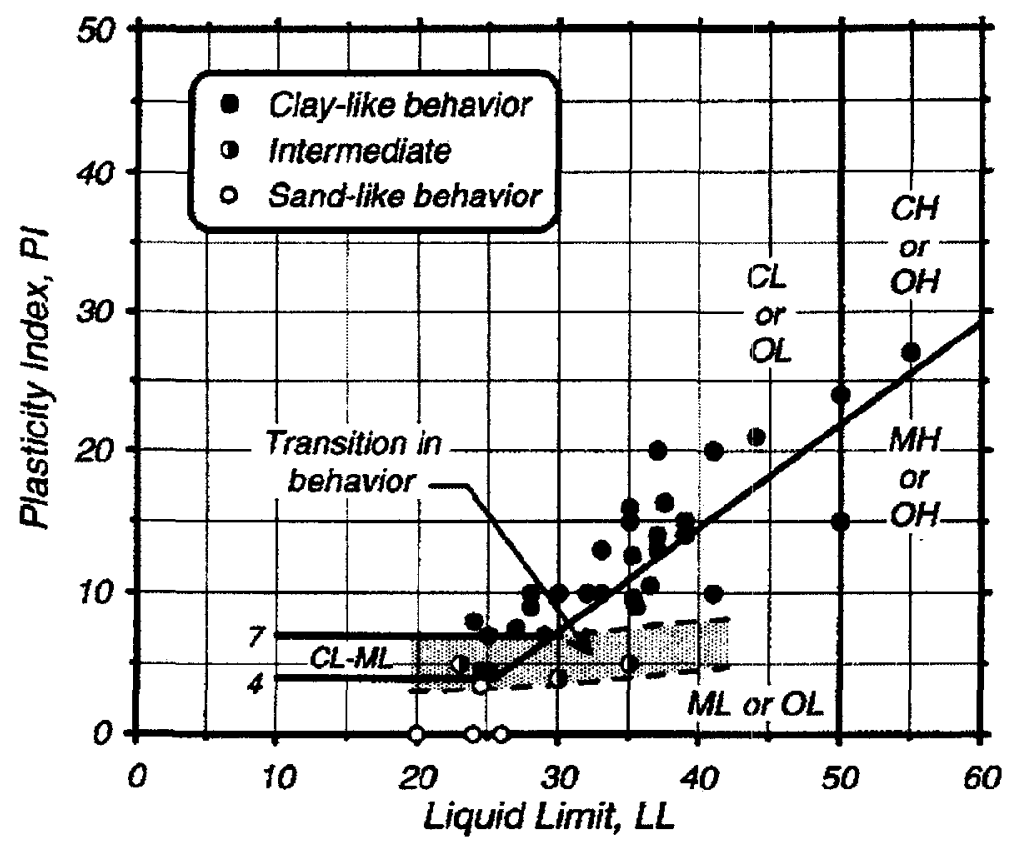

Figure 2.12 Atterberg limits chart showing Boulanger and Idriss (2004) criteria. 
Table 2.1 Review of liquefaction criteria for fine grain soil.

\begin{tabular}{|c|c|c|c|}
\hline No. & Investigator & Statement & $\begin{array}{l}\text { Characterizations should } \\
\text { be satisfied }\end{array}$ \\
\hline 1 & Wang (1979) & $\begin{array}{l}\text { Soil meeting these criteria are } \\
\text { considered to be liquefiable }\end{array}$ & $\begin{array}{ll} & \text { Particles smaller than } \\
& 0.005 \mathrm{~mm}<15 \% \\
\text { - } & \text { Liquid limit, } \mathrm{LL} \leq \\
& 35 \% \\
\text { - } & \text { Water content } \geq 0.9 \mathrm{LL} \\
\text { - } & \text { Liquidity Index } \geq 0.75\end{array}$ \\
\hline 2 & $\begin{array}{l}\text { Jennings (1980) as } \\
\text { reported by Polito } \\
(1999)\end{array}$ & $\begin{array}{l}\text { Soil meeting these criteria are } \\
\text { considered to be non- } \\
\text { liquefiable. }\end{array}$ & $\begin{array}{ll}- & \text { Clay contents }>10 \% \\
\text { - } & \text { Plasticity index }>10 \\
\text { - } & \text { Relative density }>75 \% \\
\text { - } & \text { Ooid ratio }<0.8 \\
& \text { Other parameters } \\
& \text { related to earthquake } \\
& \text { parameters and site } \\
& \text { condition. }\end{array}$ \\
\hline 3 & $\begin{array}{l}\text { Seed and Idriss } \\
\text { (1982), as } \\
\text { presented by Bray } \\
\text { and Sancio, (2004), } \\
\text { Modified Chinese } \\
\text { Criteria }\end{array}$ & $\begin{array}{l}\text { 1- Soil meeting these criteria } \\
\text { are considered to be liquefiable } \\
2 \text { - If soils with these } \\
\text { characteristics plot above the } \\
\text { A-line on the Atterberg chart, } \\
\text { run tests to determine the cyclic } \\
\text { loading characteristics. }\end{array}$ & $\begin{array}{ll}\text { - } & \text { Particles smaller than } \\
& 0.005 \mathrm{~mm}<15 \% \\
\text { - } & \text { Liquid limit, } \mathrm{LL}<35 \% \\
\text { - } & \text { Water content }>0.9 \mathrm{LL}\end{array}$ \\
\hline 4 & $\begin{array}{l}\text { Finn (1982), } \\
\text { Modified Chinese } \\
\text { Criteria. }\end{array}$ & $\begin{array}{l}\text { Soil meeting these criteria are } \\
\text { considered to be liquefiable }\end{array}$ & $\begin{array}{l}\text { Fraction fine than } \\
0.005 \mathrm{~mm} \leq 10 \% \text {, } \\
\text { Liquid limit, } \mathrm{LL} \leq \\
34 \% \text {, } \\
\text { Water content, } w \geq \\
\text { 0.88 LL. }\end{array}$ \\
\hline 5 & $\begin{array}{l}\text { Koester (1994) } \\
\text { Modified LL level } \\
\text { in Finn criteria }\end{array}$ & $\begin{array}{l}\text { Soil meeting these criteria are } \\
\text { considered to be liquefiable }\end{array}$ & $\begin{array}{l}\text { Fraction fine than } \\
0.005 \mathrm{~mm} \leq 10 \%, \\
\text { Liquid limit, } \mathrm{LL} \leq \\
36 \%, \\
\text { Water content, } w \geq \\
\text { 0.88 LL. }\end{array}$ \\
\hline 6 & Bray et al. (2004) & $\begin{array}{l}\text { 1-soil is susceptible to } \\
\text { liquefaction or cyclic mobility } \\
\text { if it meets soil characterization } \\
\text { (a and b). } \\
\text { 2-Soils may be moderately } \\
\text { susceptible to liquefaction or } \\
\text { cyclic mobility and tested are } \\
\text { requested to assess liquefaction } \\
\text { susceptibility if the soil meet (c } \\
\text { and d) } \\
3 \text {-Soils are considered to be not } \\
\text { susceptible to liquefaction if it } \\
\text { is met (e). }\end{array}$ & $\begin{array}{l}\text { (a) Ratio of water content to } \\
\text { liquid limit ( } w / L L) \geq 0.85 \\
\text { (b) Plastic index (PI) } \leq 12 \text {. } \\
\text { (c) PI is between } 12 \text { to } 20 \\
\text { (d) Ratio of water content to } \\
\text { liquid limit ( } w / L L) \text { is between } \\
0.8 \text { to } 0.85 \\
\text { (e) } \mathrm{PI}>20\end{array}$ \\
\hline
\end{tabular}




\subsection{Post-liquefaction Response}

Post-liquefaction deformation occurring in silty materials has caused severe damage to various structures including dams and embankments. Seed (1979) investigated the performance of Akiba and Sema dams due to the Ojika earthquake (1939), and reported that most of the dam failures occurred within a few hours or up to $24 \mathrm{~h}$ after the earthquake cessation. Studies by Hamada et al. (1986) and Tohno and Shamoto (1986), which are referenced in Shamoto et al. (1998) state that post-liquefaction ground deformation caused catastrophic damage to the various structures during the 1964 Niigata earthquake, the 1983 Nihonkai-Chuba earthquake and the Hyogoken-Nambu earthquake. Dobry and Alvarez (1967) observed that the Barahona tailings dam in Chile failed on October 1, 1928 a few minutes after of earthquake cessation. The post-liquefaction deformation might be the cause of dam failures, thus researchers have shown that the liquefaction phenomenon can exist in low-plastic silt as well as in sand. It is quite important to understand post-liquefaction phenomenon for safe design of tailings dams not only during the earthquakes abut also after the earthquake cessation.

Post-liquefaction deformation is generally divided into two main categories: volumetric deformation and shear deformation. Volumetric deformation causes a ground settlement and the settlement can be estimated based in Tokimatsu and Seed (1987) and Ishihara and Yoshimine's (1992) methods'. However, shear deformation causes lateral ground spreading, and this deformation can be estimated using the method proposed by Hamada et al. (1986) and Towhata et al. (1992). Shamoto et al. $(1997,1998)$ suggested a new method to predict simultaneously the post-liquefaction ground settlement and the lateral ground spreading. 


\subsubsection{Post-liquefaction Deformation Mechanisms}

During an earthquake, excess pore-water pressure develops in the soil causing the effective stress to decrease to zero, at which period liquefaction is initiated (Figure 2.13(b)). After liquefaction occurs, the excess pore pressure produces a hydraulic gradient that drives the pore-water out of the voids. The hydraulic gradient decreases as water flows out of the soil, until such time as the pore pressure dissipates. Due to the flow of water from the voids, the volume of soil mass is reduced and post-liquefaction deformation occurs (Figure 2.13(c)).

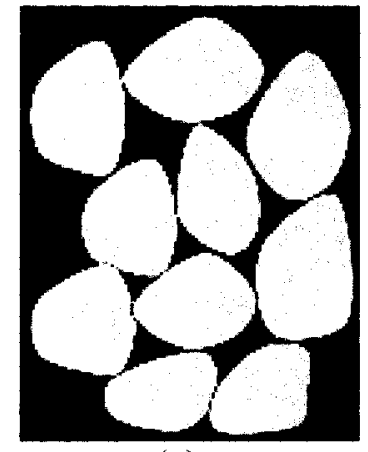

(a)

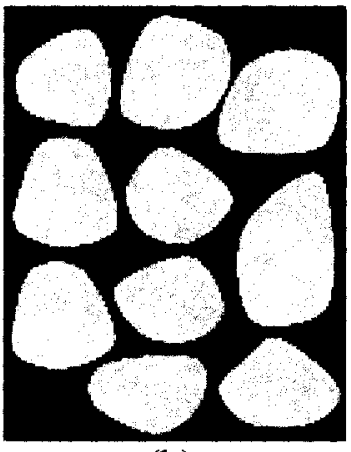

(b)

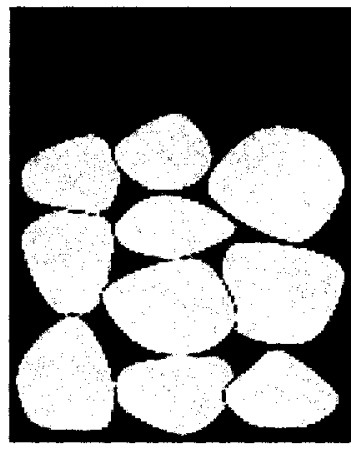

(c)

Figure 2.13 Liquefaction and post-liquefaction stats of soil: (a) Soil in natural state, (b) soil in liquefaction state, and (c) soil after post-liquefaction state.

Post-liquefaction deformation is usually accompanied by a redistribution of the void ratio, densification, and a change in stiffness and shear resistance. Because the development of pore pressure in silt is less than in sand during the earthquake, both soils exhibit different responses after the earthquake cessation and in the case of silt, it is possible to have relatively less densification and shear resistance (Hyde et al. 2004, 2007). 


\subsubsection{General Response in Post-liquefaction Loading}

Post-liquefaction behaviour can be simulated in the laboratory by applying monotonic loading to soil that has reached zero effective stress due to the initiation of flow liquefaction or cyclic mobility. As can be seen in Figure 2.14(b), as the stress path reaches instantaneous zero effective stress, due to cyclic mobility, it fluctuates along the portions of the failure envelope (compression and extension) and passes through the origin twice in one loading cycle. When monotonic loading is applied at this stage, the effective stress path exhibits a dilative behaviour, and a strain hardening response is observed in the stress-strain relationship (Figure 2.14(a)). For sandy soils, Vaid and Thomas (1995) concluded that the effective stress path exhibits a dilative behaviour and no indication of residual strength condition was reached.

Thomas (1992) suggested the characterization of a post-liquefaction (post-cyclic) stress-strain curve of sand (Figure 2.15). The stress-strain response of cyclic loadings followed by a post-cyclic loading (monotonic loading) is shown in this figure. As can be seen, the post-liquefaction response is divided into three different regions. Region 1 begins at the end of pre-liquefaction (cyclic or monotonic loading) when the effective confining stress prior to post-liquefaction is zero. In this region the shear stiffness is essentially zero and it increases gradually at a very small rate until the effective shear stress reaches small measurable values. Region 2 is called to the portion in which the post-liquefaction stress-strain curve has approximately parabolic shape. In this region, the shear stiffness increases continually as the strain increases. Region 3 is the portion in which the post-liquefaction stress-strain response becomes linear, thus the shear stiffness does not change. 


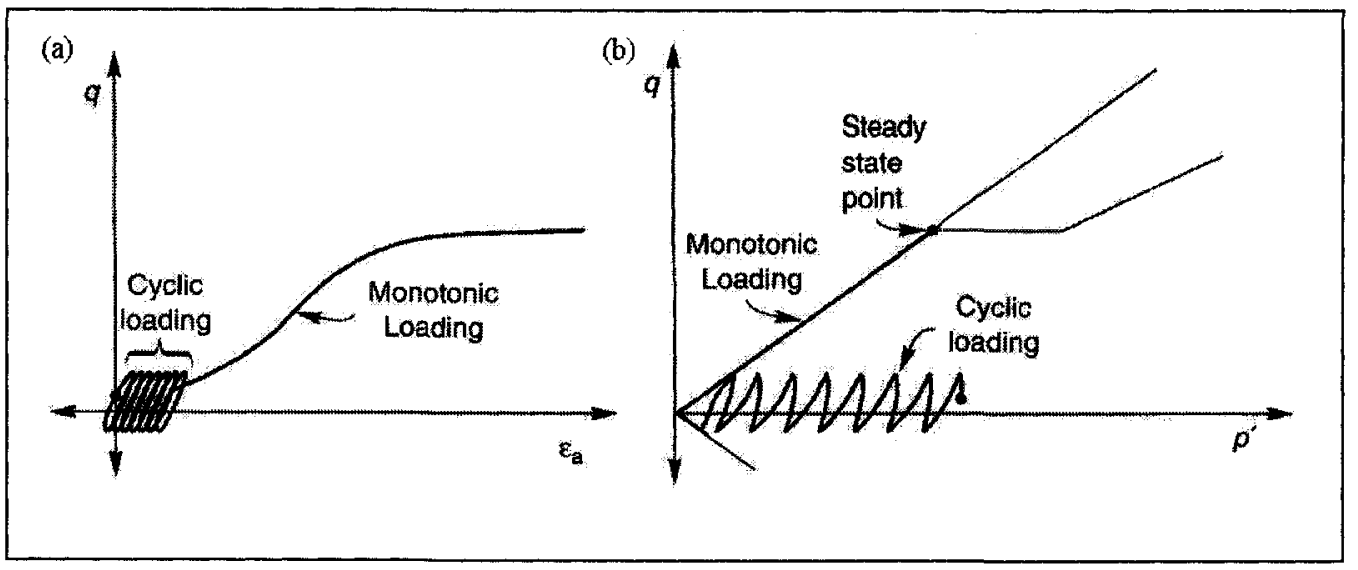

Figure 2.14 Typical post-liquefaction behaviour after cyclic mobility: (a) shear stressshear strain relationship, (b) effective stress path, (Kramer, 1996).

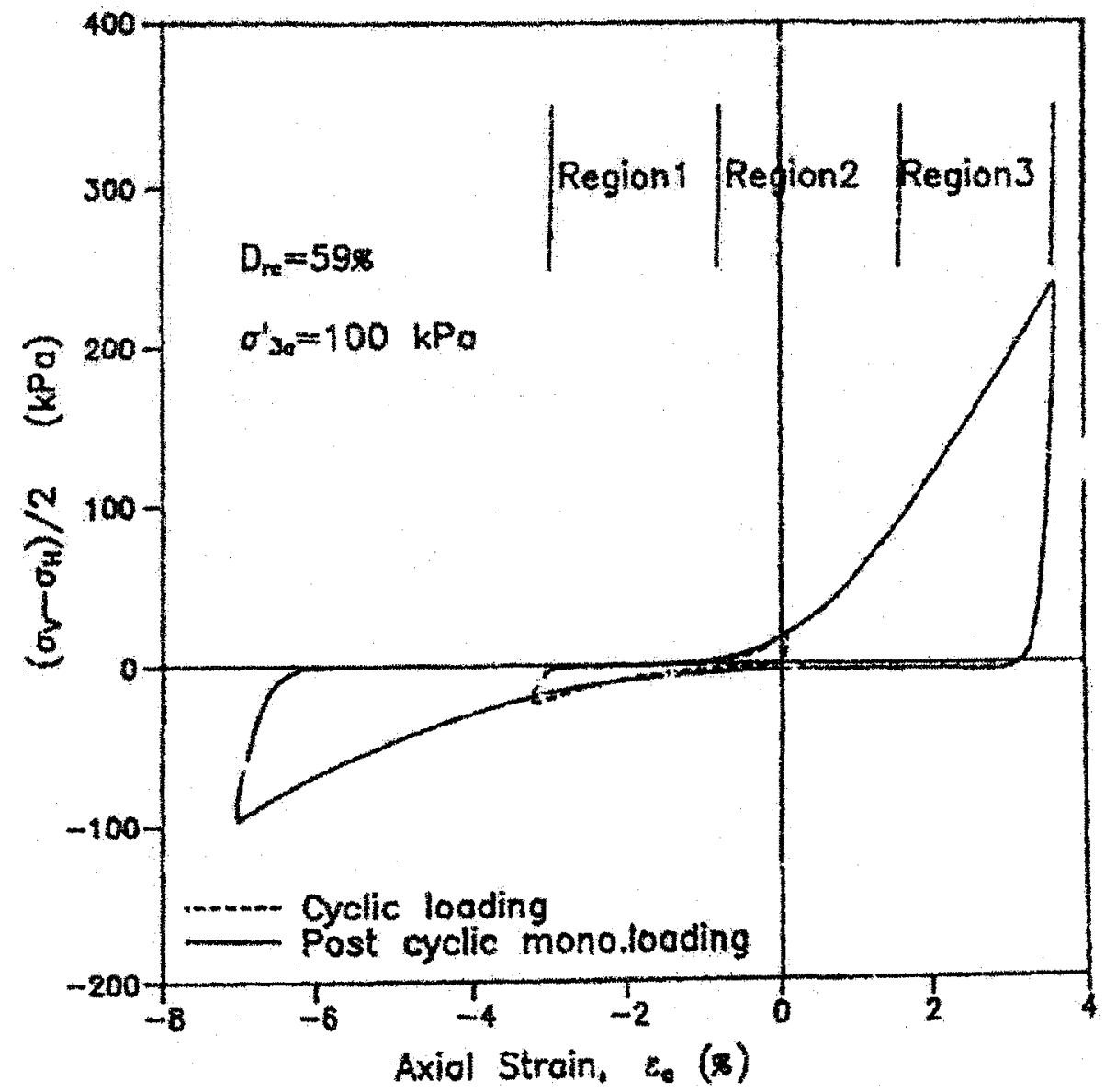

Figure 2.15 Characterization of post-liquefaction stress-strain curve (Thomas, 1992). 
Shamoto et al. (1998) characterized the post-liquefaction stress-strain response produced by cyclic loading into two regions and described them as two strain components. The first component is similar to what Thomas (1992) referred to as Region 1. However, the second component is a combination of Regions 2 and 3. Shamoto et al. showed that the post-liquefaction shear strain response is influenced by complete and incomplete liquefaction behaviour. For instance, Region 1 (first component) is not developed while the liquefaction is incomplete for curve $1\left(\gamma_{\max }=1.5 \%\right)$ and curve $2\left(\gamma_{\max }\right.$ $=2.5 \%$ ) as illustrated in Figure 2.16. The Region 1 is developed when the shear strain induced by the cyclic loading is grater than $6.8 \%$.

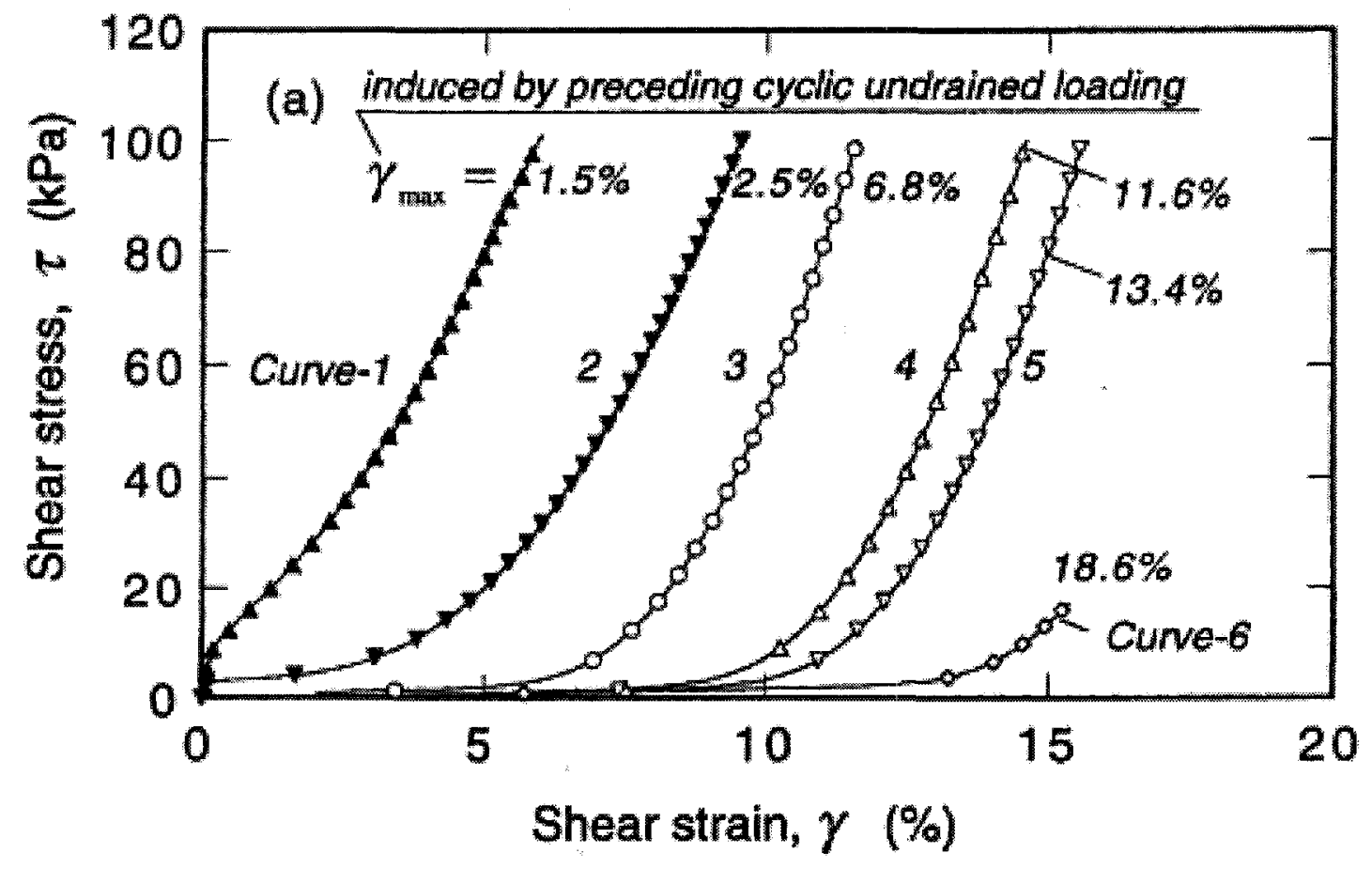

Figure 2.16 The influence of incomplete or complete liquefaction to the post-liquefaction shear strain response (Shamoto et al., 1998). 
The response of post-liquefaction stress-strain in mine tailings is quite different than in sand. The post-liquefaction stress-strain response of mine tailings has not shown a Region 1 type of response as in sand. This is because silts do not normally reach a state of zero effective stress following cyclic loading. In addition, cohesion strength may exist due to the fine material in mine tailings. Wijewickreme et al. (2005) presented three postliquefaction stress strain responses for different mine tailings samples tested using simple shear apparatus. However, in this Wijewickreme et al. work, it is unclear as to whether or not Region 1 existed, because the effective shear stress of post-liquefaction did not begin from zero and the initial shear stiffness was not close to zero.

\subsubsection{Factors Affecting Post-liquefaction Behaviour}

Studies, addressing the factors that have an effect on post-liquefaction response of mine tailings, are limited. For sand, more researchers have investigated this response (Thomas, 1992; Vaid and Thomas, 1995; Vaid and Sivathayalan, 1997; Shamoto et al., 1997; Sivathayalan and Yazdi, 2004; Yazdi, 2004). These studies show that the postliquefaction response of sand depends on relative density (or void ratio), consolidation pressure, maximum pre-cyclic strain level, and loading mode. Even though these factors may have an effect on the response of the post-liquefaction of fine material as mine tailings, the sensitivity of these factors, on post-liquefaction response for both soils, may be different. The factors that effect on post-liquefaction behaviour of fine grained material may be anisotropy of loading, consolidation ratio, and whether drainage is permitted before or during post-liquefaction. 
The mechanism involving void ratio redistribution after liquefaction for mine tailings is poorly understood. Researchers have explored the connection between the effects of void ratio after consolidation and the post-liquefaction response. However, one should keep in mind that the redistribution of voids may take place at the steady state, and using a void ratio after consolidation as criteria to investigate the post-liquefaction behaviour is not usually valid. On the other hand, the void ratio redistribution after steady state condition using laboratory testing may not be simulated as to reproduce field conditions. Wijewickreme et al. (2005) studied the effect of void ratio after consolidation on the post-liquefaction response (monotonic loading induced after cyclic mobility) of three different mine tailings. They noted that the post-liquefaction maximum shear ratio (maximum shear stress normalized by consolidation pressure) increases with decreases in the void ratio. The data was presented with respect to three mine tailing types and did not consider the effects of consolidation pressure.

In order to investigate the influence of drainage conditions in post-liquefaction resistance, undrained shear strength with different scenarios of drained/undrained cyclic loading conditions are usually preformed. Results by Yasuhara (1994) have showed the cohesive soils have strongly varying responses with the change of these scenarios. The undrained shear strength of post-liquefaction after drained cyclic loading was greater than after the undrained cyclic loading followed by drainage.

The influence of isotropic and anisotropic consolidation on the post-liquefaction of low plastic silt was investigated under two modes of failure: post-cyclic recompression, and post-monotonic compression, and extension using a cyclic triaxial apparatus by Hyde et al. (2007). The results showed that: (i) samples with high initial 
anisotropic consolidation stress have less volumetric strain, however these samples have large axial strains during post-cyclic drainage, (ii) post-cyclic strength when drainage is allowed increases with increasing anisotropic consolidation stress, and (iii) after postcyclic recompression, the cyclic strength increases for samples consolidated under anisotropic conditions.

The over-consolidation ratio (OCR) influences in the post-liquefaction response as well as the liquefaction or cyclic mobility of fine grained soil. Increasing the degree of the consolidation ratio induces greater resistance from the sample during cyclic loading, which results in higher undrained shear strength in post-liquefaction. The effect of the consolidation ratio on undrained strength after cyclic loading was investigated by Hyde and Ward (1986). The heavily over-consolidated samples experienced less reduction of undrained strength after cyclic loading as compared to samples under normal consolidation and light over-consolidation. Yasuhara et al. (2003) studied the post-cyclic strength and stiffness of low plastic silt with respect to normal and over-consolidation stresses under cyclic triaxial loading. It was suggested that using cyclic shear strain is a better parameter than cyclic induced excess pore pressure for correlating post-cyclic stiffness degradation under normal and over-consolidation stress. This suggestion is consistent with test results of Vaid and co-workers. 


\section{CHAPTER 3: EXPERIMENTAL WORK}

An NGI-type simple shear test apparatus was used to study the liquefaction and post-liquefaction characteristics of low-plastic gold mine tailings under monotonic and cyclic loading conditions. The equipment used and the testing program adopted to achieve the objectives are described in this chapter. Also, the characteristics of the materials tested are presented.

\subsection{Material Tested}

The material tested consisted of gold mine tailings were shipped as a slurry at the pumping water content of $38 \%$ from the Bulyanhulu gold mine in Tanzania. The tailings were supplied in plastic bags within $20 l$ pails to maintain the tailings in saturated condition and avoid change of the tailings characteristics due to drying. Due to the storage of the pails, a film of water was formed at the surface of the consolidated tailings and, therefore the water content of the tailings was found to decrease to between 22 to $24 \%$. 


\subsubsection{Mineralogical and Chemical Analysis of Gold Mine Tailings}

The mineralogical analysis of the gold mine tailings yielded different minerals contents which were: Silicates $(80 \%)$, Pyrite $(11 \%)$, Carbonates (Calcite $(5 \%)$, and Ankerite (4\%)), (Golder, 2005). The microscopic images of gold mine tailings tested in this study are shown in Figure 3.1 (Bryan, personal communication, 2008). Chemical analyses of solid and liquid phases of the tailings were conducted for similar gold mine tailings but different batch by Simms (personal communication, 2006). A summary of chemical analyses is presented in Table 3.1. The analyses' results showed that Lead and Arsenic existed in both the liquid and solid phases above the detection limit; however Cyanide was detected at very low concentrations $(0.082 \mathrm{mg} / \mathrm{L})$ in the liquid phase only.

\subsubsection{Control Plan for Testing of Mine Tailings}

Based on the chemical analyses, tailings were exempt from classification as hazardous waste under Ontario regulations (Simms, personal communication, 2007). Limited exposure to heavy metals may occur through skin contact, as well as by inhalation of tailings dust, and a risk of Arsine gas generation exists while drying the tailings in the oven. Therefore, a control plan was proposed to manage these risks. Workers had to wear gloves (latex), lab coats, and laboratory safety glasses as long as they worked with the tailings. During the mixing of the tailings and experimental work, tools became exposed by the tailing. Consequently, these tools were washed in a bowl by the water and that water was stored in a special bucket marked as "Tailings Wash Bucket". To reduce water use, washed water was reused for washing after the solid particles of tailings settled down. In case any tailings spilled on the floor, paper towels 
were used for cleaning and both the solid tailings residue and paper towels were disposed in a special bucket marked as "Waste Bucket". In order to measure the water content of the tailings, an oven in a ventilated shaft was used to eliminate the risk from the inhalation of Arsenic gas. Also, the N-95 respiration mask was worn whenever dealing with tailings as dust.

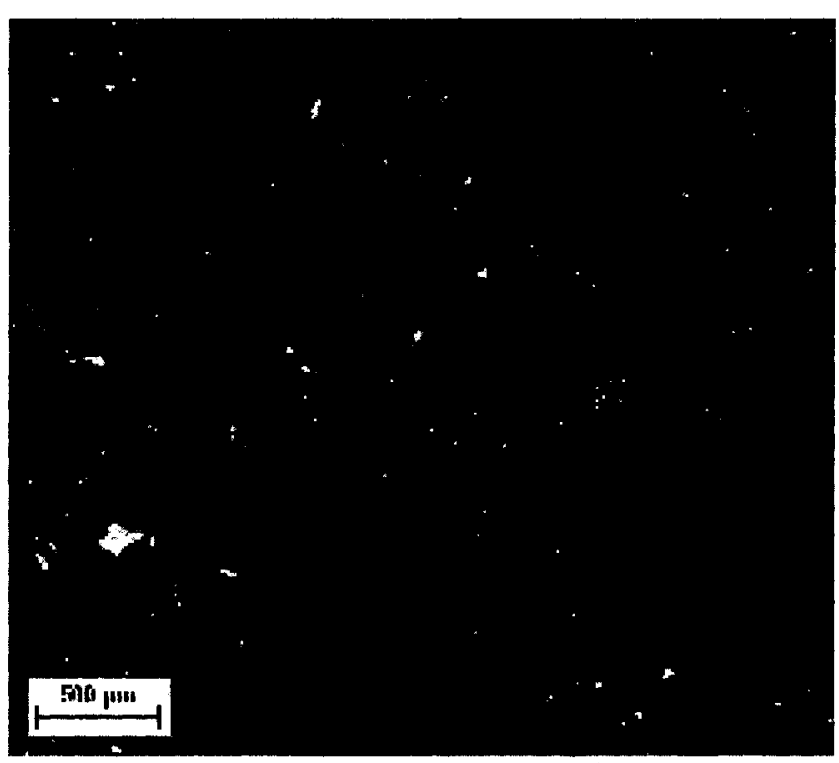

(a)

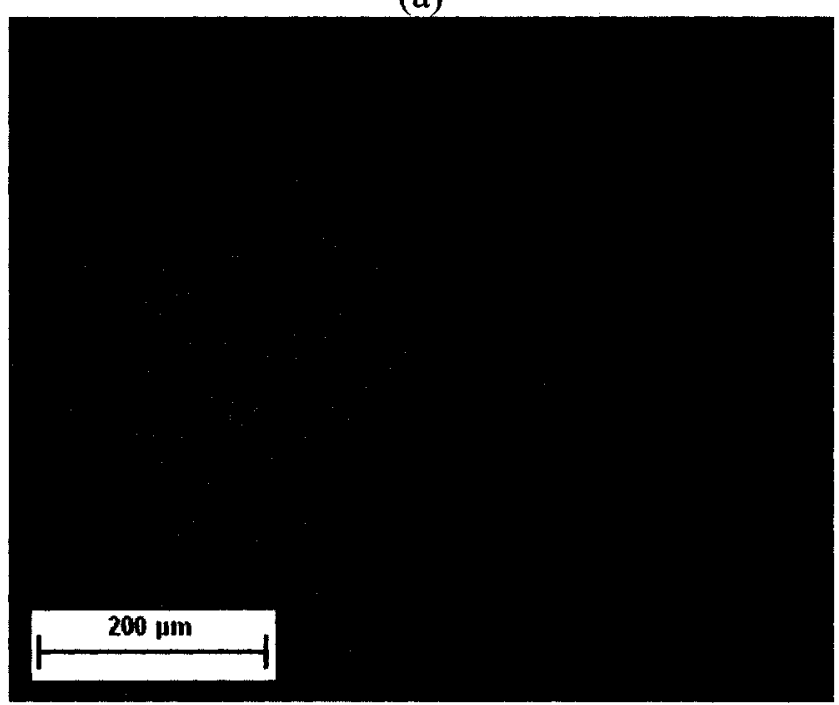

(b)

Figure 3.1 The dark gray and green minerals are Silicates and Carbonates (Quartz, Mica, Muscovite, Ankerite, and Calcite), the white-looking mineral is Pyrite and the yellowish one is Chalcopyrite (Bryan, 2008). 
Table 3.1 Results of chemical analyses of gold mine tailings (Simms, 2006).

(a) Chemical analyses of solid phase.

\begin{tabular}{|l|c|}
\hline \multicolumn{1}{|c|}{ Parameter } & $\begin{array}{c}\text { Concentration } \\
\mathrm{ug} / \mathrm{g}\end{array}$ \\
\hline Cyanide (total) & $<0.10$ \\
\hline Calcium & 17700 \\
\hline Magnesium & 5070 \\
\hline Potassium & 1670 \\
\hline Sodium & 992 \\
\hline Aluminum & 5730 \\
\hline Antimony & 2 \\
\hline Arsenic & 240 \\
\hline Barium & 22 \\
\hline Beryllium & $<1$ \\
\hline Cadmium & $<0.5$ \\
\hline Chromium & 17 \\
\hline Cobalt & 72 \\
\hline
\end{tabular}

\begin{tabular}{|l|c|}
\hline \multicolumn{1}{|c|}{ Parameter } & $\begin{array}{c}\text { Concentration } \\
\mathrm{ug} / \mathrm{g}\end{array}$ \\
\hline Copper & 317 \\
\hline Iron & 78400 \\
\hline Lead & 116 \\
\hline Manganese & 595 \\
\hline Mercury & $<0.1$ \\
\hline Molybdenum & 2 \\
\hline Nickel & 44 \\
\hline Selenium & 3 \\
\hline Silver & 2.74 \\
\hline Strontium & 42 \\
\hline Thallium & $<1$ \\
\hline Vanadium & 14 \\
\hline Zinc & 27 \\
\hline
\end{tabular}

(b) Chemical analyses of liquid phase.

\begin{tabular}{|l|c|}
\hline \multicolumn{1}{|c|}{ Parameter } & $\begin{array}{c}\text { Concentration } \\
\mathrm{mg} / \mathrm{L}\end{array}$ \\
\hline Cyanide (total) & 0.082 \\
\hline Calcium & 7030 \\
\hline Magnesium & 2010 \\
\hline Potassium & 662 \\
\hline Sodium & 394 \\
\hline Aluminum & 2280 \\
\hline Antimony & 0.97 \\
\hline Arsenic & 95.3 \\
\hline Barium & 8.80 \\
\hline Beryllium & 0.04 \\
\hline Cadmium & 0.02 \\
\hline Chromium & 6.67 \\
\hline Cobalt & 28.6 \\
\hline
\end{tabular}

\begin{tabular}{|l|c|}
\hline \multicolumn{1}{|c|}{ Parameter } & $\begin{array}{c}\text { Concentration } \\
\mathrm{mg} / \mathrm{L}\end{array}$ \\
\hline Copper & 126 \\
\hline Iron & 31100 \\
\hline Lead & 46.2 \\
\hline Manganese & 236 \\
\hline Mercury & $<0.05$ \\
\hline Molybdenum & 0.83 \\
\hline Nickel & 17.4 \\
\hline Selenium & 1.00 \\
\hline Silver & 1.09 \\
\hline Strontium & 16.4 \\
\hline Thallium & 0.05 \\
\hline Vanadium & 5.56 \\
\hline Zinc & 10.8 \\
\hline
\end{tabular}




\subsubsection{Geotechnical Characteristics of Gold Mine Tailings}

Bulyanhulu gold mine tailings were dark gray to green, aspheric to semi-platy particle shape, with angular to sub-angular grain edges (Figure 3.1). The specific gravity of tailings was 2.89 determined by ASTM D854 (2000). The particle size distribution of tailings was established by the combination of sieve (wet technique) and hydrometer analyses results based on ASTM D 422-63 (2002). Figure 3.2 shows the grain size distribution of the gold mine tailings.

The Atterberg limit was also conducted and the results showed that the liquid limit (LL), and plastic limit (PL) were 22.5\% and 20\%, respectively (ASTM D4318, 2000). The shrinkage limit test, preformed on similar tailings from Bulyanhulu, yielded a value of $20 \%$ (Simms et al., 2007). Based on Unified Soil Classification Systems (USCS), tailings were classified as low-plastic silt (ML).

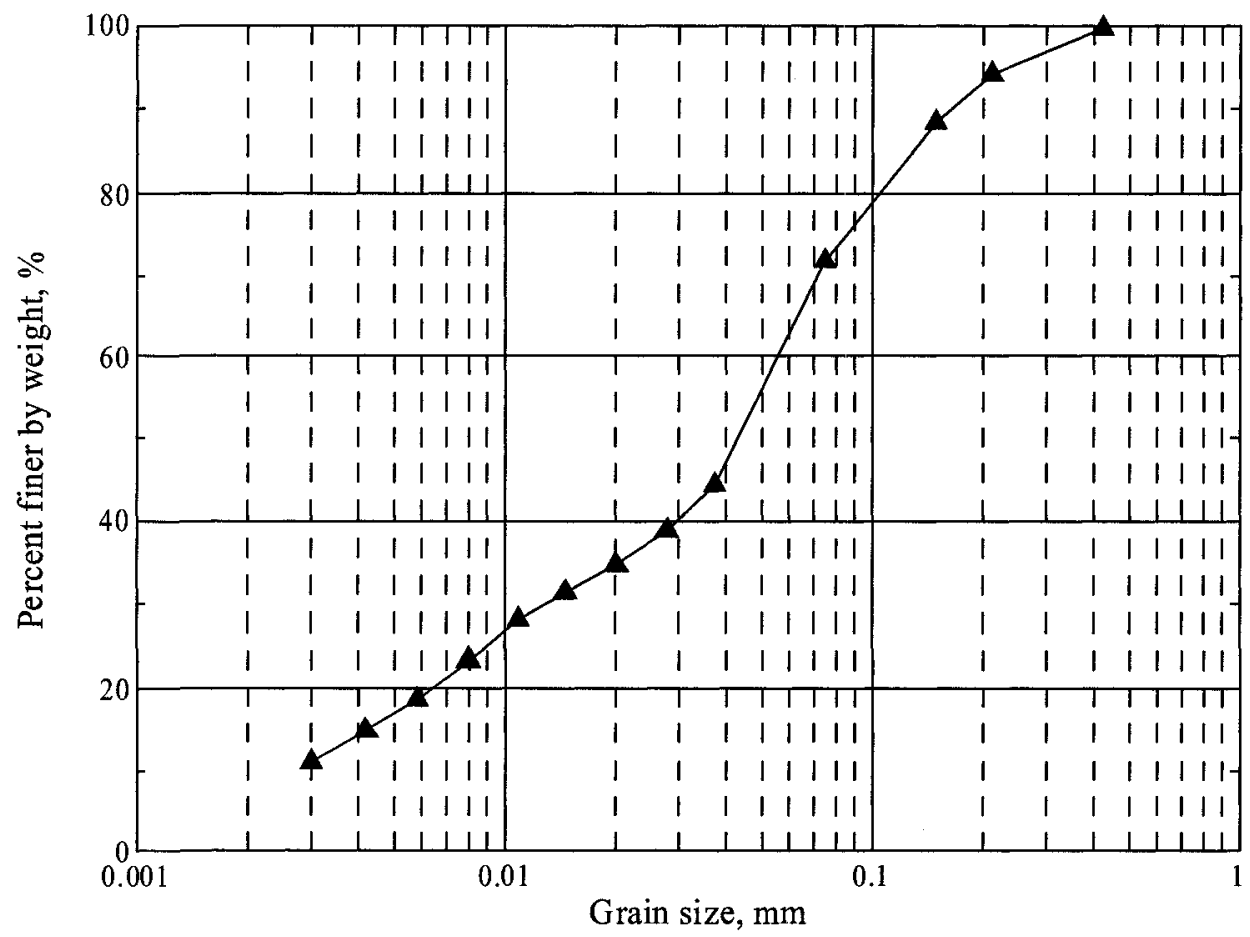

Figure 3.2 Grain size distribution of gold mine tailings. 


\subsection{Simple Shear Apparatus}

A simple shear apparatus, similar to the one that was originally developed at Norwegian Geotechnical Institute (NGI) (Bjerrum \& Landva, 1966), was used in this research. The commercially available apparatus was extended in-house to permit both stress and strain controlled loading. A schematic diagram and a photograph of the apparatus at Carleton University are shown in Figure 3.3 and Figure 3.4, respectively.

The apparatus system consists basically of a simple shear load frame, a vertical single acting air piston, horizontal double acting frictionless air piston, a constant speed motor drive, load cells, Electronic-Pneumatic Transducer (EPT), and Linear Variable Displacement Transducers (LVDT).

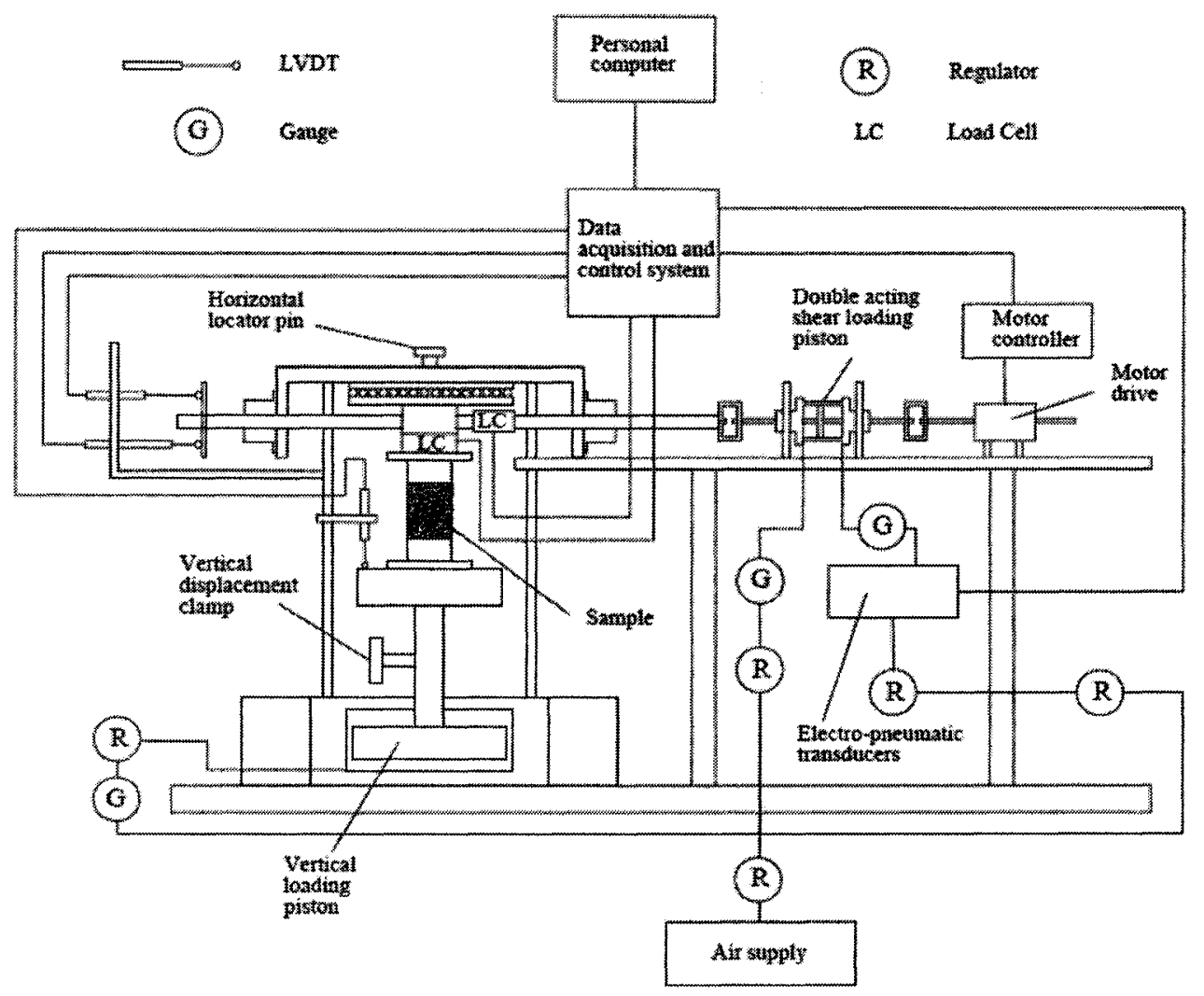

Figure 3.3 Schematic diagram of the cyclic simple shear apparatus 


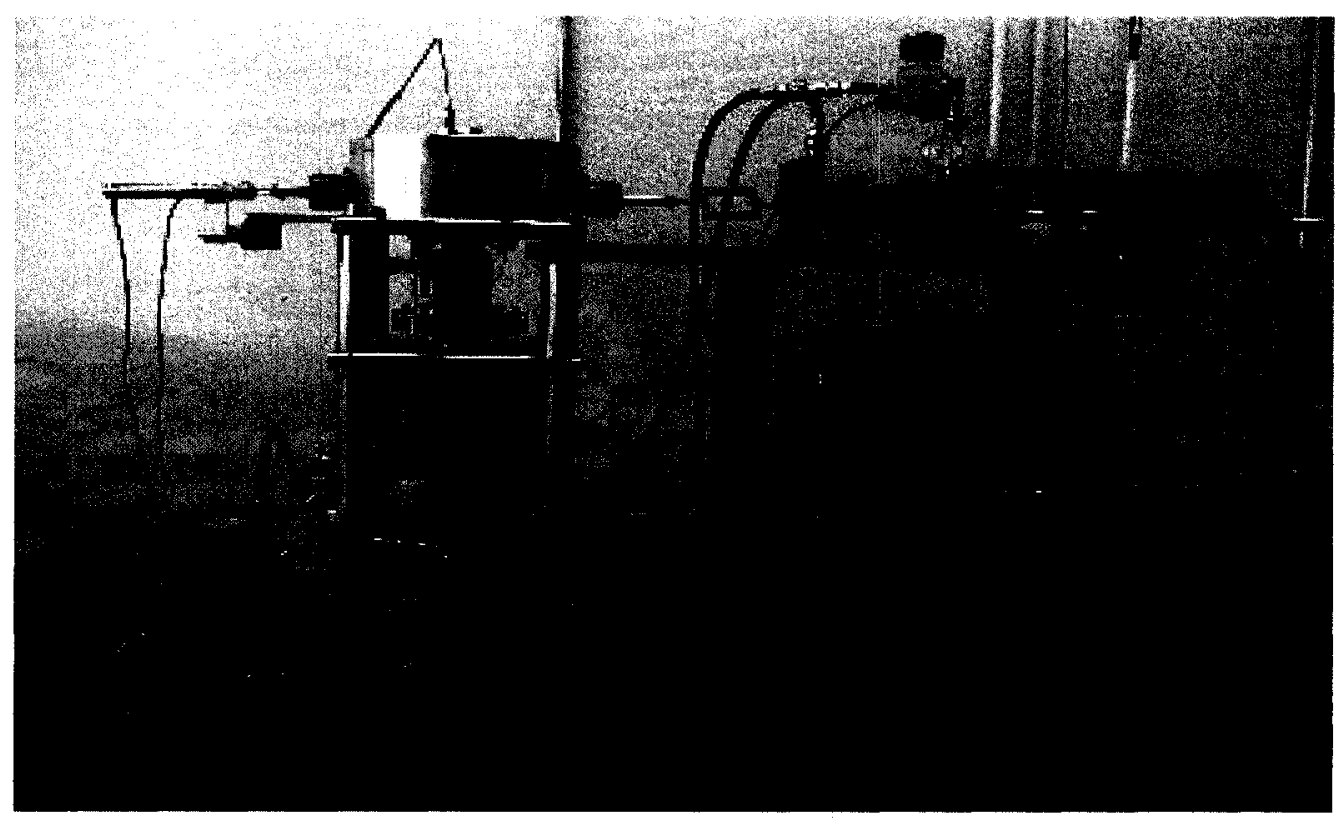

Figure 3.4 Simple shear apparatus at Carleton University

The load cells and transducers are incorporated with the data acquisition system interfaced with the computer. The vertical single air acting is controlled manually to apply a vertical load to the sample. The horizontal shear stress can be applied by using either double acting frictionless air pistons or a motor driving system. The cyclic loading produced by double acting frictionless air pistons was controlled using the EPT via the computer. The double acting frictionless air pistons are connected with the motor system to allow efficient transition from stress controlled to strain controlled conditions.

The vertical and shear loads were measured using vertical and horizontal load cells with high performance. The resolution of the measured stresses was accurate to 0.1 $\mathrm{kPa}$. The axial and horizontal displacements of the samples were measured using two LVDT's. However, an extra LVDT in the horizontal direction was installed to verify and increase the horizontal LVDT measurement range. The performance of LVDT's was 
considered as high, since their resolution outputs were better than $0.001 \mathrm{~mm}$. The LVDTs' positions were carefully chosen and were based on achieving a linear relationship between the LVDTs' reading and the displacement measurements.

In this apparatus, the sample is placed into a reinforced rubber membrane to constrain its lateral deformation. Therefore, the lateral strain components $\left(\varepsilon_{\mathrm{x}} \& \varepsilon_{\mathrm{y}}\right)$ become zero. A clamping mechanism is used to fix the height of the sample when needed. Only vertical deformation takes place during consolidation. Constant volume condition is achieved during shear loading by keeping the height of the sample constant. As a result, no volume change of the sample during the shear loading is allowed and the undrained shear condition is then simulated (Bjerrum \& Landva, 1966). In this case, the change in applied vertical stress has been shown to be equivalent to the excess pore pressure $\left(\Delta \mathrm{u}=\sigma_{\mathrm{vc}}^{\prime}-\sigma_{\mathrm{v}}^{\prime}\right)$ which would have been measured in a truly undrained test (Dyvik et al., 1987).

\subsection{Sample Preparation}

Due to the difficulty in obtaining undisturbed samples of mine tailings deposits, and the high costs associated with specialized sampling techniques (as ground freezing techniques), reconstituted sample techniques are generally used for fundamental studies. In this research, simple reconstitution techniques were adopted. These techniques provide samples with different pre-determined water contents, and the hydraulic stress history of the samples can be prescribed as a result of applying wet-dry cycles. The techniques in this study will be termed as moist preparation technique and wet-dry cycles (hydraulic stress history) preparation technique. The procedures to prepare the samples in both 
techniques are slightly different. However, the setup of the simple shear apparatus mould is similar for both techniques. In both techniques, samples were prepared with around 70 $\mathrm{mm}$ diameter and $18 \mathrm{~mm}$ height.

To prepare the samples, consolidated tailings (tailings in pail, $w=22-24 \%$ ) were mixed with the bleed water by using a mixer and spatula. For the moist technique, the initial water contents of tailings were pre-determined based on the design consolidation chart (Figure 4.1) at given consolidation stress and void ratio level. However, for the wetdry cycles technique, the initial water content was similar to the pumping water content ( $w=38 \%$ ). In both cases, a chunk of tailings was taken to double-check the water content.

To setup the apparatus mould, two pore stones were attached to two steel grooved disks. One grooved disk was placed in the sample pedestal and the other was placed in the sample cap. The reason for using grooved shaped disks is to prevent the sample from slipping during shear loading. A reinforced rubber membrane was placed around the pedestal and its lower part was sealed by an O-ring. A two-piece split mould was placed around the reinforced membrane and attached together by an external clamp. To make the reinforced membrane lined inside the two-piece mould, about $20 \mathrm{kPa}$ suction was applied through the small holes that attached in the two-piece mould. At the same time, the upper part of the reinforced membrane was folded around the top part of the two-piece mould, and then a brass ring was placed on top of the mould.

\subsubsection{Moist Preparation Technique}

Tailings, in their initial water content were spooned and distributed inside the cavity of the reinforced membrane (Figure 3.5(a)). Light tamping was applied to remove 
the air bubbles and thus creating homogenous tailings mass. Tailings were levelled gently by spatula and the top cap was carefully placed to avoid any sample disturbance. The upper and lower drain valves which attached to the top cap and pedestal were opened to prevent pore water pressure build up. A light level was placed on the top cap to ensure that the top surface was horizontal. After that, the reinforced membrane was carefully flipped on the top cap and the O-ring seal was placed around the perimeter of the cap with minimum disturbance. The brass ring and the $20 \mathrm{kPa}$ suction connecters were carefully removed and the sample height was measured (Figure 3.5(b)). In order to monitor the sample disturbance during the preparation, the sample height was measured by using a dial-gauge before and after the O-ring was placed around the reinforced membrane flipped on the top cap, and at the end of the sample preparation.

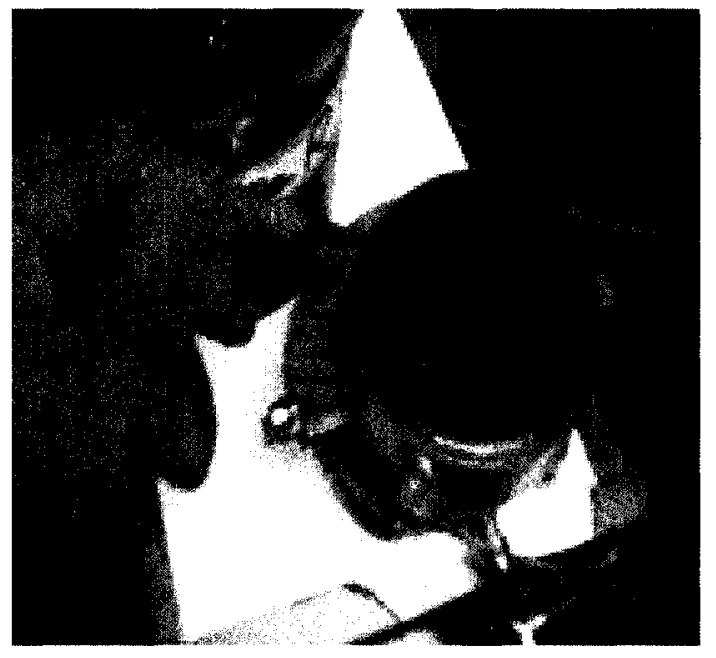

(a)

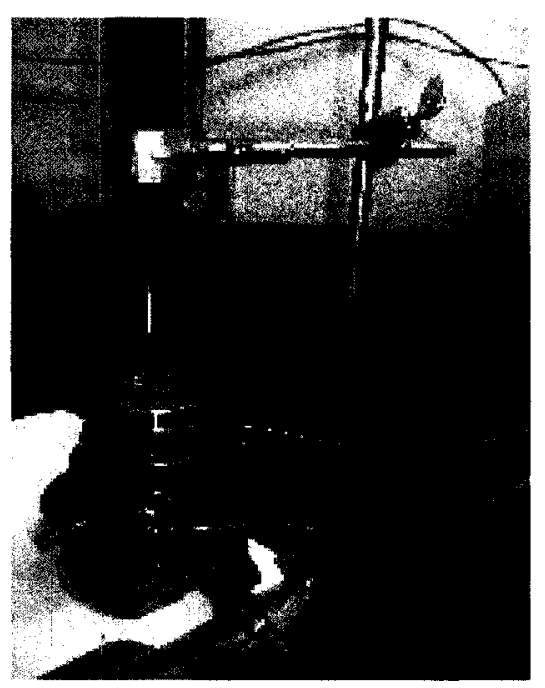

(b)

Figure 3.5 Steps sample preparation for wet conditions: (a) sample placement in the cavity of reinforced membrane, (b) measuring the sample height by using the dial-gauge. 


\subsubsection{Wet-dry Cycles Preparation Technique}

The apparatus mould was placed on a levelled digital balance that had an accuracy of $0.01 \mathrm{~g}$. The tailings at pumping water content $(w=38 \%)$ were spooned, distributed, and levelled inside the cavity of the reinforced membrane. The lower drain valve that was attached to the pedestal was opened to accelerate drying in the tailings. The weight of the apparatus mould was taken before and after the tailings was spooned in the reinforced membrane cavity to determine the sample weight. The tailings sample was exposed to the air to dry through evaporation. Since the weight of the tailings solid particles remained constant, the decrease of sample weight as monitored by the digital balance corresponded to the reduction of water content. When the sample water content decreased to the pre-determined drying water content $\left(w_{\mathrm{d}}\right)$, an amount of water was added to the tailings sample to make it wet again. The water was added to bring the sample water content to $21 \%$, and this water content was termed as initial water content $\left(w_{\mathrm{i}}\right)$. After the initial water content of the sample was set, the top cap was placed according to the moist preparation technique.

\subsubsection{Placing the Tailings Sample under the Simple Shear Apparatus}

The sample in the mould setup was moved and placed under the simple shear apparatus. Four clips, two at the bottom and two at the top, were attached to the top cap and pedestal of the sample. A normal stress equal to $5 \mathrm{kPa}$ vertical pressure was applied to the sample before the two-piece mould was removed. The reason for keeping the twopiece mould until finally placing the sample under the apparatus was to prevent sample disturbance during transportation. The height of the sample was measured from the 
computer reading via the vertical LVDT. A comparison between the sample height at the end of consolidation stage and the sample height immediately after applying $5 \mathrm{kPa}$ consolidation pressure was done in order to monitor the disturbance of the sample due to transformation to the apparatus. It is important to note that the weight of the top cap that was placed on the top of sample results in a vertical pressure of $3.5 \mathrm{kPa}$.

\subsubsection{Sample Characterizations}

In this study, the sample height after preparation (before moving the sample under the apparatus) was considered as the initial sample height. The initial volume of the sample was calculated based on the cavity volume of the reinforced membrane lined inside the two-piece mould. The void ratio $\left(\mathrm{e}_{\mathrm{i}}\right)$ was calculated based on the following:

$$
\mathrm{e}_{\mathrm{i}}=\frac{\mathrm{V}_{\mathrm{v}}}{\mathrm{V}_{\mathrm{s}}}
$$

Where: $V_{v}$ and $V_{s}$ are the volume of voids and the volume of solids after the sample preparation. The dry weight of the solids at the end of the tests was used to calculate $V_{\mathrm{s}}$. The void ratio at the end of consolidation stage was calculated using the above formula for $\mathrm{V}_{\mathrm{v}}$ at the end of consolidation. The volume and mass measurements were recorded using the techniques suggested in Vaid and Sivathayalan (1996.b). The resolution of void ratio measurements is better than about 0.003 .

The degree of saturation was also calculated for each sample after the preparation stage by using the initial water content $\left(w_{\mathrm{i}}\right)$ and the tailings specific gravity $(\mathrm{Gs}=2.89)$. The following formula was used: 


$$
\mathrm{S}=\frac{w_{\mathrm{i}}^{*} \mathrm{G}_{\mathrm{s}}}{\mathrm{e}_{\mathrm{i}}} * 100
$$

For most of the tailings samples, the calculated degree of saturation before consolidation stage was greater than $94 \%$. The effect of the degree of saturation (S) under constant volume will be discussed further in section 3.6.3. The water content at consolidation stage $\left(w_{c}\right)$ was estimated by using the above formula and based on $\mathrm{e}_{\mathrm{c}}$ and $\mathrm{S}$ for each sample.

\subsection{Testing Program}

The testing program constituted of three stages: consolidation, shearing (monotonic or cyclic shear loading), and post-shearing (monotonic shear loading). After the consolidation stage was conducted, monotonic or cyclic loading was applied according to a liquefaction criterion (see section 3.4.5). Then, post-shear was preformed to investigate the post-liquefaction behaviour of tailings after cyclic shear loading.

\subsubsection{Consolidation Stage}

Consolidation is a process in which the volume of a soil in saturated conditions decreases due to increasing effective stresses. When the consolidation pressure is applied, pore water pressure initially increases and then begins decreasing as long as the water is allowed to drain. Once the pore water pressure dissipates, all the consolidation pressure is carried on by the soil grains. After placing the samples in the simple shear apparatus, the vertical stresses were applied in steps until reaching a desired consolidation pressure. 
One-dimensional consolidation conditions prevailed since the samples were confined in wire reinforced membranes. Vertical stresses were used to characterize the consolidation stress level. The consolidation pressures used in this study were 50,100, 200400 , and $800 \mathrm{kPa}$.

\subsubsection{Monotonic Loading}

Monotonic shear loading was applied by a motor drive at a constant rate of strain. The rate of the motor drive was controlled by a control system which is connected between the data acquisition and motor drive. The rate of monotonic loading was chosen as $0.33 \% / \mathrm{min}$ (about $20 \% / \mathrm{h}$ ) for monotonic loading. The effect of strain rate on the monotonic response was investigated by conducting tests at loading rates ranging from about $20 \%$ per hour to $80 \%$ per hour; the results are presented in Figure 3.6. The figure shows that the strain rate has negligible effect on the monotonic responses of the tailings over the typical loading rates used in geotechnical testing. 

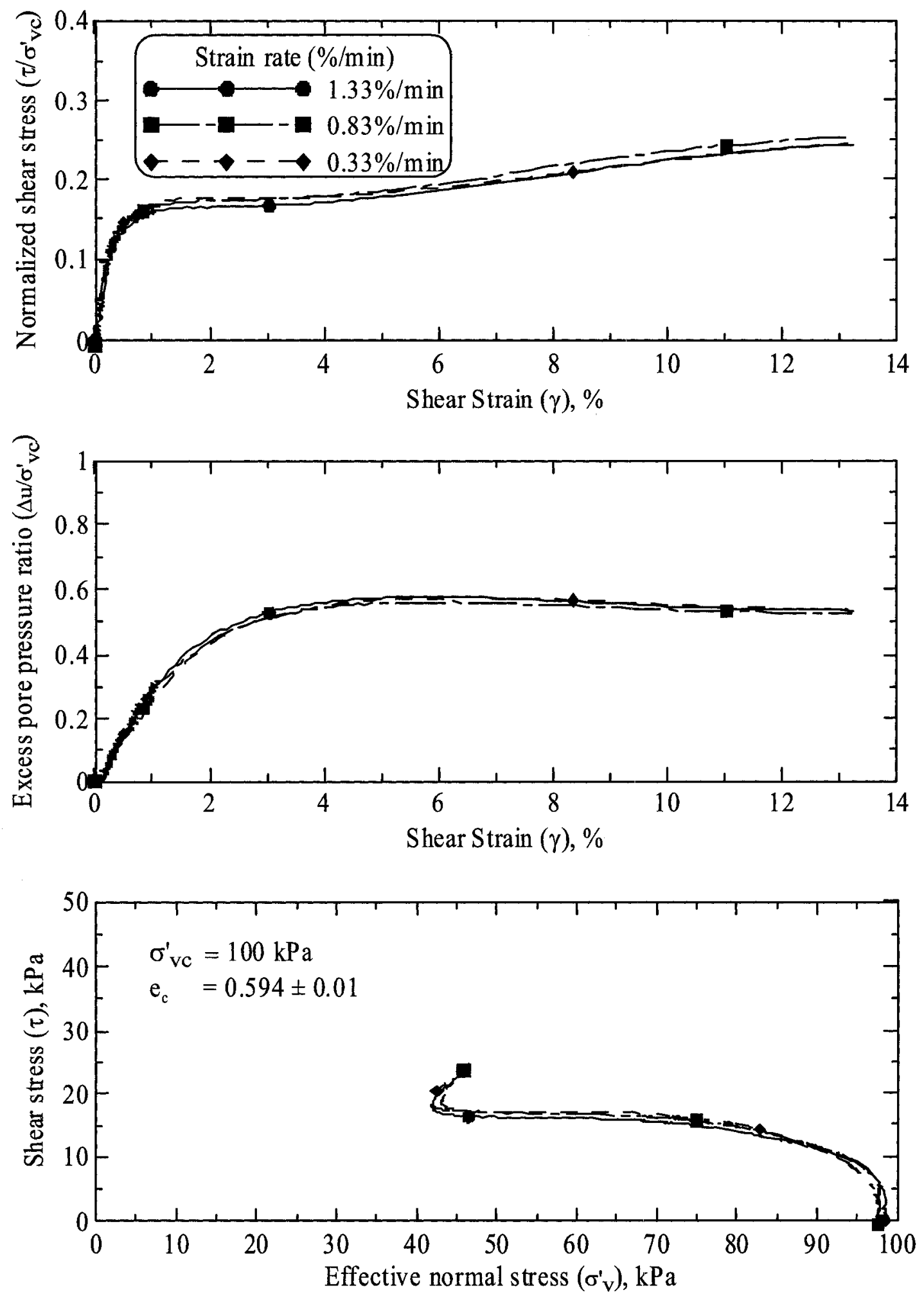

Figure 3.6 Effect of strain rate on the monotonic shear response at vertical confining stress $\sigma_{\mathrm{vc}}^{\prime}=100 \mathrm{kPa}$. 


\subsubsection{Cyclic Loading}

The double acting piston was used to apply cyclic shear loading (constant controlled cyclic loading). The pulse shape of the cyclic loading was uniform sinusoidal wave and the frequency of the pulse was $0.1 \mathrm{~Hz}$ (period $=10 \mathrm{~s}$ ). It was suggested that $10 \mathrm{~s}(0.1 \mathrm{~Hz})$ period achieved the requirement to give a reasonable resolution from the feedback control the data acquisition and instruments. Also, this frequency $(0.1 \mathrm{~Hz})$ has been used by many researchers for sandy soils (Kammerer et al., 2001; Sivathayalan and $\mathrm{Ha}, 2004$ ) and for tailings (Wijewickreme et al., 2005). As seen in Figure 3.6 the rate influence has been negligible in the tailings, and hence this rate is acceptable. It is recognized that earthquake shaking has predominate frequencies typically in the range of about 1 to $10 \mathrm{~Hz}$. The lower frequency used is expected to yield conservative results.

\subsubsection{Post-liquefaction Loading}

Appling a monotonic loading to a tailings sample after the tailings has reached liquefaction state under cyclic loading is termed as post-liquefaction loading. The postloading was applied in a fashion similar to the monotonic loading as explained in section 3.4.2.

\subsubsection{Liquefaction Criteria of Cyclic Loading}

US National Research Council (NRC 1985) suggested that the development of $3.75 \%$ shear strain of the sand samples in a single direction should be regarded as the triggering of liquefaction under cyclic loading. This shear strain may correspond to the 
development of $100 \%$ pore pressure ratio for contractive sands where no static shear stress exists on the sample. This criterion has been used also to investigate different types of fine-grained mine tailings by simple shear apparatus (Wijewickreme et al., 2005). It should be pointed out for fine grained soils including tailings, the development $100 \%$ pore pressure ratio may not occur even at high shear strain levels, and so the criteria based on the $100 \%$ pore pressure ratio is not valid (Singh, 1996). However, using the shear strain level as a criterion provides consistent triggering of liquefaction in the samples. Also, it allows a rational comparison of cyclic shear resistance data.

\subsection{Repeatability of Sample Preparation}

Two identical samples of tailings were prepared using the moist preparation technique with the same consolidation pressure and void ratio in order to investigate the repeatability of the sample preparation and test methods. Figure 3.7 shows the results of tested samples that were consolidated to $100 \mathrm{kPa}$ effective consolidation pressure and a void ratio of 0.582 . It can be seen from the figure that the response of both samples are

similar. It can be inferred from these results that the sample preparation technique is repeatable, and the performance of simple shear apparatus that was used in this study is excellent. 

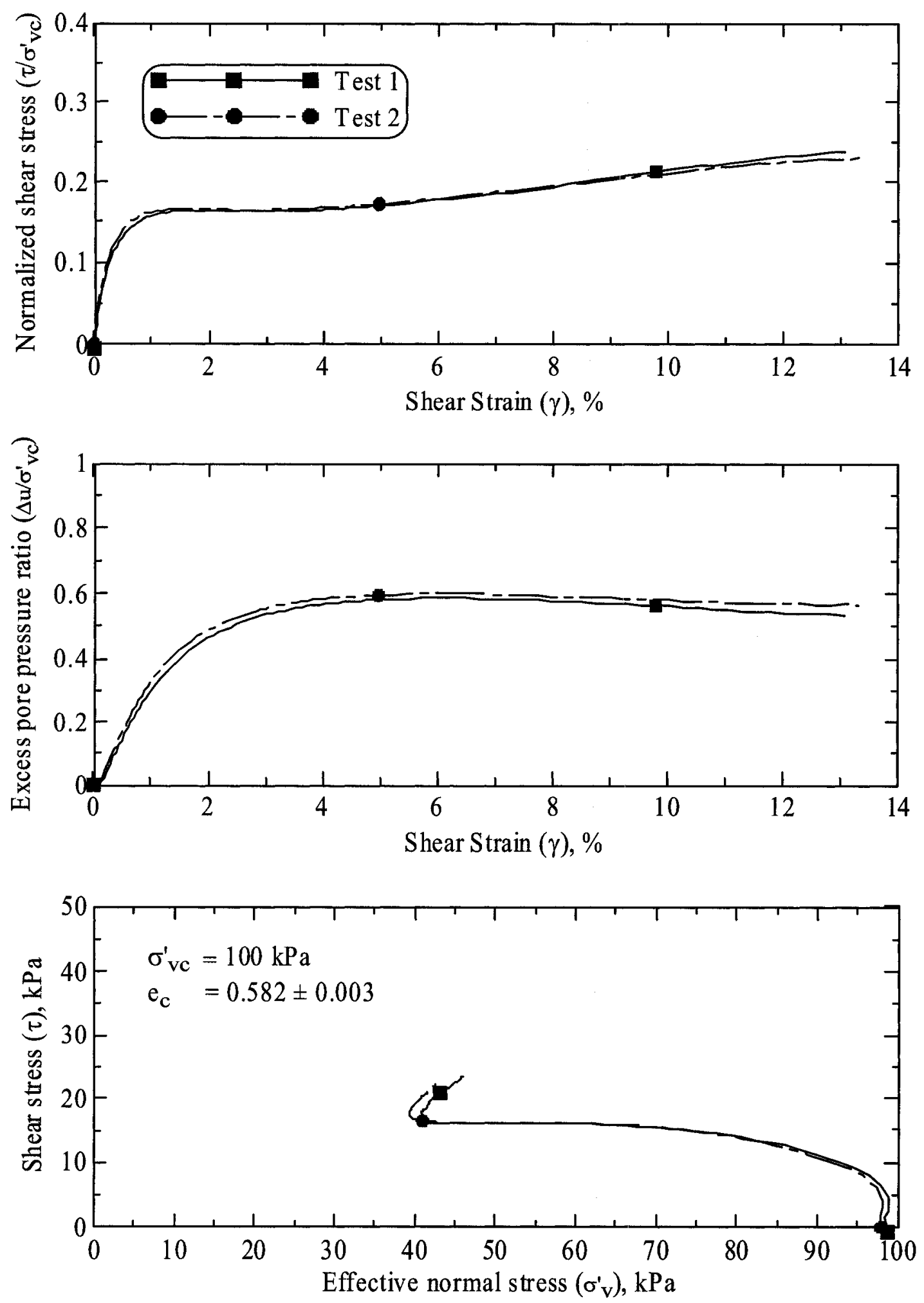

Figure 3.7 Repeatability of monotonic response using two identical samples. 


\subsection{Characteristics and Limitations of the Simple Shear Apparatus}

\subsubsection{Capability of the Apparatus}

Simple shear apparatus imposes stress conditions on the sample that are identical to those experienced in the in situ condition. While this is a great advantage, there are certain drawbacks in the conventional simple shear device. Simple shear apparatus is incapable producing complimentary shear stress on the lateral boundaries of the soil sample. In other words, simple shear apparatus does not produce a pure shear condition. Due to the lack of complimentary shear stress on the lateral boundaries and shear failure zones introduced to the sample after a certain level of shear strain, simple shear apparatus creates non-uniformities of the stresses and strains across the top and bottom of the samples. Therefore the performance of the apparatus in measuring stresses may have significant errors unless care is taken to minimize the errors. Results of simple shear apparatus should therefore be carefully analyzed.

One of the simple ways to minimize the non-uniformities is to use a sample with a small $h / d$ (height/diameter) ratio. A system with a $h / d$ of about 0.25 was used (as opposed to the traditional $h / d$ of 2 in a triaxial test). Also non-uniformities are fairly small at low strains. It was noticed in this study that measurements of the shear stress and the vertical stresses were reasonable up to about 10 to $13 \%$ of shear strain. Beyond this level of shear strain, the uncertainties in the measurements were considered too high. These errors were due to the non-uniform of stress distribution on the top and bottom of the sample and also due to the localization of deformation occurring in the sample. When the localized deformation occurs the conditions within the samples are not uniform and the boundary condition of the sample does not remain constant (Airey et al. 1985; Airey and Wood, 
1987). Therefore, the constant volume condition at this level of the strain is not valid and the measured stresses and strains are not reliable. It can be seen clearly from Figure 3.8 that when the stress path of the tailings moves to the left it reaches about $13 \%$ of shear strain exhibiting an apparent contractive behaviour of tailings. This possibly occurs on account of the relatively severe stress non-uniformities within the sample at this large strain level. Thus the notion of an "element test" may not be valid at theses large strains. To prevent miss-interpretation of the data, $13 \%$ of shear strain was taken as the cut off strain level, and data beyond this strain level has been discarded. 

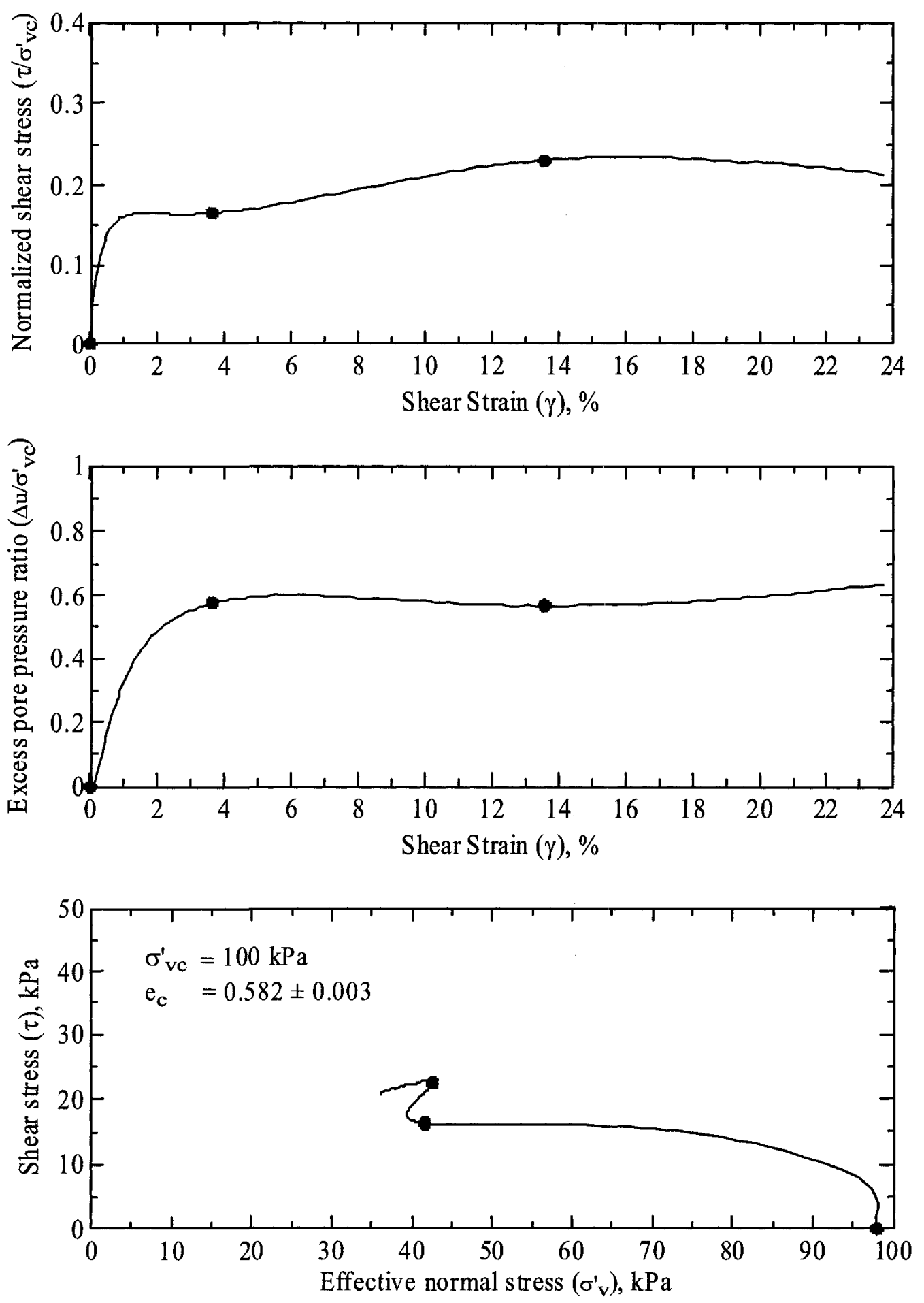

Figure 3.8 Errors to measure the stresses and strains after the sample fail under simple shear loading. 


\subsubsection{Transmission of Shear Stress}

Two types of loading caps are generally used to transmit the horizontal shear stress in simple shear. The influence of the interaction between the tailings sample and the loading cap in terms of stress-strain response under monotonic loading was investigated. Three sets of identical tailings samples were consolidated under $100 \mathrm{kPa}$ and tested using two different loading caps. Type 1 (grooved caps) had two steel discs for the top cap and pedestal and had steel grooves protruding into the sample. Each blade is about $2 \mathrm{~mm}$ high and less than $0.6 \mathrm{~mm}$ thick. This type was used for all tests in this study. Type 2 (frictional caps) had high frictional sand discs and their shape was flat. Type 2 was used only to investigate the influence of the loading caps on the monotonic response. The setup of frictional caps is similar to the grooves caps (see section 3.3).

Figure 3.9 shows the monotonic response of the two identical samples $\left(e_{c}=0.560\right)$ which were prepared using the moist technique and were consolidated under $100 \mathrm{kPa}$ consolidation pressure. From the figure, the stress paths of frictional loading caps and grooves loading caps are almost identical and the stress-strain responses are also similar up to $10 \%$ shear strain. Some difference in the stress-strain curves might be associated to the small differences in consolidation pressures.

The effect of localized deformation (rupture) and non-uniformity of the stress distribution occurred in both moulds regardless of the type of material disc and shape of the disc. The other two testing sets $\left(e_{c}=0.576\right.$ and $\left.e_{c}=0.621\right)$ also show the same conclusion as demonstrated in Figure 3.9. The results of both sets are presented in Appendix I. 

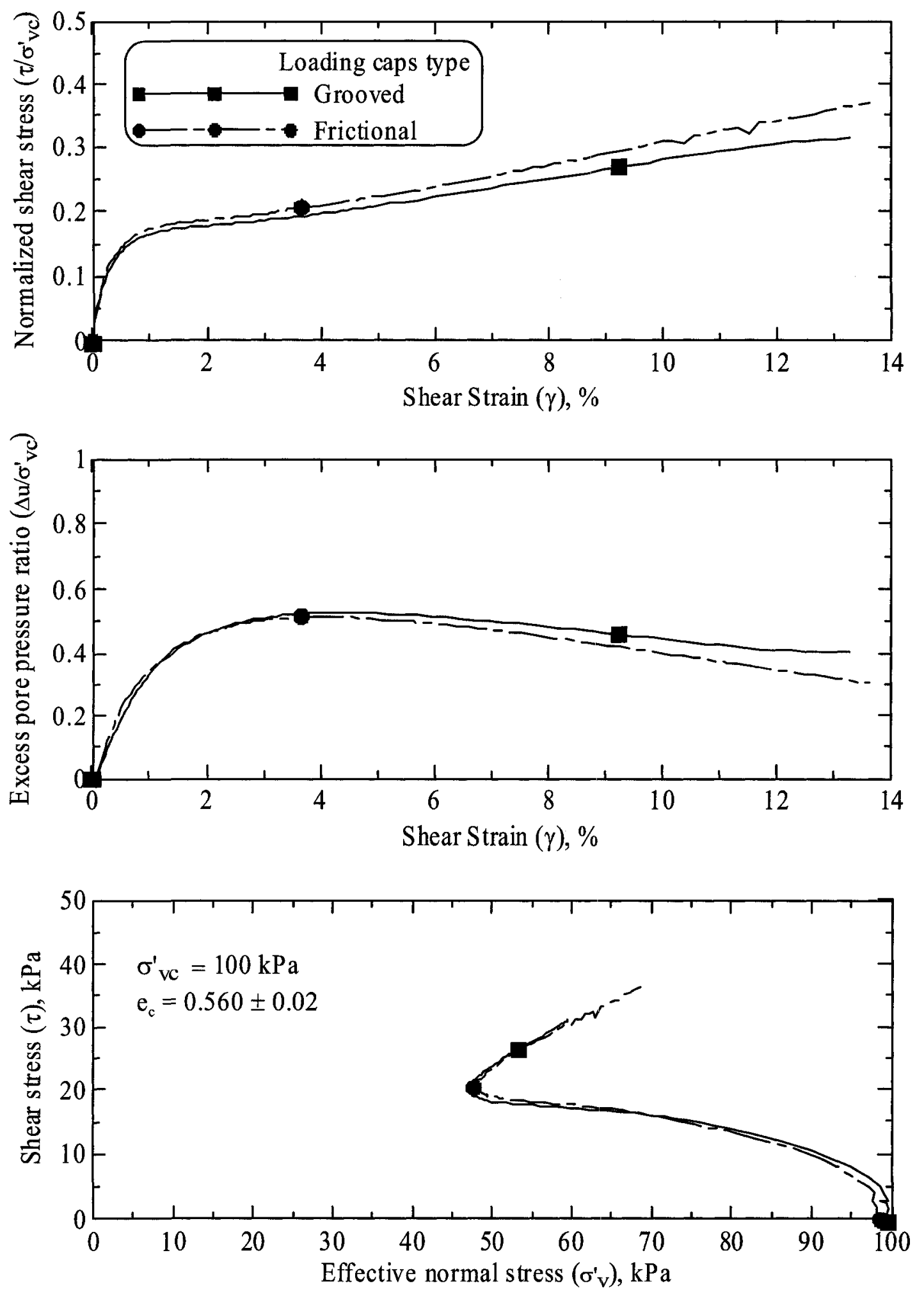

Figure 3.9 Influence of the interaction between the tailings sample, discs material and shape on the monotonic behaviour. 


\subsubsection{Influence of the Degree of Saturation under Constant Volume}

It was observed that the water content at the end of the simple shear tests was less than the consolidation water content when shear tests (monotonic and cyclic) were conducted with the pore space open to the atmosphere (Drained constant volume). Some pore water may have drained out under these boundary conditions and hence the final (end of test) water content was lower than the end of consolidation water content. This changes the apparent degree of saturation in the sample. In order to assess the effect of this change in degree of saturation on the response of tailings, tests were conducted under constant saturation. For this purpose, two identical samples were prepared using the moist technique and were consolidated under $200 \mathrm{kPa}$. One of the samples had its top and bottom valves attached to a drainage system connected to a small water reservoir. In this case, the sample was not permitted to contact air during testing (consolidation and shearing) and hence the degree of saturation did not decrease. The other sample was not attached to the saturation system and the drainage valves were open to the atmosphere. The monotonic responses of the two samples are presented in Figure 3.10. It can be seen from the figure that even though the degrees of saturations after the tests are somewhat different, the stress-strain responses of both samples were essentially identical. This demonstrates that the decrease in the degree of saturation at the end of the tests do not have an influence on the stress-strain response of tailings under the simple shear apparatus. This is expected since the simple shear apparatus enforces constant volume conditions during monotonic/cyclic loading, and the response under such loading is not dependent on the degree of saturation. 

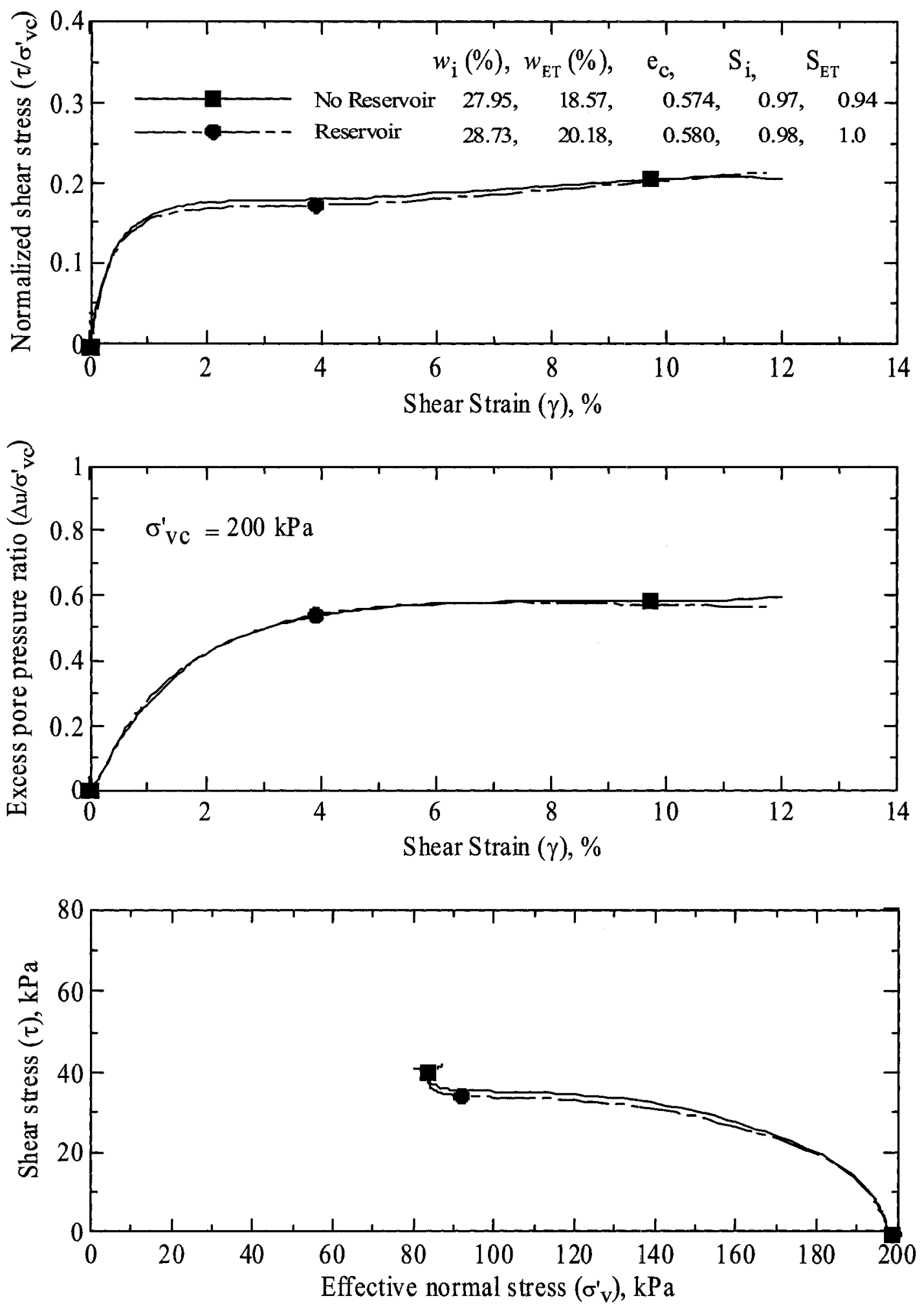

Figure 3.10 Influence of changing degree of saturation on the monotonic behaviour of tailings under simple shear apparatus. 


\section{CHAPTER 4: TEST RESULTS AND DISCUSSIONS}

In this chapter, the liquefaction and post-liquefaction behaviour of gold mine tailings under simple shear loading are presented. These behaviours were explored by using monotonic and cyclic loading conditions. Most of tailings samples were prepared using the moist preparation technique. However, the wet-dry cycles preparation technique was used to investigate the effect of desiccation on the cyclic loading resistance for a limited number of samples.

The tests conducted encompass different consolidation stress levels $(50,100,200$, 400 , and $800 \mathrm{kPa}$ ), and range of the void ratios after consolidation $\left(\mathrm{e}_{\mathrm{c}}\right)$. Tables 4.1 to 4.3 show lists of monotonic and cyclic loading test conditions that were carried out in this study. The initial conditions of post-liquefaction loading are similar to those for cyclic loading.

Table 4.1.Conditions of monotonic loading tests

\begin{tabular}{|c|c|c|}
\hline No. & $\begin{array}{l}\text { Consolidation } \\
\text { pressure, } \mathrm{kPa}\end{array}$ & Void ratio, $\left(\mathrm{e}_{\mathrm{c}}\right)$ \\
\hline 1 & \multirow{7}{*}{100} & 0.654 \\
\hline 2 & & 0.561 \\
\hline 3 & & 0.581 \\
\hline 4 & & 0.625 \\
\hline 5 & & 0.654 \\
\hline 6 & & 0.591 \\
\hline 7 & & 0.587 \\
\hline 8 & \multirow[t]{3}{*}{200} & 0.549 \\
\hline 9 & & 0.574 \\
\hline 10 & & 0.666 \\
\hline
\end{tabular}


Table 4.1.Continued

\begin{tabular}{|c|c|c|}
\hline No. & $\begin{array}{l}\text { Consolidation } \\
\text { pressure, } \mathrm{kPa}\end{array}$ & Void ratio, $\left(\mathrm{e}_{\mathrm{c}}\right)$ \\
\hline 11 & \multirow[t]{6}{*}{200} & 0.625 \\
\hline 12 & & 0.607 \\
\hline 13 & & 0.565 \\
\hline 14 & & 0.625 \\
\hline 15 & & 0.667 \\
\hline 16 & & 0.631 \\
\hline 17 & \multirow{6}{*}{400} & 0.542 \\
\hline 18 & & 0.596 \\
\hline 19 & & 0.634 \\
\hline 20 & & 0.654 \\
\hline 21 & & 0.586 \\
\hline 22 & & 0.532 \\
\hline
\end{tabular}

Table 4.2 Conditions of cyclic loading tests (samples prepared by moist technique)

\begin{tabular}{|c|c|c|}
\hline $\begin{array}{c}\text { Consolidation } \\
\text { pressure kPa }\end{array}$ & Void ratio $\left(\mathbf{e}_{\mathbf{c}}\right)$ & CSR \\
\hline \multirow{2}{*}{50} & $0.642 \pm 0.01$ & $\begin{array}{c}0.075,0.100,0.125, \text { and } \\
0.150\end{array}$ \\
\hline \multirow{4}{*}{100} & $0.548 \pm 0.01$ & $\begin{array}{c}0.075,0.100,0.125, \text { and } \\
0.150\end{array}$ \\
\cline { 2 - 3 } & $0.581 \pm 0.01$ & $\begin{array}{c}0.075,0.100,0.125, \text { and } \\
0.150\end{array}$ \\
\cline { 2 - 3 } & $0.6201 \pm 0.01$ & $\begin{array}{c}0.075,0.100,0.125, \text { and } \\
0.135\end{array}$ \\
\hline \multirow{3}{*}{200} & $0.554 \pm 0.01$ & $\begin{array}{c}0.075,0.100,0.125, \text { and } \\
0.150\end{array}$ \\
\cline { 2 - 3 } & $0.585 \pm 0.01$ & $\begin{array}{c}0.075,0.100,0.110, \text { and } \\
0.135\end{array}$ \\
\cline { 2 - 3 } & $0.615 \pm 0.01$ & $\begin{array}{c}0.075,0.100,0.125, \text { and } \\
0.135\end{array}$ \\
\hline \multirow{2}{*}{400} & $0.544 \pm 0.01$ & $\begin{array}{c}0.075,0.100,0.125, \text { and } \\
0.150\end{array}$ \\
\cline { 2 - 3 } & $0.579 \pm 0.01$ & $\begin{array}{c}0.075,0.100,0.125, \text { and } \\
0.145\end{array}$ \\
\hline \multirow{2}{*}{800} & $0.537 \pm 0.01$ & $\begin{array}{c}0.075,0.100,0.125, \text { and } \\
0.145\end{array}$ \\
\hline
\end{tabular}


Table 4.3 Conditions of cyclic loading (samples prepared by wet-dry cycles technique)

\begin{tabular}{|c|c|c|c|}
\hline $\begin{array}{c}\text { Consolidation } \\
\text { pressure }\left(\sigma_{\mathrm{vc}}^{\prime}\right), \\
\mathrm{kPa}\end{array}$ & $\begin{array}{c}\text { Water content } \\
\text { after controlled } \\
\text { desiccation } \\
\left(w_{\mathrm{d}}\right) \%\end{array}$ & $\begin{array}{c}\text { Water } \\
\text { content } \\
\left(w_{\mathrm{ET}}\right), \%\end{array}$ & CSR \\
\hline \multirow{3}{*}{50} & 18 & $20.2 \pm 0.4$ & $\begin{array}{c}100,0.125, \text { and } \\
0.150,0.200\end{array}$ \\
\cline { 2 - 4 } & 16 & $19.1 \pm 0.4$ & $\begin{array}{c}100,0.125, \text { and } \\
0.150,0.200\end{array}$ \\
\cline { 2 - 4 } & 13 & $19.2 \pm 0.4$ & $\begin{array}{c}100,0.125, \text { and } \\
0.150\end{array}$ \\
\hline
\end{tabular}




\subsection{Consolidation}

All tests were conducted on normally consolidated mine tailings, under $K_{o}$ condition. The consolidation pressures were $50,100,200,400$ and $800 \mathrm{kPa}$. A family of consolidation curves was generated for different initial water contents and the resulting chart has been termed the consolidation design chart for gold mine tailings. Figure 4.1 shows the design chart which was composed from normally consolidated testing results. The samples were tested with different initial water contents (void ratio) and consolidation pressures. After each consolidation test, the water contents of the samples were measured.

The water content after consolidation is a function of initial water content at a given consolidation pressure. The design chart (Figure 4.1) was created in order to prepare samples for the shearing tests with similar initial conditions (void ratio) after the consolidation stage. In practice, it was realized that using the initial water content as a guide to obtain samples with similar void ratios $\left(\mathrm{e}_{\mathrm{c}}\right)$ after consolidation is an efficient technique. For example, if the water content (void ratio) after consolidation was desired to be $18 \%$ for all the consolidation pressures, based on the design chart (Figure 4.1), the initial water content for $100,200,400$ and $800 \mathrm{kPa}$ consolidation pressures would have had to be $23.5,25,26.5$ and $30 \%$, respectively. Figure 4.2 shows the design chart in terms of void ratio at $15 \mathrm{kPa}$ and at the end of consolidation for different consolidation pressures.

It was recognized that the initial water contents of the samples may influence the type of fabric created (Flocculated to dispersive fabric). However, the mechanical responses of simple shear tests do not show any clear dependency on initial water content 
for gold mine tailings tested in this study. A similar result was observed for gold mine tailings when the results of cyclic loading were compared between the samples prepared by slurry technique and the undisturbed samples (Wijewickreme et al., 2005). It was reported that two out of three samples prepared by using slurry deposition agree with undisturbed samples in terms of cyclic stress ratio.

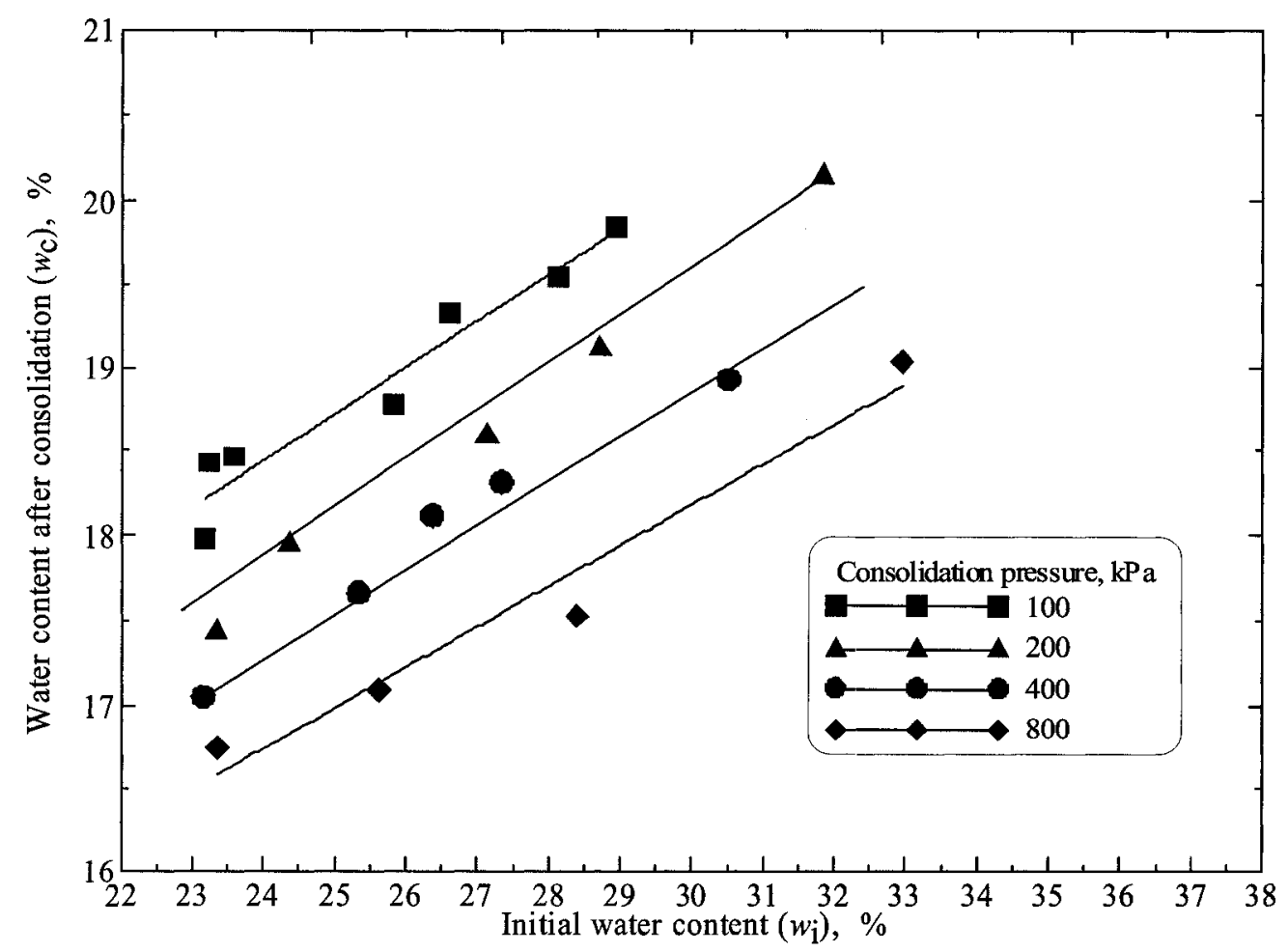

Figure 4.1 Design consolidation chart to predict the initial water content of tailings samples. 


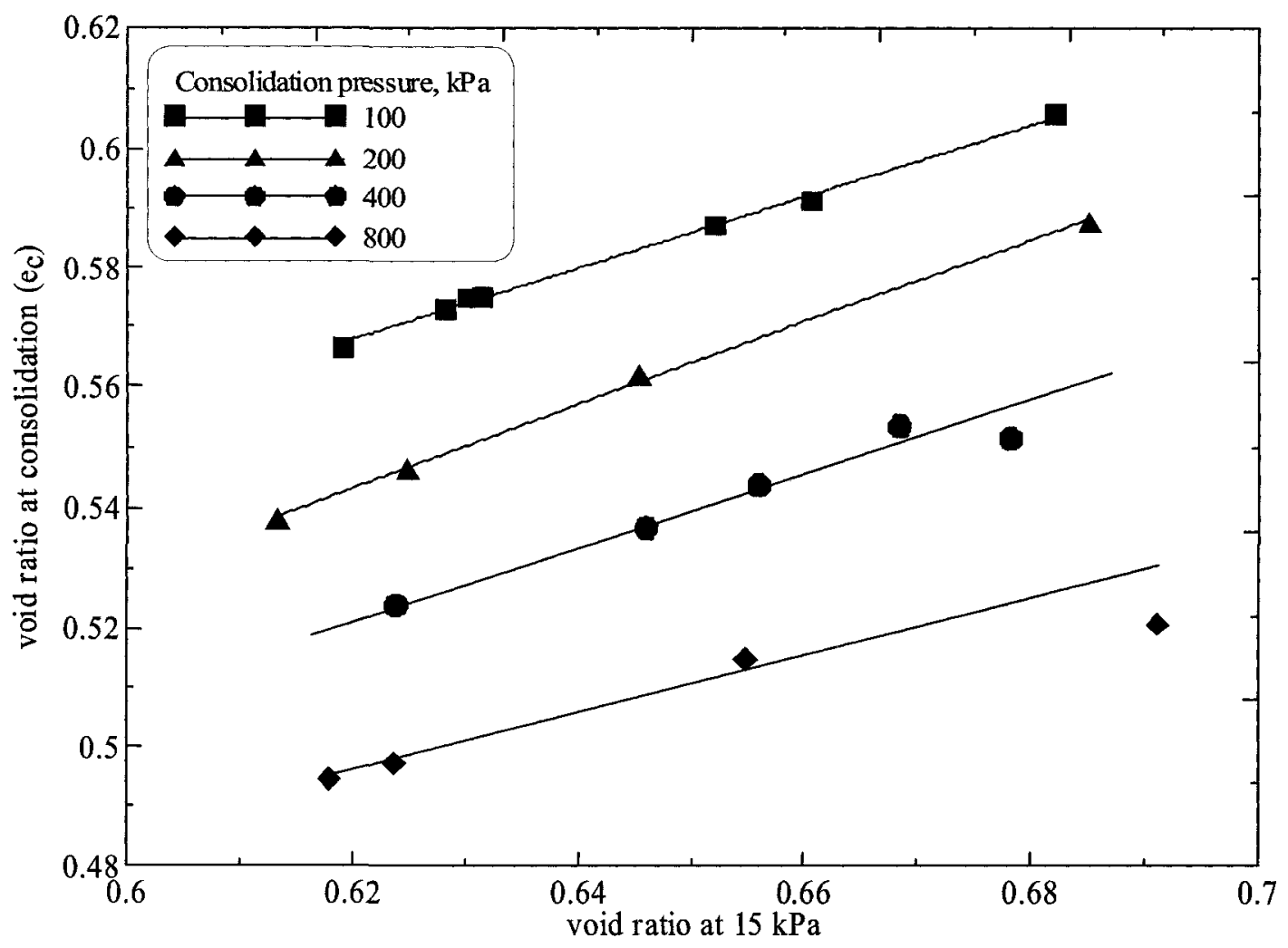

Figure 4.2 Design consolidation chart in terms of void ratio. 


\subsection{Monotonic Loading Behaviour}

Monotonic loading was applied to tailings samples prepared using the moist technique with different void ratios and consolidation pressures. The consolidation design chart was used as a guideline for achieving the desired target void ratio at each consolidation pressure level.

\subsubsection{Monotonic Response at a given Void Ratio}

The undrained monotonic response of gold mine tailings at three fixed void ratios after consolidation pressure is shown through Figures 4.3 to 4.6 . Fixing the void ratio enables one to explore the effect of consolidation pressure in the monotonic behaviour of tailings. The stress-strain relationship is presented in terms of normalized shear stress. At low void ratios (low water content) all the sample responses are dilative (Figure 4.3(a)). The normalized shear stress-strain relationship for the consolidation pressures 100,200 , and $400 \mathrm{kPa}$ are essentially similar until about $3 \sim 4 \% \gamma$ (Figure $4.3(\mathrm{a})$ ). At low void ratios any increase of the consolidation pressure does not significantly affect the dilative response. Some decrease in the dilative tendency can be noted with increasing stress levels at higher strain levels (Figure 4.3(b)).However, by increasing the void ratio (Figure 4.3 and 4.4 ), the dilative response gradually changes to contractive response. This is fairly clear at high consolidation pressure. For instance, Figure 4.4 shows a dilative a response for a consolidation pressure of $100 \mathrm{kPa}$, but a contractive response for 200,400 $\mathrm{kPa}$. At relatively high void ratios (water content) it is clear that tailings are susceptible to liquefaction at all consolidation pressures (Figure 4.6). At all consolidation pressures, 
tailings response is contractive, where the $\mathrm{e}_{\mathrm{c}}=0.660 \pm 0.01$ (about $w_{\mathrm{c}}=21.54$ ). Increases in consolidation pressure transfers the tailings response from dilative to contractive. However, the degree of transformation to the contractive response is also a function of the tailings void ratio (water content). 

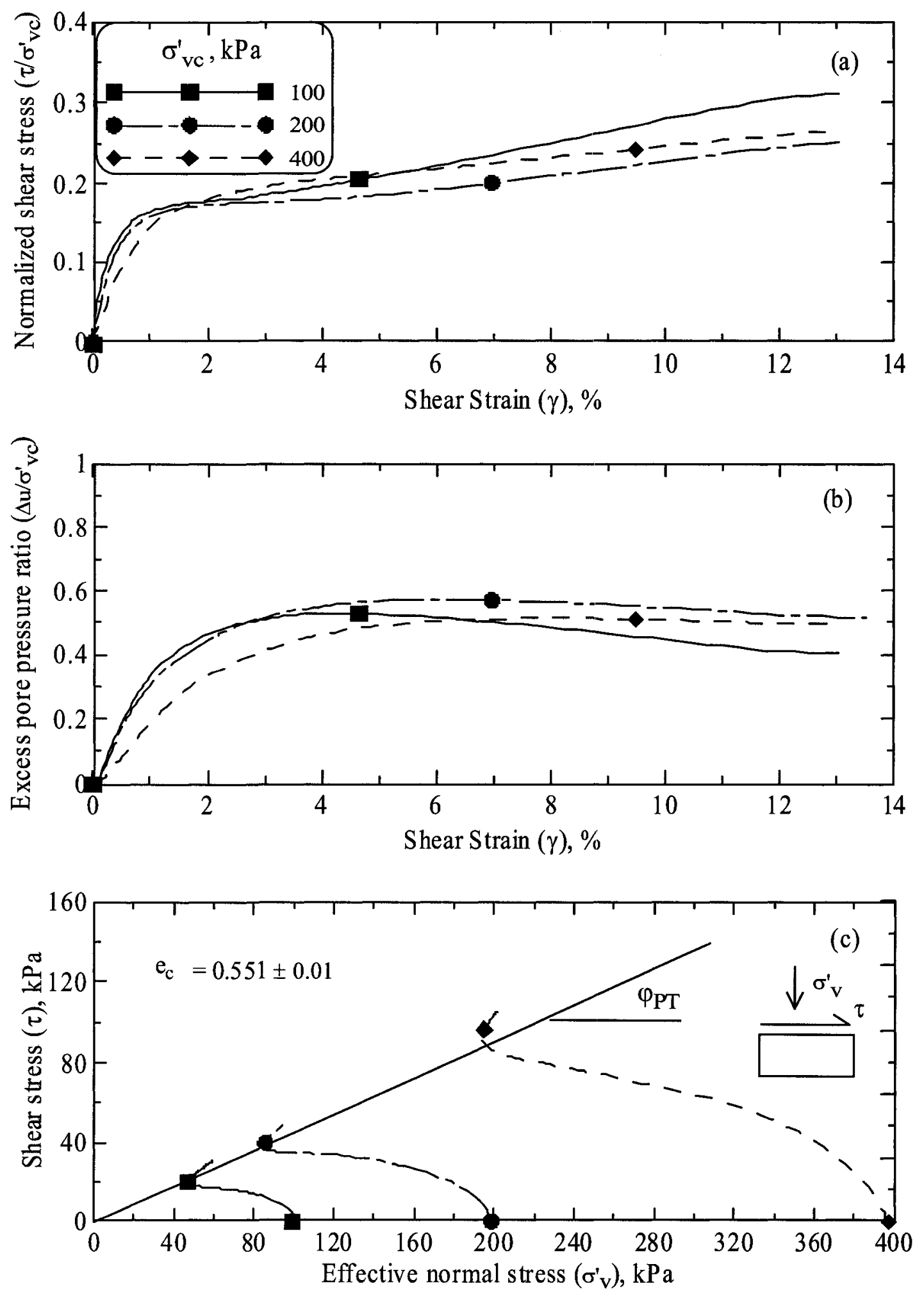

Figure 4.3 Effect of consolidation pressure on monotonic behaviour of gold mine tailings at consolidated void ratio $\left(\mathrm{e}_{\mathrm{c}}=0.551\right)$ 

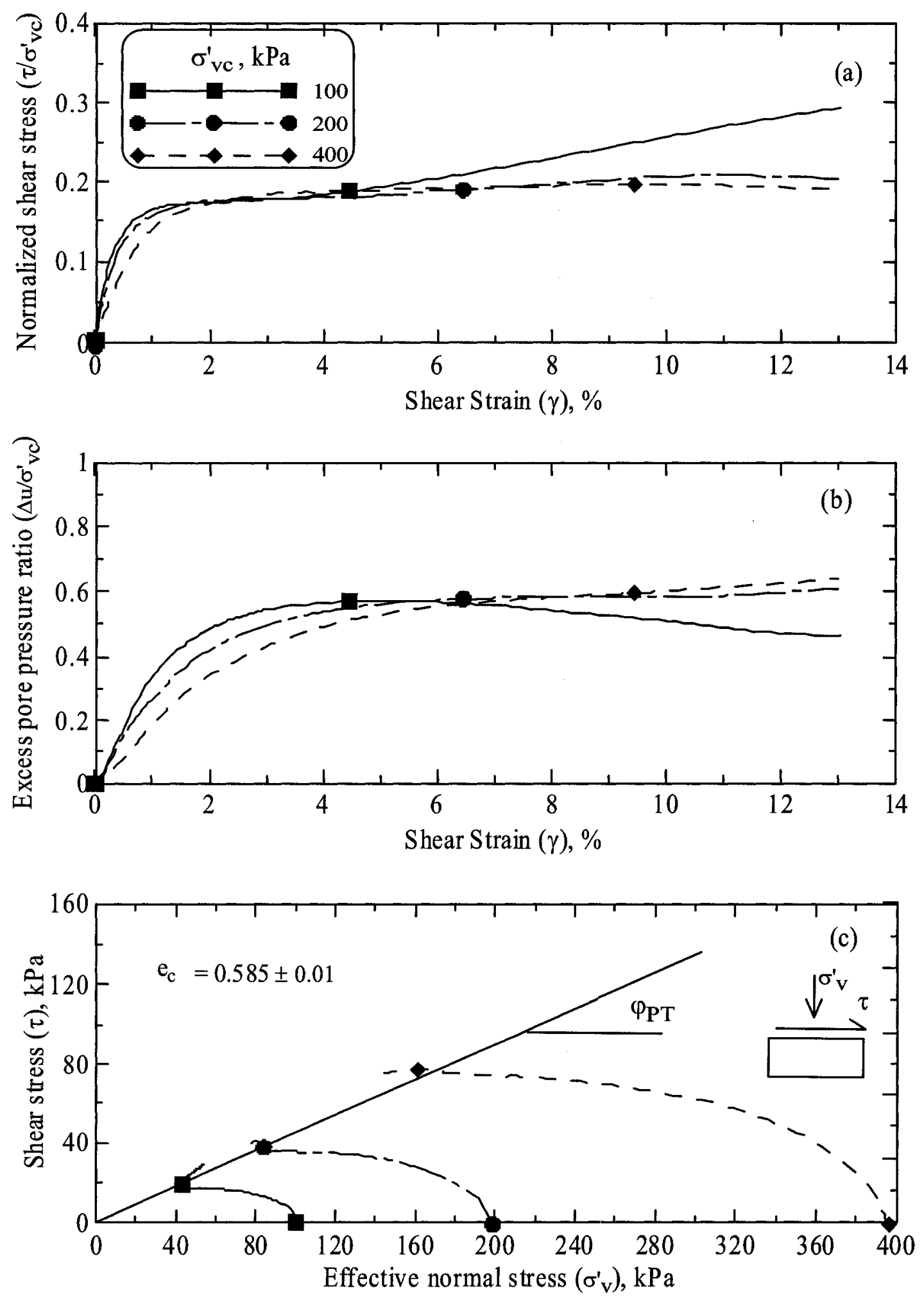

Figure 4.4 Effect of consolidation pressure on monotonic behaviour of gold mine tailings at consolidated void ratio $\left(e_{c}=0.585\right)$ 

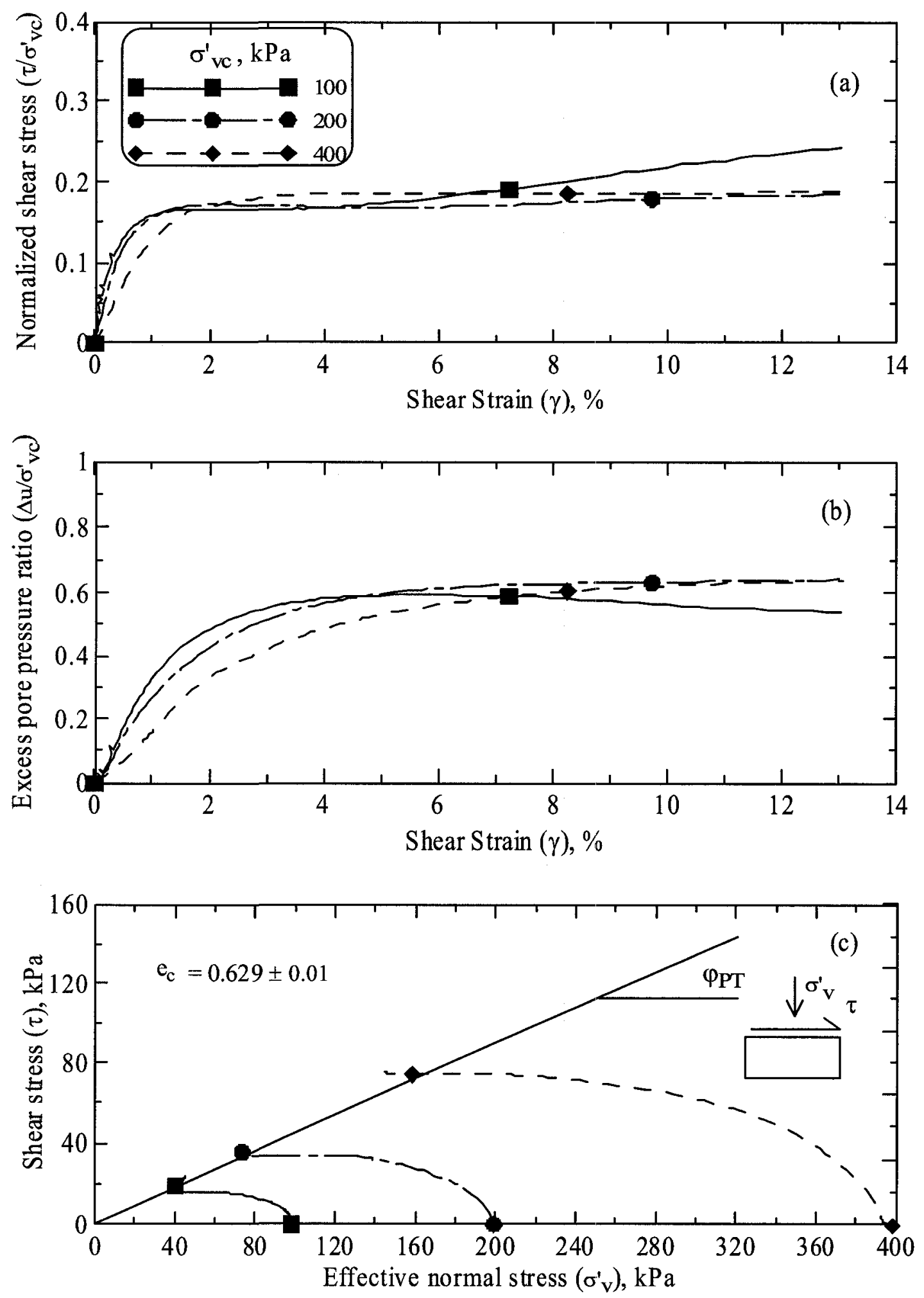

Figure 4.5 Effect of consolidation pressure on monotonic behaviour of gold mine tailings at consolidated void ratio $\left(\mathrm{e}_{\mathrm{c}}=0.629\right)$ 

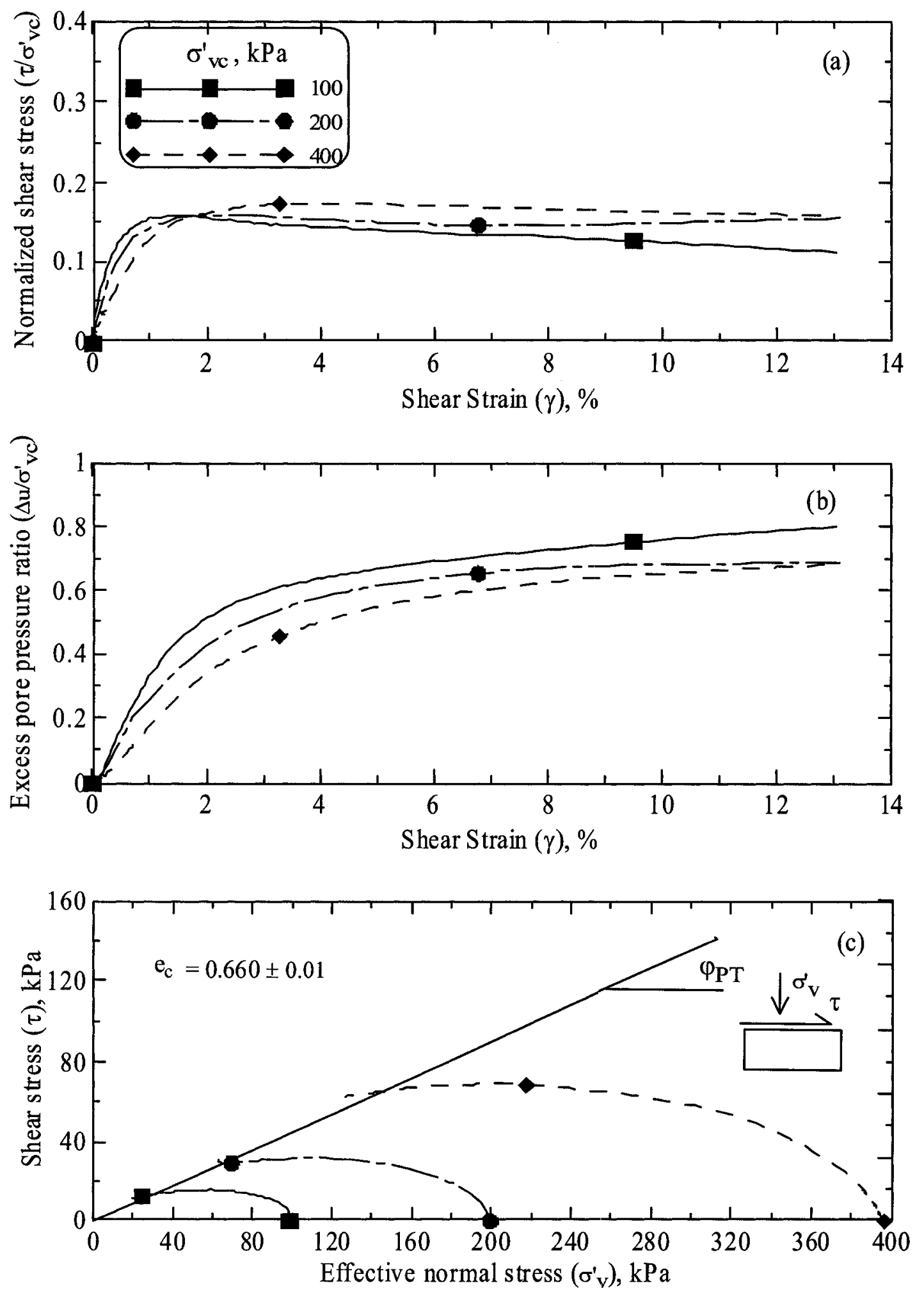

Figure 4.6 Effect of consolidation pressure on monotonic behaviour of gold mine tailings at consolidated void ratio $\left(e_{c}=0.660\right)$ 


\subsubsection{Monotonic Response at a given Consolidation Pressure}

Presenting the undrained monotonic results at given consolidation pressures allows to explore the effect of void ratio of the tailings on its response. The monotonic response at three consolidation pressures at a fixed void ratio is shown through Figures 4.7 to 4.9. For all the consolidation pressures, there is a gradual transformation from the dilative response to the contractive response as the void ratio (water content) increases. However, this effect is more significant at low consolidation pressures than at high consolidation pressures. For $100 \mathrm{kPa}$ consolidation pressure, the effect of void ratio is more obvious to the change of the dilative response to contractive response. However, this effect is less predominant at $400 \mathrm{kPa}$ consolidation pressure. It is clear that the increase in void ratio leads to more contractive responses in the tailings, but the degree of this effect is governed somewhat by the consolidation pressure. 

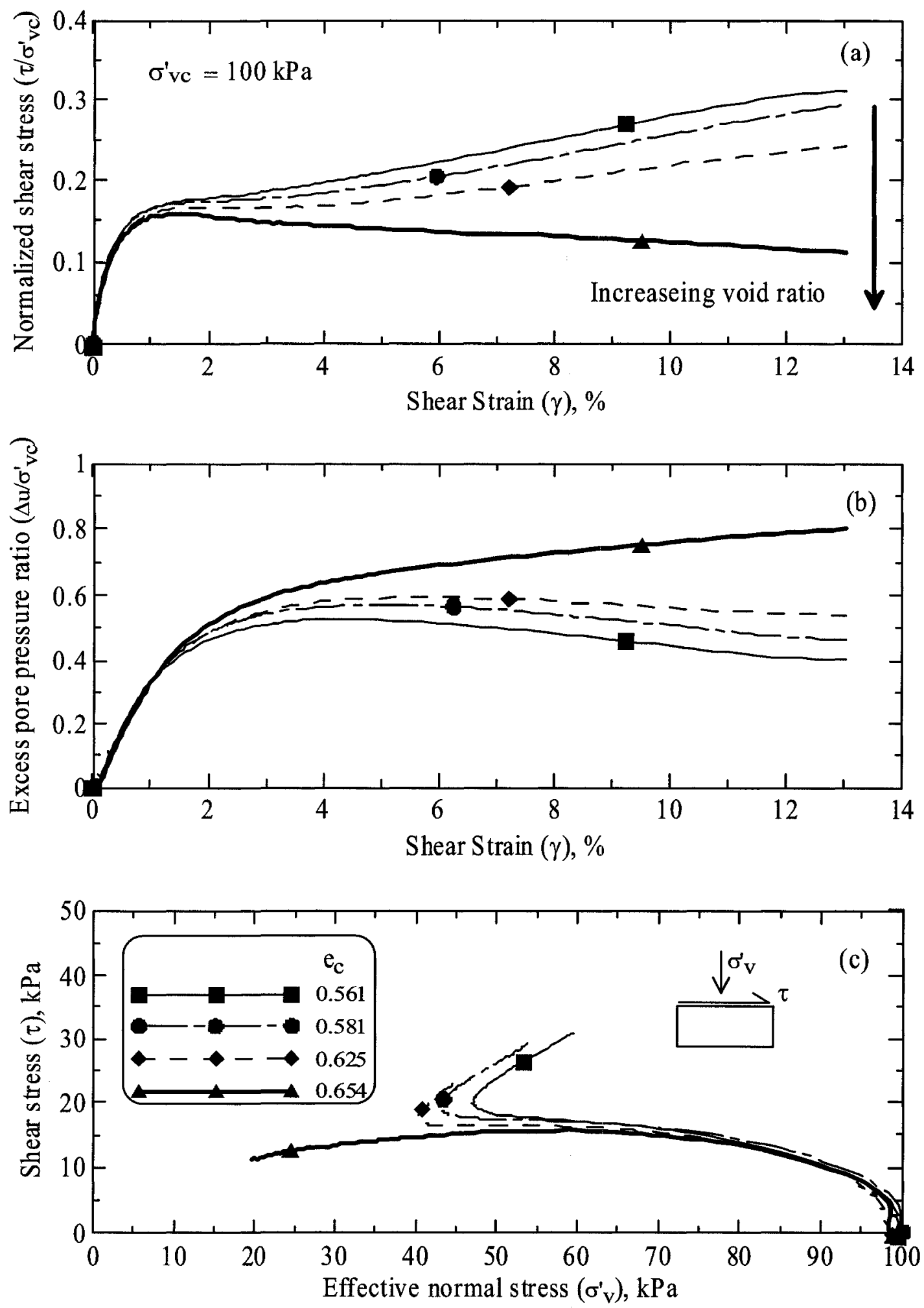

Figure 4.7 Effect of void ratio (water content) on monotonic behaviour of gold mine tailings at consolidated pressure $\sigma_{\mathrm{vc}}^{\prime}=100 \mathrm{kPa}$. 

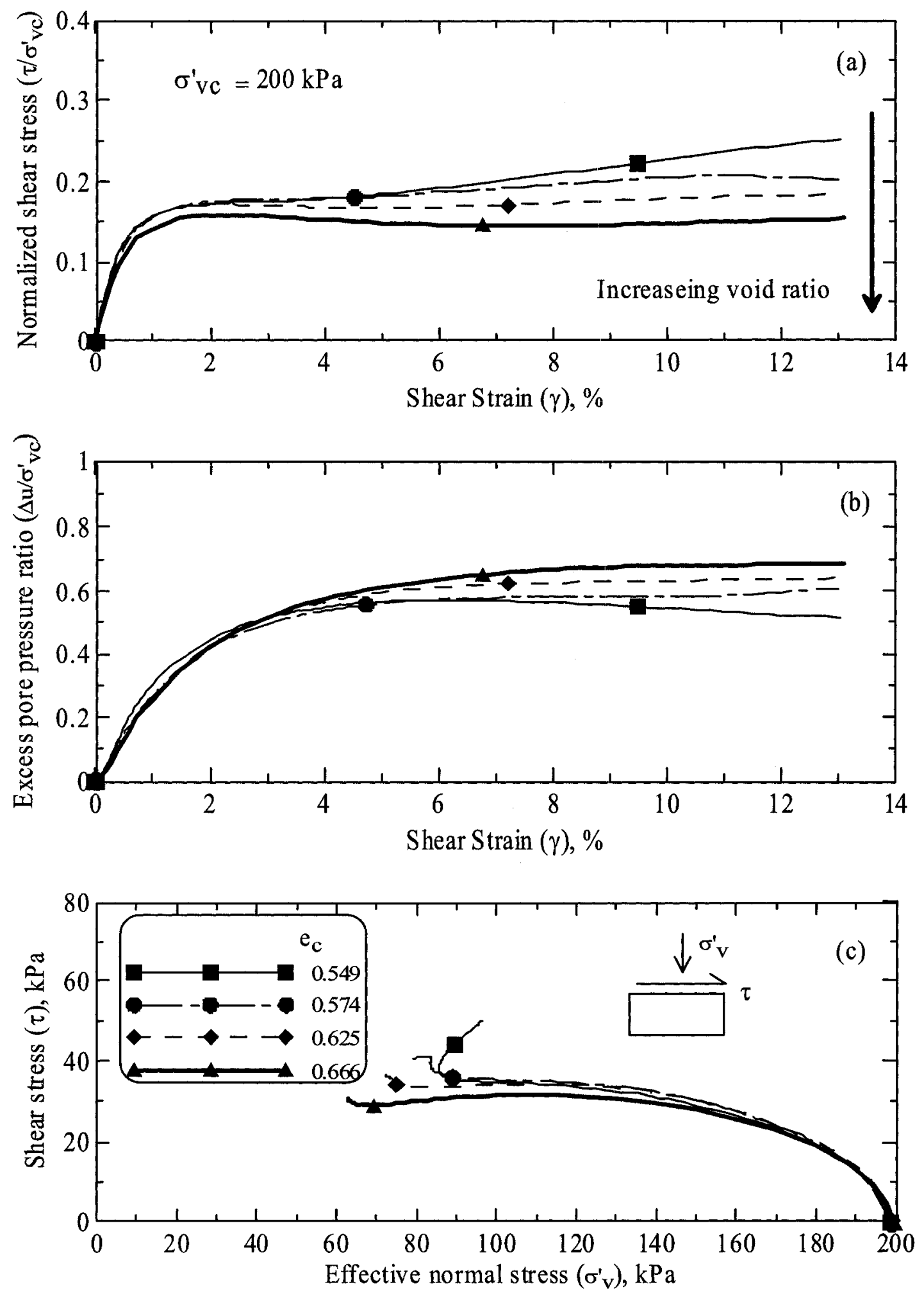

Figure 4.8 Effect of void ratio (water content) on monotonic behaviour of gold mine tailings at consolidated pressure $\sigma_{\mathrm{vc}}^{\prime}=200 \mathrm{kPa}$. 

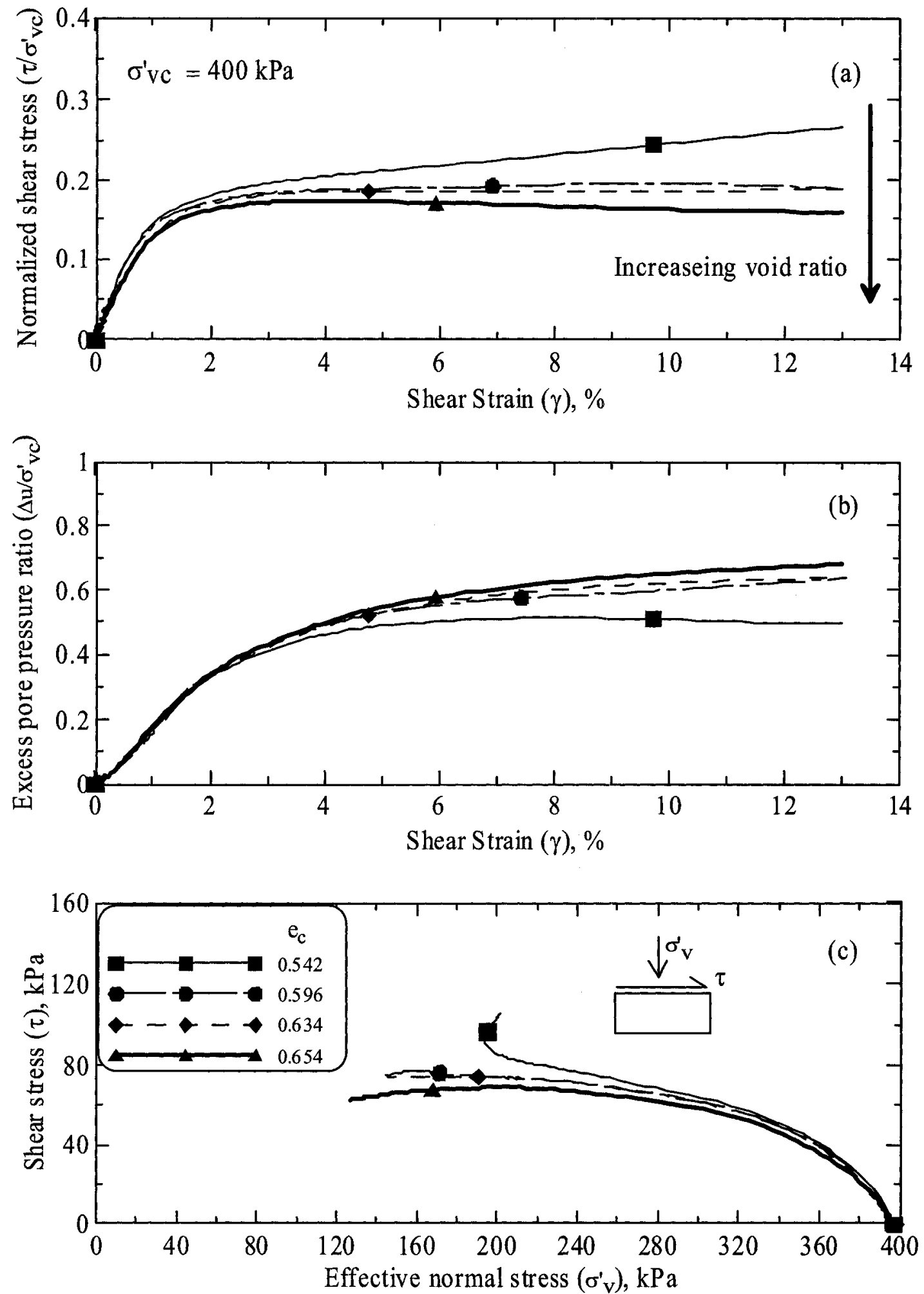

Figure 4.9 Effect of void ratio (water content) on monotonic behaviour of gold mine tailings at consolidated pressure $\sigma_{\mathrm{vc}}^{\prime}=400 \mathrm{kPa}$. 


\subsubsection{Effect of Stress Path}

Gold mine tailings (from Bulyanhulu mine in Tanzania) similar to that used in this study were tested under triaxial compression loading by Crowder (2004). The tailings samples were prepared by using the moist tamping technique. Samples consolidated to 50,100 , and $150 \mathrm{kPa}$ hydrostatic stress and to a void ratio of $0.72 \pm 0.02$. Figure 4.10 shows the measured monotonic response of the tailings under undrained triaxial compression loading. The stress-strain responses for all three consolidation pressures exhibit strain hardening type of response (Figure 4.10(a)), even though the negative pore pressure development following phase transformation is fairly limited (Figure 4.10(b)). In contrast, the simple shear tests, which were undertaken at smaller void ratios $\left(e_{c}=0.660\right)$ show a contractive response (Figure 4.6). Based on Figure 4.10, it was concluded that the tailings are generally not susceptible to static liquefaction (Crowder, 2004). However, they are indeed susceptible to static liquefaction under simple shear loading. The apparently conflicting conclusions of the potential for static liquefaction are simply a reflection of the effect of stress path on the undrained response of the tailings.

The difference in behaviour between the triaxial compression and simple shear tests may occur on account of material anisotropy and/or due to differences in stress conditions. It is well recognized that triaxial (compression and extension) and simple shear loading modes have different principal stress directions and different intermediate principal stress (relative to major and minor principal stresses). 

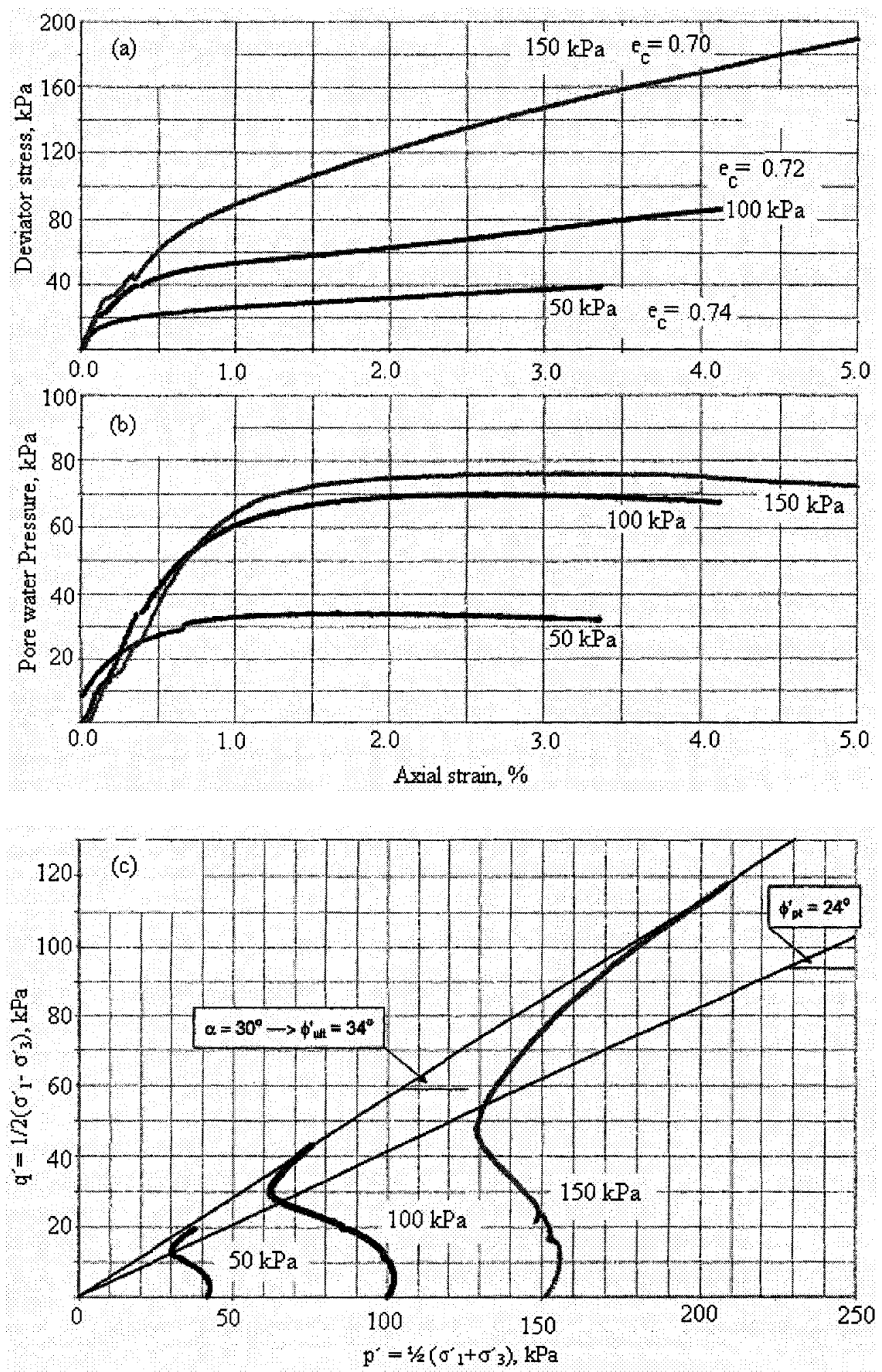

Figure 4.10 Monotonic responses of gold mine tailings under triaxial compression tests at isotropic consolidation pressures 50,100, and $150 \mathrm{kPa}$ (Crowder, 2004). 
Experimental results of hollow cylinder torsional shear on sandy soils have shown that two variables termed $\alpha_{\sigma}$ (is the angle of $\sigma_{1}$ with the vertical direction), and dimensionless parameter $b\left(=\left(\sigma_{2}-\sigma_{3}\right) /\left(\sigma_{1}-\sigma_{3}\right)\right)$ influence the response of sandy soil (Uthayakumar and Vaid, 1998; Yoshimine et al., 1998). An evaluation of the stress conditions in the triaxial tests show that $\alpha_{\sigma}=90^{\circ}$ and $b=1$ for triaxial extension, and $\alpha_{\sigma}$ $=0^{\circ}$ and $b=0$ for triaxial compression. Yoshimine et al. (1998) confirmed that these values are $\alpha_{\sigma}=45^{\circ}$ and $b=0.3-0.4$ for simple shear. The aforementioned studies generally showed that the behaviour of sand becomes more contractive as $\alpha_{\sigma}$ increases from $0^{\circ}$ to $90^{\circ}$ and an $\alpha_{\sigma}$ of $45^{\circ}$ (simple shear) produces an intermediate stress-strain response between the triaxial compression and extension. .

The boundary value problems in-situ often involve deformation under different loading modes. Using the triaxial compression tests alone to investigate whether the tailings are susceptible to liquefaction is unsafe since that loading mode represents the strongest response. Therefore the use of strength values measured in triaxial compression is not conservative for practical engineering design use. Simple shear test is more appropriate for characterizing the response since it represents a conservative measure of the strength. In addition, simple shear imposes stress conditions that are very similar to those experienced in the in situ conditions under earthquake loading.

\subsubsection{Critical Stress Ratio}

The effective stress ratios $\left(p^{\prime} / q\right)$ corresponding to the peak shear stresses of monotonic responses which are represented through Figures 4.3 to 4.6 are used to illustrate how the CSR (defined as the stress ratio at the peak shear stress state) changes 
with the void ratio. Figure 4.11 shows the friction angle mobilized at the critical state $\left(\varphi_{\mathrm{CSR}}\right)$ with different void ratios. It can be seen that the stress at which strain softening is triggered is dependent on the void ratio of the tailings samples after consolidation

pressure. Generally, an increase of void ratio $\left(\mathrm{e}_{\mathrm{c}}\right)$ leads to a decrease in friction angle at CSR $\left(\varphi_{C S R}\right)$. This behaviour is similar to the testing results of sandy soils under simple shear and triaxial tests (Vaid \& Thomas, 1994; Vaid \& Sivathayalan, 1996.a).

\subsubsection{Phase Transformation and Steady State}

The effective stress ratios corresponding to the phase transformation state (PT) which represent the temporary state when the behaviour transforms from contractive to dilative are shown in Figure 4.12. The effective stress states at this state falls within a unique straight line (termed the PT line) passing through the origin regardless of the void ratio (water content), and confining stress. This demonstrates that the friction angles at PT state are equal for both contractive and dilative responses. The uniqueness of the friction angle at PT was initially reported for sandy soil, for which the friction angle at PT is unique regardless of the relative density, confining stress and load mode (Vaid \& Chern, 1985; Thomas, 1992; Uthayakumar \& Vaid, 1998). The results of this study indicates that friction angle at PT is a unique property for tested mine tailings as well. 


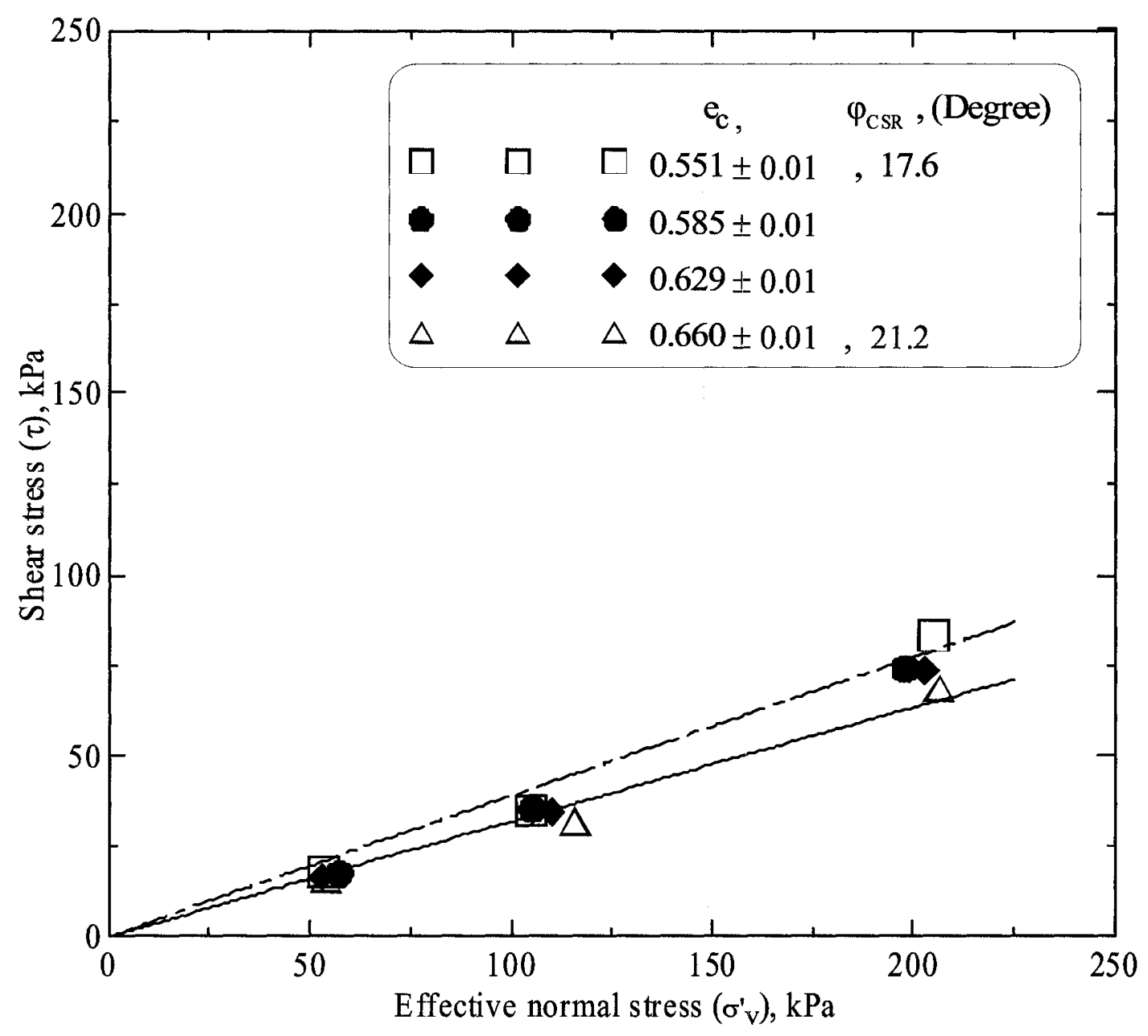

Figure 4.11 Friction angles at critical stress ratio $\left(\varphi_{\mathrm{CSR}}\right)$ for different void ratios of gold mine tailings under monotonic loading.

The friction angle at PT of the gold mine tailings tested in this research is $24.6^{\circ}$. This angle is almost equal to the friction angle $\left(24^{\circ}\right)$ for similar tailings from the Bulyanhulu gold mine tested under a triaxial compression mode (Crowder, 2004). This observation confirms that the angle at PT is indeed unique and unaffected by the load mode which is also the case for sand.

The steady state (SS) condition of gold mine tailings was not clearly defined. The reason might be that the steady state (SS) deformation is reached at large strains, and the 
simple shear apparatus limits the maximum shear strain (that can yield confident measurements) to about $13 \%$ of shear strain. Therefore the cut-off point of the shear strain is not enough to represent the steady state which occurs in large strain levels. Fourie and Papageorgiou (2001) also faced difficulties in identifying the steady state line for mine tailings and silty sand soils because of errors in measurement of the initial sizes of the tailings specimens. Yamamuro and Lade (1998) reported that the steady state line of silty sands may not always exist.

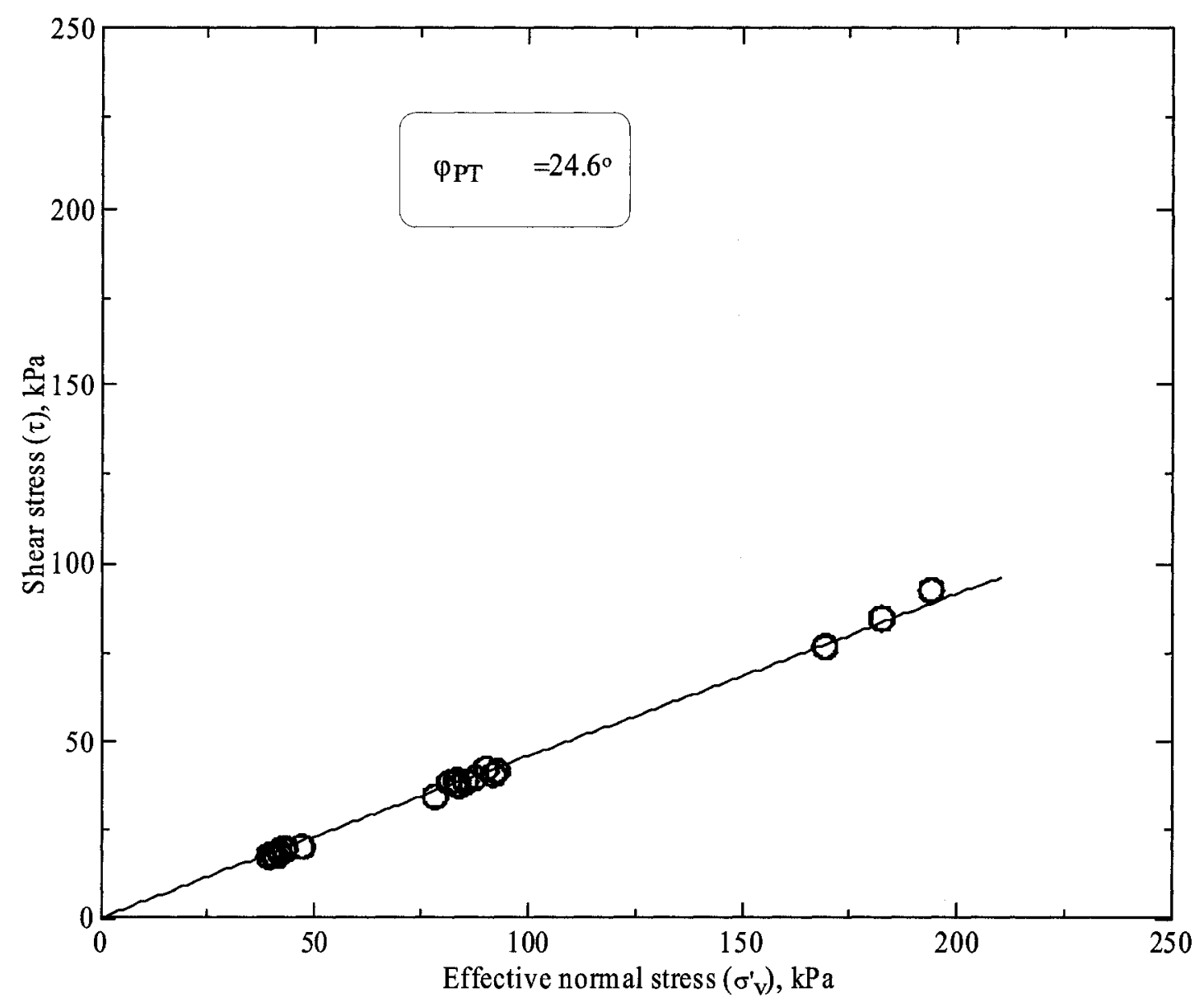

Figure 4.12 Friction angles at phase transformation state $\left(\varphi_{\mathrm{PT}}\right)$ of gold mine tailings under monotonic loading. 


\subsubsection{Failure Line}

Figure 4.13 shows the effective stress conditions at a shear strain level of $13 \%$. As mentioned before, this level was chosen as the failure level since the localized deformation occurs and introduces measurement errors at high strains. It can be seen in the stress path plots that an essentially constant stress ratio has been reached well before this strain level. It is clearly shown that the effective stress ratios at $13 \%$ are lying in the unique straight line. A straight line implies a constant mobilized friction angle (about $27.2^{\circ}$ ) regardless of the type of behaviour (contractive or dilative), void ratio and consolidation pressure.

The uniqueness of the failure line of the gold mine tailings is in agreement with other researchers studies for sandy soils (Vaid and Chern, 1985; Kuerbis, 1989; Thomas, 1992). However, the failure angle reported to be $34^{\circ}$ when the Bulyanhulu gold mine tailings were tested under triaxial compression condition by Crowder (2004) is significantly different from that measured in this study. It should be noted that the difference in friction angle between failure and PT is about $3^{\circ}$ in this study and $10^{\circ}$ in the study by Crowder. In most soils this difference is fairly small, and differences exceeding about $5^{\circ}$ have been rare in the literature. 


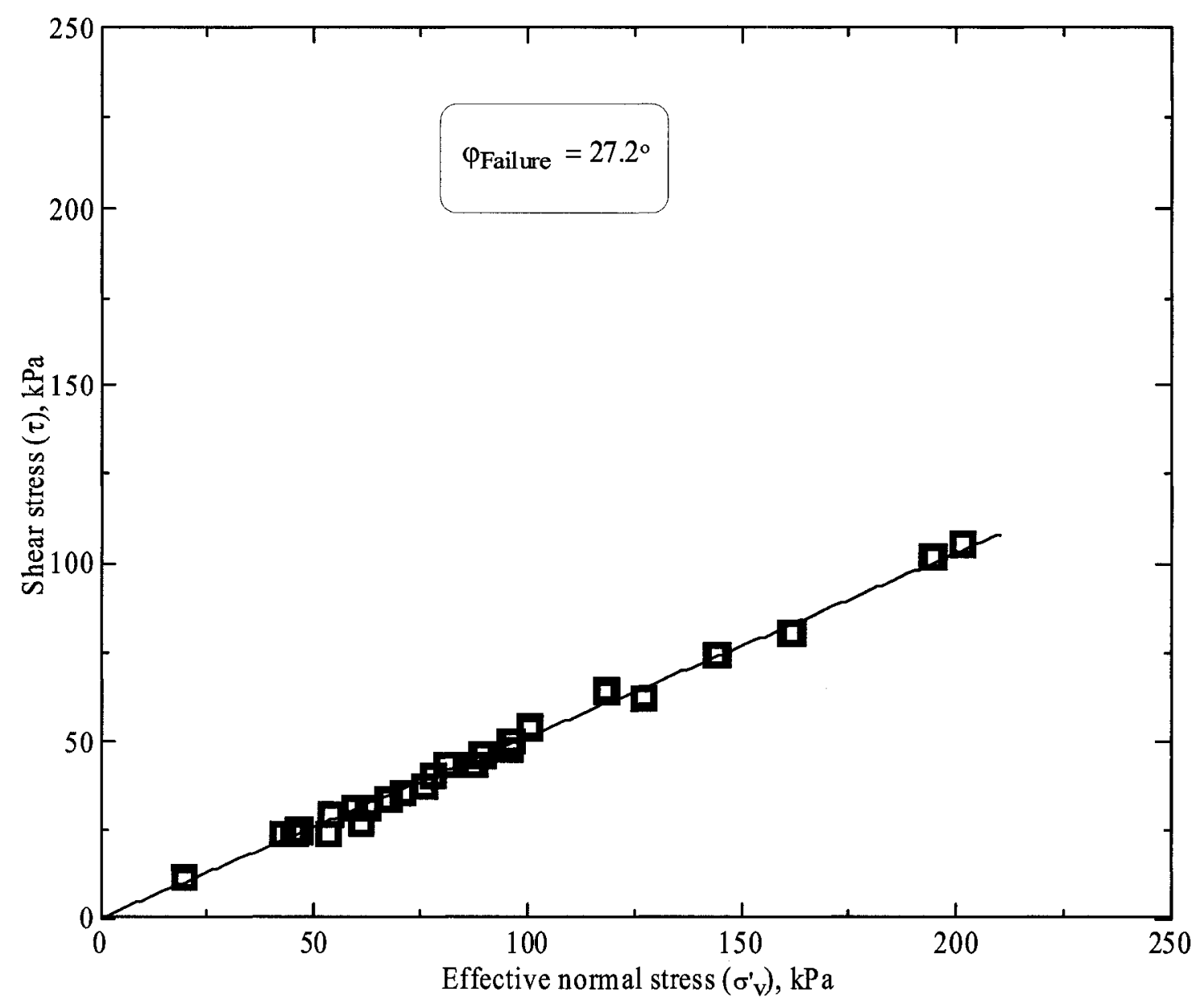

Figure 4.13 Failure friction angles ( $\varphi_{\text {Failure }}$ ) of gold mine tailings under monotonic loading. 


\subsection{Cyclic Loading Behaviour}

The cyclic loading behaviour of gold mine tailings was investigated at different consolidation pressure levels $(50,100,200,400$, and $800 \mathrm{kPa})$ over a range of void ratios $\left(e_{c}\right)$ from 0.537 to 0.620 . Moist preparation and wet-dry preparation techniques were used to prepare the samples. The wet-dry cycles preparation technique was used only to investigate the influence of the desiccation on the cyclic resistance of tailings at $50 \mathrm{kPa}$ consolidation pressure.

\subsubsection{Stress-strain Response of Cyclic Loading}

Figure 4.14 and 4.15 illustrate the typical stress-strain response, pore pressure ratio verses the number of cycles relationship, and stress path obtained from the tailings samples which were consolidated to $\sigma_{v c}^{\prime}=400 \mathrm{kPa}$, and to a similar void ratios $\left(\mathrm{e}_{\mathrm{c}}\right)$. Cyclic shear loading with Cyclic Stress Ratio (CSR) amplitudes of 0.075 and 0.15 were applied to the samples as shown in Figure 4.14 and 4.15, respectively. Initially, the stress path of both samples experiences contractive behaviour. In the event of an increase in the number of cycles the stress path moves to the origin due to the generation of excess pore pressure. The increase of pore pressure ratio $\left(r_{u}\right)$ is dependent on the CSR amplitude and number of cycles. For instance, the sample that was tested with $\operatorname{CSR}=0.075$ developed $r_{u}=0.8$ in about 66 cycles; however, the sample subjected to $C S R=0.15$ developed a similar $r_{u}$ in 3 cycles. This example demonstrates that the CSR has a significant influence to the cyclic loading behaviour of tailings. The observed behaviour of cyclic mobility in this study is similar in fashion to cyclic responses that have been observed from different types of 
tailings and natural silt tested by Wijewickreme et. al (2005), and Sanin and Wijewickreme (2006).

It is interesting to note that all tailings samples have not reached $100 \%$ of pore pressure ratio $\left(r_{u}\right)$ even though their shear strain $(\gamma)$ exceeded $3.75 \%$. It seems for some tailings material and natural silt with specific characteristics that the pore pressure ratio does not accumulate to $100 \%$. This is even true for the sample that failed by cyclic mobility type. This statement is supported by results from studies that have been done in silty soils and tailings where $100 \%$ of the pore pressure ratio was not realized (Vaid, 1994; Singh, 1996). 

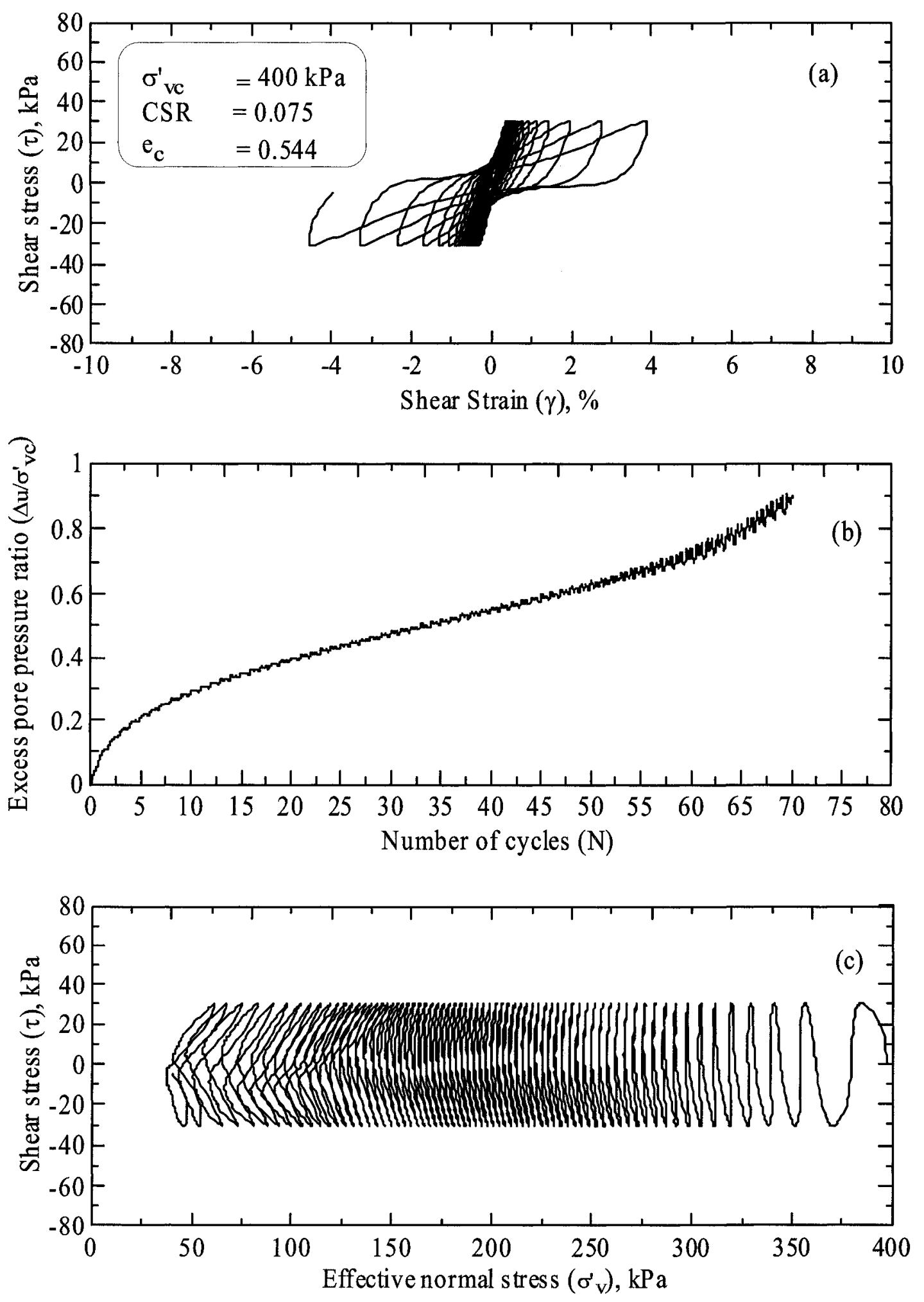

Figure 4.14 Typical cyclic loading response of gold mine tailings sample consolidated to $400 \mathrm{kPa}$ and subjected to a CSR of 0.075 . 

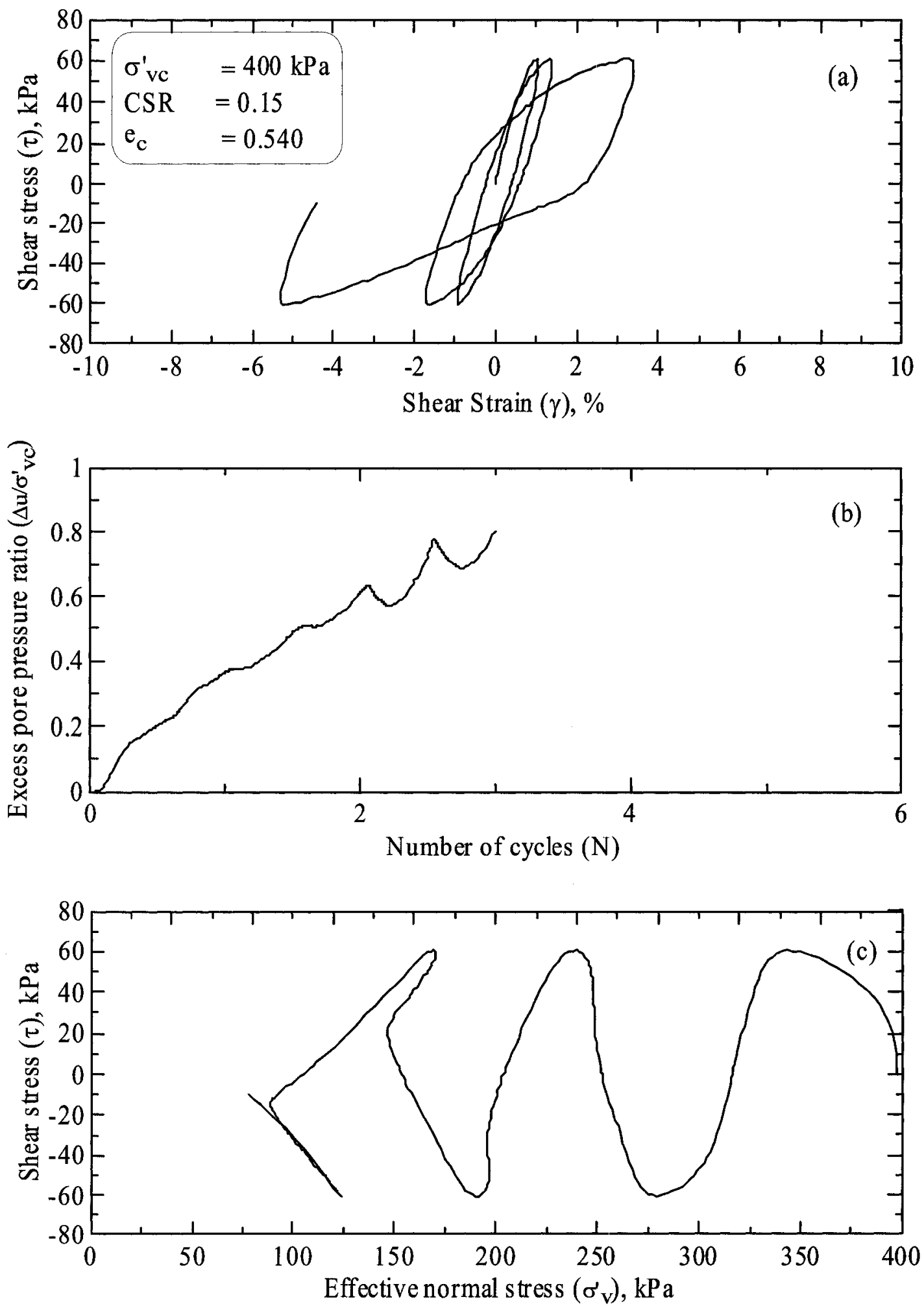

Figure 4.15 Typical cyclic loading response of gold mine tailings sample consolidated to $400 \mathrm{kPa}$ and subjected to a CSR of 0.15 . 


\subsubsection{Cyclic Resistance Ratio}

A series of cyclic loading tests were performed on the tailings to explore the relationship between number of cycles to liquefaction and cyclic stress ratio. This will yield the cyclic resistance ratio (CRR). The CRR is defined herein as the capacity of the tailings samples to resist a cyclic loading without liquefaction in 10 cycles of loading $(\gamma=$ $3.75 \%)$. The factors that affect cyclic resistance are presented in this section.

\subsubsection{Influence of Void Ratio}

Figure 4.16 shows cyclic stress ratio versus number of cycles of tailings samples at three different void ratio levels $(0.548,0.581$, and 0.620$)$ and at $100 \mathrm{kPa}$ consolidation pressure. At a given number of cycles, the cyclic resistance increases with the decreasing of void ratio. For example at number of cycles $=10$, the $C R R$ is increasing from about 0.1 to 0.115 , when the void ratio is decreasing from 0.620 to 0.548 . Even though the change in the CRR is not significant, it clearly demonstrates that there is a relationship between the CRR and the void ratio of tailings. This conclusion is apparently in contradiction with that of Ishihara et al. (1981) who reported that CRR is independent of the void ratio of different mine tailings tested under a triaxial machine.

Figures 4.17 to 4.18 show the influence of void ratio on CRR as consolidation pressure changes. The figures show a series of relationships between the void ratio and the cyclic stress ratio at 200 , and $400 \mathrm{kPa}$. Obviously, increasing the void ratio decreases the CRR of tailings even at high consolidation stress levels. Figure 4.19 shows only one void ratio $\left(\mathrm{e}_{\mathrm{c}}=0.537\right)$ at consolidation pressure $800 \mathrm{kPa}$ and the reason for not 
representing the other is that it was not capable to prepare samples with initially high water content.

A comparison of Figures 4.16 and 4.18 shows that the influence of the void ratio on the cyclic resistance reduces somewhat as consolidation pressure increases. Figure 4.20 demonstrates the CSR at $100 \mathrm{kPa}$ consolidation pressure in the form of void ratio versus number of cycles. Each line represents the constant amplitude of CSR. The slope of the lines in Figure 4.20 represents the influence of void ratio on cyclic resistance. A comparison of Figures 4.20 and 4.21 shows that the influence of void ratio on cyclic resistance is smaller at $200 \mathrm{kPa}$ compared to $100 \mathrm{kPa}$.

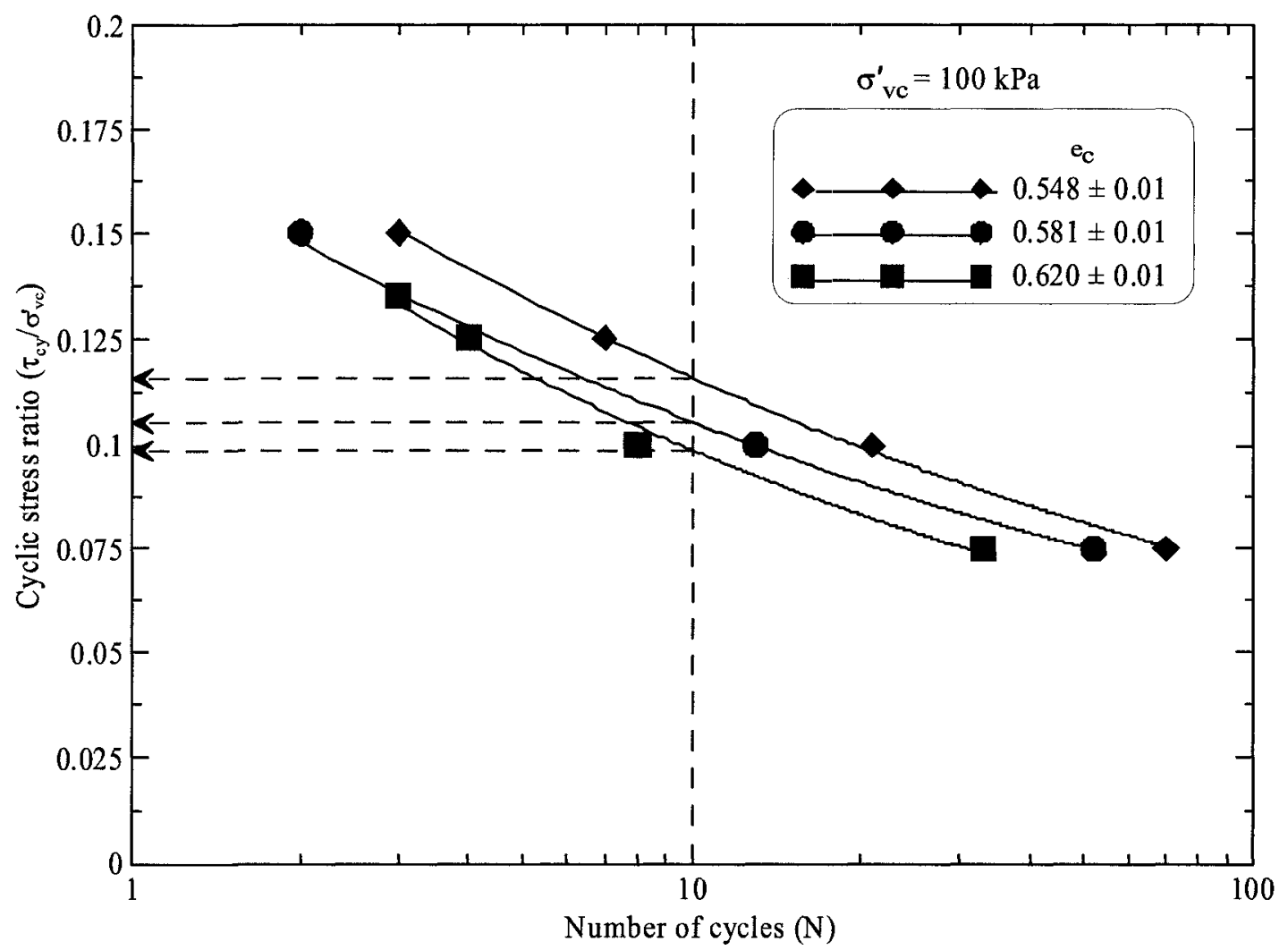

Figure 4.16 Cyclic stress ratio versus number of cycles to reach $(\gamma=3.75 \%)$ for tailings samples at consolidated pressure $\sigma_{\mathrm{vc}}^{\prime}=100 \mathrm{kPa}$ and range of void ratio. 


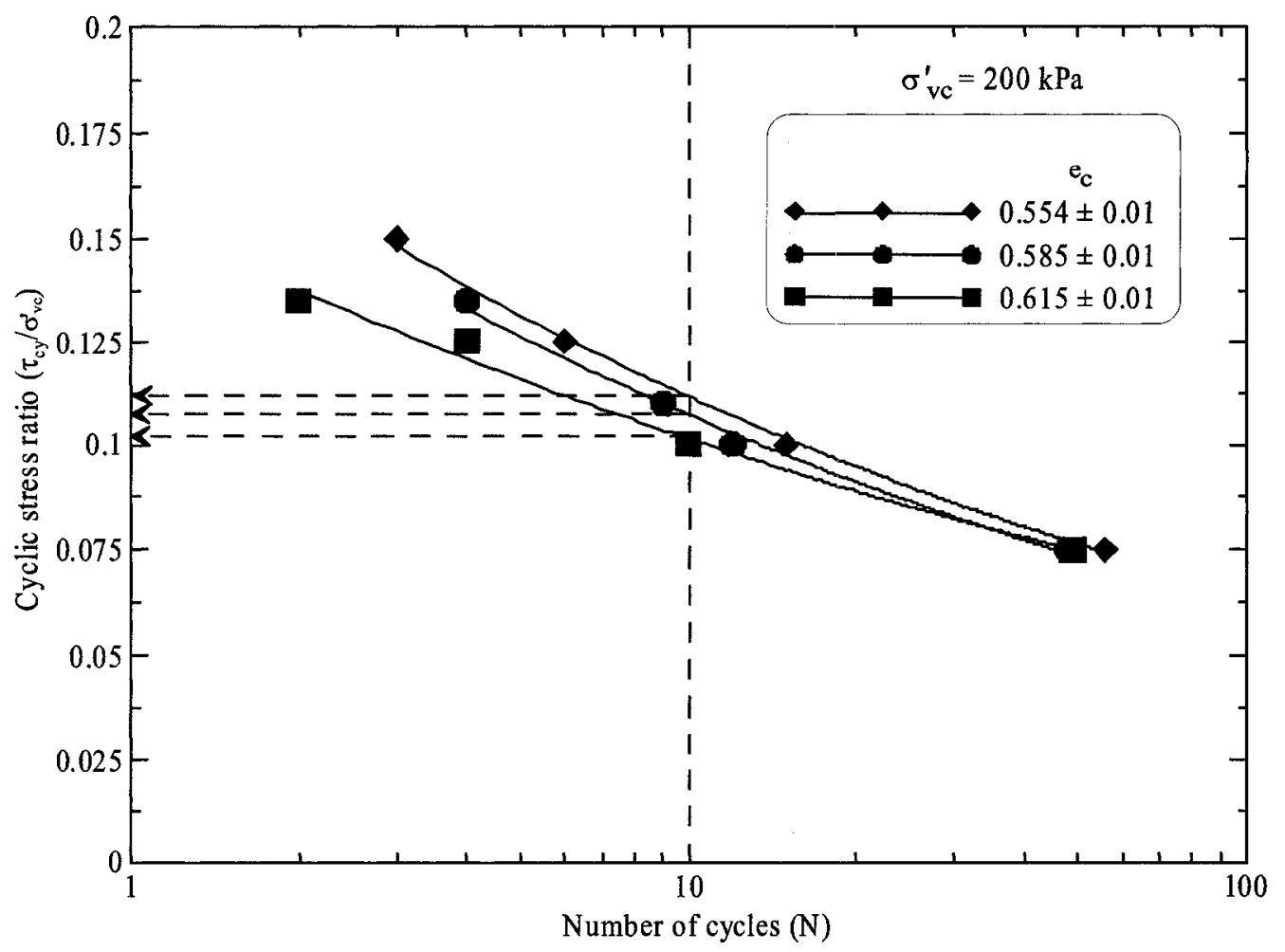

Figure 4.17 Cyclic stress ratio versus number of cycles to reach $(\gamma=3.75 \%)$ for tailings samples at consolidated pressure $\sigma_{\mathrm{vc}}^{\prime}=200 \mathrm{kPa}$ and range of void ratio.

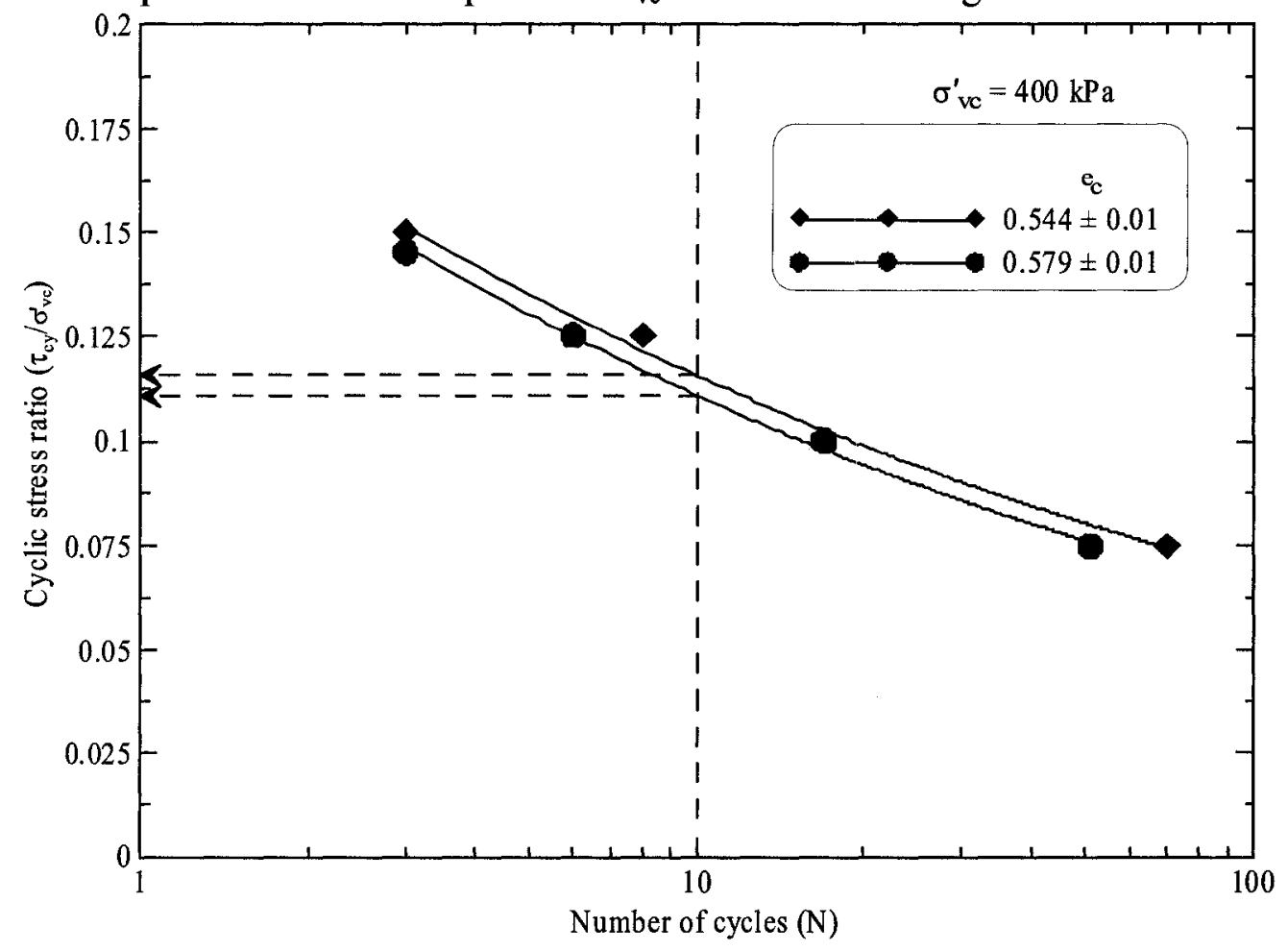

Figure 4.18 Cyclic stress ratio versus number of cycles to reach $(\gamma=3.75 \%)$ for tailings samples at consolidated pressure $\sigma_{\mathrm{vc}}^{\prime}=400 \mathrm{kPa}$ and range of void ratio. 


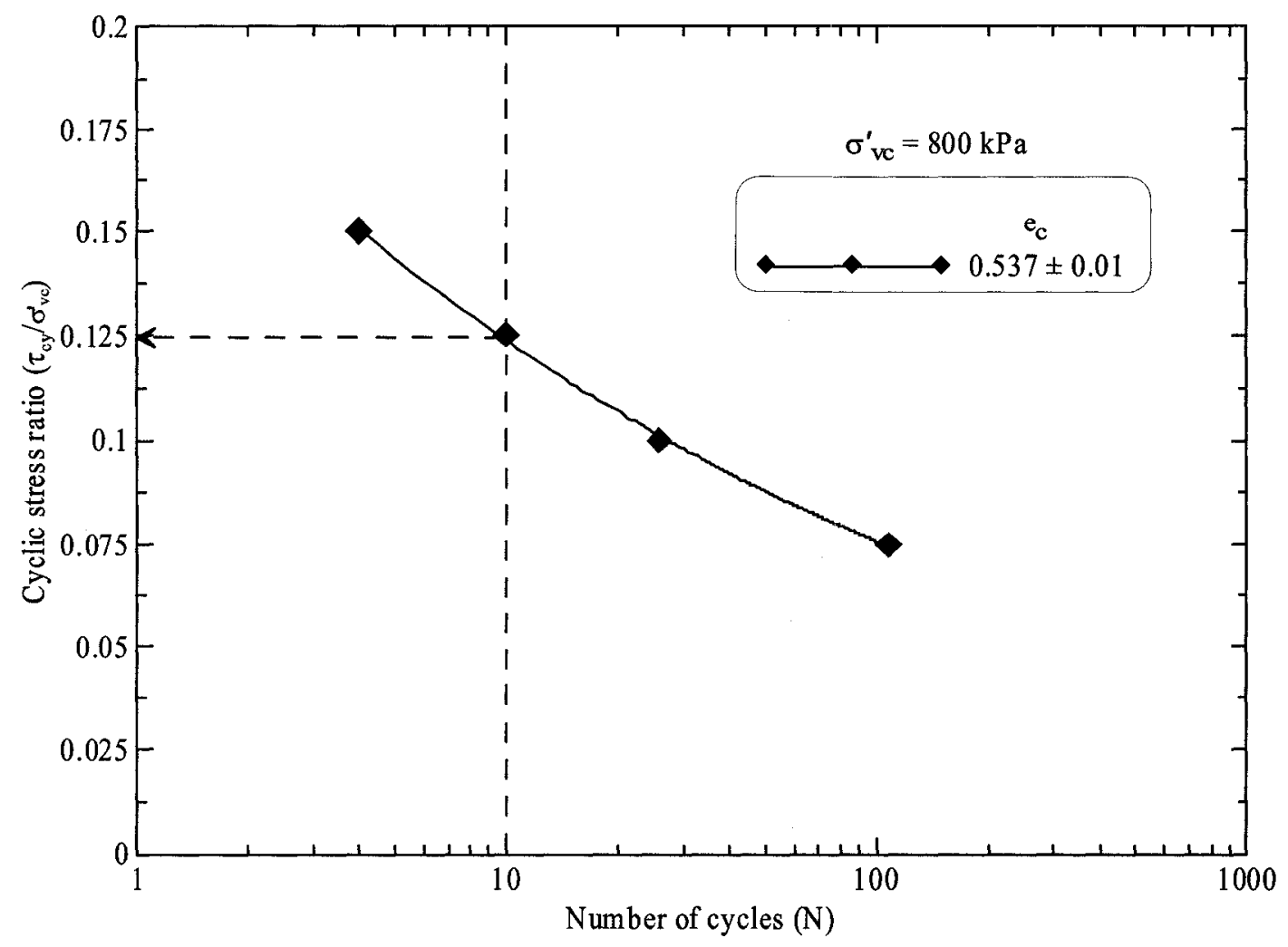

Figure 4.19 Cyclic stress ratio versus number of cycles to reach $(\gamma=3.75 \%)$ for tailings samples at consolidated pressure $\sigma_{\mathrm{vc}}^{\prime}=800 \mathrm{kPa}$ at $\mathrm{e}_{\mathrm{c}}=0.537$.

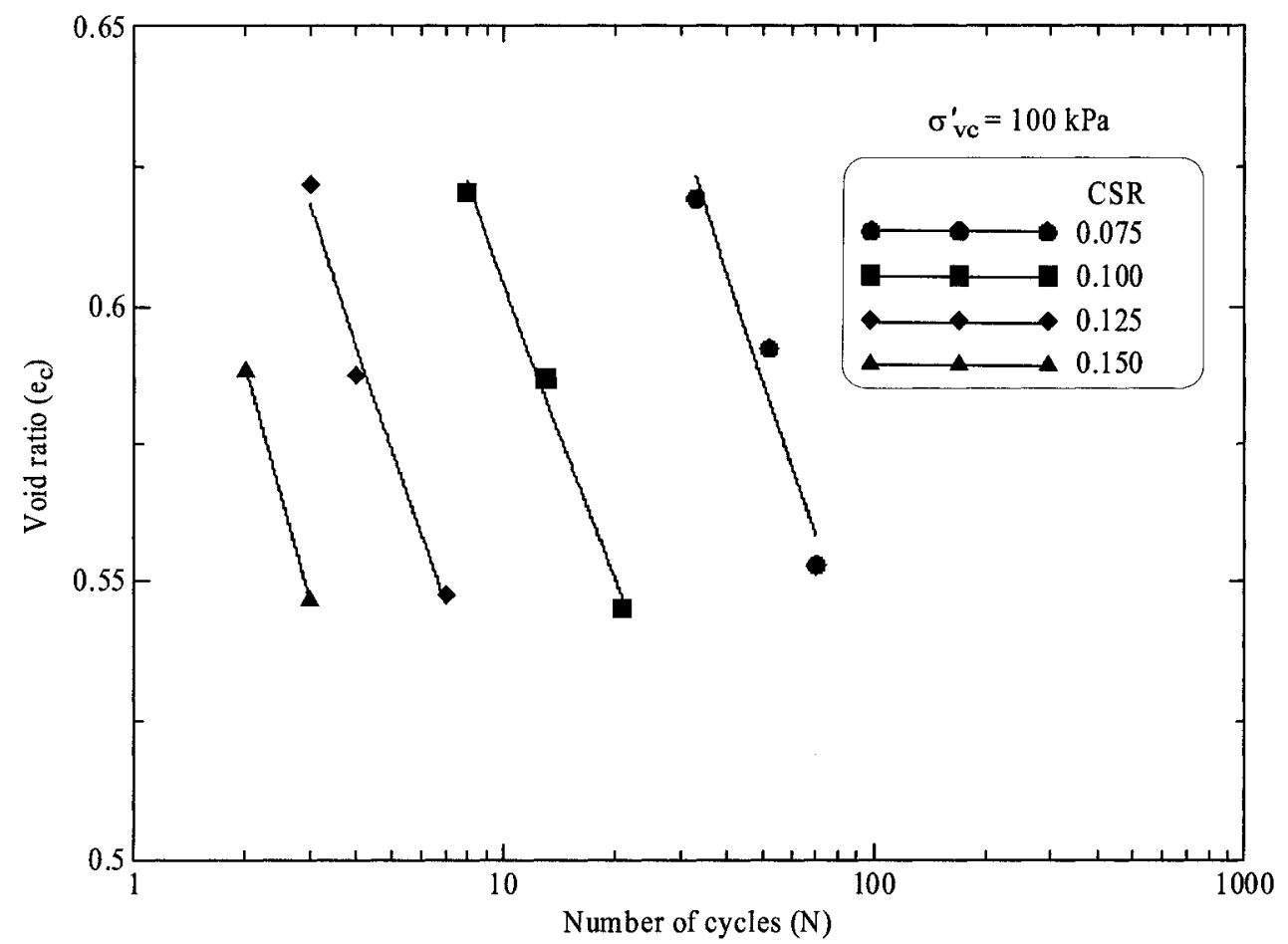

Figure 4.20 Void ratio $\left(e_{c}\right)$ versus number of cycles to reach for tailings samples at consolidated pressure $\sigma_{\mathrm{vc}}^{\prime}=100 \mathrm{kPa}$ and different CSR. 


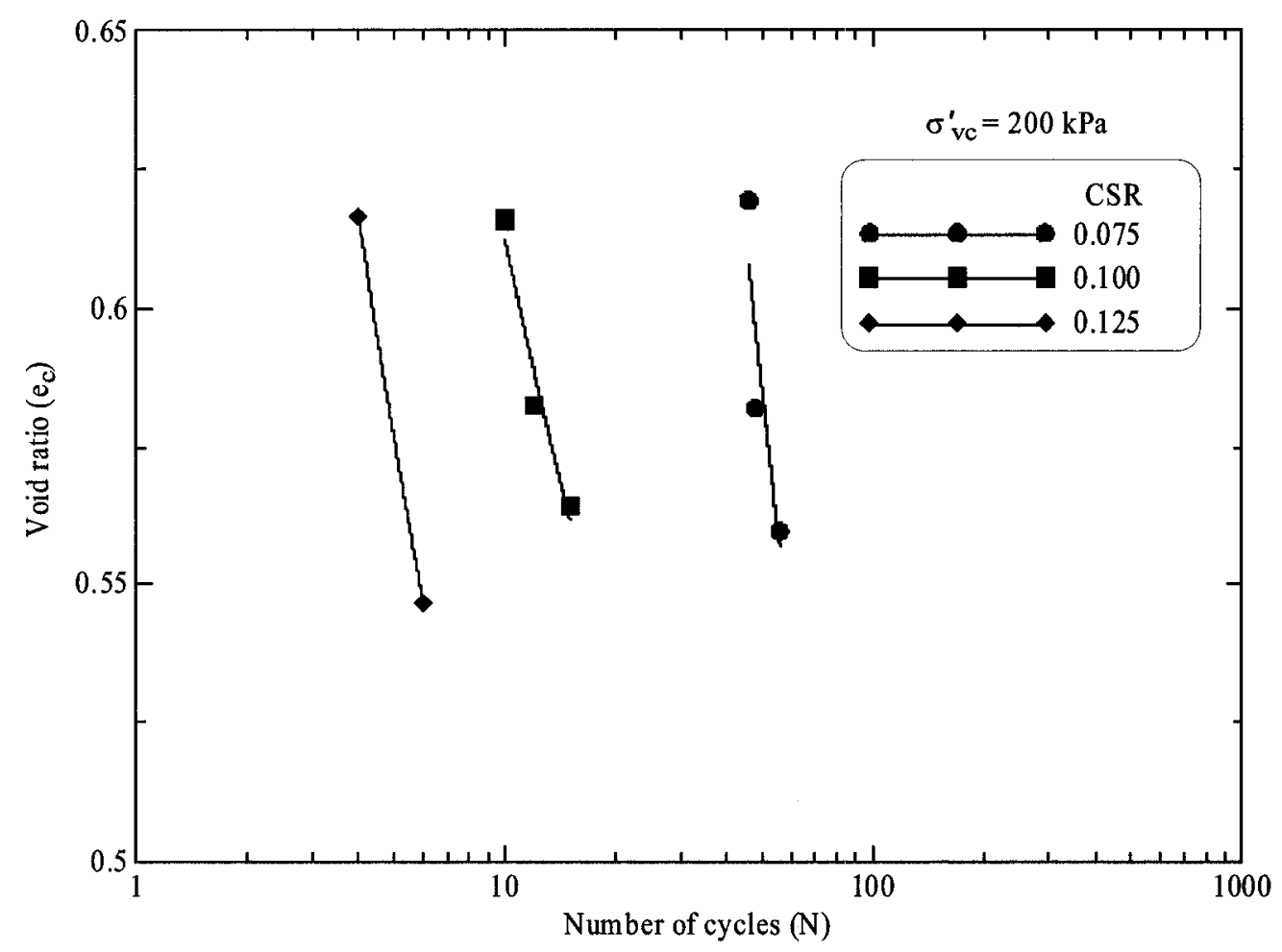

Figure 4.21 Void ratio $\left(\mathrm{e}_{\mathrm{c}}\right)$ versus number of cycles to reach for tailings samples at consolidated pressure $\sigma_{\mathrm{vc}}^{\prime}=200 \mathrm{kPa}$ and different CSR.

\subsubsection{Influence of Consolidation Pressure}

In order to study the influence of consolidation pressure on the cyclic resistance of tailings, a series of tests were performed at four stress levels $100,200,400,800 \mathrm{kPa}$. The cyclic stress ratio versus number of cycles at of theses stress levels with different void ratios are shown in Figures 4.22 to 4.24 . From these figures, no clear trend can be observed by increasing or decreasing the consolidation pressure to the CRR. This ambiguous relationship of influence to the consolidation pressure may be because the strain criteria $\gamma=3.75 \%$ is not sufficiently high to display the actual consolidation pressure responses. This supposition is supported by the influence of consolidation pressure under monotonic loading. It is shown from monotonic response data (e.g. Figures 4.6(a)) that 
the influence of consolidation pressure almost starts beyond $4 \%$ of shear strain. More studies are suggested to use different strain level criteria to investigate the consolidation pressure influences under cyclic loading mode.

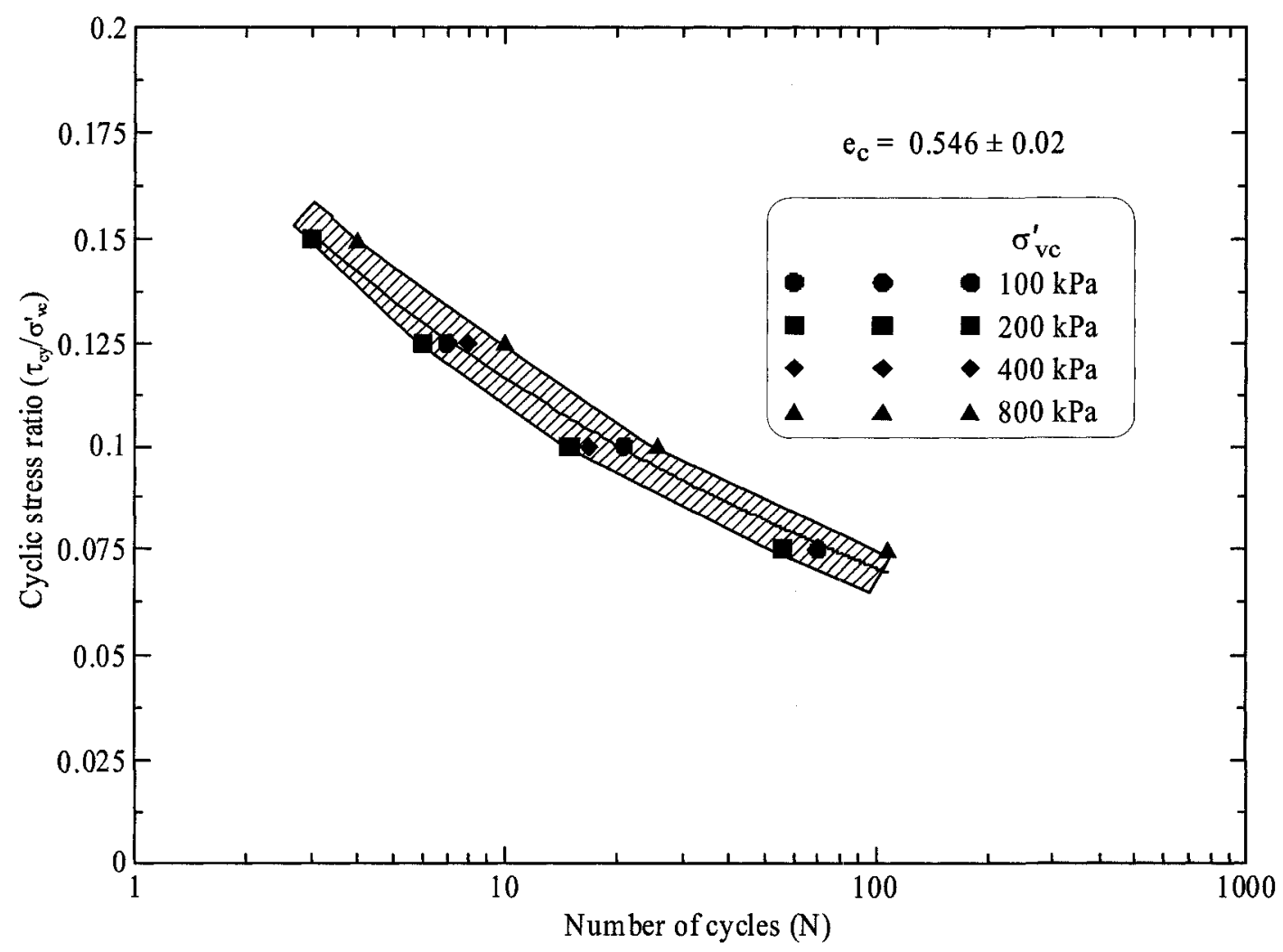

Figure 4.22 Cyclic stress ratio versus number of cycles to reach $(\gamma=3.75 \%)$ for tailings samples at a void ratio of $\mathrm{e}_{\mathrm{c}}=0.546$ and different consolidated pressure levels. 


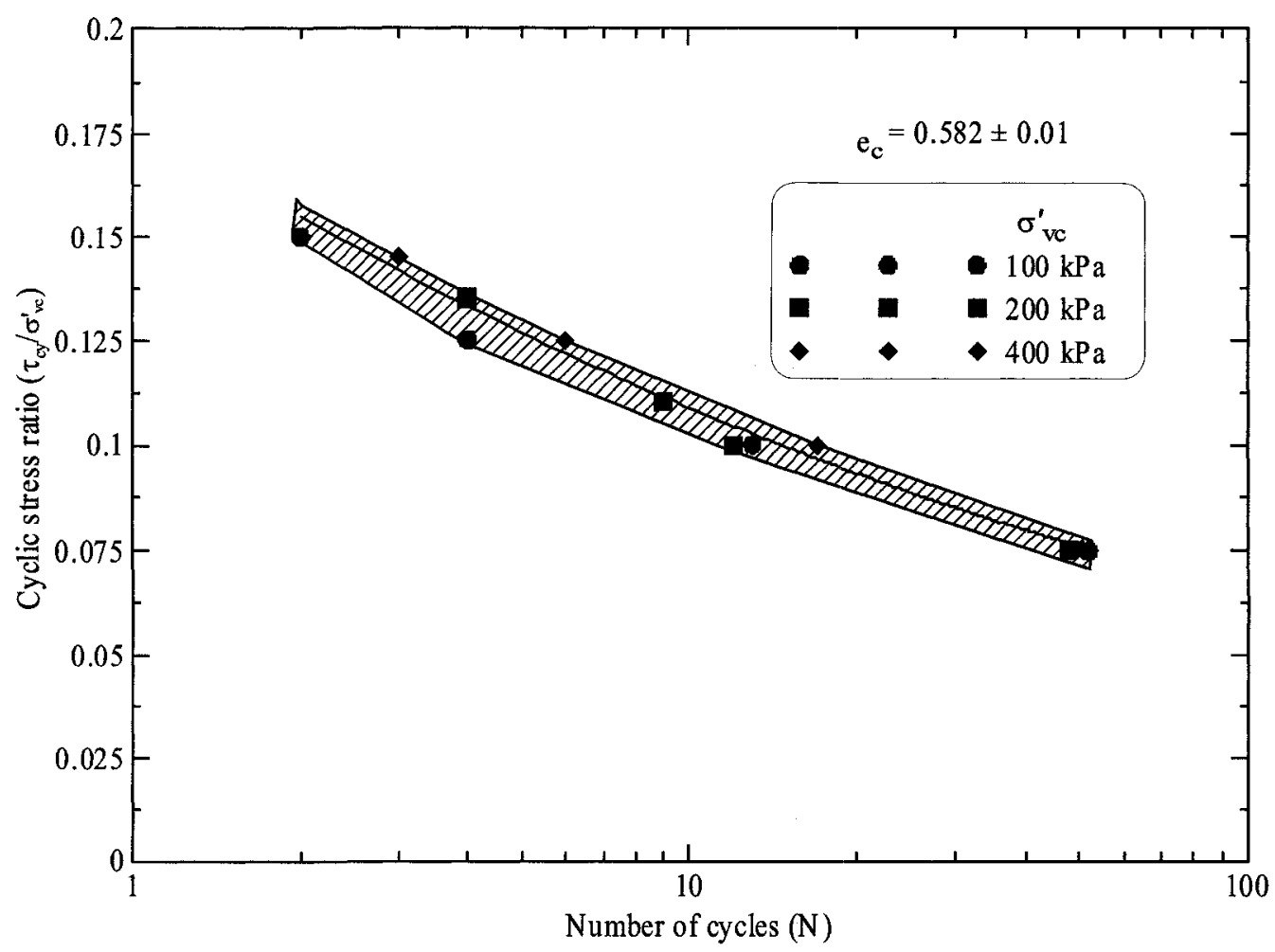

Figure 4.23 Cyclic stress ratio versus number of cycles to reach $(\gamma=3.75 \%)$ for tailings samples at a void ratio of $e_{c}=0.582$ and different consolidated pressure levels.

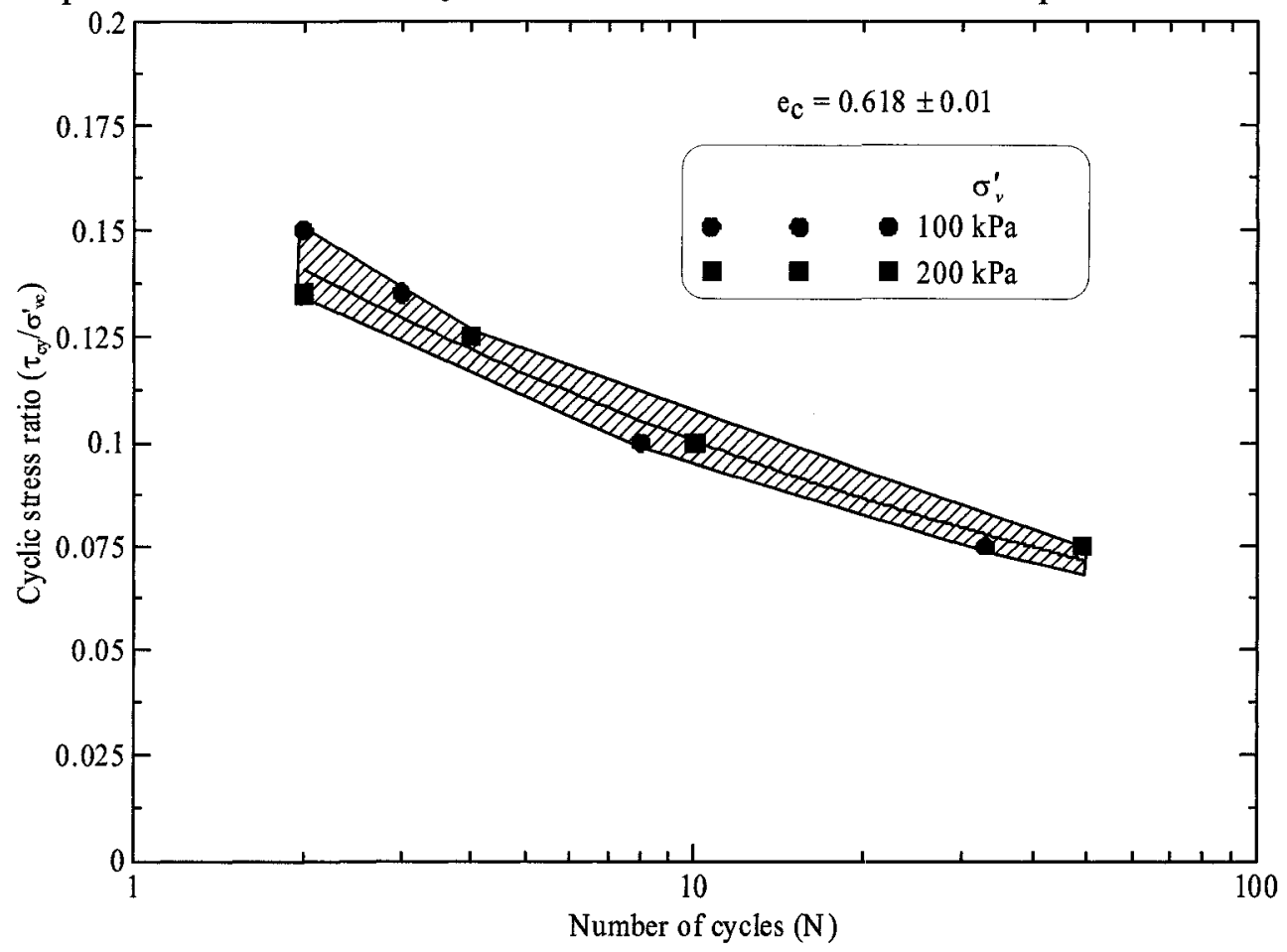

Figure 4.24 Cyclic stress ratio versus number of cycles to reach $(\gamma=3.75 \%)$ for tailings samples at a void ratio of $e_{c}=0.618$ and different consolidated pressure levels. 


\subsubsection{Effect of Loading Mode on Cyclic Resistance}

The general range of cyclic resistance measured under simple shear loading in this study is superimposed into the cyclic resistance measured using the triaxial device of the same gold mine tailings reported in the literature (Crowder, 2004) in Figure 4.25. This figure also shows data from another tailings material that was tested by Ishihara (1980) under triaxial loading. In Crowder's study, two consolidation pressure levels and two void ratios were used (50, and $150 \mathrm{kPa}$ and 0.65 and 0.62 respectively). A larger range of consolidation pressures and void ratios were used in this study. It is clearly shown from Figure 4.25 that the cyclic triaxial resistance is significantly higher than cyclic resistance in simple shear. This shows that the direct use of cyclic triaxial results for design purposes is also non conservative. This finding is similar to that reported by Seed and coworkers in the early 1970s for sands. They suggested the use of a reduction factor when using cyclic triaxial data in design to account for loading mode effects. Adopting the results of cyclic simple shear tests eliminate this uncertainty. Consequently, it is recommended that only cyclic simple shear resistance be used for design purposes. A comparison of the simple shear and triaxial test results on Bulyanhulu tailings suggests that if cyclic triaxial results are to be used then a reduction factor of at least $33 \%$ should be applied to the measured cyclic resistance. 


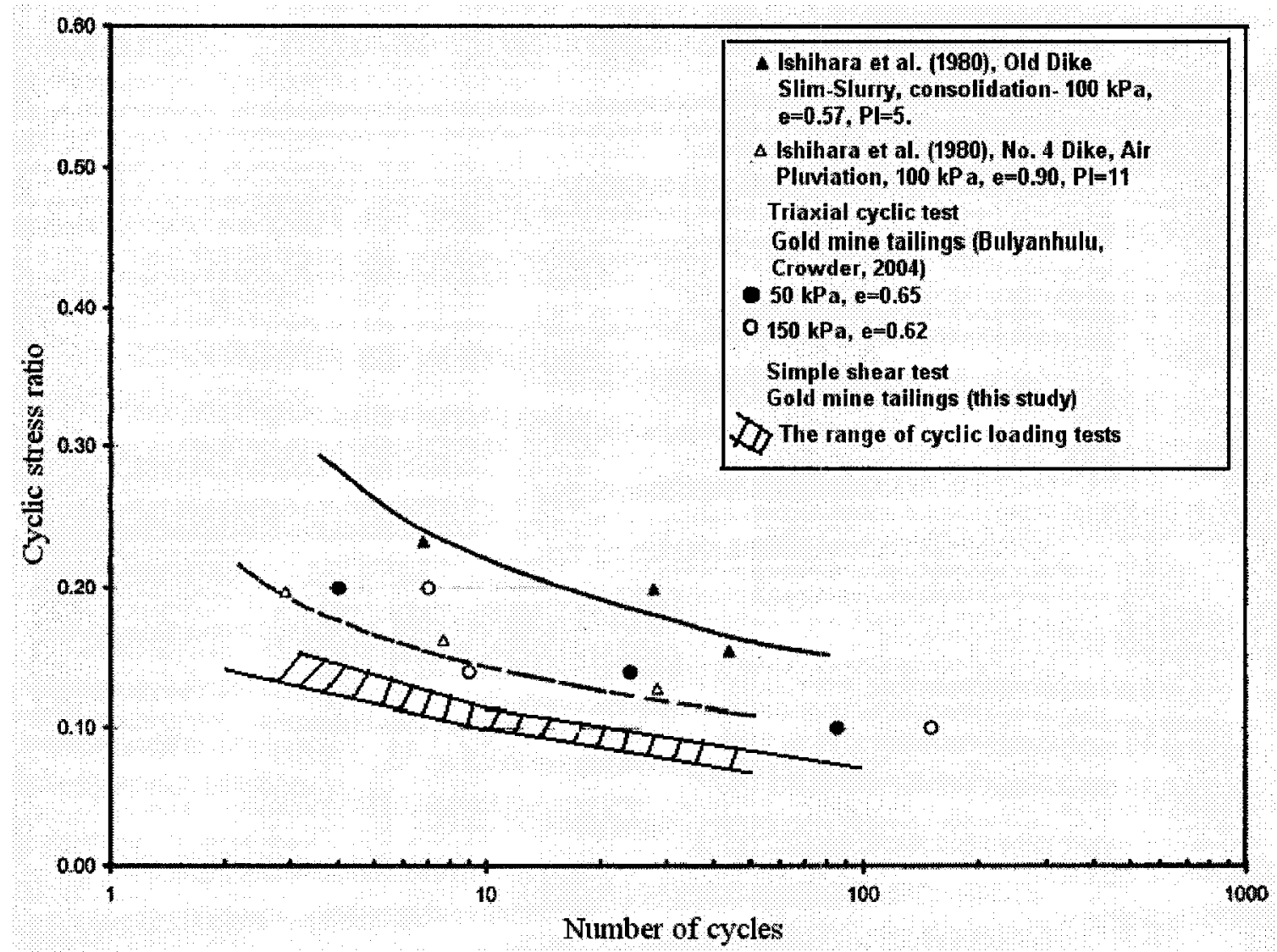

Figure 4.25 Cyclic triaxial tests results from Crowder (2004) and the cyclic simple shear results of this study.

\subsubsection{Characterization of Cyclic Loading Resistance}

In engineering design, cyclic resistance ratio corresponding to the number of cycles of 10 has been used for assessment of the liquefaction susceptibility due to earthquake loading. Ten uniform cycles (number of cycles $=10$ ) have been shown as being equivalent to an earthquake magnitude of $M=7$ (Seed et al., 1975). From cyclic loading results, cyclic resistance ratio corresponding to the number of cycles of 10 at different consolidation pressures and void ratios is presented in Figure 4.26. The figure shows the relationship between the CRR and void ratio $\left(e_{c}\right)$. Obviously, cyclic resistance ratio increases as the void ratio decreases for all the consolidation pressure levels. 
However, the effect of consolidation pressure is unclear. For the purpose of design, the fit line for all consolidation pressure levels has been suggested for use.

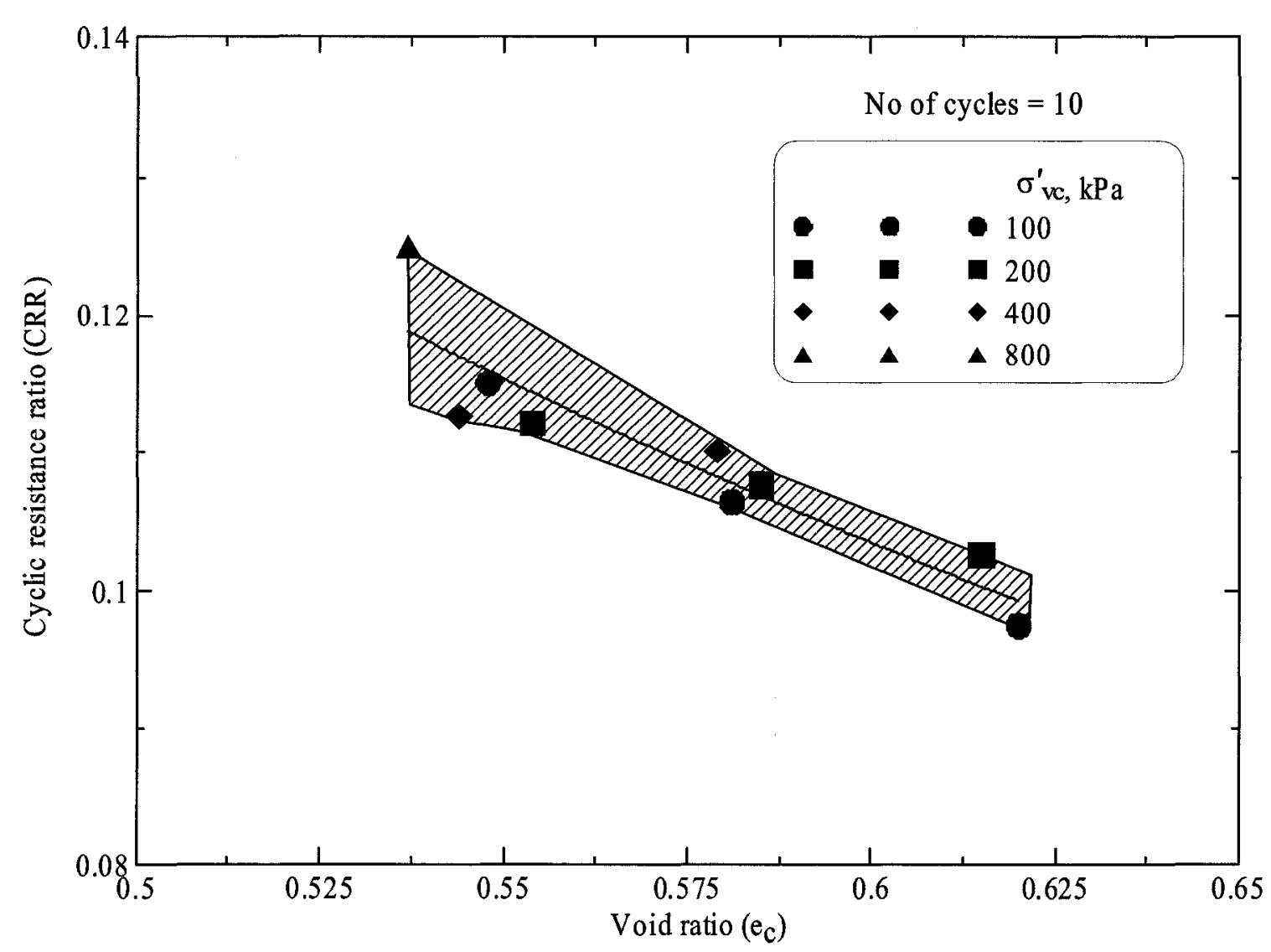

Figure 4.26 Cyclic resistance ratio versus void ratio to reach $(\gamma=3.75 \%)$ for tailings

\subsubsection{Influence of Desiccation}

In order to study the influence of desiccation on the cyclic resistance of tailings, three sets of samples prepared by the wet-dry technique were consolidated at $\sigma_{\mathrm{vc}}^{\prime}=50 \mathrm{kPa}$ and sheared under cyclic loading. Samples with water content $38 \%$ were dried to a predetermined water content after controlled desiccation $\left(w_{\mathrm{d}}\right)$ based on the soil-water characteristic curve (SWCC) as shown in Figure 4.27. The SWCC in terms of matric 
suction and degree of saturation at similar initial condition is illustrated in Figure 4.28. From Figure 4.27 , the water contents $\left(w_{\mathrm{d}}\right)$ are 18,16 , and $13 \%$ which correspond to the negative pore pressure of approximately 150,250 and $400 \mathrm{kPa}$, respectively. Using SWCC as a tool to choose the water contents after controlled desiccation gives an indication of the negative pore pressure at levels of water contents after controlled desiccation.

After the samples had reached the water contents after controlled desiccation, water was added to bring their water contents to about $21 \%$ and then the samples became re-saturated. To ensure no negative pore pressure (suction) existed to re-saturate the samples, suction was measured in identical samples prepared for this purpose. The suction was measured by using a small Tensiometer probe (UMS T5). The measurements showed that the samples almost saturated after adding the water as their suction measurements were almost zero $(0.3 \mathrm{kPa})$. 


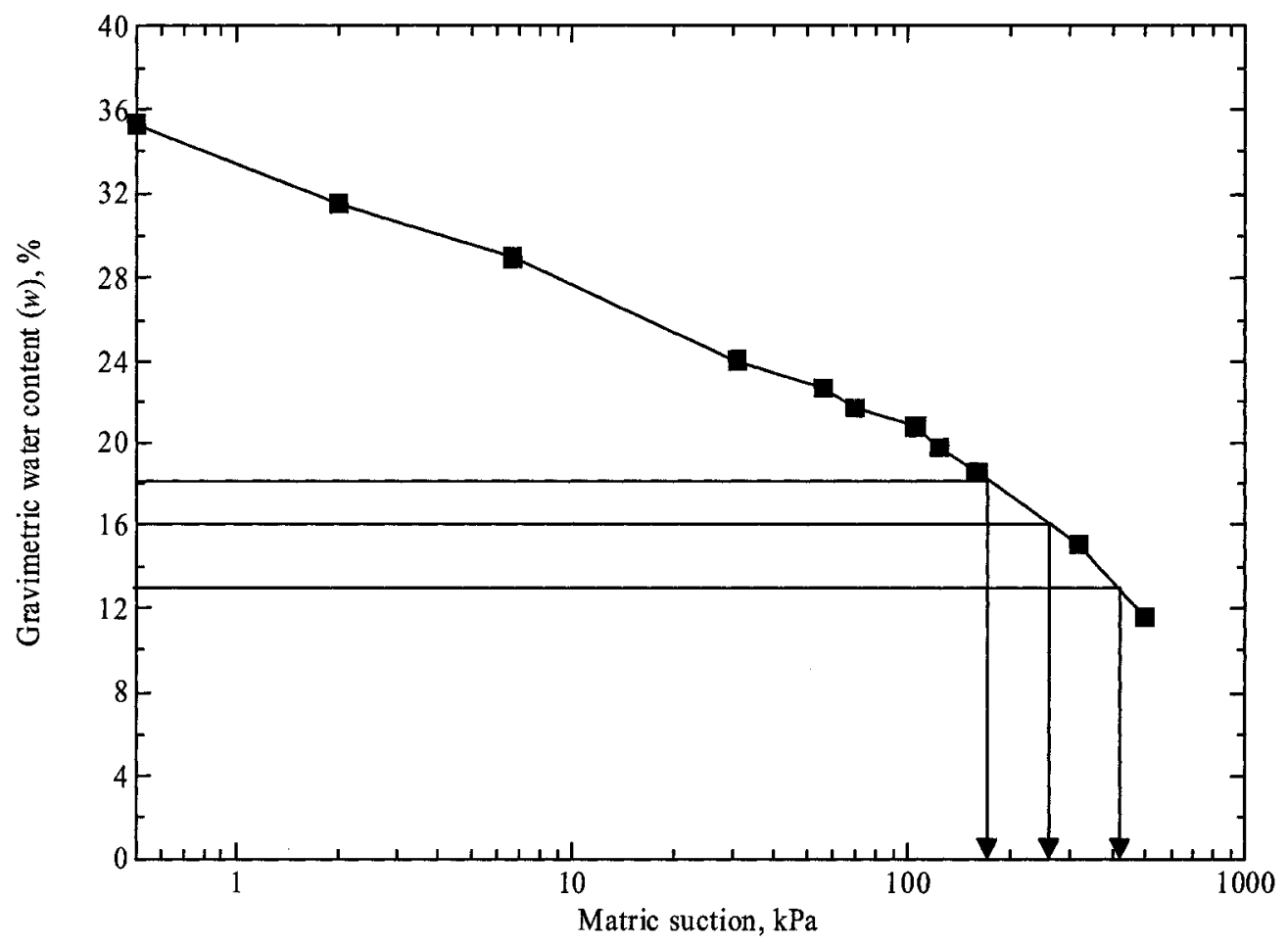

Figure 4.27 Soil-water characteristic curve in terms of gravimetric water content of gold mine tailings from Bulyanhulu mine (Fisseha, 2008).

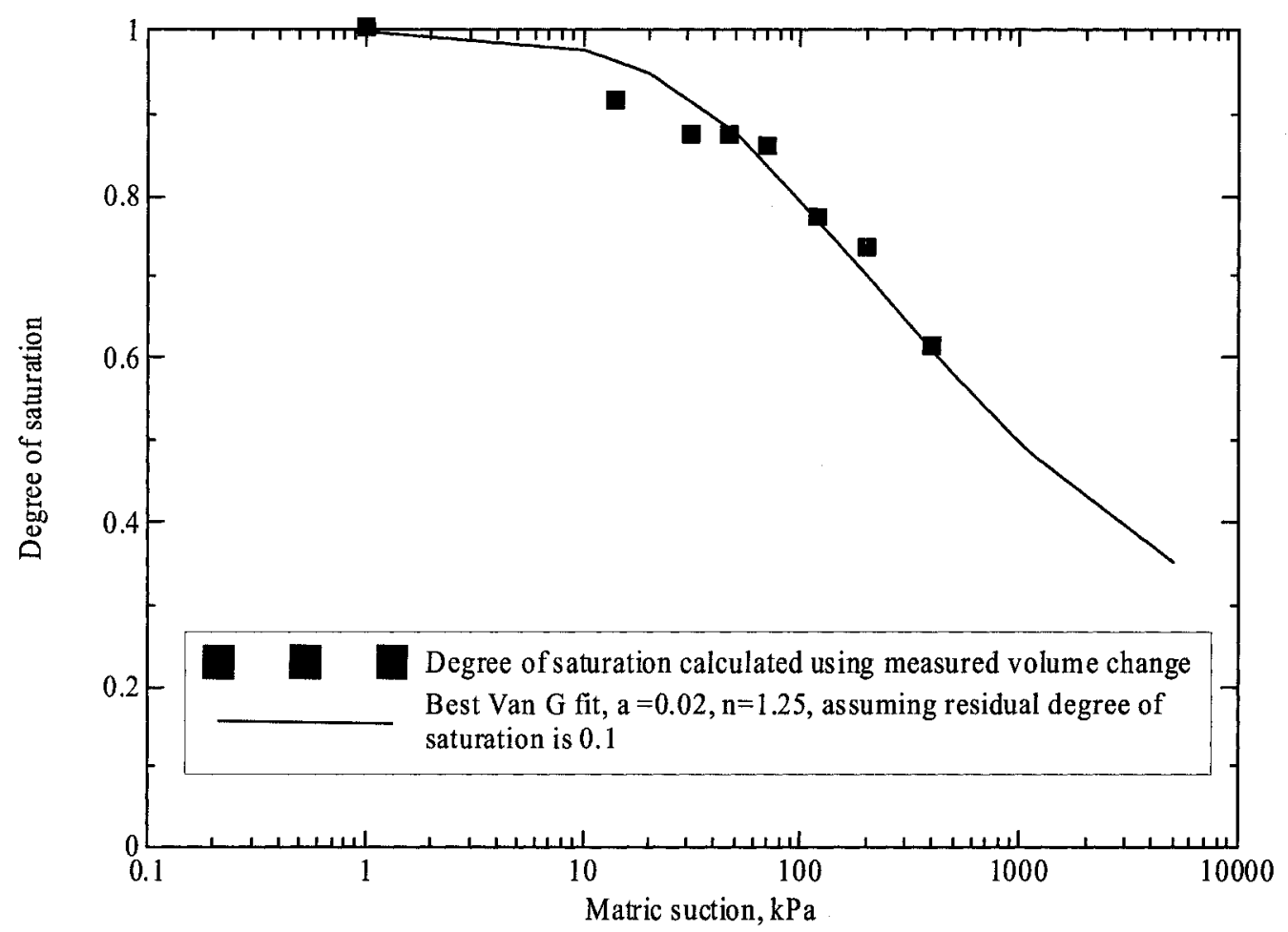

Figure 4.28 Soil-water characteristic curve in terms of degree of saturation of gold mine tailings from Bulyanhulu mine (Simms et al., 2007). 
Figure 4.29 shows the comparison between the results of cyclic stress ratio versus number of cycles for samples prepared by wet-dry cycles preparation technique and moist technique, and consolidated at $50 \mathrm{kPa}$. The cyclic resistance ratios of the samples prepared by the wet-dry technique (samples had applied to hydraulic stress history) are significantly higher compared to the samples prepared by the moist technique. The gain in resistance is due to the desiccation of the samples to $18 \%$ water content after controlled desiccation. This desiccation process produced an over-consolidation pressure equivalent to negative pore pressure $(150 \mathrm{kPa})$ as shown in Figure 4.27. Fleureau et. al. (1993) suggested that the effect of a negative pressure applied to the material studied was equivalent to the effect of isotropic stress.

The results of cyclic stress ratio of two sets of wet-dry technique which their water contents after controlled desiccation were 16 and 13\% are superimposed on Figure 4.29 and shown in Figure 4.30. Unlike the results of wet-dry technique at $w_{\mathrm{d}}=18 \%$, the cyclic resistance ratio of samples with $w_{\mathrm{d}}=13$ and $16 \%$ show a scattered relation with number of cycles. In addition, their cyclic resistance ratios are less than for $w_{\mathrm{d}}=18 \%$. The unclear relation between the cyclic stress ratio (CSR) and number of cycles for the samples with low water content after controlled desiccation might be due to one or both the following observations during the sample preparation; Firstly, the gap between the tailings sample and the reinforced membrane became greater than $0.6 \mathrm{~mm}$ after the shrinkage process. The incompletely confined sample invalidates the assumption of constant volume. Secondly, cracks occurred around the edges of the samples and in some cases were inside the samples. These cracks might have caused vertical plane failures 
which would weaken the sample. The effect of desiccation on the cyclic resistance needs more research and the noted experimental errors should be eliminated.

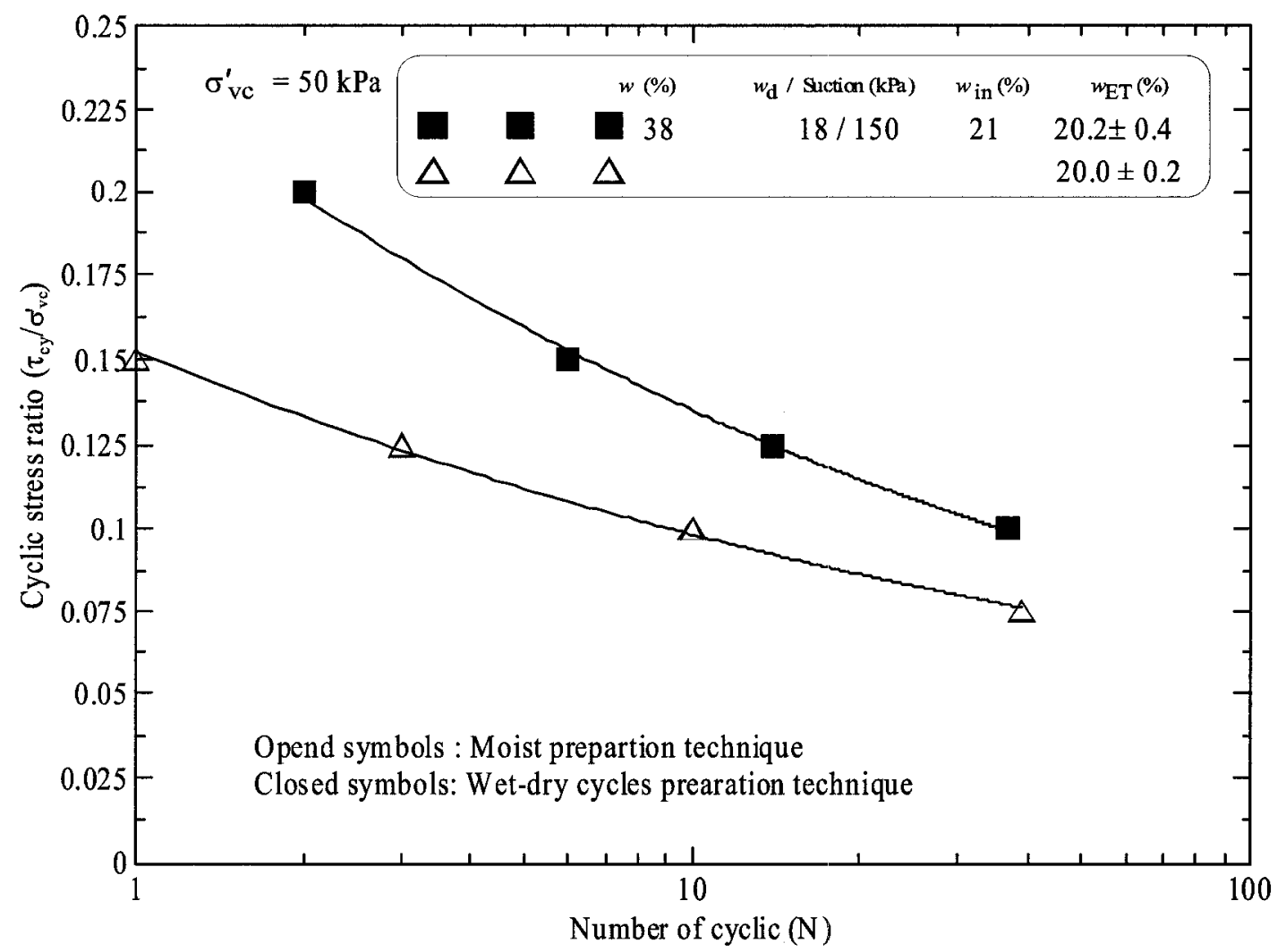

Figure 4.29 Comparison between cyclic stress ratio for tailings samples prepared by moist preparation technique and wet-dry cycles preparation technique $\left(w_{\mathrm{d}}=18 \%\right)$ at consolidation pressure $\sigma_{\mathrm{vc}}^{\prime}=50 \mathrm{kPa}$. 


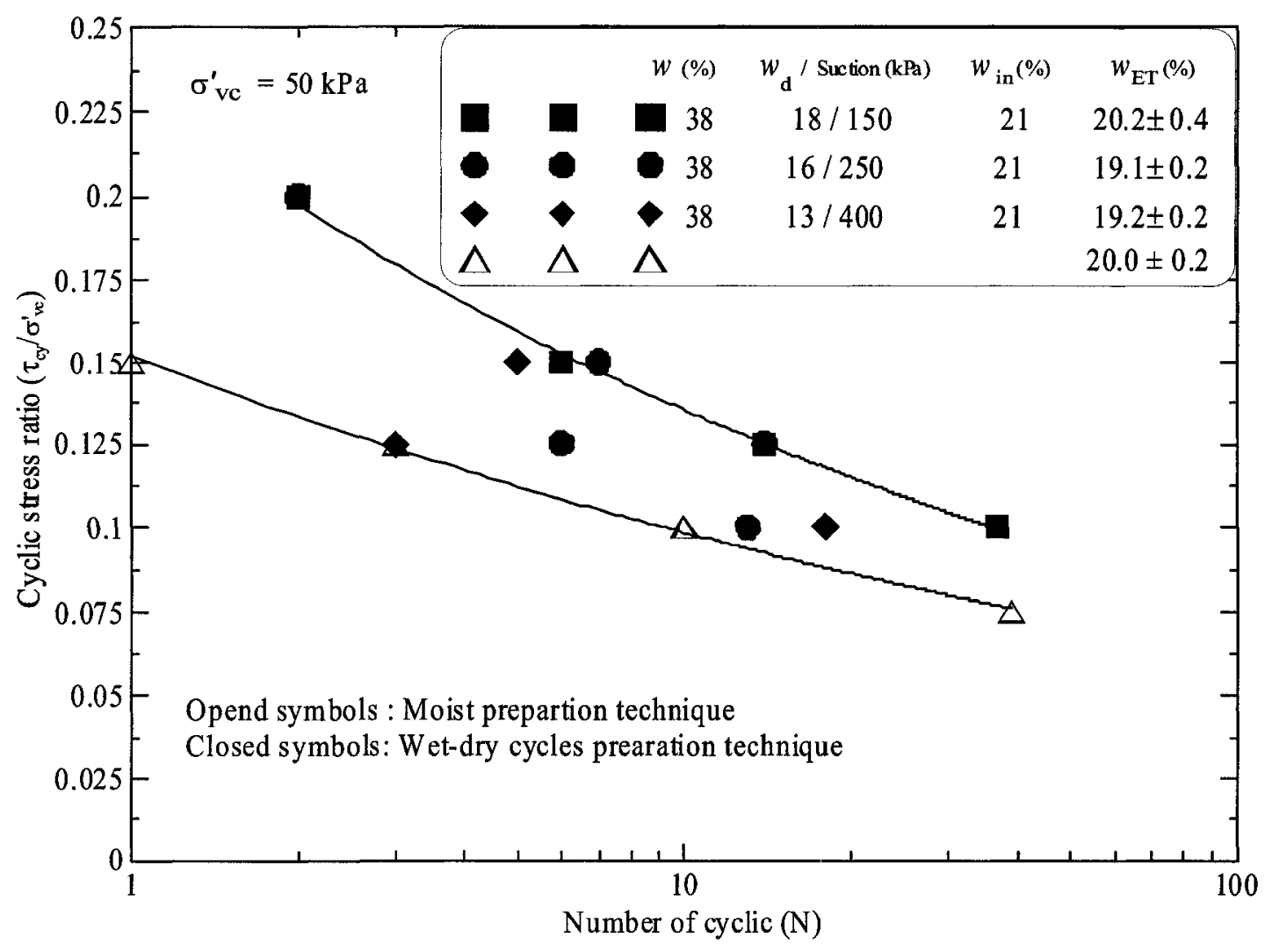

Figure 4.30 Comparison between cyclic stress ratio for tailings samples prepared by moist preparation technique and samples prepared by wet-dry cycles preparation technique $\left(w_{\mathrm{d}}=18,16\right.$, and $\left.13 \%\right)$ at consolidation pressure $\sigma_{\mathrm{vc}}^{\prime}=50 \mathrm{kPa}$. 


\subsection{Liquefaction Criteria}

Experimental results of the cyclic loading were used to investigate the applicability of the liquefaction criteria (represents in Table 2.1) for the gold mine tailings. The liquefaction criteria were used to explore their capability to capture the liquefaction produced under monotonic loading. It should be noted that liquefaction criteria were established based on the observation from natural soil sites where the liquefaction did or did not occur under earthquake loading (cyclic loading).

\subsubsection{Evaluation of Liquefaction Criteria Based on Cyclic Loading Results}

The criteria were assessed in terms of water content to liquid limit ratios $\left(w_{\mathrm{c}} / \mathrm{LL}\right)$ for cyclic loading tests. It should be mentioned that all tested samples at different water contents (void ratio) and consolidation pressures were liquefied. The gold mine tailings properties which were represented in Chapter 3 were also used to evaluate the criteria. The tailings properties are as follows: $\mathrm{LL}=22.5 \%, \mathrm{PI}=2.5$, Fraction fine smaller than $0.005 \mathrm{~mm}=17 \%$, and Fraction fine smaller than $0.002 \mathrm{~mm}=8 \%$.

The ratios $w_{\mathrm{c}} / \mathrm{LL}$ for cyclic loading tests are plotted in the Bray et al. (2004) chart according to their criteria as shown in Figure 4.31. It is seen, that most cyclic loading data fall into the category of "susceptible and moderately susceptible to liquefaction". However, some samples with $w_{\mathrm{c}} / \mathrm{LL}$ ratio less than 0.8 are located in the category "not susceptible to liquefaction". Similar observations were reported for mine tailings when Bray et al. (2004) criteria were used to assess other experimental results of cyclic loading tests (Wijewickreme et al, 2005). 
Other criteria which are Wang (1979), Seed \& Idriss (1982), Finn (1982), and Koester, do not conform to the results of cyclic loading about liquefaction assessment. This disagreement is mainly due to the percentage of fine fraction. The fine fraction of the gold tailings studied in this research is $17 \%$. Tailings with this fine content are considered as not susceptible to liquefaction by using the above criteria (see Table 2.1). It is recognized that different criteria have been used to defined liquefaction, and liquefaction in this research is based on a strain criteria as noted earlier.

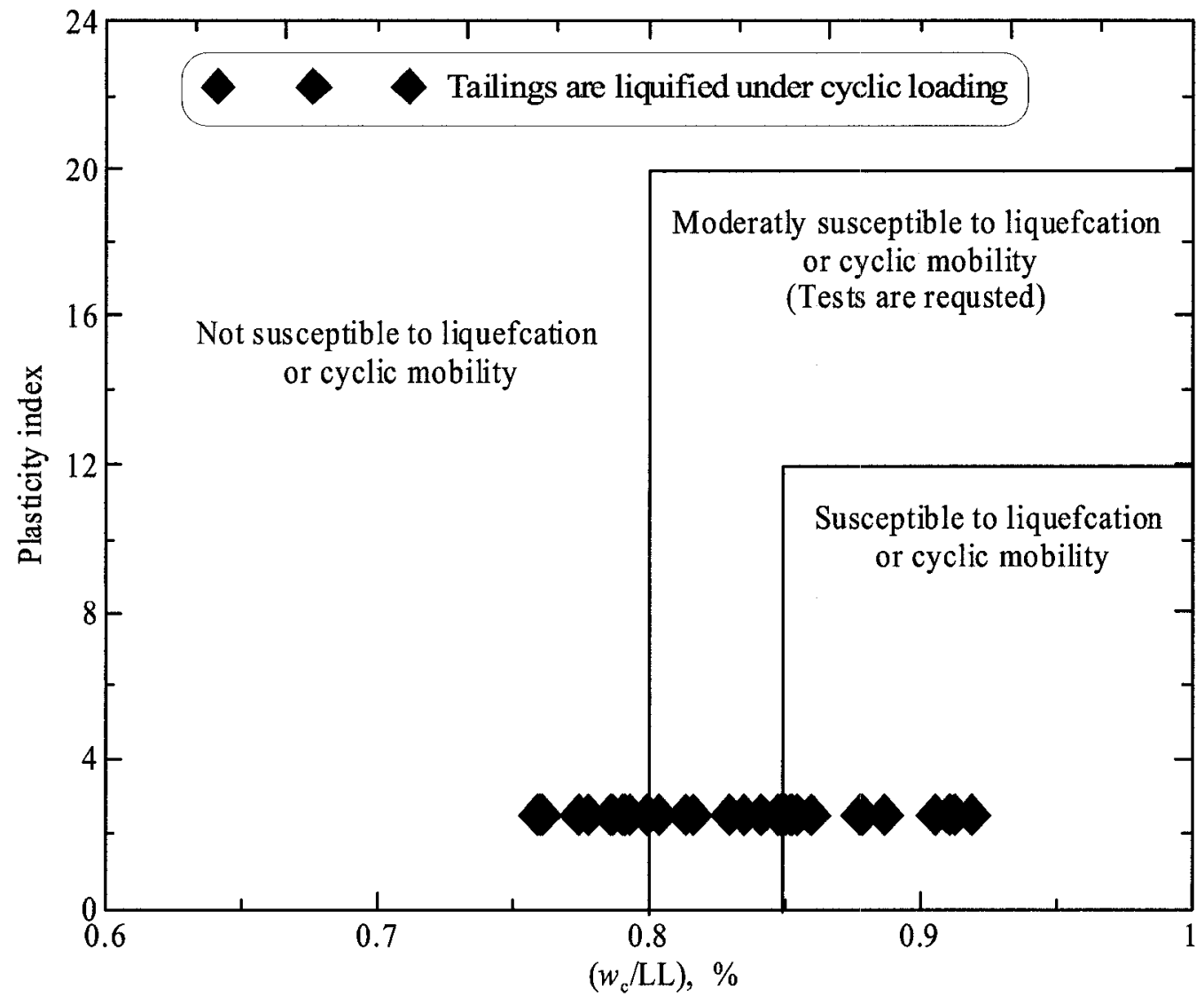

Figure 4.31 Assessment of Bray et al. (2004) criteria based on cyclic loading results. 


\subsubsection{Applicability of Liquefaction Criteria for Assessment of Liquefaction under}

\section{Monotonic Loading}

To investigate whether liquefaction behaviour under monotonic loading can be captured by using the liquefaction criteria proposed in the literature for cyclic liquefaction, water content-liquid limit ratios $\left(w_{\mathrm{c}} / \mathrm{LL}\right)$ were used for samples which did and did not liquefy under monotonic loading. Figure 4.32 shows the monotonic loading data compared with Bray et al. (2004) criteria. All the samples which are liquefied fall in the category of "susceptible to liquefaction". This demonstrates that liquefaction under monotonic loading can also captured by using Bray criteria. It should also be noted, that samples which are not liquefied under monotonic loading fall in the category of "susceptible to liquefaction" as shown in Figure 4.32.

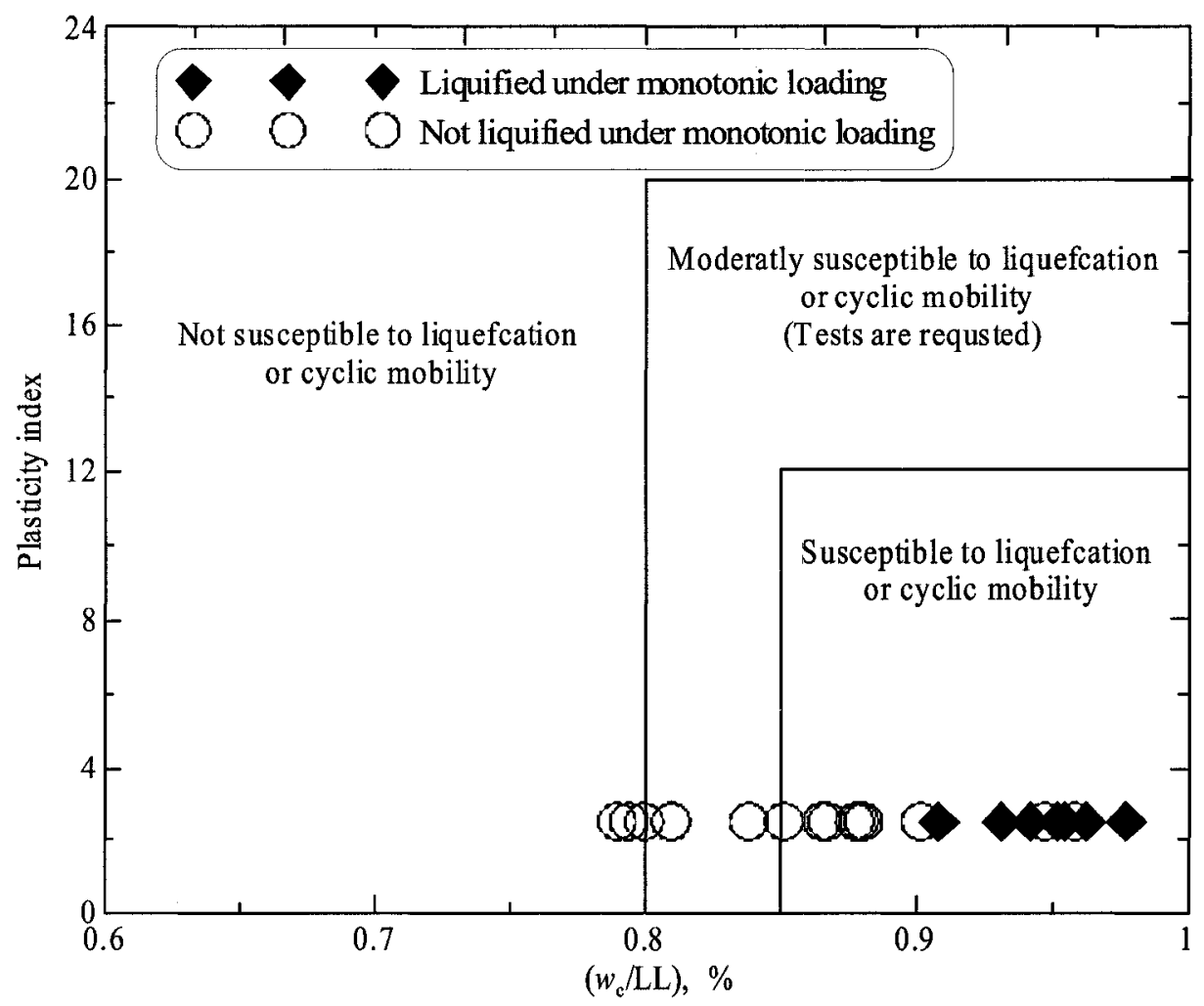

Figure 4.32 Applicability of Bray et al. (2004) criteria based on monotonic loading results. 


\subsection{Post-liquefaction Behaviour}

The post-liquefaction loading was conducted by applying a monotonic loading following liquefaction by cyclic loading (based on shear strain criteria of $3.75 \%$ ). For post-liquefaction, the consolidation pressure levels and initial conditions were considered as the same conditions for cyclic loading. However, samples were also classified based on the cyclic stress ratio and maximum shear strain level $\left(\gamma_{\mathrm{c}-\max }\right)$. All the tailings samples were prepared by using the moist preparation technique. The stress-strain response and the shear strength characteristics were studied under a range of consolidation pressures and initial conditions $\left(\mathrm{e}_{\mathrm{c}}\right)$ following liquefaction. The measured post-liquefaction stressstrain response of gold mine tailings is shown in the Appendix II. In this section the testing results are discussed and comparisons between the shear strength characteristics of pre- and post-liquefaction are presented.

\subsubsection{Post-liquefaction Response}

Figure 4.33 shows a typical post-liquefaction behaviour of gold mine tailings. The sample was consolidated at $100 \mathrm{kPa}$ and loaded under cyclic loading with the cyclic stress ratio $(\mathrm{CSR})=0.1$. The maximum shear strain $\left(\gamma_{\mathrm{c}-\mathrm{max}}\right)$ that the sample had reached during the cyclic loading was $4.2 \%$. It can be seen from the figure that very small initial shear strength was exhibited in the post-liquefaction stress-strain curve. 

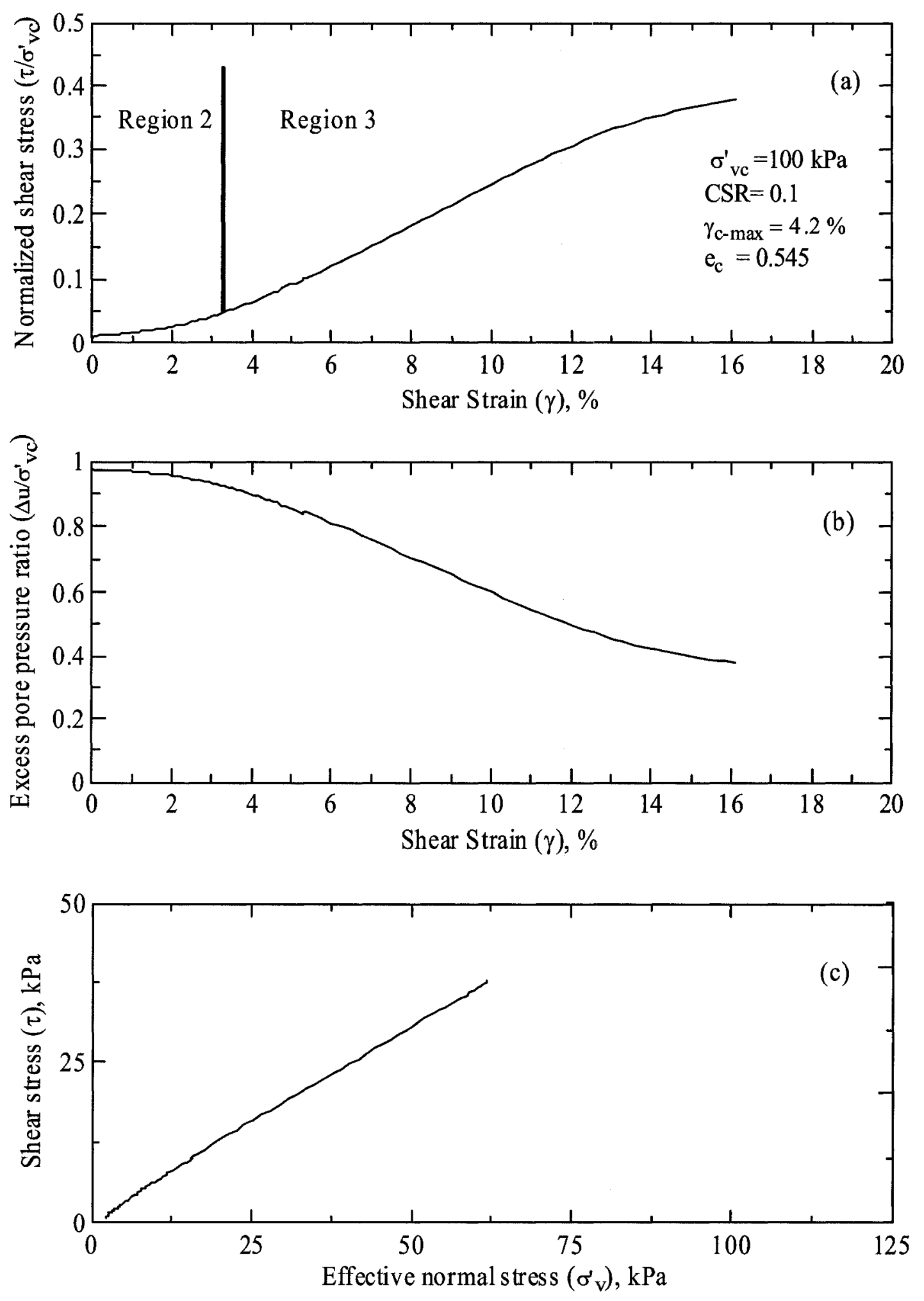

Figure 4.33 Typical post-liquefaction behaviour of gold mine tailings under simple shear loading. 
The initial non zero shear stresses (vertical effective stress and shear stress) are related to the stress conditions of the sample at the end of the cyclic loading stage. The pore pressure of gold mine tailings in this research never reached $100 \%$ after cyclic or monotonic loading. However, the excess pore pressure as high as $96 \%$ (Figure 4.33(b)) was generated. In these tests, even though the state of zero effective stress was not realized in the tailings, very low effective stresses were present in some post-liquefaction tests.

As can be seen from Figure 4.33(a), the post-liquefaction stress-strain curve of gold mine tailings has not shown initial zero shear stiffness (Region 1) as has been reported in the case of sandy soil by Vaid \& Thomas (1995) and Sivathayalan \& Yazdi (2004). For tailings material that has not reached the $100 \%$ excess pore pressure, Region 1 does not exist. Immediately after the monotonic loading was applied, the shear stress increased as the shear strain increased. However, the rate of the increases is relatively small up to about $5 \%$ of $\sigma_{v c}^{\prime}$. This region is analogous in response to what has been called Region 2 in the literature for sandy soils.

Region 3 describes the portion of the stress-strain curve where the rate of shear stress increases rapidly and the stiffness of the tailings becomes almost constant with the increase of shear strain. This region became linear in shape at the beginning and then curved to reach the maximum post-liquefaction strength. However, attempts have not been made to interpret the data at high strain levels. Region 3 for gold mine tailings is equivalent to what is called the second component as reported by Shamoto et al. (1998) and Region 3 as described by Vaid and Thomas (1995). 
It is clearly demonstrated that the behaviour of post-liquefaction is always dilative (Figure 4.33(c)). The excess pore pressure ratio versus the shear strain shows that the pore pressure decreases with increases of the shear strain. The stress path of postliquefaction behaviour is a straight line, (unless significant effective stress remains at the end of cyclic loading) and follows the dilative parts of the pre-liquefaction failure envelop that was determined under monotonic loading. The purely dilative response in post-liquefaction has been reported for sandy soils (Vaid \& Thomas, 1995; Kramer, 1996; and Sivathayalan \& Yazdi, 2004).

\subsubsection{Factors Influencing the Post-liquefaction Response}

\subsubsection{Dependency of Void Ratio}

In order to investigate the influence of void ratio (water content) on the postliquefaction response, test results at three different levels of void ratio for a fixed $\sigma_{\mathrm{vc}}^{\prime}=100 \mathrm{kPa}$ are presented in Figure 4.34. The cyclic stress ratio (CSR) and the maximum shear strain $\left(\gamma_{-c-\max }\right)$ for the samples are 0.075 , and $4 \%$, respectively. The figure clearly indicates that the post-liquefaction response is highly dependent on the void ratio of tailings for the given CSR and $\gamma_{\mathrm{c}-\max }$. In Region $2\left(\sigma_{\mathrm{vc}}^{\prime}<5 \mathrm{kPa}\right)$, the stress-strain response is essentially the same for all samples. The rate of the shear stress and the average shear stiffness increase rapidly at the end of Region 2. At Region 3, the stressstrain response becomes linear for all the samples and then flattens depending on the void ratio. In the linear portion of the stress-strain curve, it can be observed that shear stiffness increases as the void ratios decrease. For a given shear stress, the shear strain increases as 
the void ratio increases. Similar observations were noted in sands by Vaid \& Thomas (1995) and Sivathayalan \& Yazdi (2004).

Similar dependency of the post-liquefaction response on the void ratio is observed in tests at different consolidation pressures as well. Figures 4.35 and 4.36 demonstrate the post-liquefaction stress-strain response for $\sigma_{\mathrm{vc}}^{\prime}=200$ and $400 \mathrm{kPa}$, respectively. Increases in the void ratio cause a decrease in the post-liquefaction shear strength in all stress levels.

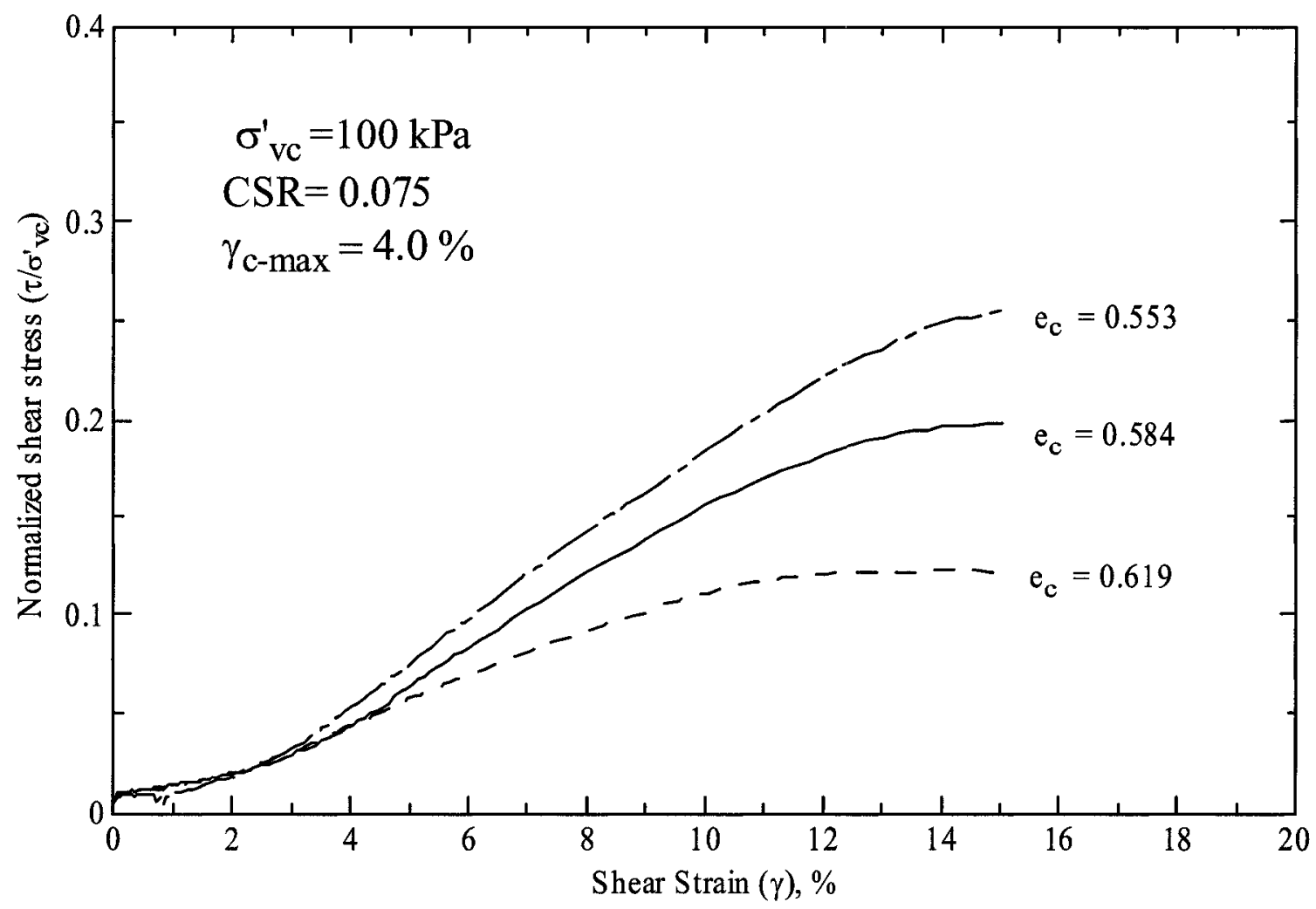

Figure 4.34 Effective of initial conditions on the post-liquefaction stress-strain response at $\sigma_{\mathrm{vc}}^{\prime}=100 \mathrm{kPa}$. 


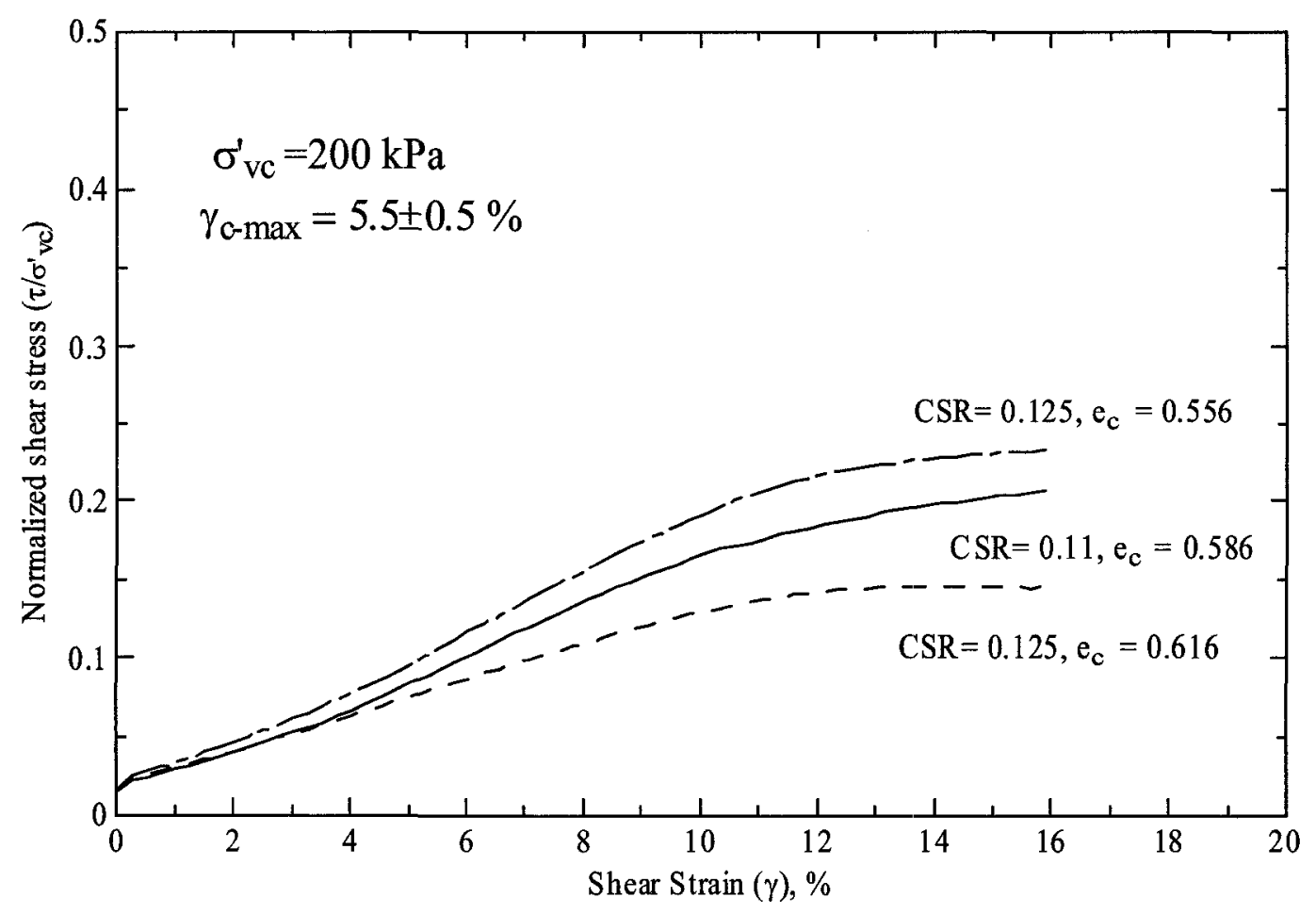

Figure 4.35 Effective of initial conditions on the post-liquefaction stress-strain response at $\sigma_{\mathrm{vc}}^{\prime}=200 \mathrm{kPa}$.

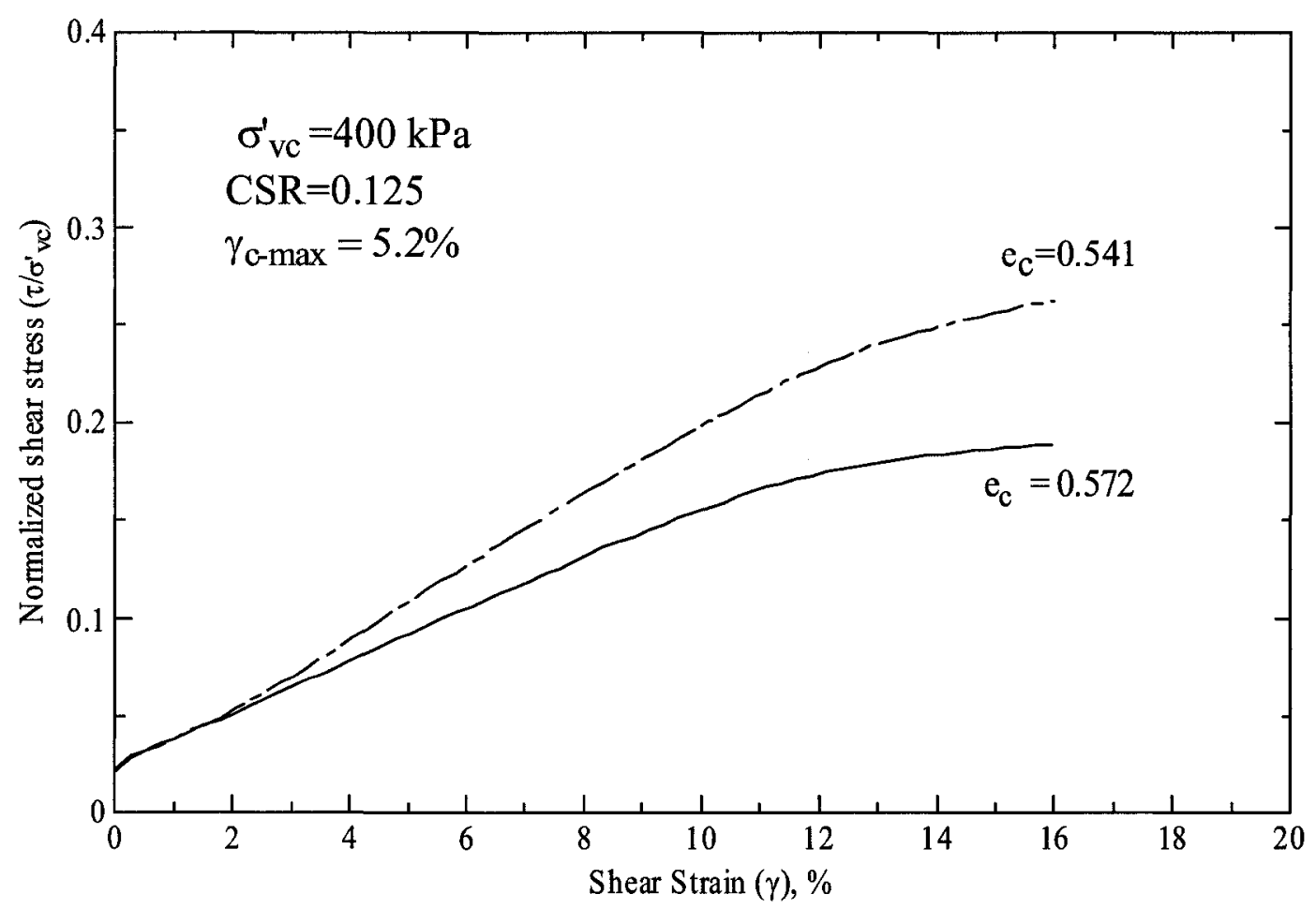

Figure 4.36 Effective of initial conditions on the post-liquefaction stress-strain response at $\sigma_{\mathrm{vc}}^{\prime}=400 \mathrm{kPa}$. 


\subsubsection{Effect of Maximum Pre-liquefaction Strain Level and Cyclic Stress Ratio}

The maximum strain levels of tailings samples were ranged 3.8 to $10.13 \%$, even the criteria of cyclic loading was fixed at $\gamma=3.75 \%$. Figures 4.37 to 4.39 illustrate that the maximum strain level is somewhat dependant on the consolidation pressure, CSR and void ratio, especially for consolidation pressures 100 and $200 \mathrm{kPa}$. The maximum strain level is strongly related to stresses and initial conditions of the tailings samples at the last cyclic of loading when the liquefaction is near the trigger threshold. At this stage, simple shear apparatus cannot block or control the tailings flow, and therefore the tailings experience large strain (e.g. Figure 4.15)

In order to study the effect of maximum strain level, it is necessary to keep the samples under constant CSR and initial conditions. In this study, the CSR was not fixed, because cyclic loading data at various CSR was needed to investigate the cyclic behaviour of tailings. Figure 4.40 is an example of the sensitivity of post-liquefaction stress-strain responses to the effect of CSR and maximum strain level at a consolidation pressure of $400 \mathrm{kPa}$. From the figure, the influence of CSR and $\gamma_{\mathrm{c}-\max }$ on the stress-strain response is unclear. There is no obvious indication that the changes in CSR and $\gamma_{c-m a x}$ increase or decrease the post-liquefaction strength. This conclusion has been observed for most post-liquefaction results (Appendix II). It has been suggested that more comprehensive research is needed to isolate the effect of $\gamma_{\mathrm{c}-\max }$ and CSR level, because the results of post-liquefaction responses demonstrate that response is dependent on several variables. 


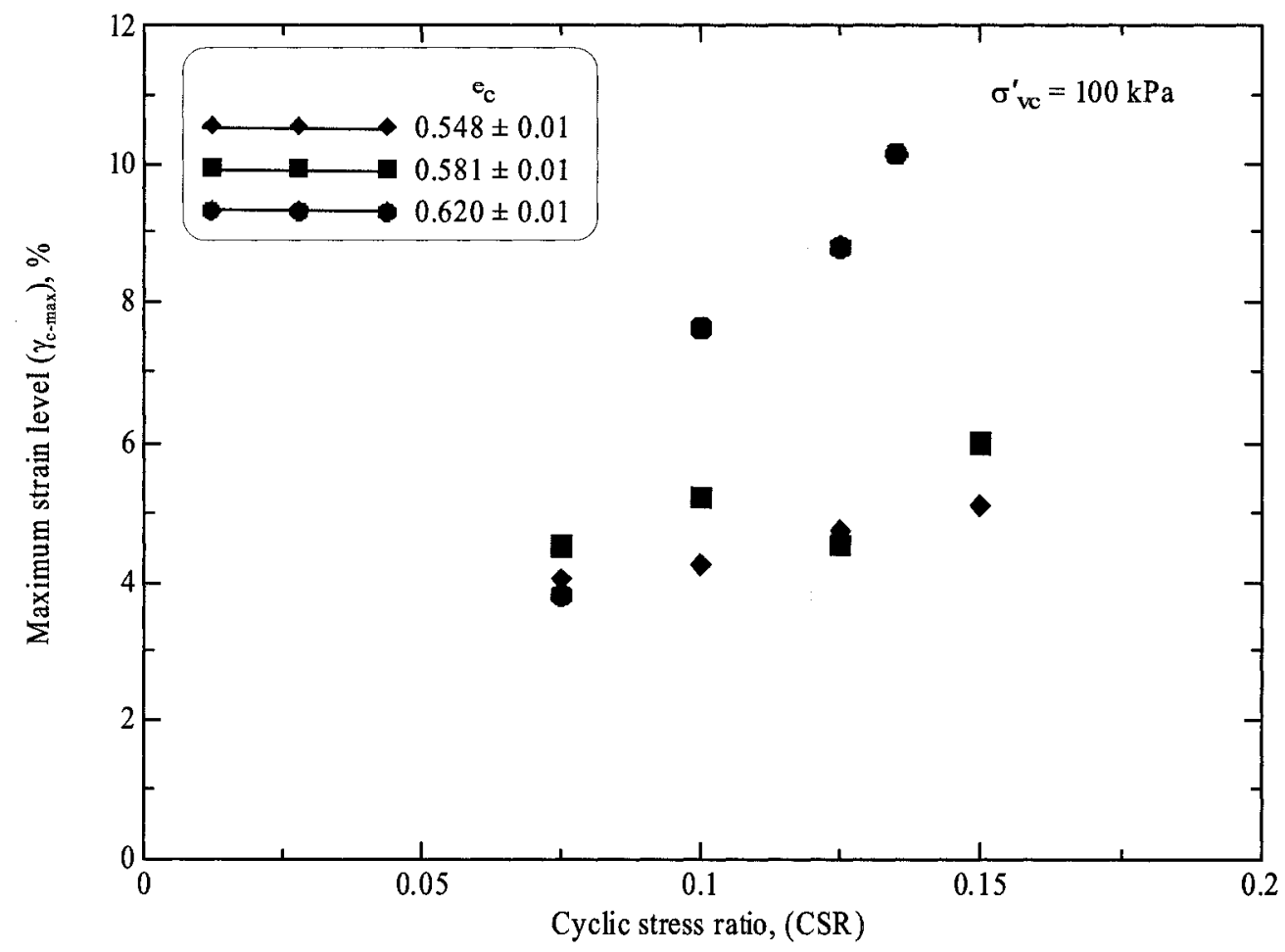

Figure 4.37 Cyclic stress ratio versus maximum strain level during cyclic loading at

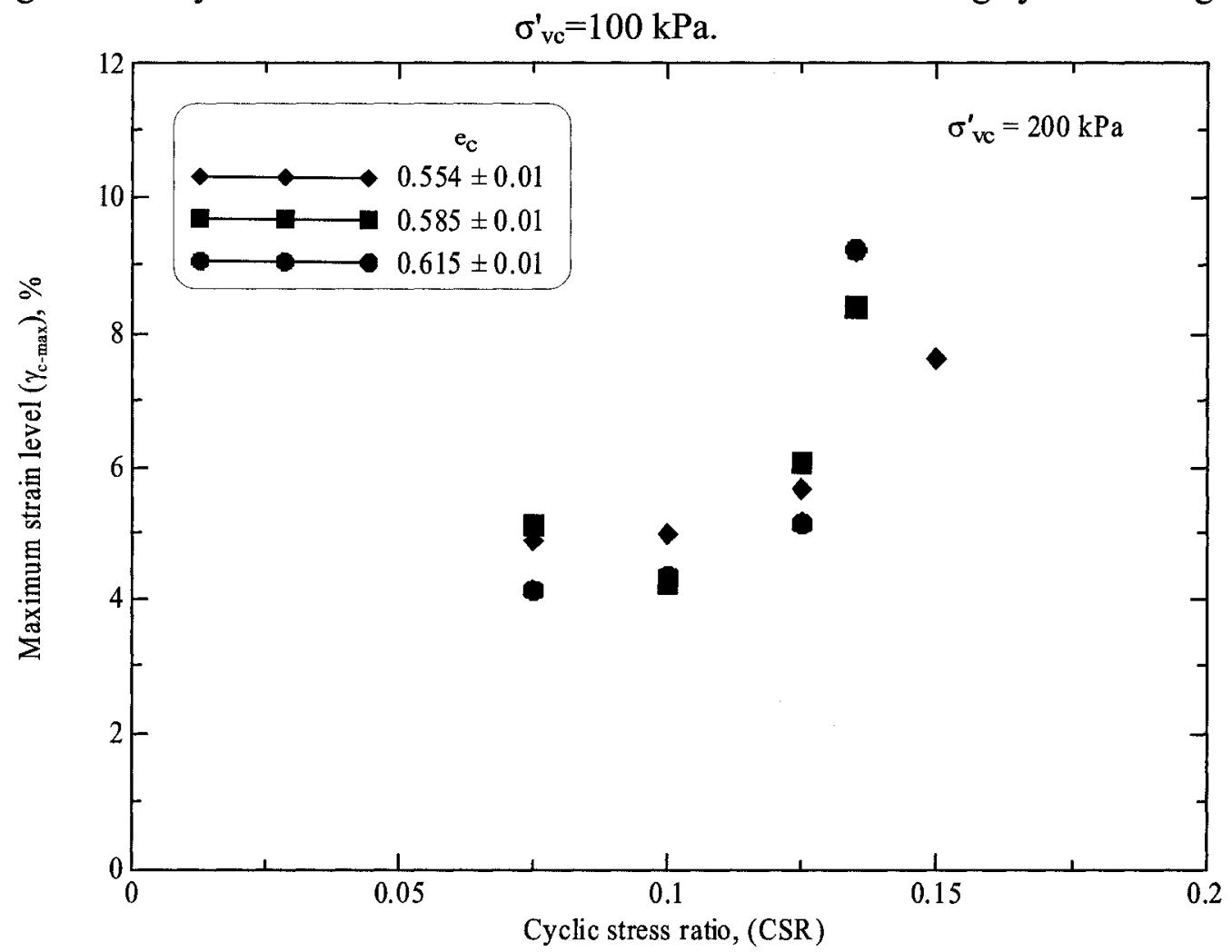

Figure 4.38 Cyclic stress ratio versus maximum strain level during cyclic loading at $\sigma_{\mathrm{vc}}^{\prime}=200 \mathrm{kPa}$. 


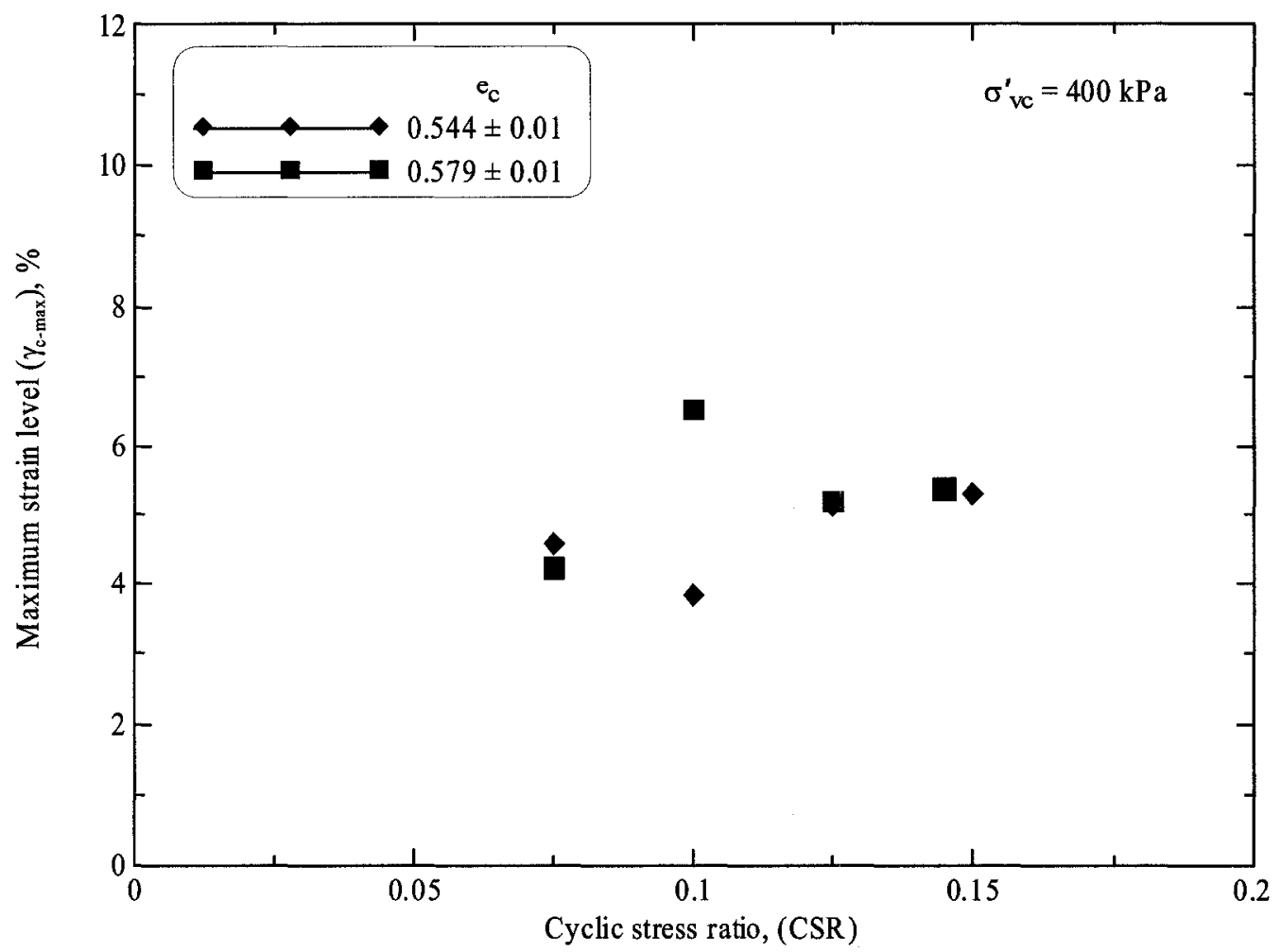

Figure 4.39 Cyclic stress ratio versus maximum strain level during cyclic loading at $\sigma_{\mathrm{vc}}^{\prime}=400 \mathrm{kPa}$.

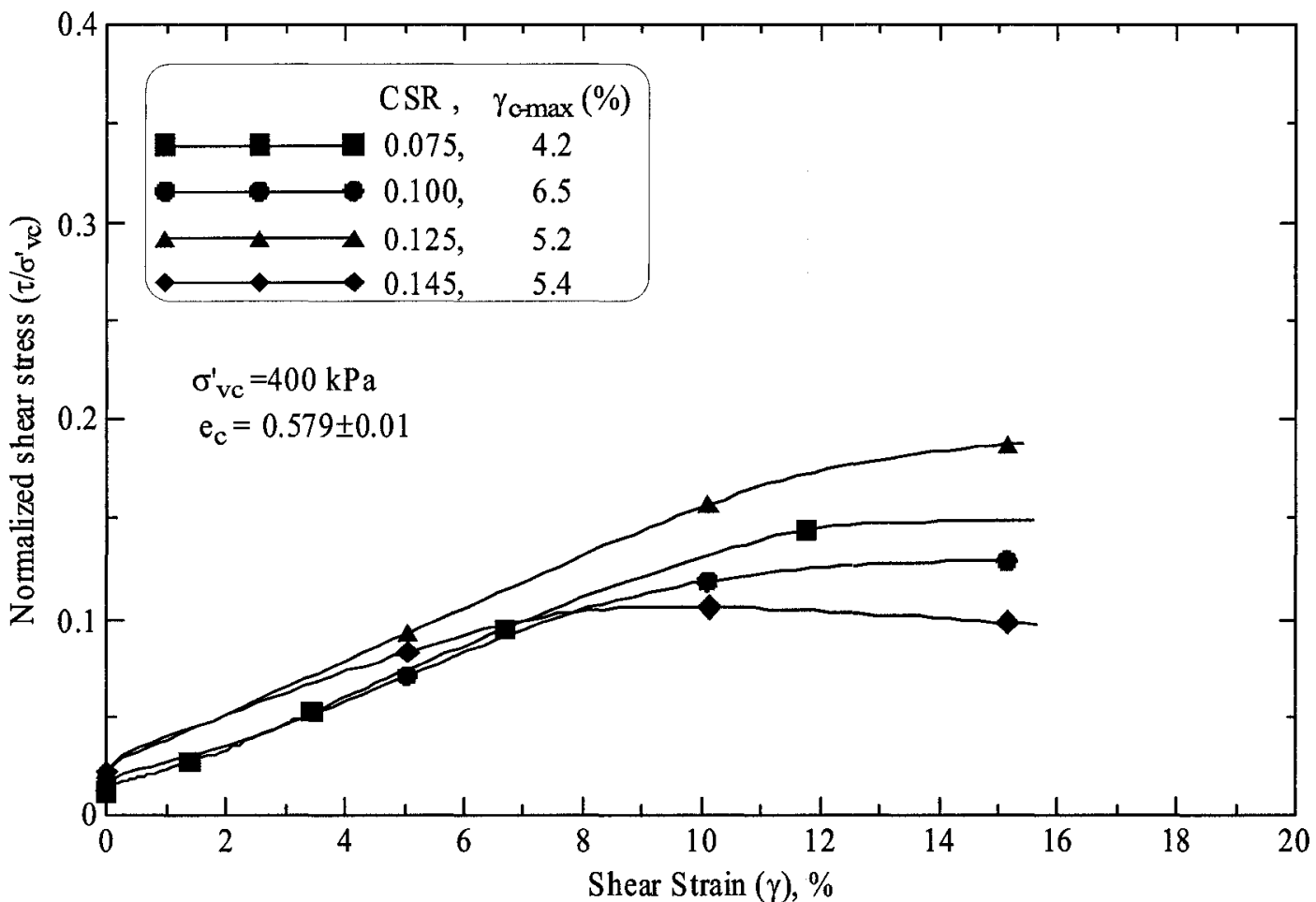

Figure 4.40 Effective of CSR and $\gamma_{\mathrm{c}-\max }$ on the post-liquefaction stress-strain response at $\sigma^{\prime} \mathrm{vc}=400 \mathrm{kPa}$. 


\subsubsection{Effect of Consolidation Pressure}

Figures 4.41 to 4.43 show the influence of consolidation pressure on the postliquefaction stress-strain response of gold mine tailings. The post-liquefaction responses displayed in Appendix II are represented based on the void ratio and cyclic stress ratio and regardless of the maximum strain level. The figures clearly show that the increases in the consolidation pressures lead to increases in both the shear modulus and the strength of tailings. It is observed too that increases in consolidation pressure often results in an increase in the initial shear stress which is the shear stress induced before the postliquefaction loading. The figures also demonstrate that the range of Region 2 decrease as the consolidation pressure increases. The amount of the strain in which the sample experiences essentially zero stiffness decreases as the consolidation pressure increases, this observation has also been reported for sand (Yazdi, 2004). 

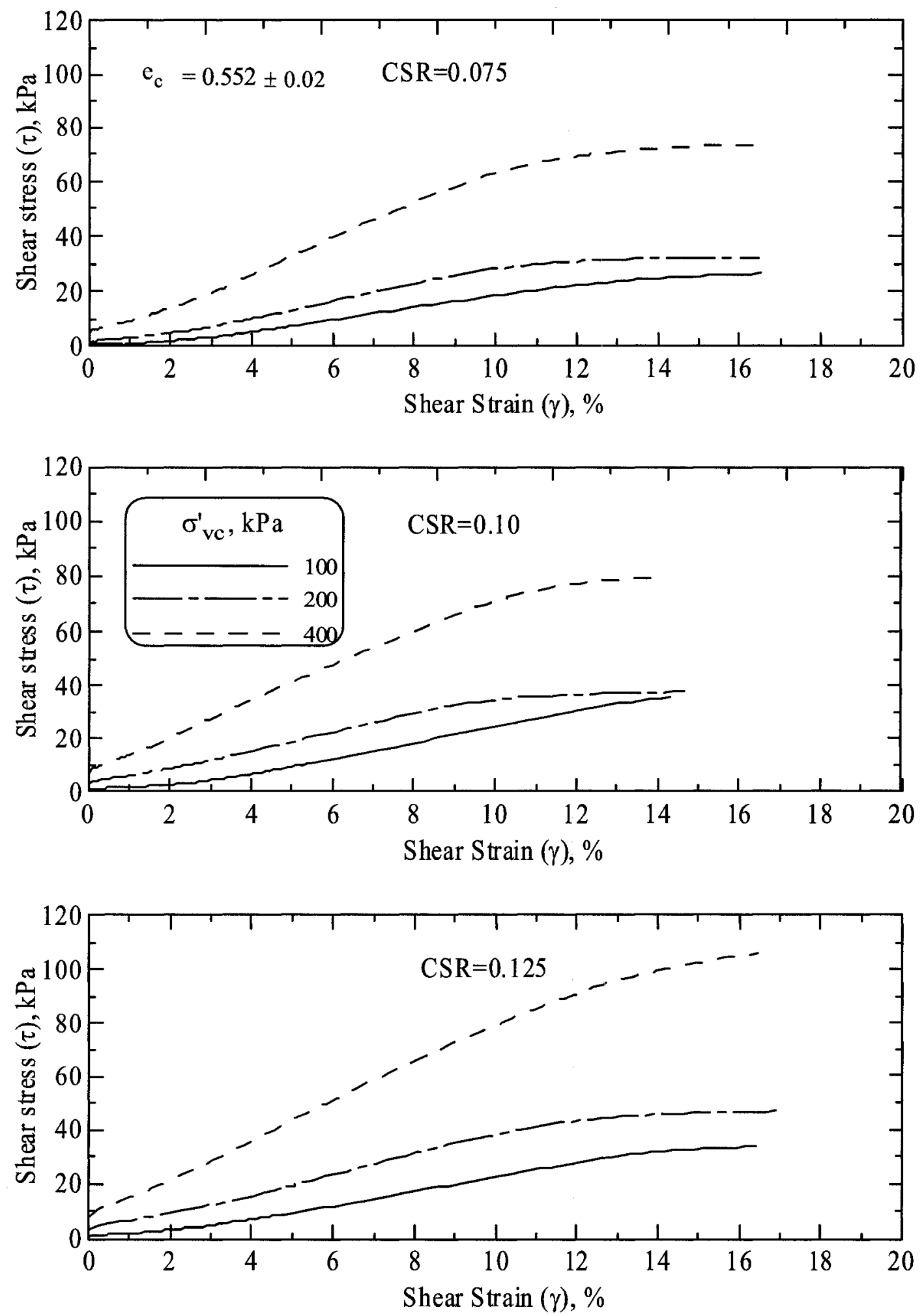

Figure 4.41 Effect of consolidation stress on post-liquefaction stress-strain response and at fixed void ratio $\left(e_{c}=0.552\right)$. 

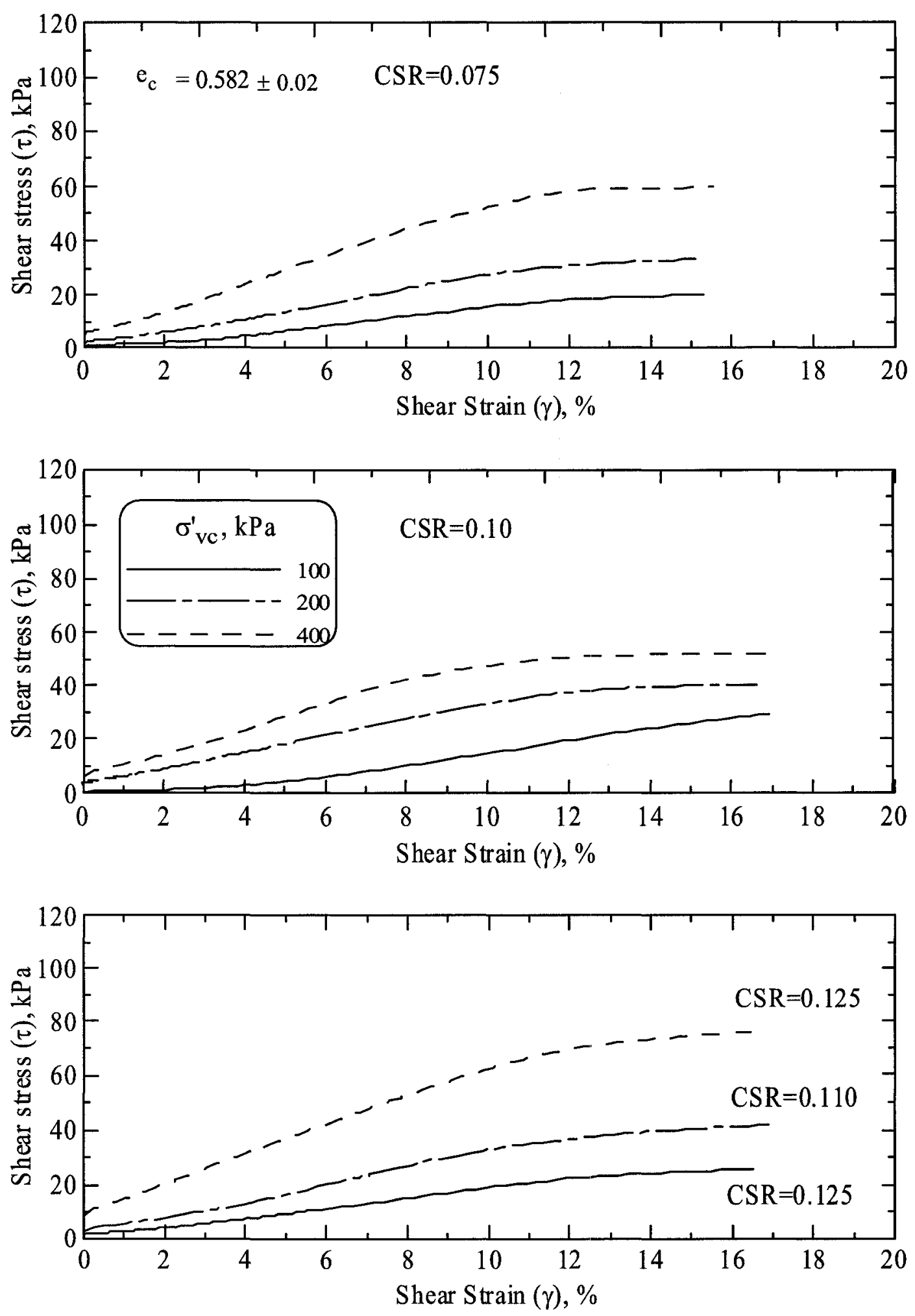

Figure 4.42 Effect of consolidation stress on post-liquefaction stress-strain response and at fixed void ratio $\left(\mathrm{e}_{\mathrm{c}}=0.582\right)$. 

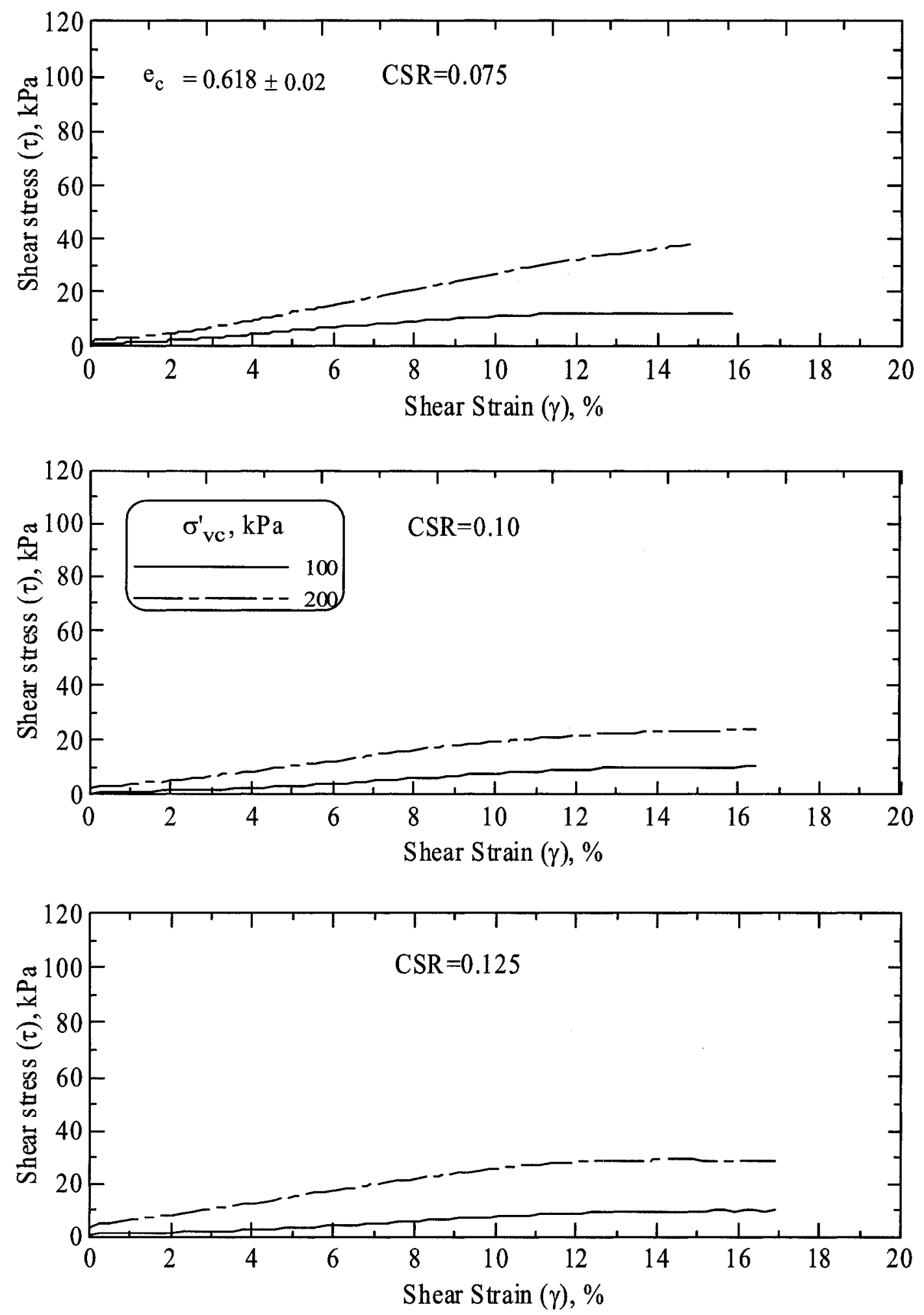

Figure 4.43 Effect of consolidation stress on post-liquefaction stress-strain response and at fixed void ratio $\left(e_{c}=0.618\right)$. 


\subsubsection{Failure Line}

The stress ratios at the end of post-liquefaction tests (Region 3) are superimposed onto the stress ratio at failure in pre-liquefaction state (Figure 4.13) and shown in Figure 4.44. The data is plotted regardless of the initial conditions at consolidation, consolidation pressure, cyclic stress ratio, and maximum liquefaction strain level. Obviously, the stress ratios at Region 3 of post-liquefaction lay on one the same straight line of pre-liquefaction failure, making a unique friction angle with an average $27.5^{\circ}$. This angle is almost equal to the failure line angle $\left(27.2^{\circ}\right)$ of the monotonic loading which was measured at failure. This demonstrates that the friction angle mobilized at the failure is unique. Similar observations but for sandy soil have been reported in the literature (Vaid \& Thomas, 1995; and Yazdi, 2004).

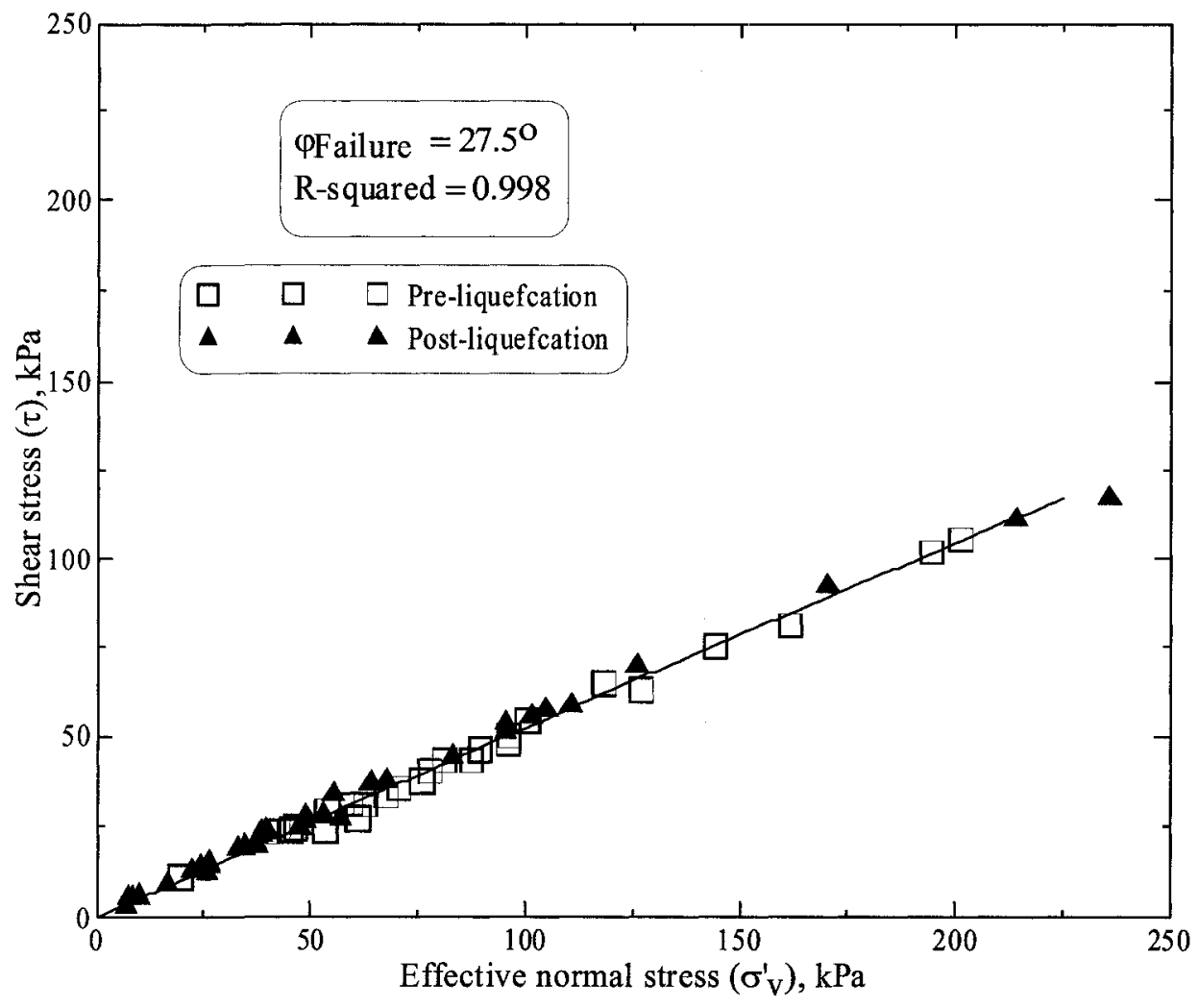

Figure 4.44 Stress ratios at the end of post-liquefaction tests superimposed on stress ratios at failure in pre-liquefaction. 


\subsubsection{Post-liquefaction Shear Strength}

Post-liquefaction shear strength $\left(\mathrm{S}_{\mathrm{PL}}\right)$ is determined at a strain level of $13 \%$. This level is adopted in this study because it provides a basis for comparison of the postliquefaction strength as a function of void ratio and also to prevent the inclusion of uncertain data due to the limitations of simple shear measurements at high strain levels. Figure 4.45 show the post-liquefaction shear strength at different consolidation pressure levels as a function of void ratio. The data is presented regardless of cyclic stress ratio, but the maximum strain level was ranged between 3.8-6.5 \%. Obviously, the postliquefaction strength decreases with an increase in void ratio. At a given void ratio, the post-liquefaction strength increases as the consolidation pressure increases.

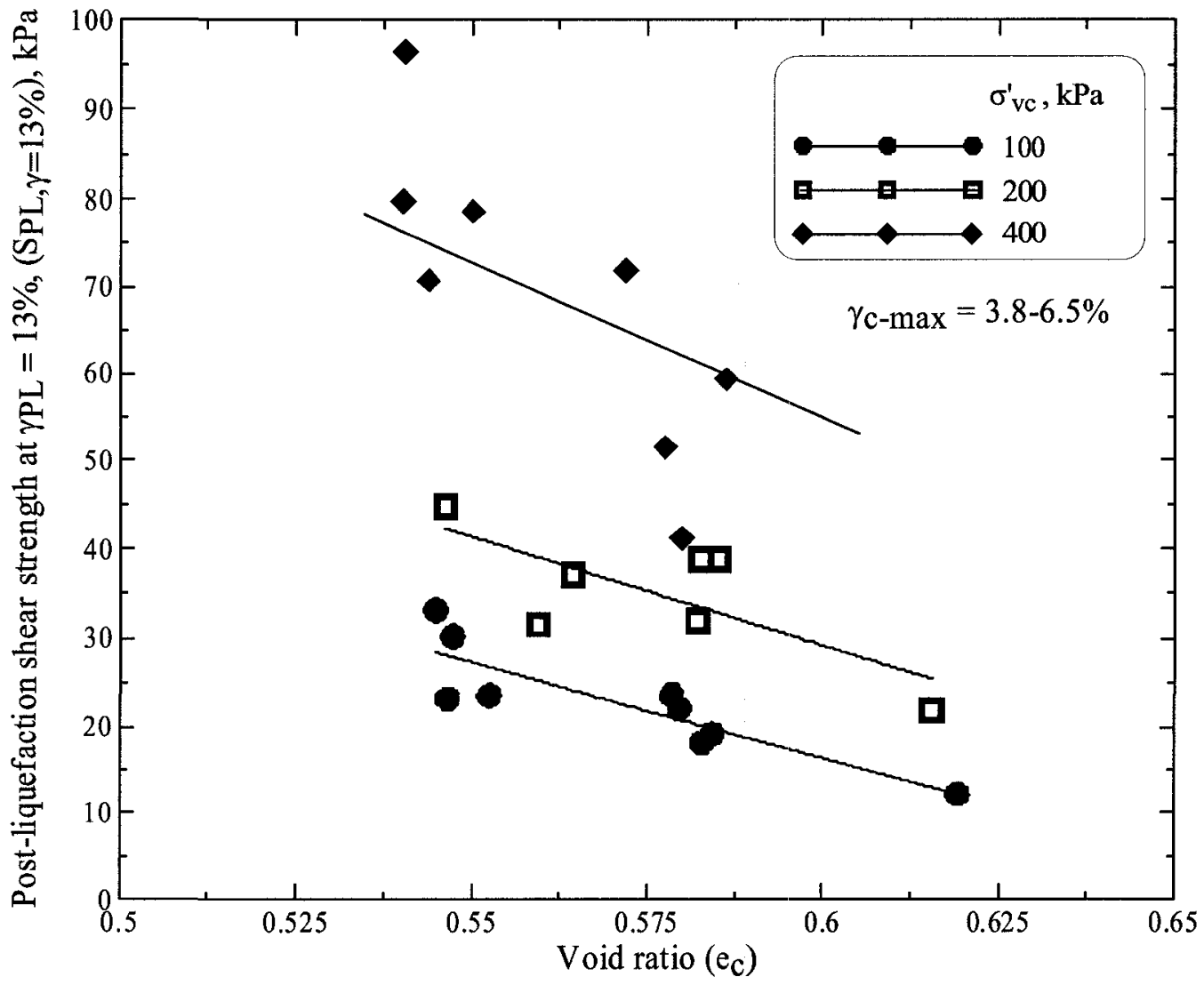

Figure 4.45 Mobilized post-liquefaction shear strength at $13 \%$ shear strain. 
The values of post-liquefaction shear strength $\left(\mathrm{S}_{\mathrm{PL}}\right)$, which are represented in Figure 4.45, were normalized based on consolidation pressure and re-plotted in Figure 4.46. The normalization of shear strength at a liquefied state has been called "liquefied strength ratio" (Olson \& Stark, 2002). From Figure 4.46, similar influence of the void ratio can be observed as in Figure 4.45. However, increasing consolidation pressure yields lower normalized strength. This result is in contradiction with the observations for sandy soils (Olson and Stark, 2003; Vaid and Sivathayalan, 1996.a). The aforementioned studies have reported that the normalized post-liquefaction shear strength ratio is not dependent on the stress level.

The range of liquefied strength ratio $\left(\mathrm{S}_{\mathrm{PL}} / \sigma_{\mathrm{vc}}^{\prime}\right)$ for soil which is susceptible to liquefaction has become a routine parameter used in design in recent years. Researchers have reported several ratio-ranges for different soil types (Table 4.4). Based on Figure 4.46, the ratio of $\left(\mathrm{S}_{\mathrm{PL}} / \sigma_{\mathrm{vc}}^{\prime}\right)$ for the tested gold mine tailings ranges between 0.1 to 0.36 . This range is higher than that reported for sands by Olson \& Stark (2003) and Vaid \& Sivathayalan (1996.a). However, it is closer to the range reported for mine tailings by Wijewickreme et al (2005). From this comparison, it seems that the $\left(\mathrm{S}_{\mathrm{PL}} / \sigma_{\mathrm{vc}}^{\prime}\right)$ ratio for tailings materials can vary by a larger range compared to sandy soils.

Table 4.4 Liquefied strength ratio reported in the literature

\begin{tabular}{|l|l|c|}
\hline \multicolumn{1}{|c|}{ Investigator } & \multicolumn{1}{c|}{ Tested material } & $\left(\mathrm{SPV}_{\mathrm{PL}} / \sigma_{\mathrm{vc}}^{\prime}\right)$ \\
\hline \multirow{2}{*}{ Wijewickreme et al (2005) } & Laterite tailings & 0.41 to 0.60 \\
\cline { 2 - 3 } & Copper-gold-zinc tailings & 0.13 to 0.53 \\
\hline $\begin{array}{l}\text { Olson and stark (2003), } \\
\text { (data from Castro, 1969) }\end{array}$ & Sandy soil & 0.08 to 0.26 \\
\hline $\begin{array}{l}\text { Vaid and Sivathayalan } \\
\text { (1996.a) }\end{array}$ & Sand soil & 0.10 to $0.26^{*}$ \\
\hline
\end{tabular}

- Vaid and Sivathayalan (1996.a) include $\mathrm{S}_{\mathrm{PT}}$ (strength at phase transformation state) in their residual strength data. 


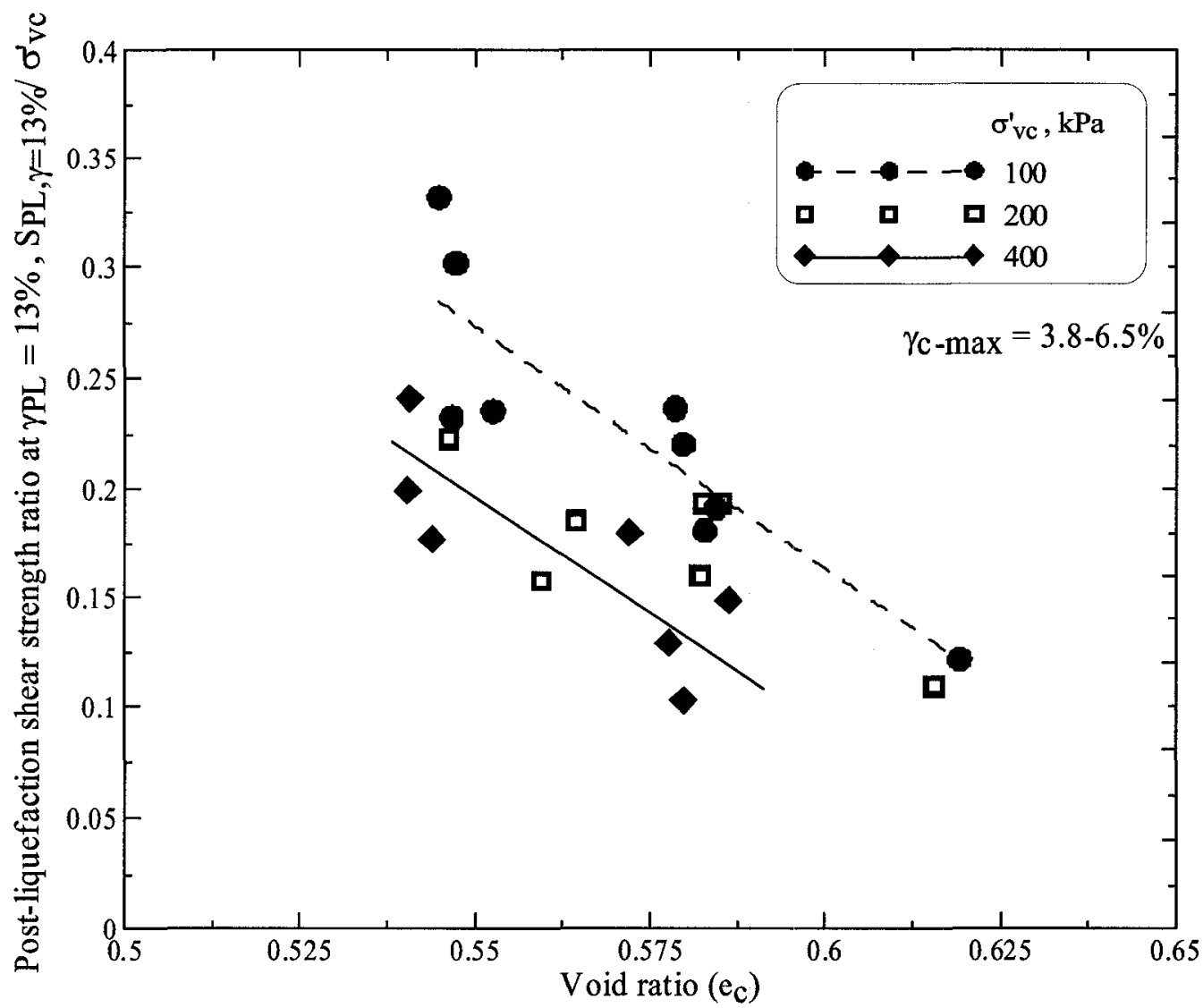

Figure 4.46 Normalized post-liquefaction shear strength at $13 \%$ shear strain.

\subsubsection{Comparison between Pre-liquefaction and Post-liquefaction Stress-strain}

\section{Responses}

The comparison between pre-liquefaction and post-liquefaction responses of gold mine tailings at the consolidation pressure of $100 \mathrm{kPa}$ and different void ratios is shown in Figure 4.47. For pre-liquefaction, the degradation of the stiffness occurs with an increase in strain until the phase transformation state is reached. However, the shear modulus in the post-liquefaction loading is essentially close to zero and it increases with the shear strain resulting in several orders of magnitude differences. At large strain levels, 
the post-liquefaction shear modulus is of the same order as the pre-liquefaction shear modulus at a given void ratio. The pre-liquefaction behaviour could be contractive or dilative depending on the load of mode, consolidation pressure, and initial conditions. In contrast, post-liquefaction behaviour is always dilative.

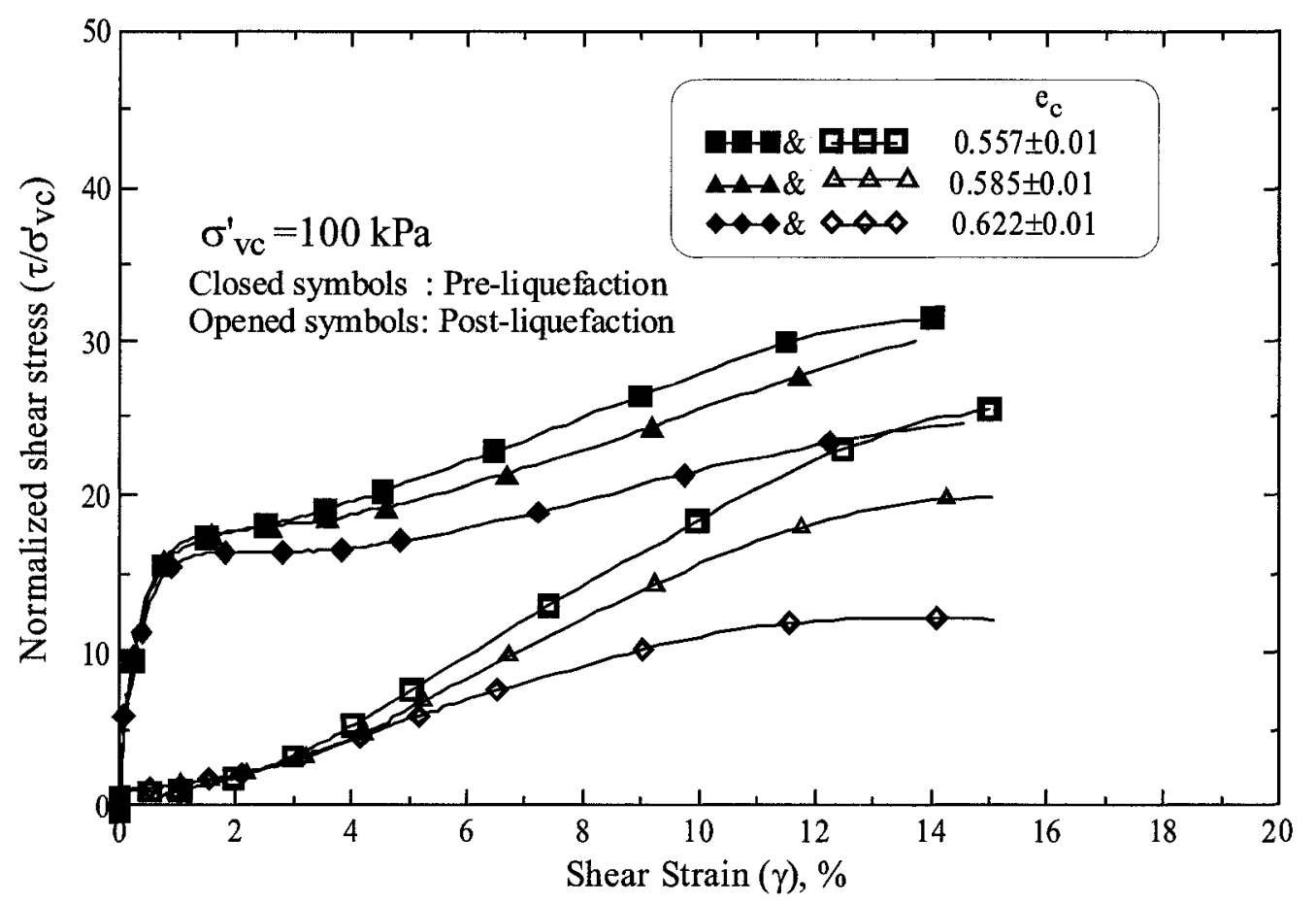

Figure 4.47 Comparison of pre-liquefaction and post-liquefaction stress-strain response for gold mine tailings at $\sigma_{\mathrm{vc}}^{\prime}=100 \mathrm{kPa}$. 


\section{CHAPTER 5: CONCLUSIONS}

An NGI-type simple shear apparatus has been used to investigate the liquefaction and post-liquefaction behaviour of gold mine tailings over a range of confining stresses and void ratios (water content). Monotonic and cyclic loading tests were conducted to explore the liquefaction behaviour. Post-liquefaction behaviour was investigated by applying the monotonic loading to the samples that liquefied during cyclic loading (under the strain criteria of $\gamma=3.75 \%$ ). The gold mine tailings used in this study were classified as low-plastic silt based on USCS. The tested samples were prepared by using the moist preparation and the wet-dry cycles preparation techniques. A compressibility design chart, used to target the required void ratio and water content at various consolidation pressures, was found to be very useful. The experimental results lead to the following conclusions:

- The monotonic simple shear response of tailings is dilative at denser void ratios (low water contents), and it transforms to contractive when the void ratio (water content) increases. The degree of contractiveness increases with any increase of void ratio (water content) and consolidation pressure.

- The friction angle mobilized at the critical state $\left(\varphi_{\mathrm{CSR}}\right)$ increases as the void ratio (water content) decreases. However, the friction angle mobilized at the phase transformation state $\left(\varphi_{\mathrm{PT}}\right)$ is essentially a constant regardless of the void ratio, 
confining stress and loading mode. The effective stress ratio at failure is also unique, and yielded a friction angle at failure of $27.5^{\circ}$.

- The gold mine tailings are susceptible to static liquefaction at certain initial states only and at cyclic liquefaction/mobility for all void ratios and consolidation pressures tested.

- The most current liquefaction criteria (Wang, 1979; Jennings, 1980; Seed and Idriss, 1982; Finn, 1982; Koester, 1994; and Bray et al., 2004) have been assessed by using the experimental results of the cyclic loading in terms of the water content-liquid limit $\left(w_{\mathrm{c}} / \mathrm{LL}\right)$, fine content, and plasticity index. This assessment demonstrated that the criteria based on fraction of fines content do not apply to the studied tailings, since the percent of fine of gold mine tailings is greater than $15 \%$ and yet the tailings liquefied.

- Not all the experimental results of the monotonic loading conform to the criteria set out by Bray et al. (2004). The samples which are liquefied under monotonic loading are considered "susceptible to liquefaction" under the criteria. However, some samples that are not liquefied under monotonic loading do fall in the liquefied zone of the chart.

- At a given number of cycles, the cyclic resistance ratio is highly influenced by void ratio (water content); it increases as the void ratio decreases. An increase of the water content renders the tailings softer which in turn decreases its resistance to cyclic loading.

- Unlike in sands, the cyclic resistance ratio of the tailings appears to be invariant with the effect of consolidation pressure for the gold mine tailings in this research. 
Consolidation pressure does not seem to influence the cyclic resistance ratio at a given void ratio $\left(e_{c}\right)$. The sensitivity of the consolidation pressure was greater for static loading than for cyclic loading. An increase in the consolidation pressure leads to an increase in the tendency of contractive behaviour in static loading especially at high void ratio. However, this sensitivity was not translated into a decrease in cyclic resistance.

- It has been observed that the excess pore pressure ratio did not reach $100 \%$ when the monotonic and cyclic loadings were being conducted even at high strain levels. Therefore, the effective shear strength has never reached zero.

- The stress path/loading mode influences the response of the tailings both under monotonic and cyclic loading. Response measured under triaxial conditions is stronger than that measured under simple shear.

- Cyclic resistance of samples which have experienced hydraulic stress history (wet-dry cycles) were considerably higher than those of samples prepared by using the wet preparation technique. It was observed that cyclic resistance decreases when the water content after controlled desiccation goes below $18 \%$. This might be because cracks are produced when the tailings become highly desaturated and those very same cracks remain even after the tailings re-saturate. However, the CRR never decreases below that of the moist preparation technique. Therefore, while the gain in cyclic resistance may be optimal for a certain degree of drying, initial drying does not appear to ever weaken the tailings.

- The assertion that thickened disposal technique prevents the possibility of liquefaction by drying the tailings layers to the water content near the shrinkage 
limit as outlined by ICOLD and UNEP (2001) is not completely valid. Even though the results of the wet-dry preparation technique show the cyclic resistance ratio increasing, the tailings still liquefy when re-saturated.

- Post-liquefaction response of liquefied tailings is dilative regardless of consolidation pressure void ratio (water content), cyclic stress ratio, and strain level at pre-liquefaction state.

- The shear modulus of post-liquefaction response is initially several orders of magnitude less than the shear modulus of pre-liquefaction response. However, at high strain levels, both moduli become essentially similar. The friction angle mobilized at failure which was obtained from the monotonic loading response is essentially equal to the friction angle mobilized at the end of post-liquefaction loading. This finding supports the contention that the failure friction angle is a unique material property.

- Void ratio (water content) has major influence on the post-liquefaction response of tailings. Increases in the void ratio (water content) render the post-liquefaction response of the tailings softer. At a given consolidation pressure, cyclic stress ratio and maximum strain level, the shear modulus increases as the void ratio (water content) decreases. Increases in the consolidation pressure lead to increases in post-liquefaction shear strength. However, this relation does not stand when the post-liquefaction shear strength is normalized by consolidation pressure. 


\section{Recommendations for Future Studies}

- Additional comprehensive experimental research is necessary to investigate the influence of initial static shear stress on the liquefaction and post-liquefaction behaviours of tailings. This study is very important especially for tailings that are disposed by thickened techniques because no confined impoundment is utilized in this technique.

- Studies to investigate the desiccation effect should be extended to prepare samples with different dried layers. Also, it is recommended that a flat bowl be used to dry the tailings instead of pouring the tailings inside a reinforced membrane if the tailings are prepared for simple shear apparatus.

- Influences of the cyclic stress ratio and the maximum shear strain on postliquefaction responses require full investigation. 


\section{REFRENCES}

- ASTM, (2002), "Standard test method for particle-size analysis of soils", (D422-63), In the Annual bock of ASTM standards. Sect 4, Vol. 04-08.

- ASTM, (2000), "Standard test method for liquid limit, plastic limit and plasticity index of soils", (D4318), In the Annual bock of ASTM standards. Sect. Vol. 0408 .

- ASTM, (2000), "Standard test method for specific gravity of soil solids by water pycnometer", (D845), In the Annual bock of ASTM standards. Sect. Vol. 04-08.

- Airey, D.W., Budhu, M. and Wood, D.M., (1985), "Some aspects of the behaviour of soils in simple shear", In: Development in Soil Mechanics and Foundation Engineering, (Editors: P K Banerjee and R Butterfield), Elsevier, Vol. 2, pp.185213.

- Airey, D.W., and Wood, D.M., (1987), "An evaluation of direct simple shear tests on clay”, Geotechnique, Vol 37, No. 1, pp. 25-35.

- Alarcon-Guzman, A., Leonards, G. A., and Chameau, J.L., (1988), "Undrained monotonic and cyclic strength of sands", Journal of Geotechnical Engineering, ASCE, Vol. 114, No. 10, pp. 1089-1108.

- Atukorala, U. D., Wijekickreme, D., and McCammon, N.R., (2000), "Some observations related to liquefaction susceptibility of silty soil" Proc. of the $12^{\text {th }}$ World Conference on Earthquake Engineering, Auckland, New Zealand, 30 January to 4 February $2000,1324 \mathrm{p}$.

- Bishop, A. W., (1971), "The influence of progressive failure on the choice of the method of stability analysis", Geotechnique, Vol. 21, No. 2, pp. 168-172.

- Bjerrum, L. and Landva, A., (1966), "Direct simple-shear tests on a Norwegian quick clay", Geotechnique, Vol. 16, No 1, pp. 1-20.

- Boulanger, R. W., and Idriss, I. M., (2006) " Liquefaction susceptibility criteria for silts and cays", Journal of Geotechnical and GeoEnvironmental Engineering, Vol. 132, No. 11, pp. 1413-1426.

- Bray, J. D., Sancio, R. B., Riemer, M., and Durgunoglu, H. T., (2004), "Liquefaction susceptibility of fine-grained soils." Proc., Joint Conf., the $11^{\text {th }}$ Int. Conf. on Soil Dynamics and Earthquake Engineering (SDEE), the $3^{\text {rd }}$ Int. Conf. on Earthquake Geotechnical Engineering (ICEGE), Berkeley, Calif., pp. 655-662. 
- Casagrande, A., (1975), "Liquefaction and cyclic deformation of sand: a critical review", Proc. Fifth Pan-American Conference on Soil Mechanics and Foundation Engineering, pp. 79-133.

- Castro, G. (1969), "Liquefaction of sands", PhD Thesis, Harvard University, Cambridge, Massachusetts.

- Castro, G. and Poulos, S.J., (1977), "Factors affecting liquefaction and cyclic mobility", Journal of the Geotechnical Engineering Division, ASCE. Vol. 103, No. 6, pp. 501-516.

- Castro. G., Poulos, S.J., France, J.W. and Enoso, J.L. (1982),"Liquefaction induced by cyclic loading" Report to National Science Foundation, Report No. (NSF/CEE-82018), Washington, DC.

- Chang, N. Y., (1990), "Influence of fines content and plasticity on earthquakeinduced soil liquefaction"' Rep., Contract No. DOCW3988-C- 0078, U.S. Army Engineer Waterways Experiment Station, Vicksburg, Miss.

- Chern , J.C (1985), “ Undrained response of saturated sands with emphasis on liquefaction and cyclic mobility", Ph.D. Thesis, University of British Colombia, Vancouver, Canada, 213 p.

- Crowder, J. J., (2004), "Deposition, consolidation, and strength of a non-plastic tailings paste for surface disposal", Ph.D. thesis, Toronto University, Toronto, $162 \mathrm{p}$.

- Davies, M.P., Chin, B.G. and Dawson, B.G., (1998), "Static liquefaction slump of mine tailings - a case history", Proc., 51st Canadian Geotechnical Conference, Edmonton.

- Davies, M. P., McRoberts E., and et al., (2002), "Static liquefaction of tailingsFundamentals and Case Histories", Proc: Tailings Dams 2002, ASDSO/USCOLD, Las Vegas, $23 \mathrm{p}$.

- Dobry, R. and Alvarez, L., (1967),"Seismic failure of Chilean tailings dams", Journal of Soil Mechanics and Foundation Division. Proc. of the ASCE. No. SM6, November. pp. 237-260.

- Dyvik, R., Berre, T., Lacasse, S., and Raadim, B., (1987), “ Comparison of truly undrained and constant volume direct simple shear tests, Geotechnique, Vol. 37, No. 1, pp. 3-10.

- Engels J. and Dixon-Hardy, D., (2008), (http://www.tailings.info accessed on April 22,2008 ). 
- Erten, D. and Maher, M. H., (1995), "Cyclic undrained behaviour of silty sand", Soil Dynamics and Earthquake Engineering, Vol. 14, Is. 2, pp. 115-123.

- Finn, W.L., (1982), "Soil liquefaction studies in the People's Republic of China" Soil Mechanics-Transient and Cyclic Loads, John Wiley and Sons, New York, pp. 609-626.

- Fisseha, B., (2008), "Flow Behaviour in Multilayer Deposits of Unsaturated Paste Tailings", M.A.Sc. Thesis, Carleton University, Ottawa, 217 p.

- Fleureau, J.M., Kheirbek-Saoud, S., Soemitro, R., and Taib, S., (1993), "Behaviour of clayey soils on drying-wetting paths", Canadian Geotechnical Journal, Vol. 30, No. 2, pp. 287-296.

- Fourie, A. B., and Papageorgiou, G., (2001),'Defining an appropriate steady state line for Merriespruit gold tailings, Canadian Geotechnical Journal, Vol. 38, No. 4, pp. 695-706.

- Golder, (2005), "Report on Bulyanhulu gold mine tailings storage facility optimization of deposition", Report No. 5098/6586/5/S. Golder Associates Africa, $42 \mathrm{pp}$.

- Hamada, M., Yasuda, S., Isoyama, R., and Emoto, K., (1986), "Study on liquefaction induced permanent ground displacements", Association for the Development of Earthquake Prediction, Japan.

- Hyde, A. F. L., Higuchi, T., and Yasuhara, K., (2004), "Liquefaction and cyclic failure of low plasticity silt" Int. Conf. on Cyclic Behaviour of Soils and Liquefaction Phenomena, Bochum, Taylor and Francis, London, pp.137-146.

- Hyde, A. F. L., Higuchi, T. and Yasuhara, K., (2006), "Liquefaction, cyclic mobility, and failure of silt", Journal of Geotechnical and GeoEnvironmental Engineering, ASCE 132, No. 6, pp. 716-735.

- Hyde, A. F. L., Higuchi, T., and Yasuhara, K., (2007),"Post cyclic recompression, stiffness, and consolidated cyclic strength of silt", Journal of Geotechnical and Geoenvironmental Engineering, Vol. 133, No. 4, pp. 416-423.

- Hyde, A. F. L., and Ward, S. J., (1986),"The effect of cyclic loading on the undrained shear strength of a silty clay", Marine Geotechnology, Vol. 6, No. 3, pp. 299-314.

- ICOLD and UNEP, (2001), "Tailings dams - risk of dangerous occurrences, Lessons learnt from practical experiences. International Commission on Large Dams (ICOLD) and United Nations Environment Program (UNEP), Report: Bulletin 121, Paris. 144 p. 
- Ishihara, K., Trancoso, J., Kawase, Y., and Takahashi, Y., (1980), "Cyclic strength characteristics of tailings materials", Soil and Foundations, Vol. 20, No. 4, pp. $127-142$.

- Isihara, K., Tatsuoka, F. and Yasuda, S. (1975), "Undrained deformation and liquefaction of sand under cyclic stresses", Soils and Foundations, Vol. 15, No. 1, pp. 29-44.

- Ishihara, K., Yasuda, S., and Yokota, K., (1981), "Cyclic strength of undisturbed mine tailings", In Proc. of the Int. Conf. on Recent Advances in Geotechnical Earthquake Engineering and Soil Dynamics, St. Louis, Vol. 1, pp. 53-58.

- Ishihara, K. and Yoshimine, M., (1992), "Evaluation of settlements in sand deposits following liquefaction during earthquakes", Soils and Foundations, Vol. 32, No. $1, \mathrm{pp} 173-188$.

- Jennings, P.C., (1980), "Earthquake engineering and hazards reduction in China", CSCPRC Report No. 8, National Academy of Sciences, Washington, D.C

- Kammerer, A. M., Wu, J., Riemer, M., and Seed, R.B., (2001), “Use of cyclic simple shera testing in evaluation of the deformation potential of liquefaction soils", Proc., Fourth Intr. Conf. on Recent Advances in Geotechnical Earthquake Engineering and Soil Dynamics and Symposium in Honor of Prof. W. D. Liam Finn, San Diego, California, March 26-31, 200, Paper No. 1.20, pp. 1-6.

- Koester, J. P., (1993), "Effects of fines type and content on liquefaction potential of low-to-medium plasticity fine-grained soils" Proc., Nat. Earthquake Conf., Central United States Earthquake Consortium, Memphis, Tenn., Vol. 1, pp. 67-75.

- Koester, J. P., (1994), "The influence of fines type and content on cyclic strength", Ground Failures under Seismic Conditions, ASCE, Geotech. Special Pub., No 44, S. Prakash and P. Dakoulas (eds), October, pp. 17-33.

- Kramer, S. L. (1996),"Geotechnical Earthquake Engineering", University of Washington. Prentice-Hall International Series of Civil Engineering and Mechanics. pp. 348-415.

- Kuerbis, R. H. (1989), "Effect of gradation and fines content on the undrained response of sand", M.A.Sc. Thesis, University of British Columbia, Vancouver. B.C.

- Lee, K.L. and Seed, H. B. (1967), "Drained strength characteristics of sands", Journal of Soil Mechanics and Foundation Division, ASCE, Vol. 93, No. 6, pp. 117-141. 
- Miura, S., and Toki, S., (1982), "A sample preparation method and its effect on static and cyclic deformation-strength properties of sand", Soil and Foundations, Vol. 22, No. 1, pp. 61-77.

- NRC, (1985), "Liquefaction of soils during earthquakes", Commission on Engineering and Technical System, National Research Council, Washington, D. C., Report No. CETS-EE-01.

- Newman, P., and Landriault, D., (1997), "The use of paste technology in the surface disposal of mineral waste", Waste Minimisation and Recycle, Birmingham.

- Olson, S.M., and Stark, T.D., (2002), "Liquefied strength ratio from liquefaction flow failure case histories", Canadian Geotechnical Journal, Vol., 39, No. 3, pp. 629647.

- Olson, S.M., and Stark, T.D, (2003), "Use of laboratory data to confirm yield and liquefied strength ratio concepts", Canadian Geotechnical Journal, Vol. 40, No. 6, pp. 1164-1184.

- Polito, C.P., (1999), "The effects of non-plastic and plastic fines on the liquefaction of sandy sands", Ph.D. Thesis, Blacksburg, Virginia Polytechnic Institute and State University, $274 \mathrm{p}$.

- Poulos, S.J.,(1981),"The steady state of deformation", Journal of the Geotechnical Engineering Division, ASCE, Vol. 107, No. GT5, pp. 553-562.

- Riemer, M. F., and Seed, R. B., (1997), "Factors affecting apparent position of the steady state line", Journal of Geotechnical Engineering, ASCE, Vol. 123, No. 3, pp. 281-288.

- Sanin, M.V., and Wijewickreme, D., (2006), "Cyclic shear loading response of channel-fill Fraser River Delta silt", Soil Dynamics and Earthquake Engineering, Vol. 26, Is. 9, pp. 854-869.

- Seed, H.B (1979), "Soil liquefaction and cyclic mobility evaluation for level ground during earthquakes", Journal of Geotechnical Engineering, ASCE, Vol. 105, No. 2, pp. 201-255.

- Seed, H. B., (1983), "Earthquake-resistance design of earth dams", Proc. Symposium on Seismic Design of Earth Dams and Caverns, ASCE, New York, pp 41-46.

- Seed, H. B., and Idriss, I. M., (1982), "Ground motions and soil liquefaction during earthquakes”, EERI Monograph, Berkeley, CA, 134 p.

- Seed, H. B., Lee, K.L., Idrriss, I. M., and Makdisi, F. I. (1975), "Representation of irregular stress time histories by equivalent uniform stress series in liquefaction 
analyses", Earthquake Engineering Research Center, Report EERC 75-29, University of California, Berkeley, $40 \mathrm{p}$.

- Shamoto Y., Zhang, J-M., and Goto, S., (1997), "Mechanisms of large postliquefcation deformation in saturated sand", Soils and Foundations, Vol. 37, No. 2, pp. 71-80.

- Shamoto, Y., Zhang, J.-M., Goto, S. and Tokimatsu, K., (1996), "A new approach to evaluate post-liquefaction permanent deformation in saturated sand", Proceedings, $11^{\text {th }}$ WCEE, Acapulco, Mexico.

- Shamoto Y., Zhang, J-M., and Tokimatsu, K., (1998), "New charts for predicting large residual post-liquefaction ground deformation", Soil Dynamics and Earthquakes Engineering, Vol. 17, Is. (7-8), pp. 427-438.

- Shuttleworth, J. A., Thomson, B.J., and Wates, J. A., (2005), "Surface disposal at Bulyanhulu-practical lessons learned, In Proc. of the $6^{\text {th }}$ International Conference on Paste and thickened tailings, Santiago, Chile, 20-22- April 2005. Edited by R. Jewel and S. Barerra. pp. 207-2016.

- Simms, P., Grabinsky M., and Zhan G., (2007), "Modeling evaporation of paste tailings from the Bulyanhulu mine", Canadian Geotechnical Journal, Vol. 44, No. 12, pp. 1417-1432.

- Singh, S., (1996),"Liquefaction characteristic of silts", Geotechnical and Geological Engineering, Vol. 14, No. 1, pp. 1-19.

- Sivathayalan, S., and Ha. D., (2004), "Effect of initial stress on the cyclic simple shear behaviour of sands", Cyclic Behaviour of Soil and Liquefaction Phenomena, Triantafyllidis (ed), Taylor \& Francis Group, London, pp. 207-214.

- Sivathayalan, S., and Y. P. Vaid, (2002), "Influence of generalized initial state and principal stress rotation on the undrained response of sands", Canadian Geotechnical Journal, Vol. 39, No. 1, pp. 63-76.

- Sivathayalan, S., and Yazdi A. M., (2004), "Post liquefaction response of initially strain softening sand", Cyclic Behaviour of Soil and Liquefaction Phenomena, Triantafyllidis (ed), Taylor \& Francis Group, London, pp. 215-221.

- Taylor, R. K. (1987), "Tailings dams: The liquefaction hazard". Memoir of the Geological Society of China. December, 1987, No.9, pp.109-122.

- Terzaghi, R. and Peck, R.B., (1948/1967),"Soil Mechanics in Engineering Practice", $2^{\text {nd }}$ edition, John Wiley and sons, New York, $729 \mathrm{p}$. 
- Theriault, J., Frostiak, J., and Welch, D., "2003), " Surface disposal of paste tailings at the Bulyanhulu gold mine, Tanzania", In Proc. of Sudbury 2003, Mining and the Environment, Sudbury, Ont., 26-28 May 2003. Edited by G. Spiers, P. Beckett, and H. Conroy. pp. 265-269.

- Thevanayagam, S. and Martin, G.R., (2000), "Liquefaction and post-liquefaction dissipation/densification characteristics of silty soils" MCEER Annual Report for Research Year 1, June 1, 1999 to September 30, 2000, MCEER Highway Project 094: Seismic Vulnerability of the Highway System.

- Thomas, J. (1992), "Static, cyclic and post liquefaction undrained behaviour of Fraser River sand", M.A.Sc. Thesis, University of British Colombia, Vancouver, Canada, $117 \mathrm{p}$.

- Tohno, I. and Shamoto, Y., (1986) "Liquefaction damage to the ground during the 1983 Nihonkai-Chubu earthquake in Akita Prefecture", Natural Disaster Science, Vol. 8, No. 1, pp. 85-116.

- Tokimatsu, K. and Seed, H.B. (1987), "Evaluation of settlements in sands due to earthquake shaking", Journal of the Geotechnical Engineering Division, ASCE, Vol. 113, No. 8, pp. 861-878.

- Towhata, I., Sasaki, Y., Tokida, K., Matsuoka, H., Tamari, Y. and Yamada, K., (1992), "Prediction of permanent displacement of liquefied ground by means of minimum energy principle", Soils and Foundations, Vol. 32, No. 3, pp. 97-116.

- Troncoso, J. H., (1990), “Failure risks of abandoned tailings dams" Proc., Int. Sym. on Safety and Rehabilitation of Tailings Dams, International Commission on Large Dams, Paris, pp. 82-89.

- Uthayakumar, M. and Vaid, Y. P. (1998), "Static liquefaction of sands under multriaxial loading", Canadian Geotechnical Journal, Vol. 35, No. 2, pp. 273-283.

- Vaid, Y. P., (1994), "Liquefaction of silty soils", Proc. Ground failure under seismic conditions. (eds. Prakash S., Dakoulas P.), ASCE, Spec. Pub. No. 44, pp. 1-16.

- Vaid, Y. P., and Chern, J.C. (1983), "Effect of static shear on resistance of liquefaction", Soils and Foundations, Vol. 23, No. 1, pp. 47-60.

- Vaid, Y. P., and Chern, J.C. (1985), "Cyclic and monotonic undrained response of saturated sands", Proc. Advances in the art of testing soils under cyclic loading conditions, Detroit, pp. 120-147.

- Vaid, Y. P., Chung, E. K. F., and Kuerbis, R. H., (1990), "Stress path and steady state", Canadian Geotechnical Journal, Vol. 27, No. 1, pp. 1-7. 
- Vaid, Y. P. and Finn, W. D. L., (1978), "Static shear and liquefaction potential", Journal of Geotechnical Engineering Division, ASCE, Vol. 105, No. GT10, pp. $1233-1246$.

- Vaid, Y. P. and Thomas, J., (1994), "Post liquefaction behaviour of sand", Proc. $13^{\text {th }}$ International Conference on Soil Mechanics and Foundation Engineering, New Delhi, India, pp. 1305-1310.

- Vaid, Y. P. and Thomas, J., (1995), "Liquefaction and Post liquefaction behaviour of sand", Journal of Geotechnical Engineering, ASCE, Vol. 121, No. 2, pp. 163-173.

- Vaid, Y. P. and Sivathayalan, S., (1996.a), "Static and dynamic liquefaction potential of Fraser Delta sand in simple shear and triaxial tests", Canadian Geotechnical Journal, Vol. 33, No. 2, pp. 281-289.

- Vaid, Y. P. and Sivathayalan, S., (1996.b), "Errors in estimates of void ratio of laboratory sand specimens", Canadian Geotechnical Journal, Vol. 33, No. 6, pp. 1017-1020.

- Vaid, Y. P. and Sivathayalan, S., (1997), "Post liquefaction behaviour of saturated sands under simple shear loading", Proc. Int. Conf. on Soil mechanics and Foundations Engineering, Hamburg, Vol. 14, No. 1, pp. 221-224.

- Vick, S. G., (1990), "Planning, Design, and Analysis of tailings dams", Bi-Tech, Publishers, Vancouver, Canada, $369 \mathrm{p}$.

- Wang, W., (1979), "Some findings in soil liquefaction", Water Conservancy and Hydroelectric Power Scientific Research Institute, Beijing, China, pp 1-17.

- Wijewickreme, D., Sanin, M. V. and Greenaway, G. R., (2005), "Cyclic shear response of fine-grained mine tailings", Canadian Geotechnical Journal, Vol. 42, No. 5, pp. 1408-1421.

- Yamamuro, J. A., and Lade, P. V. (1998)," Steady-state concept and static liquefaction of silty sand". Journal of Geotechnical and GeoEnvironmental Engineering, ASCE, Vol. 124, No 9, pp. 868-877.

- Yasuhara, K.(1994), " Postcyclic undrained strength for cohesive soils", Journal of Geotechnical Engineering, ASCE, Vol. 120, No. 11, pp. 1961-1979.

- Yasuhara, K., Murakami, S., Song B., Yokoawa, S., and Hyde, A. F., (2003), “ Postcyclic degradation of strength and stiffness for low plasticity silt", Journal of Geotechnical and GeoEnvironmental Engineering, ASCE, Vol. 129, No. 8, pp. 756-769. 
- Yazdi, A. M., (2004), "Post liquefaction behaviour of sands under simple shear and triaxial loading modes", M.A.Sc. Thesis, Carleton University, Ottawa, 119 p.

- Yoshimine, M., Ishihara, K, and Vargas, W., (1998),"Effects of principle stress direction and intermediate principle stress on undrained shear behaviour of sand", Soil and Foundations, Vol. 38, No. 3, pp. 179-188.

- Youd, T.L., Idriss, I.M., Andrus, R.D., Arango, I., Castro, G., Christian, J.T., Dobry, R., Finn, W.D.L., Harder Jr, L.F., Hynes, M.E., Ishihara, K., Koester, J.P., Liao, S.C., Marcuson III, W.F., Martin, G.R., Mitchell, J.K., Moriwaki, Y., Power,M.S., Robertson, P.K., Seed, R.B., and Stokoe II, K.H., (2001), "Liquefaction resistance of soils: Summary report from the 1996 NCEER and 1998 NCEER/NSF workshops on evaluation of liquefaction resistance of soils", Geotechnical and GeoEnvironmental Engineering, Vol. 127, No. 10, pp. 817-833. 
APPENDIX I 

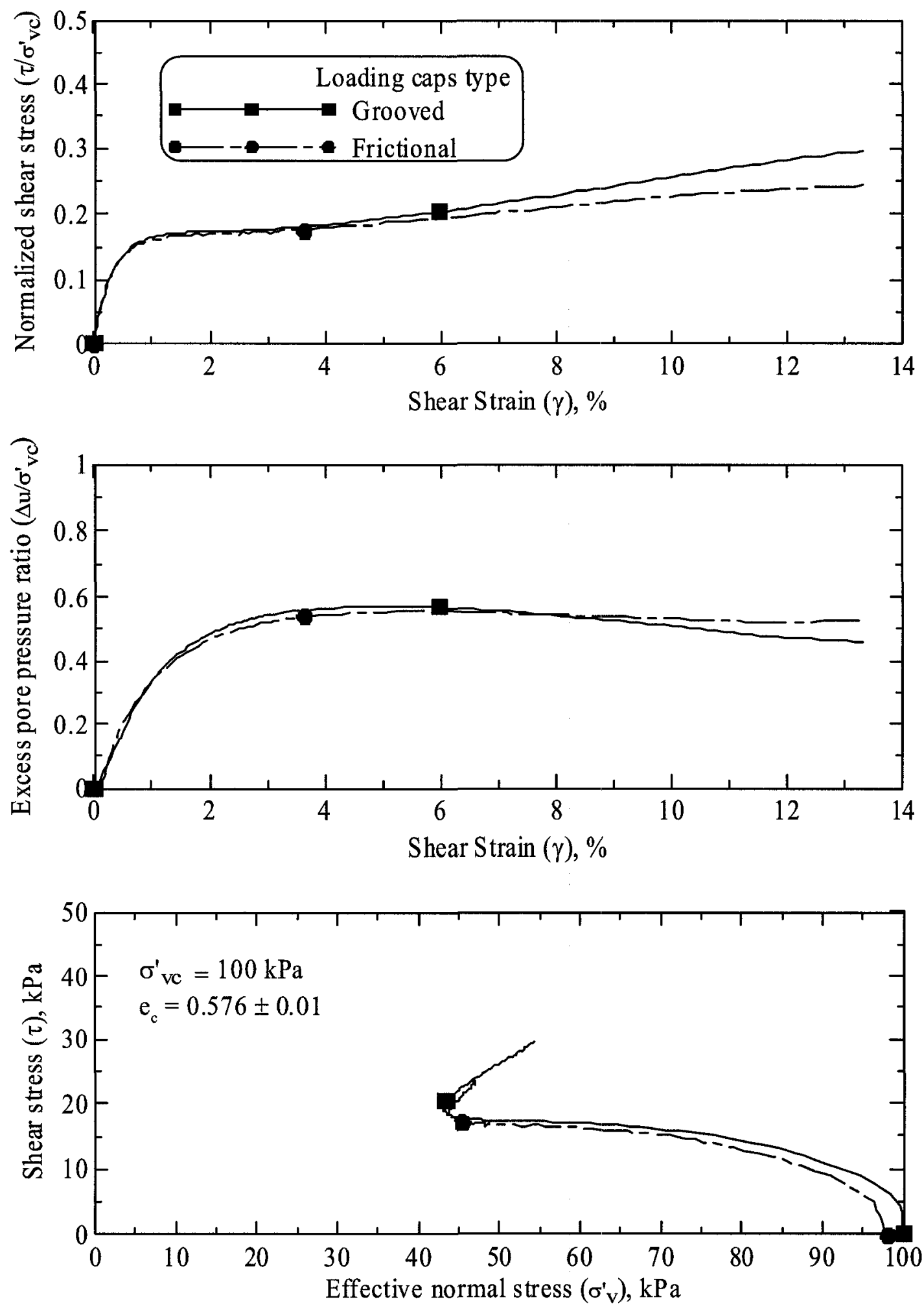

Figure A1 Influence of the interaction between the tailings sample discs material and shape on the monotonic behaviour. 

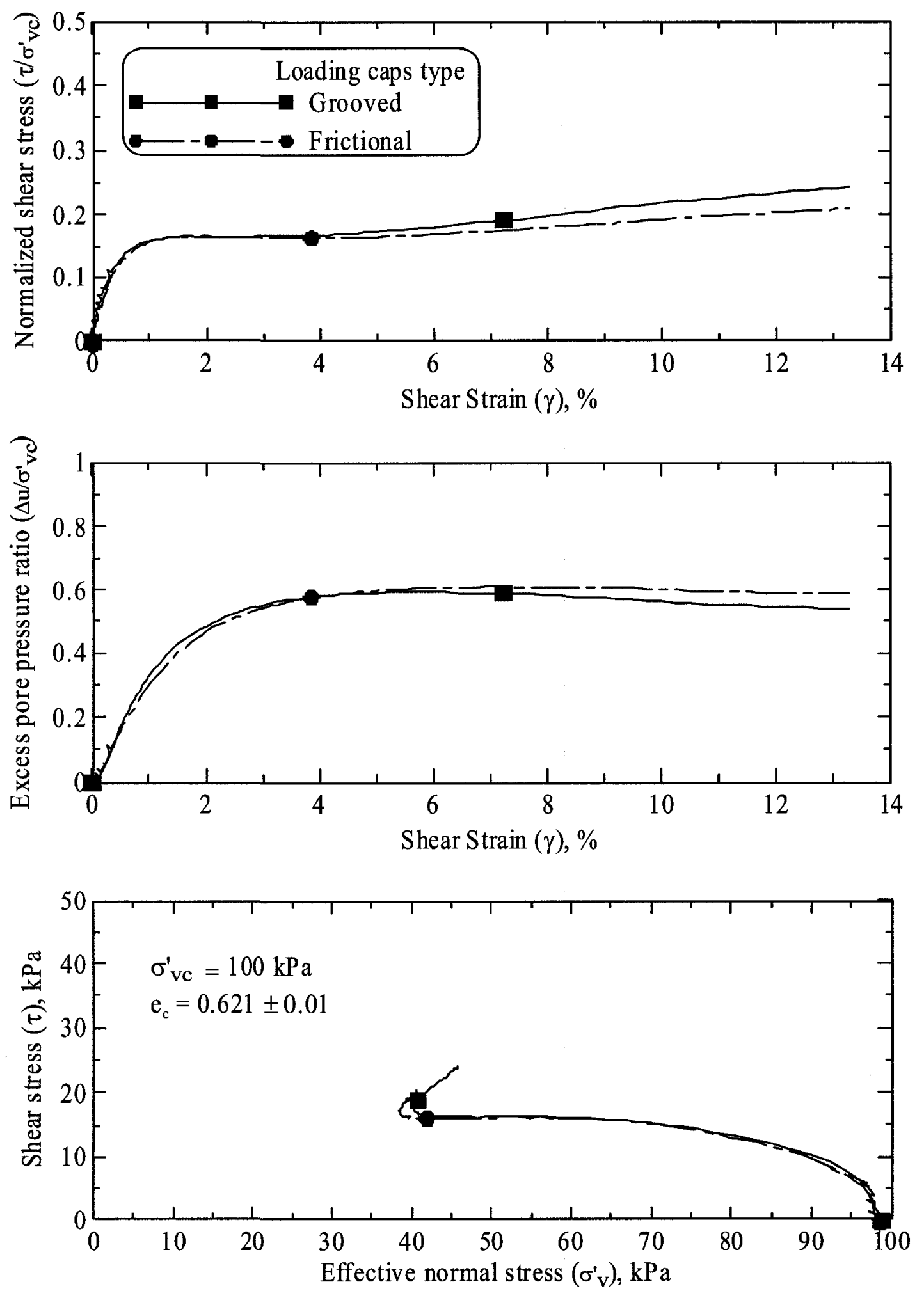

Figure A2 Influence of the interaction between the tailings sample discs material and shape on the monotonic behaviour. 
APPENDIX II 


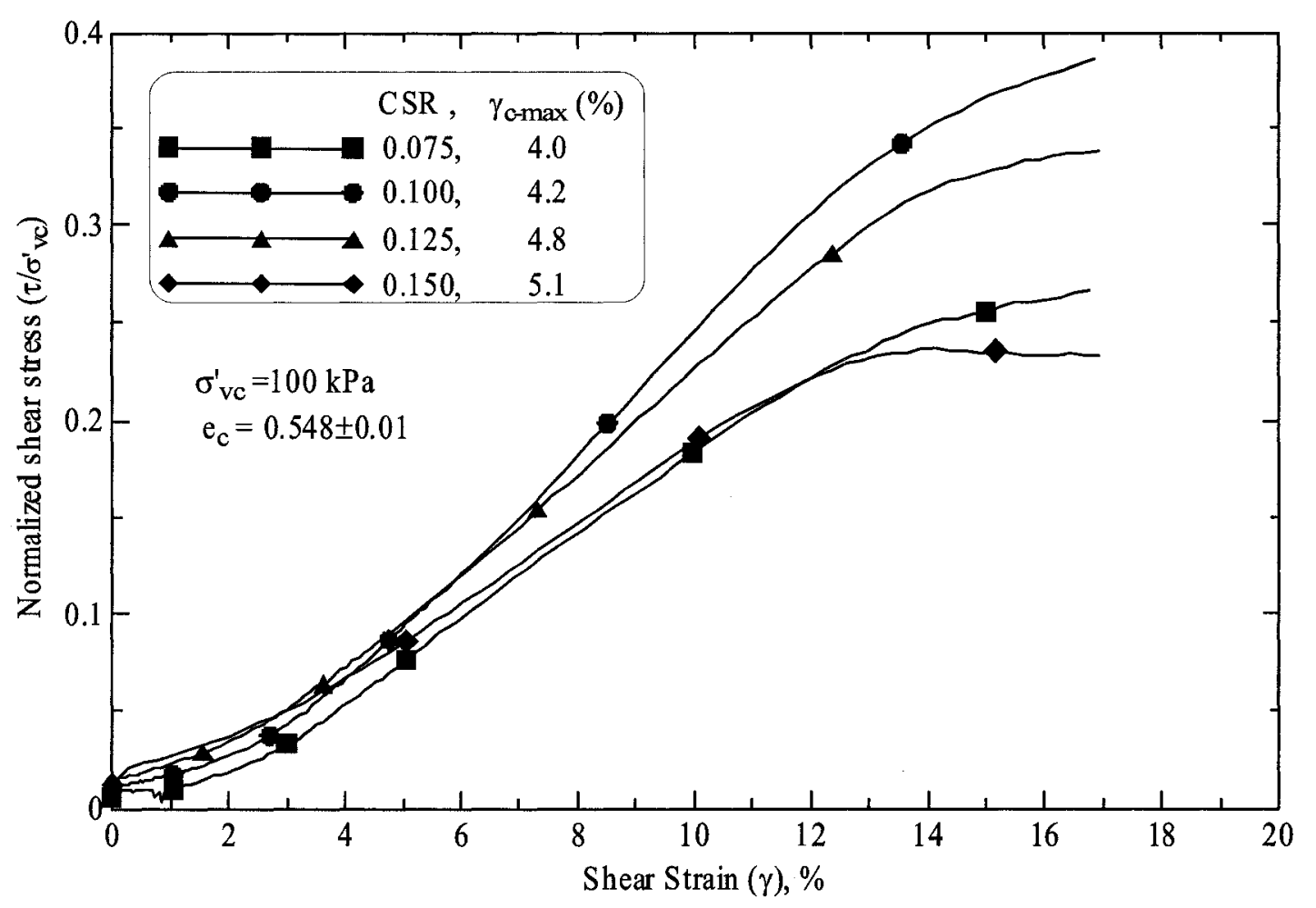

Figure B1 Post-liquefaction response of gold mine tailings at $\sigma_{\mathrm{vc}}^{\prime}=100 \mathrm{kPa}$.

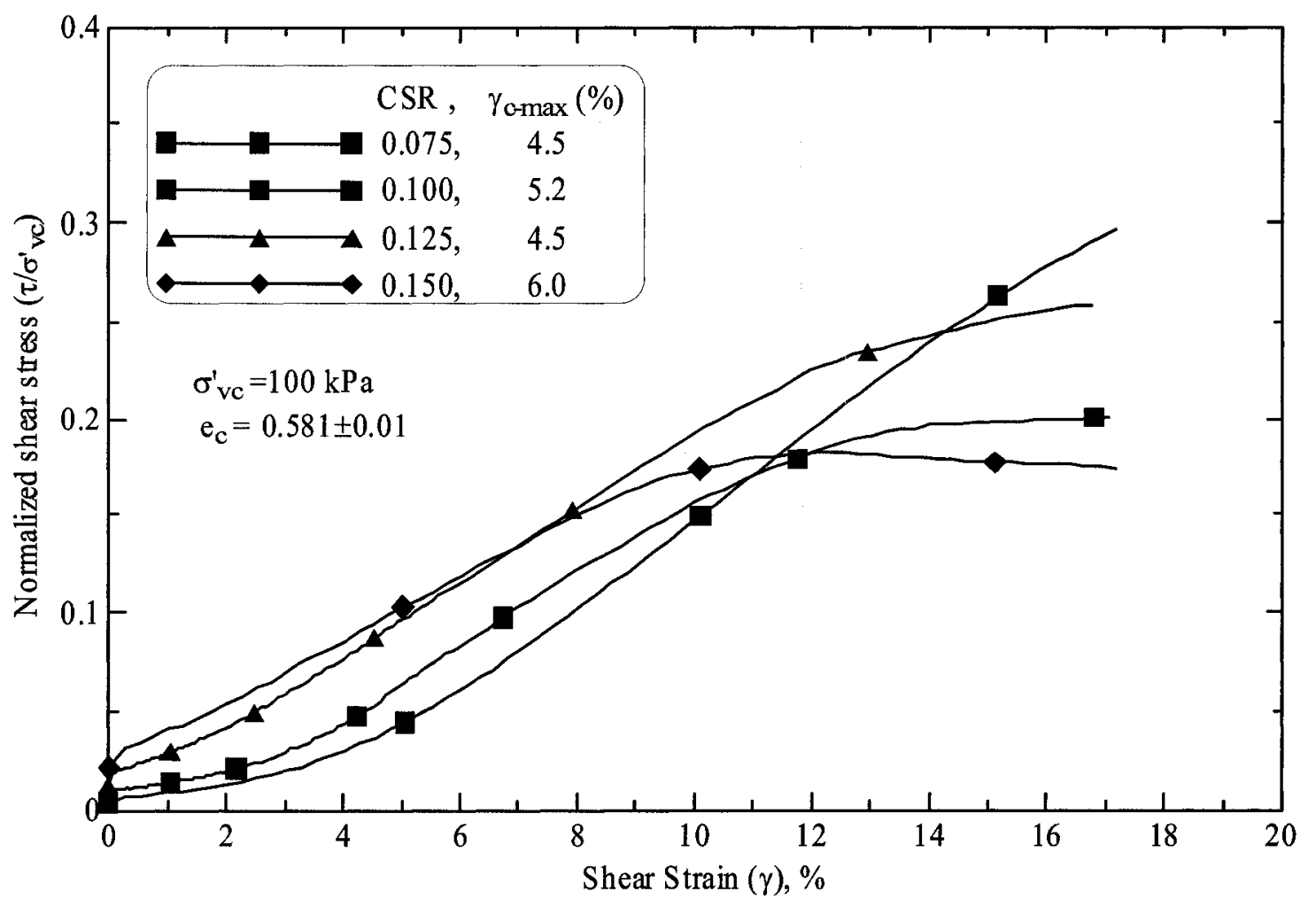

Figure B2 Post-liquefaction response of gold mine tailings at $\sigma_{\mathrm{vc}}^{\prime}=100 \mathrm{kPa}$. 


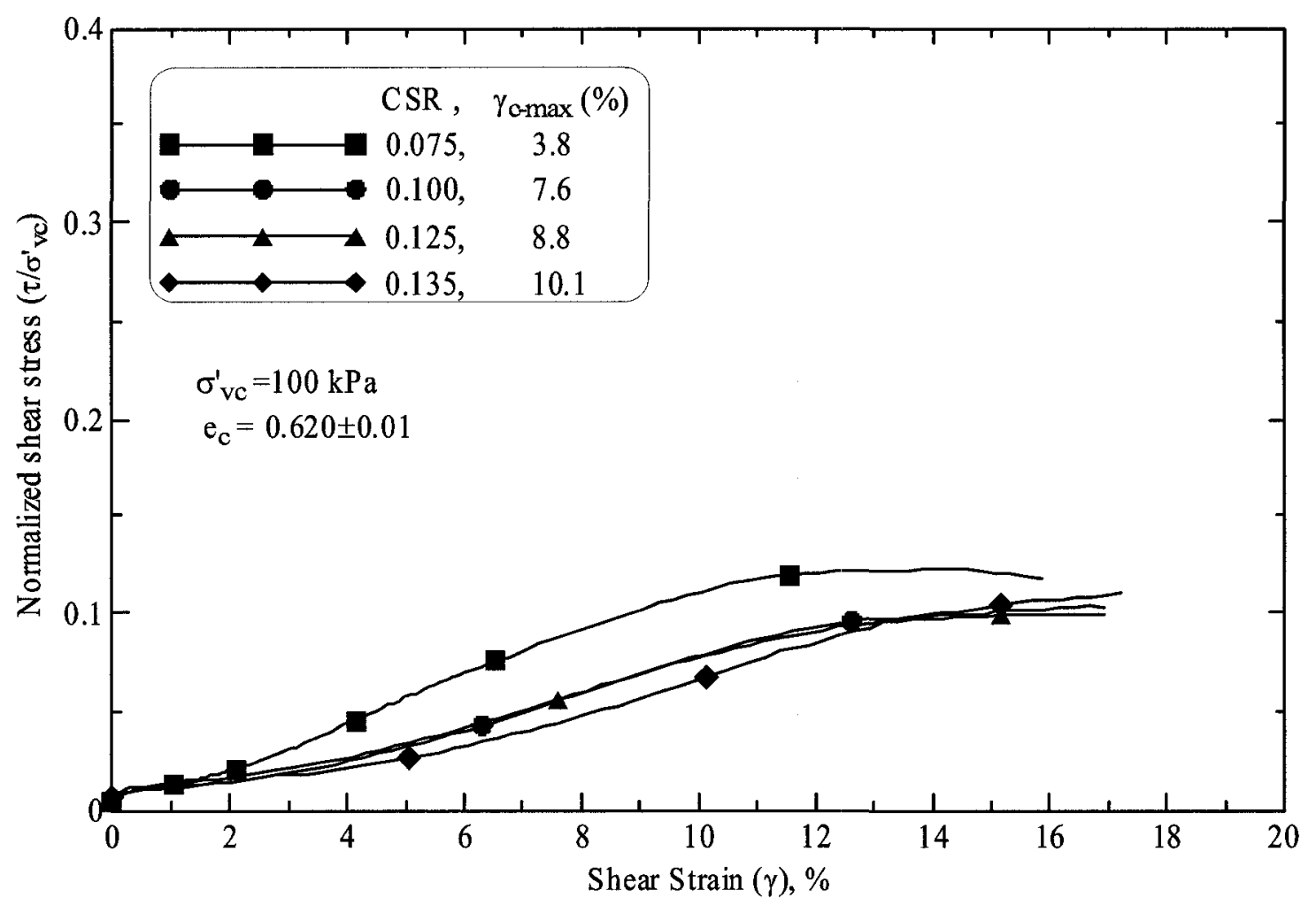

Figure B3 Post-liquefaction response of gold mine tailings at $\sigma_{\mathrm{vc}}^{\prime}=100 \mathrm{kPa}$.

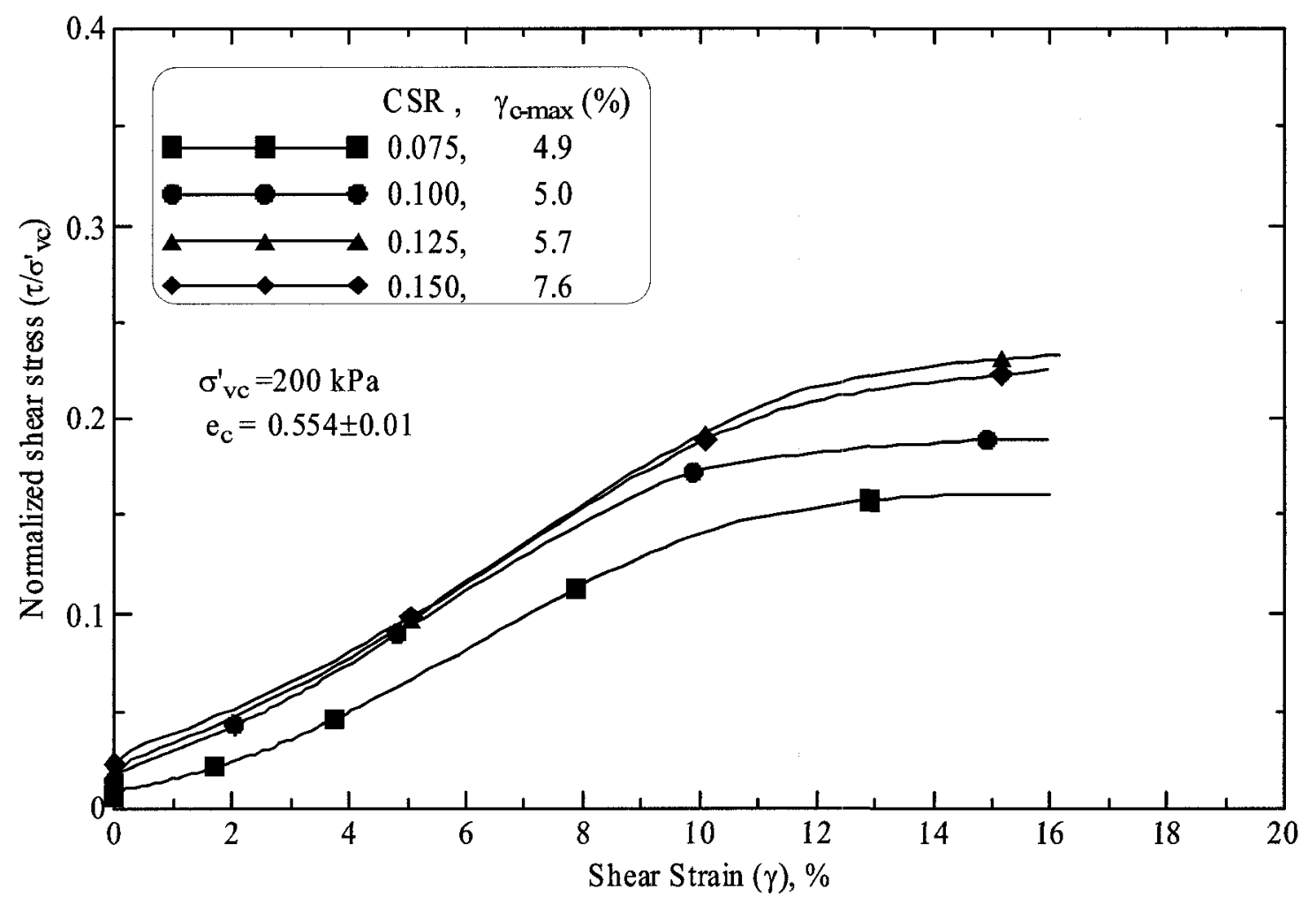

Figure B4 Post-liquefaction response of gold mine tailings at $\sigma_{\mathrm{vc}}^{\prime}=200 \mathrm{kPa}$. 


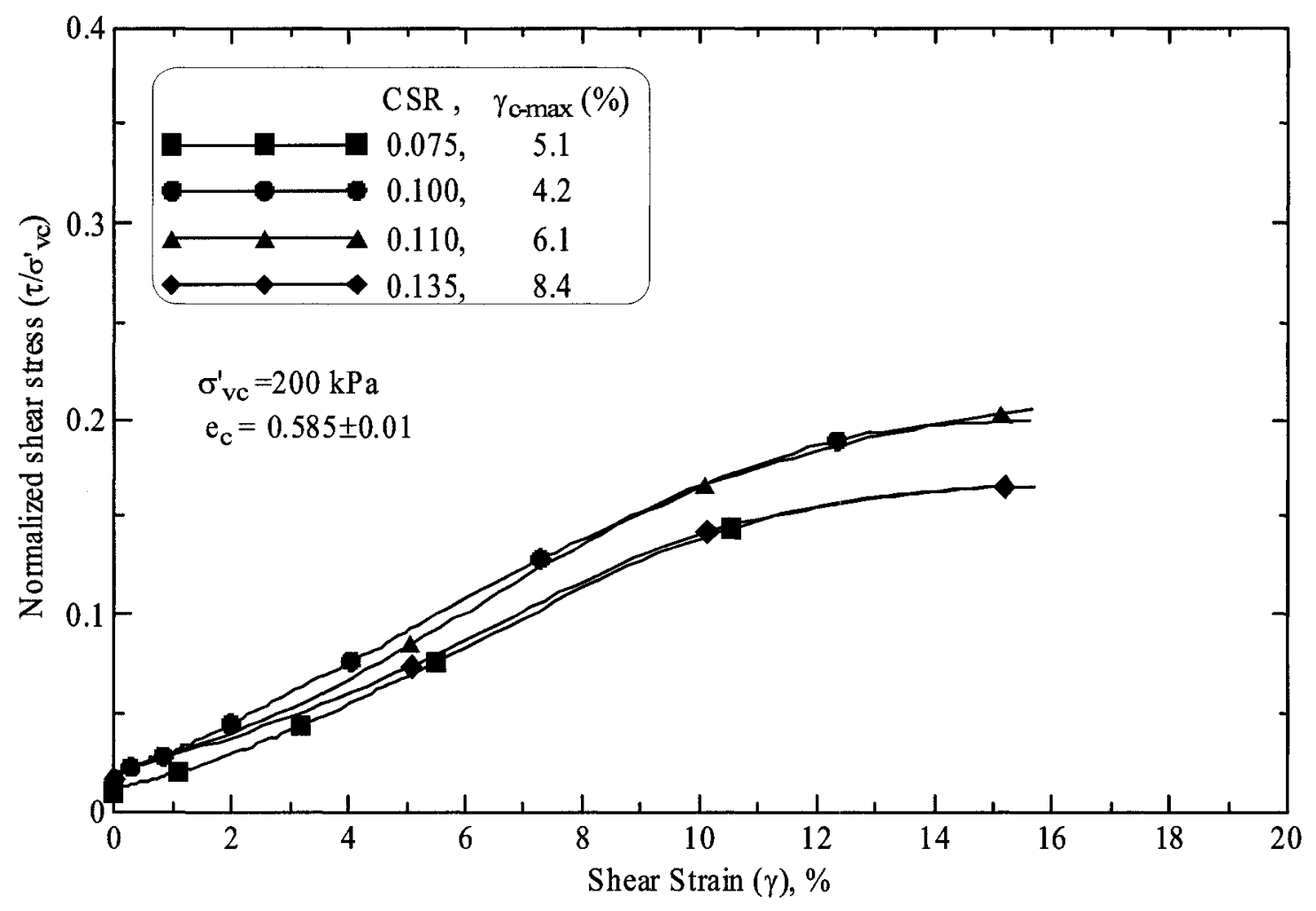

Figure B5 Post-liquefaction response of gold mine tailings at $\sigma_{\mathrm{vc}}^{\prime}=200 \mathrm{kPa}$.

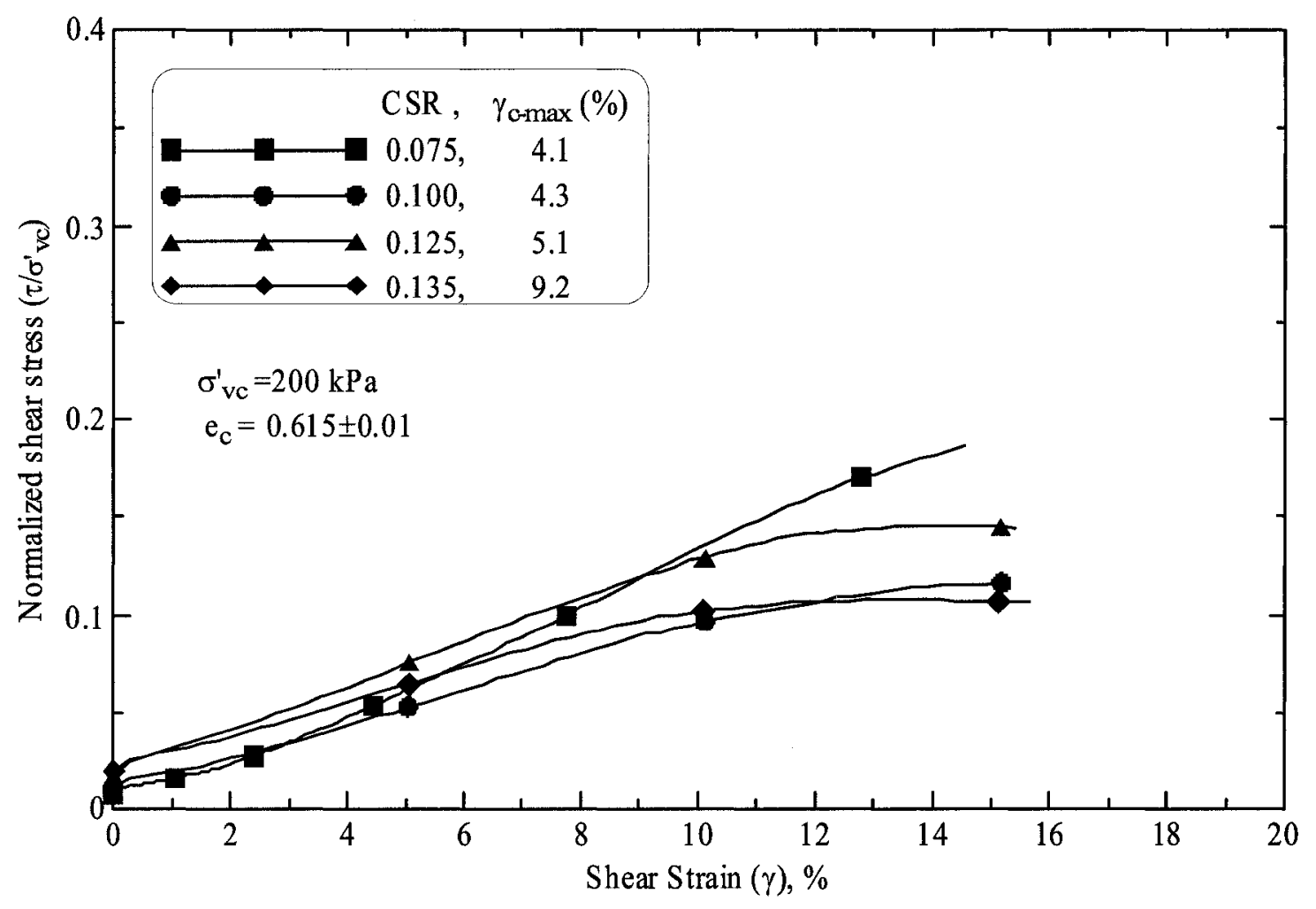

Figure B6 Post-liquefaction response of gold mine tailings at $\sigma_{\mathrm{vc}}^{\prime}=200 \mathrm{kPa}$. 


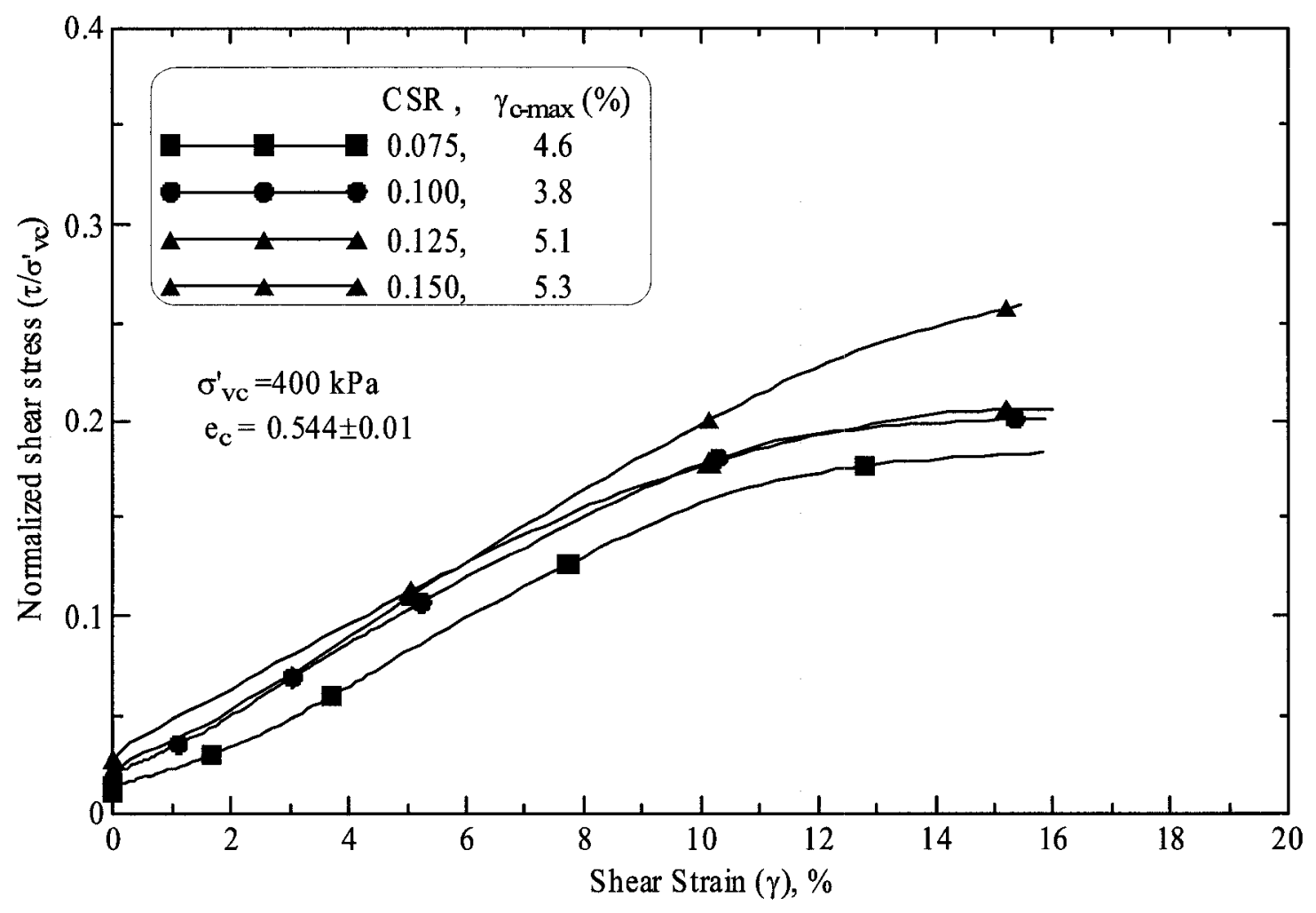

Figure B7 Post-liquefaction response of gold mine tailings at $\sigma_{\mathrm{vc}}^{\prime}=400 \mathrm{kPa}$.

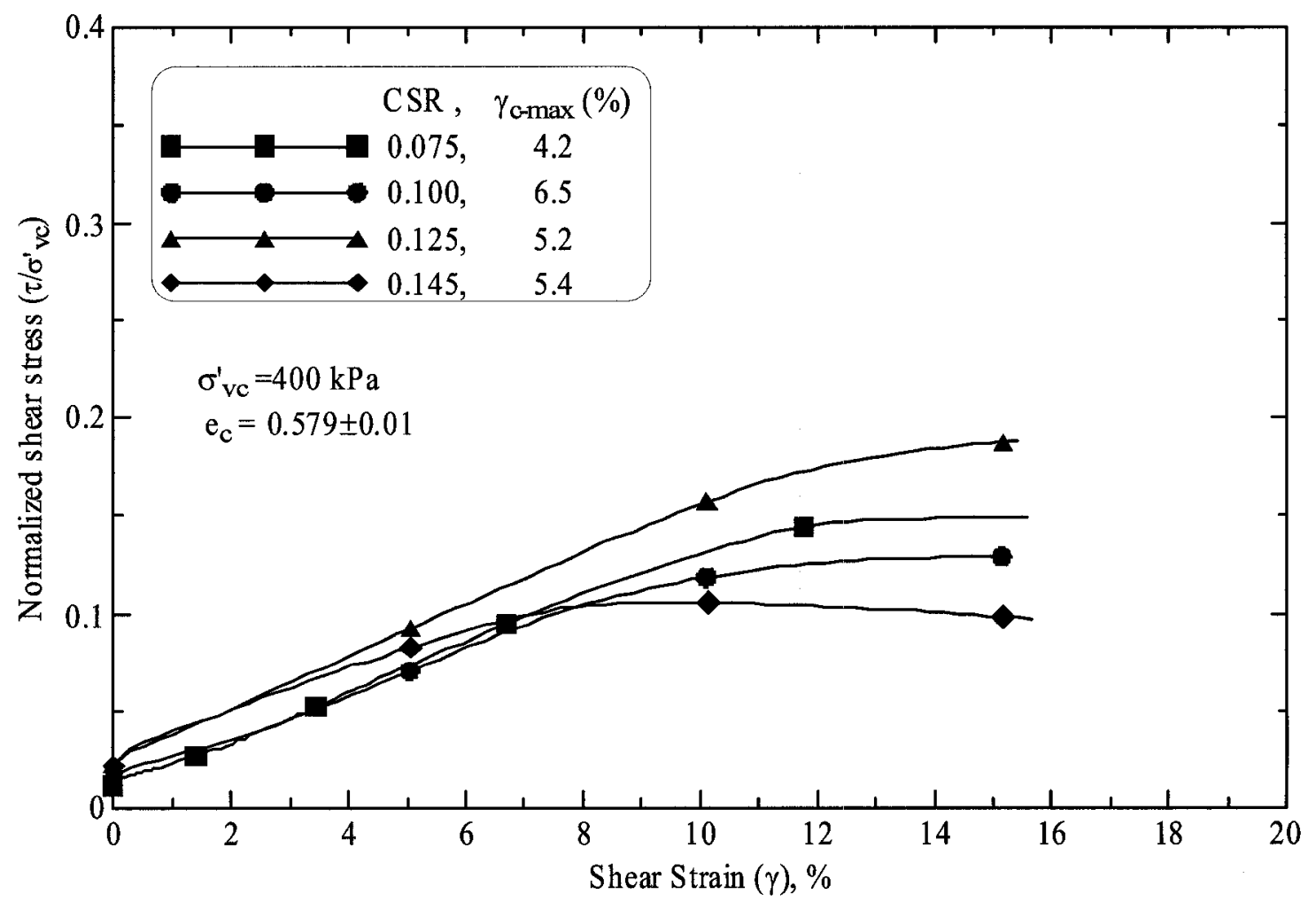

Figure B8 Post-liquefaction response of gold mine tailings at $\sigma_{\mathrm{vc}}^{\prime}=400 \mathrm{kPa}$. 


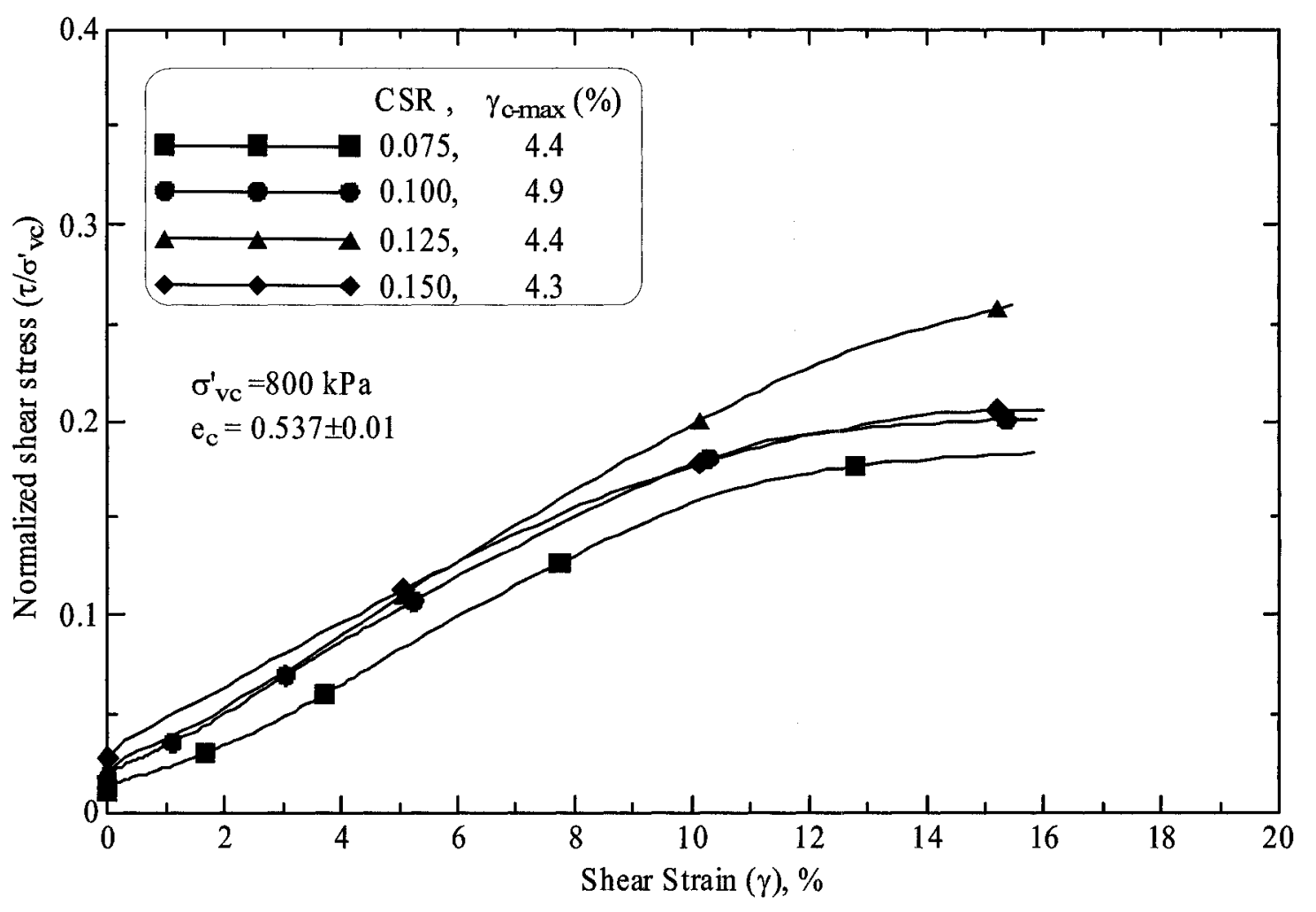

Figure B9 Post-liquefaction response of gold mine tailings at $\sigma_{\mathrm{vc}}^{\prime}=800 \mathrm{kPa}$. 